\title{
Poverty, Inequality and the Decarbonization of Economic Development
}

\author{
Sebastian Renner \\ Fachbereich Wirtschaftswissenschaften \\ Georg-August-Universität Göttingen
}

Dissertation zur Erlangung des

wirtschaftswissenschaftlichen Doktorgrades

Oktober 2016 



\section{Gutachter}

Erstgutachter: Prof. Dr. Jann Lay

Zweitgutachter: Prof. Dr. Stephan Klasen 



\section{Acknowledgements}

Over the past few years, I have received support and encouragement from a great number of individuals. First and foremost, I would like to thank my wife Kerstin for her unconditional support, strength, and love during this difficult time. Certainly, there are easier ways than a scientific career, with higher income, less job uncertainty, and more leisure time - therefore it is assuring to have a supportive family behind me. I am deeply indebted to my parents, Ute and Bernd, and my sister Tine, who supported me on my way through higher education and life in general. Special thanks go to my father, who brought me to visit the slums of Nairobi at a young age, where I developed the idea of becoming an economist.

I would also like to express my sincere gratitude to my advisors, Jann Lay and Stephan Klasen, for their continuous support of my research, patience, motivation, and funding. In this regard, I would like to particularly thank Jann Lay for his outstanding support in providing secure and stable employment in an otherwise poorly financed and societally underappreciated field.

I share the credit of my work with my coauthors Michael Schleicher, Jan Minx, Jann Lay, Hannes Greve, Viola Bold, and Nicole Grunewald. Thilo Schroth, Nils Westerhaus, Eric Victor and Kerstin Nolte provided valuable comments on earlier revisions of the included papers and introductory chapter, thank you very much. Last but not least, I am indebted to my numerous colleagues at the GIGA German Institute of Global and Area Studies and the economics department of the University of Göttingen for helping out with feedback, technical advice, and for me having a good time after all. 



\section{Table of contents}

List of figures $\quad$ xi

List of tables $\quad$ xiii

1 Introduction $\quad 1$

1.1 Anthropogenic climate change and developing countries . . . . . . . . . 1

1.2 Mitigation and development: discussions of trade-offs and synergies . . . . 4

1.3 Distributional effects: decisive for the feasibility of climate policy . . . . 7

1.4 Contribution to the literature . . . . . . . . . . . . . . . 11

2 The carbon footprint of Indian households 17

2.1 Introduction . . . . . . . . . . . . . . . . 17

2.2 Literature review . . . . . . . . . . . . . . . . . . 18

2.3 Methodology ......................... 20

2.3.1 Deriving the carbon footprint . . . . . . . . . . . . 20

2.3.2 Income dynamics of the carbon footprint . . . . . . . . . 23

2.4 Results . . . . . . . . . . . . . . . . . . . 25

2.4.1 Household $\mathrm{CO}_{2}$ requirements . . . . . . . . . . . 25

2.4.2 Income and carbon elasticities of consumption . . . . . . . . 32

2.5 Conclusion . . . . . . . . . . . . . . . . . . 37

3 Poverty and Distributional Effects of a Carbon Tax in Mexico 39

3.1 Introduction . . . . . . . . . . . . . . . . . . . . . . . . . 39

3.2 Methodology ......................... 40

3.2.1 Input-output analysis and price changes per sector . . . . . . . 41

3.2.2 Effects on household welfare . . . . . . . . . . . . . . . 44

3.2 .3 Scenarios . . . . . . . . . . . . . . . . . 45

3.3 Emissions, consumption and poverty . . . . . . . . . . . . . 46

3.4 Results . . . . . . . . . . . . . . . . . . . . 51 


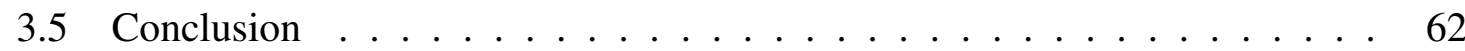

4 Household Welfare and $\mathrm{CO}_{2}$ Emission Impacts of Energy and Carbon Taxes in Mexico

4.1 Introduction . . . . . . . . . . . . . . . . . . 65

4.2 Household energy use . . . . . . . . . . . . . . . 67

4.3 Methodology ......................... 69

4.3.1 Demand system . . . . . . . . . . . . . . . . . 69

4.3.2 Simulation and welfare effects . . . . . . . . . . 72

$4.3 .3 \quad \mathrm{CO}_{2}$ emissions . . . . . . . . . . . . . . 74

4.4 Poverty, welfare and $\mathrm{CO}_{2}$ emissions . . . . . . . . . . . . 75

4.4.1 Energy price changes . . . . . . . . . . . 76

4.4 .2 Carbon tax ....................... 84

4.5 Discussion and conclusion $\ldots \ldots \ldots \ldots \ldots$

5 The effects of energy price changes: Heterogeneous welfare impacts, energy poverty and $\mathrm{CO}_{2}$ emissions in Indonesia $\quad 91$

5.1 Introduction . . . . . . . . . . . . . . . . . . . . 91

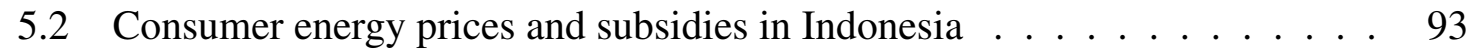

5.3 Literature review . . . . . . . . . . . . . . . . . . . 95

5.4 Household energy use and energy poverty . . . . . . . . . . . . . 96

5.5 Welfare measurement, demand estimation and $\mathrm{CO}_{2}$ Emissions . . . . . . 102

5.5.1 Demand system . . . . . . . . . . . . . . . . . . 102

5.5 .2 Welfare effects . . . . . . . . . . . . 105

5.5.3 Household $\mathrm{CO}_{2}$ emissions . . . . . . . . . . . . . 106

5.6 Energy price changes, poverty, welfare effects and $\mathrm{CO}_{2}$ emissions $\ldots \ldots$

5.6 .1 Estimation results . . . . . . . . . . . . . . . 108

5.6 .2 Welfare and poverty effects . . . . . . . . . . . 112

5.6 .3 Energy poverty . . . . . . . . . . . . . 118

$5.6 .4 \mathrm{CO}_{2}$ emission effects . . . . . . . . . . . . . 121

5.7 Conclusion . . . . . . . . . . . . . . . . . . . 122

$\begin{array}{ll}\text { References } & 125\end{array}$

$\begin{array}{ll}\text { Appendix A } & 137\end{array}$

$\begin{array}{ll}\text { Appendix B } & 149\end{array}$ 
$\begin{array}{ll}\text { Appendix C } & 171\end{array}$

Appendix D

173 



\section{List of figures}

2.1 Carbon intensities India $(2011 / 12) \ldots \ldots$

2.2 Household carbon footprint per capita India . . . . . . . . . . . . . 27

2.3 Expenditure and carbon footprint per capita growth incidence curves India . 28

2.4 Carbon intensity of consumption India . . . . . . . . . . . . . . . 29

2.5 Carbon footprints and sociodemographic factors 2011/12 India . . . . . . . 30

$3.1 \mathrm{CO}_{2}$ emissions, $\mathrm{GDP}$ and $\mathrm{CO}_{2}$ intensities Mexico . . . . . . . . . . . 46

3.2 Household per capita expenditures Mexico (2014) . . . . . . . . . . . . 48

$3.3 \mathrm{CO}_{2}$ intensity of expenditures and $\mathrm{CO}_{2}$ footprints Mexico (2014) . . . . . . 48

3.4 Relative and absolute welfare effects Scenario A . . . . . . . . . . . . 55

3.5 Relative welfare effects scenario A and B . . . . . . . . . . 55

3.6 Decomposition welfare loss, bottom 10 percent $\ldots \ldots \ldots 6$

3.7 Average relative welfare losses per federal state . . . . . . . . . . . . 56

3.8 Welfare effects lump-sum vs. PROSPERA redistribution Scenario B . . . . 60

4.1 Energy expenditures (Mexico) . . . . . . . . . . . . . . 67

4.2 Energy budget shares and usage rates . . . . . . . . . . . . . . . 68

4.3 Welfare effects first- and second-order (CV), energy items . . . . . . . . 79

4.4 Welfare effects first- and second-order (CV), energy and food . . . . . . . . 80

4.5 Welfare effects first- and second-order (CV), users vs. average . . . . . . 82

4.6 Poverty rate (FGT0, wellbeing poverty line) and price increases _ . . . . 83

4.7 Welfare effects redistribution scenarios . . . . . . . . . . . . . . . 84

4.8 Welfare effects of carbon taxes . . . . . . . . . . . . . . . 86

5.1 Nominal energy prices over time . . . . . . . . . . . . . . . . . 95

5.2 Energy expenditure shares . . . . . . . . . . . . . . . 100

5.3 Rural energy expenditure shares and usage rates . . . . . . . . . . . . . 100

5.4 Urban energy expenditure shares and usage rates . . . . . . . . . . . . 101

5.5 Urban and rural energy expenditure shares and usage rates . . . . . . . . 101 
5.6 Welfare effects Scenario I . . . . . . . . . . . . . . . . . 116

5.7 Welfare effects Scenario II _ . . . . . . . . . . . . . . . . . 116

5.8 Welfare effects simultaneous increase Scenarios I \& II _ . . . . . . . . . . 117

5.9 Welfare effects with lump-sum transfers Scenario I . . . . . . . . . . . 117

A.1 Carbon Intensities India $(2004 / 05) \quad \ldots \ldots \ldots$

B.1 Decomposition welfare loss, top 10 percent $\ldots \ldots \ldots$. . . . . . . . . 149 


\section{List of tables}

2.1 Expenditure share of consumption categories f . . . . . . . . . 31

2.2 Income elasticities (urban) . . . . . . . . . . . . . . . . . . . . . . . . . . 33

2.3 Income elasticities (Rural) . . . . . . . . . . . . . . . . . . . 34

2.4 MPE Engel curve estimates (urban) $\ldots \ldots \ldots$

2.5 MPE Engel curve estimates (rural) . . . . . . . . . . . . . . . 37

3.1 WIOD sector description . . . . . . . . . . . . . . . . 42

3.2 Sectoral $\mathrm{CO}_{2}$ production emissions and $\mathrm{CO}_{2}$ intensities (Scenario B) . . . . 47

3.3 FGT poverty indices and Gini index (2014) . . . . . . . . . . . . . 51

$3.4 \mathrm{CO}_{2}$ Intensities for final demand and price changes (Scenario A) . . . . . . 52

3.5 $\mathrm{CO}_{2}$ Intensities for final demand and price changes (Scenario B) . . . . . 53

$3.6 \mathrm{CO}_{2}$ Intensities for final demand and price changes (Scenario C) . . . . . 54

3.7 FGT poverty indices (in \%), changes from baseline (Scenario A) . . . . . . 57

3.8 FGT poverty indices (in \%), changes from baseline (Scenario B) . . . . . . 58

3.9 FGT poverty indices (in \%), changes from baseline (Scenario C) . . . . . . 59

4.1 Demand elasticities . . . . . . . . . . . . . . . . . . . . 77

4.2 Probit energy demand (marginal effects) . . . . . . . . . . . . . 78

4.3 FGT poverty indices (in \%), changes from baseline, minimum wellbeing poverty line . . . . . . . . . . . . . . . . . . 81

4.4 FGT poverty indices (in \%), changes from baseline, wellbeing poverty line . 81

$4.5 \mathrm{CO}_{2}(\mathrm{e})$ emission impacts energy price changes $(20 \%) \ldots \ldots . \ldots . \ldots 8$

$4.6 \mathrm{CO}_{2}$ intensities and price changes carbon tax $\ldots \ldots \ldots . \ldots . \ldots 5$

4.7 FGT changes carbon tax . . . . . . . . . . . . . . . 87

$4.8 \mathrm{CO}_{2}(\mathrm{e})$ emission impacts $\left(\mathrm{USD} 25 / \mathrm{CO}_{2}(\mathrm{e})\right) \ldots \ldots \ldots$

5.1 Gasoline demand, vehicle ownership and poverty . . . . . . . . . . . . . . 99

5.2 Energy poverty . . . . . . . . . . . . . . . . . . . . 102

5.3 First stage probit model (marginal effects at means) . . . . . . . . . . . 109 
5.4 Budget elasticities . . . . . . . . . . . . . . . . . . . . . 110

5.5 Price elasticities . . . . . . . . . . . . . . . . . . . . 111

5.6 FGT poverty indices (in \%), changes from baseline (Scenario I\&II) . . . . . 113

5.7 FGT poverty indices (in \%), changes from baseline (Scenario I\&II + lumpsum transfer $\ldots \ldots \ldots \ldots$. . . . . . . . . . . . . . . 114

5.8 FGT energy poverty indices (in \%), changes from baseline (Scenario I) . . . 119

5.9 FGT energy poverty indices (in \%), changes from baseline (Scenario II ) . . 120

5.10 Firewood cross-price elasticities . . . . . . . . . . . . . . . . . 121

5.11 Household $\mathrm{CO}_{2}$-price elasticities . . . . . . . . . . . . . . . 122

A.1 NSS-CSO Matching 2011/12 . . . . . . . . . . . . . . 138

B.1 Inequality effects (Gini Index) $\ldots \ldots \ldots$. . . . . . . . . . 150

B.2 ENIGH-WIOD Matching $2014 \ldots \ldots \ldots$. . . . . . . . . . . . 150

C.1 ENIGH-WIOD reduced matching and carbon intensities . . . . . . . . 171

D.1 SUSENAS-WIOD Matching $2014 \ldots \ldots \ldots \ldots \ldots$ 


\section{Chapter 1}

\section{Introduction}

\subsection{Anthropogenic climate change and developing countries}

The influence of human activity on the climate is increasingly considered as secured knowledge in the academic community. Driven by economic and population growth, anthropogenic greenhouse gas emissions (GHG) have increased since the pre-industrial era and "led to atmospheric concentrations of carbon dioxide, methane and nitrous oxide that are unprecedented in at least the last 800,000 years" (IPCC, 2013). Anthropogenic drivers are, according to a large majority in the scientific community, extremely likely to have been the dominant cause of the observed warming since the mid-20th century. If mankind continues to emit GHG emissions at current magnitudes, major changes in the climate system can be expected to occur. Despite a considerable uncertainty, contemporary model predictions show high chances for severe consequences in all regions of the world (IPCC, 2013).

Developing countries are particularly threatened by negative consequences of global warming and they are increasingly contributing to man-made climate change through their growing share in global GHG emissions (Olivier et al., 2015). ${ }^{1}$ They are thus confronted with a two-fold challenge: on the one hand, effects of climate change can potentially threaten the existence of some countries via higher temperatures, changed precipitation patterns, higher sea levels, and more-likely extreme weather events (IPCC, 2014). For the majority of humans living in developing countries, this will likely be a major challenge for improving livelihoods. On the other hand, effective climate change mitigation options are in conflict with developing countries' legitimate development goals. With economic growth being a major explanatory

\footnotetext{
${ }^{1}$ The term "developing countries" is used as a broad categorization for "low- and middle countries" as defined by the World Bank. Both terms are used interchangeably in the text.
} 
variable for both GHG emissions and poverty alleviation, developing countries face a difficult but critical trade-off with consequences for their inhabitants' livelihoods and global climate change trajectories. With this thesis I seek to contribute to the understanding of this dual challenge by analyzing the relationship of poverty, inequality and greenhouse gas emissions on the household level in three countries, India, Mexico and Indonesia. By adopting a micro perspective, my work tries to add a much needed viewpoint for the question of how households in developing countries will be affected by climate mitigation policies, and how they are able to contribute to global GHG emission reduction efforts.

Strong mitigation commitments by developing countries are indispensable despite the historical debt of developed countries. Although rather political than scientific, the consensus emerged that negative consequences from climate change could be manageable if the global mean surface temperature rise remained below 2 degrees Celsius (Knutti et al., 2016). Despite the scientific uncertainty, reaching the 2-degree target or similar goals requires significant reductions of global GHG emissions. How much each country should reduce its emission level has always been and continues to be a major dispute at the international policy level. A major conflict line lies between developed and developing countries and culminates in the question of accounting principles for determining each country's reduction responsibilities. Depending on the point of view, which often relates to the perspective of developed or developing countries, emissions should either be calculated at the production or consumption level, with further refinements in per capita and historical time dimensions. Current production emission levels in the world are dominated by low- and particularly middle-income countries. Together, they account for two thirds of annual global emissions with a rising trend (Olivier et al., 2015). Although today's developed countries have a declining share in total global GHG emissions, their historical responsibility is still large. Considering cumulated emissions since 1850, the developed countries' share is at 50 percent, although with a declining trend and predicted to fall to 45 percent by 2020 (Elzen et al., 2013; WRI, 2014). However, the use of production emissions is problematic. A large share of goods produced in developing countries is exported to developed countries. In fact, a non-marginal share of emission stabilization in high income countries can be explained by production and thus emission outsourcing to developing countries (Peters et al., 2011). ${ }^{2}$

Due to these antagonistic approaches to accounting for national GHG emissions and consequently differing understandings of responsibility (Cole, 2015; Ostrom, 2010), international climate negotiations have been in a deadlock for years. On the one hand, historical emission paths suggest a clear policy implication that developed countries have to reduce

\footnotetext{
${ }^{2}$ The production perspective provides already enough evidence against an Environmental Kuznets Curve for GHG emissions (Sanchez and Stern, 2016; Stern, 2004). A demand side accounting approach adds more evidence against it.
} 
GHG emissions drastically and immediately if extreme climate effects are to be avoided (Althor et al., 2016). On the other hand, reducing global GHG emissions to a level, which allows staying within the 2 degrees Celsius target, is simply not achievable anymore without developing countries' mitigation commitments (IEA, 2011). The situation is exacerbated since there is growing evidence that the world is already locked-in on a 1.5 degree increase until the middle of the century (World Bank, 2014). The current speed of emission growth from simulation studies suggest that the world is likely on a path towards a 4 degree warming scenario and that recent increases in developing countries emissions puts considerably more pressure on emission reduction efforts.

The Paris agreement represents a major advancement compared to prior efforts at the international policy level, but developing countries' legitimate development aspirations are still capable of threatening effective emissions reductions. Whether or not current scientific predictions have any direct impact on national policy making remains to be seen. However, major movement occurred recently on the international climate policy stage. 191 United Nations Framework Convention on Climate Change (UNFCCC) member countries signed the first-ever universal and legally binding global climate treaty at the Paris climate conference (COP21) in December 2015. Unlike the Kyoto protocol of 1997, almost all countries are expected to set mitigation goals including the large low- and middle-income countries. The Intended Nationally Determined Contributions (INDC) are unilaterally determined and supposed to reflect each country's ability to contribute to mitigation efforts.

A look into published INDCs of developing countries reveals three major issues, which make the assessment of emission reductions and its economic implications difficult. First, emission reduction goals are usually stated relative to a baseline scenario, which are easily manipulated to claim larger projected emission reductions. Second, mitigation goals are typically formulated along two different scenarios. Unilateral goals are less ambitious than goals that can be achieved by drawing on bilateral or multilateral assistance. Since the size of multilateral transfers is uncertain today, there is also considerable uncertainty regarding future emission savings. Third, INDCs hardly contain specific policy details and further steps for achieving emission reductions. A general trend observable in developing countries' INDCs is the strong emphasis on development goals. Behind this reasonable interest is an inconvenient truth that will be decisive for successful climate stabilization. The ratified Paris agreement will only be implemented starting 2020, at a time when a large fraction of energy infrastructure will already be locked into fossil fuels (IEA, 2014). Investments in replacing this infrastructure are costly, and unlikely to be made when they threaten the development agenda of a poor country. Therefore, a closer look at and thorough analysis of trade-offs is an important issue for understanding the political feasibility of ambitious mitigation policies. 


\subsection{Mitigation and development: discussions of trade-offs and synergies}

Economic growth has shown to be a necessary condition for reaching development goals and the improvement of living conditions of the poor. The worldwide poverty headcount ratio at the \$1.9/day poverty line decreased from 44 percent in 1981 to 12.7 percent in 2012 (World Bank, 2016). A large share of the population, which has escaped extreme poverty, can be found in India and particularly China, but plenty of other countries all over the world, such as Indonesia, the Philippines, Mexico, Pakistan, Uganda, or Ghana among them, have experienced substantial reductions in extreme poverty as well. The assertion of economic growth being the single most important driver behind this reduction in income poverty is well supported. On a cross-country level Dollar and Kraay (2002) show a proportionate relationship between average income growth and the income of the poorest 20 percent of the population. Revisiting the question Dollar et al. (2016) find that about 75 percent of income growth for the poorest 40 percent of the population is explained by average income growth. At the country level there is also overwhelming evidence of the strong effect of growth on poverty reduction. Ravallion and Datt (1996) report a strongly negative elasticity of poverty incidence with respect to mean household consumption for India. Certainly, there are also examples demonstrating that growth is not the only important factor for poverty reduction, as recently described for India by Dreze and Sen (2013). Finally, a consensus in the literature appears to be that economic growth is a necessary but not sufficient condition for an improvement in living conditions of the poor. In any case, without sustained economic growth in low- and middle-income countries, a complete eradication of poverty will be doomed to failure.

The economic growth needed for the achievement of development goals is tightly associated with increased energy use and respective GHG emissions, creating a dilemma which amounts to one of the biggest challenges in the history of humankind. No country has ever managed to reach a high level of economic development without crossing an energy threshold of about 40 GJ per capita (Steckel et al., 2013; Steinberger and Roberts, 2010). Without a widely-available modern energy infrastructure supply and large energy inputs in production, development goals are impossible to achieve. Current price differentials of fossil fuels versus renewable energy clearly favor the former, although renewables have recently become more competitive (IRENA, 2015). To avoid risking long-term lock-ins into the fossil energy supply, the discussion is ongoing how low- and middle-income countries can achieve economic growth with a low carbon intensity at an earlier stage of development compared to high income countries which started this process only recently. One frequently debated 
strategy trying to overcome this dilemma is "greening the economy," which is broadly defined as structural rearrangement of economic and especially energy conversion processes by large-scale applications of low carbon technology while maintaining productivity and competitiveness at the same time.

Conceptual reports on greening the economy by international institutions such as the World Bank, OECD or UNEP draw an overall optimistic picture while theoretical and empirical backing of the concept's capability to solve the dilemma is still lacking. UNEP (2011) takes the strongest stance on the synergies of economic growth and environmental policies, stating that "greening the economy can generate consistent and positive outcomes for increased wealth, growth in economic output, decent employment and reduced poverty". The arguments for strong green growth synergies are debatable for two reasons, as they imply that non-converters to a green economy might miss out on potential extra achievements in their development agendas. First, there is neither a theoretical argument nor empirical evidence available in support of seeing natural capital stock reduction as a major slow down factor for conventionally measured GDP in the short to medium run (Schmalensee, 2012). In the case of climate change and fossil fuels, there is no indication for fossil fuel usage slowing down economic growth and poverty reduction in the near future. According to the latest information on the fossil fuel resource availability (Shafiee and Topal, 2009), in the next decades there is neither an expected resource shortage inducing growth decline, nor an expected self-regulation of energy prices, which could make renewables more competitive. Second, simulation studies of mitigation policies usually conclude that strong emission reduction goals, contrary to synergistic arguments, reduce GDP compared to the business as usual scenario (Carraro et al., 2012; Edmonds et al., 2012). When the cost of transforming energy from fossil fuels is cheaper compared to renewable energy sources, production costs rise. It can also be ruled out that the general growth effects from these studies cannot be applied to developing countries as well. The extra costs generated by the more expensive fossil fuel substitutions will consequently be at some party's expense, which in turn is the simple reason for most countries' cemented reliance on fossil fuels.

However, strategies for internalizing externalities, e.g. by taxation of carbon emissions, possibly help leverage synergy potentials of development goals and GHG emission reductions. Adding to the environmental benefits of reduced GHG emissions in the atmosphere, taxation of GHG emissions might provide a so called second dividend. A reduction of other distortionary taxes may result in an efficiency gain and improved total welfare. The literature on the so called "double dividend" often focuses on employment gains through a reduction in labor taxes (Bovenberg, 1999; Goulder, 1995) but also capital tax reductions are shown to lead to aggregate welfare gains (Jorgenson et al., 2013). There are also arguments in favor 
of "triple dividends", although the definitions here differ widely: Garbaccio et al. (2000) find additional health benefits through a reduction of air pollution, which was termed the "third dividend" by Dale Jorgenson (Shaw, 2014). Heerden et al. (2006) define their "third dividend" as a reduction in poverty, which appears not to be fundamentally different from the second dividend after all. Again another definition is used by Pereira et al. (2016) who speak of lowering public indebtedness as the third dividend. All these potential efficiency gains are important factors to consider for a concluding judgement about the overall growth effect of mitigation policies. Due to the small number of implemented mitigation policies in real world contexts, and the complexity of modelling these effects ex-ante, the literature has little to offer on these points for developing countries.

Despite some well-founded arguments in favor of possible synergies between climate mitigation policies and economic development, there are still major obstacles to be overcome in the short-run. The OECD, although advocating green and low carbon growth, is cautious by considering potential problems such as distributional impacts in the transformation process (OECD, 2011). In a recent stock-taking of the green growth agenda, it is emphasized that a better understanding of opportunities and trade-offs of green growth policies is crucial for any realistic change in their implementation (OECD, 2015). The World Bank has also become very active recently in the green growth debate. Hallegatte et al. (2011) provides a very general discussion of possible green growth scenarios. Adding the term "inclusive" in a subsequent report, green growth is described as "necessary, efficient and affordable" (World Bank, 2012, p. 3). Although sharing an optimistic tone, most advocates of low carbon growth can certainly not be blamed for a careless handling of possible trade-offs with development goals. Striking however is the relatively large abstraction of the discussion and a major lack of specific policy guidance, particularly for low carbon development in low- and middle-income countries. A skeptical and more focused perspective on low carbon development is shared by Jakob et al. (2014), who recommend a modest approach in identifying mitigation actions with clear benefits for developing countries. They identify feasible policy options, such as the reduction of fossil energy subsidies and decentralized renewable energy for rural areas. However, these policies' suggestions partly miss to answer the urgent question of how large emission reductions can be realized in the short-run. Other economists are also generally skeptical of synergistic green economy programs and point to the short-run costs in developing countries as a major obstacle in implementing low carbon policies (Bowen and Hepburn, 2014; Dercon, 2014).

Exploiting mitigation cost differentials on the global level as another possible way to overcome the mitigation-development dilemma is seemingly also not living up to its promise. In line with the size of GHG emissions, the largest mitigation potential lies in non-OECD 
countries (Akimoto et al., 2010; van Vuuren et al., 2009). Developed countries thus could contribute to mitigation and development by financing the installation of renewable energy capacity in developing countries. Large cost differentials can often be found in studies based on Marginal Abatement Costs (MAC) Curves. This approach is widely and often advocated by the private consulting firm McKinsey (Nauclér and Enkvist, 2009). Academic economists have criticized these cost assessments on various grounds (Kesicki and Ekins, 2012): among many methodological issues, the allurement of negative abatement costs, which are hailed as cost-free low hanging fruits, are an elusive promise and proof of their existence still needs to be delivered. The Clean Development Mechanism (CDM), part of the Kyoto protocol and most prominent example for this approach, has not lived up to its expectation either and a succeeding mechanism is not in sight. Large capital transfers to developing countries for boosting renewable energies are also potentially problematic. Based on historical experience with development aid, large capital transfers may come with a "climate finance curse" (Jakob et al., 2015) analog to the effects described in the resource curse literature (van der Ploeg, 2011). In total, the mitigation-development dilemma does not seem to be easily resolved into a synergistic win-win situation, leaving developing countries with an unclear perspective regarding potential outcomes of climate policies.

\subsection{Distributional effects: decisive for the feasibility of climate policy}

The unclear impacts of climate policies on household incomes and especially the distribution of these impacts are particularly problematic. They depend on a variety of often underresearched factors. However, the elucidation of these factors is important regardless of their existence and implementation problems in international carbon finance projects. For low carbon development strategies, developing countries will likely be dependent upon international assistance to some extent. However, multilateral assistance will not be able to fundamentally change the incentive structure and determine how much renewable energy is used over the next decades. National policies are needed to supplement climate finance in setting the incentives towards low carbon energy sources. However, as a critical review of the catchy green or low carbon growth slogans show, many problems await for those countries, which are planning to go down the road of climate policies. Much of the political discussion on low carbon development focuses on abstract discussions with limited substantial analytical value and policy guidance. This is surprising, considering that the economic literature can deliver analytical tools to access complicated topics, such as the incidence of market-based 
environmental policies. These instruments, putting a price on GHG emissions either in the form of taxes or emission permits, will have to play a major role in any ambitious decarbonization process. Like any other policy, putting a price on carbon will produce winners and losers. The identification of these groups and quantifying the impacts are a highly needed deliverable by the scientific community that this work tries to contribute to.

Fullerton $(2008,2011)$ discusses six distributional effects, which are worth looking at in more detail and guide the way for the subsequent chapters in this work. Market based climate mitigation policies try to correct for the environmental externalities created by the polluting fossil fuels. The public economics literature has much to say on the general distributional effects of taxes, but environmental policies are in fact more complicated and interesting as Fullerton (2011) points out. The reasons behind this are that environmental policies are not exclusively taxes but also include quantity regulations, such as emission trading schemes or command and control policies. Specifically, the different effects are (1) higher prices of carbon intensive products, (2) changes in relative returns to factors like labor, capital, and resources, (3) allocation of scarcity rents from a restricted number of permits, (4) distribution of the benefits from improvements in environmental quality, (5) temporary effects during the transition, and (6) capitalization of all those effects into the prices of land, corporate stock, or house values. With the exception of effect (3), which only holds for an emission trading scheme, all of these effects are also present in the cases of carbon or energy taxes. Under particular circumstances, all these single effects can be regressive (a higher burden as a fraction of income for the poor compared to the rich) or progressive and the overall effect is a priori unknown. A discussion of these effects and the available evidence in detail is helpful in understanding their importance and the current state of research.

First, prices of fossil fuel-intensive products are likely to rise, which will affect the consumption costs of households, the so called "uses" side. In developed countries, the uses side is found to be dominantly regressive since poor households spend relatively more on high carbon intensive goods, such as electricity and fuels (Grainger and Kolstad, 2010; Mathur and Morris, 2014). How regressive the impact is depends on whether welfare effects are calculated relative to household income or expenditures, the latter usually claimed to better represent lifetime income measures. Expenditure based assessments are found to be less regressive than effects relative to income (Bull et al., 1994; Dinan and Rogers, 2002; Metcalf, 1999). Shah and Larsen (1992) have warned early of applying the standard regressivity result unquestioned to developing countries, as direct use of modern energy can be lower for poor households. In urban areas the electricity grid connectivity is higher, which correlates positively with income. Private motorized transport expenditures are closely tied to the ownership of motorized transport vehicles, again positively correlated with income. Also 
modern fuels for cooking, such as gas, are unlikely to be used more by the poor who often depend on traditional biomass fuels such as wood and dung for cooking. The uses side incidence of energy and carbon taxes may therefore be progressive in developing countries. Finally, the extent to which higher prices are passed through to consumers will depend on the shape of their demand curve. Since energy markets are usually dominated by international market forces and national regulation, it is very likely that energy price increases are entirely passed through to consumers. The substitution between fuels is then ultimately deciding on the monetary burden from taxation.

Second, depending on how factor demand changes through the price increase, the income of workers or capital owners will be affected through the "sources" side. If energy or fossil fuel intensive goods can best be replaced by new capital intensive technologies, relative wages will fall, returns to capital rise and the policy will be regressive. On the other hand, a carbon tax may be more burdensome to capital-intensive industries and disproportionately reduce the return to capital. If so, and if capital provides a higher share of income for richer households, then the sources side incidence may be progressive. In particular, the effect on the sources side depends on the elasticities of substitution in production for polluting industries, elasticities in labor supply and demand, and capital market conditions. There is very little empirical literature on this question, which forces modelers of simulation studies to use "plausible values". The results in this branch of literature are naturally mixed. Fullerton and Heutel (2007) describe the effects of carbon taxation on the different factor prices and conclude they depend critically on the substitutability of capital, labor, and emissions. In a follow-up paper, Fullerton and Heutel (2011) show that the incidence of a carbon tax on the uses side is regressive, the incidence on the sources side can be progressive, Ushaped, or regressive, depending on the parameters. Rausch et al. (2010) find that under certain circumstances, the progressive impacts of a carbon tax on the sources side exceed the regressive impacts on the uses side, which in sum leads to a mildly progressive effect even without recycling of the revenues. Fullerton and Monti (2013) show that even when accounting for potential progressivity on the uses side, the burden a carbon tax places on the lowest income cohort can never be offset completely. Concluding, results on the sources side are sensitive to parameter values in numerical simulation models and remain an unresolved subject of empirical research. For labor abundant developing countries, the chances of progressive effects through capital intensive renewable energy installments are relatively low as put forward for Africa by Collier and Venables (2012).

If the climate policy is a quantity based instrument, there will be a third effect consisting of scarcity rents following the hand out of pollution permits which will benefit the individuals who own those firms. In the first phase of the European Emission Trading Scheme (EU ETS), 
almost all emission permits have been grandfathered to companies. Since emission permits are afterwards traded and therefore worth the resulting market price, consumers face rising energy prices while financing the permits with their taxes (Dinan and Rogers, 2002; Parry, 2003). The only immediate beneficiaries are the stockholders of the polluting companies, which are unlikely to sit at the bottom of the income distribution. Plain and simple, giving permits away for free is a way of combining environmental policy with redistribution from the bottom to the top.

Fourth, climate policies have the ultimate goal to reduce greenhouse gas emissions, and the associated environmental improvements may lead to a heterogeneous effect in the population. Air quality improvements through less fossil fuel intensive electricity generation, road transport, and industry production is likely to affect the urban more than the rural population. In this case, the distributional impact depends on the spatial distribution of income in polluted and less polluted areas. Although this intra-country distribution hasn't been analyzed in the literature thus far, in a cross country comparison Markandya et al. (2009) report large health benefits of low carbon electricity generation in poor countries like India. Agricultural productivity, which is already lower in less temperate regions of the world, would further decrease in poor countries with climate change. Developing countries with large agricultural shares in their gross domestic product would benefit more from climate mitigation efforts than developed countries in temperate world regions. Dell et al. (2009) come to the conclusion that higher temperatures reduced income growth in poor but not in developed countries. Beyond an increase in temperatures, the possible increase in extreme events and natural disasters may also hurt the poor more than the rich. In this case, the difference may not be entirely explained by agricultural activities, also non-agricultural growth is affected (Fomby et al., 2013; Raddatz, 2009). The benefits of climate mitigation would therefore likely be progressive, also within these countries.

Fifth, the transition towards a low carbon economy may have very different effects on poor and rich households. With imperfect mobility of production factors, returns to capital or wages are not the only effects on the sources side. Additionally, large disruptive changes in employment and capital degradation might occur. Deschenes (2010) analyzes the effects of electricity prices on labor demand for the US and finds a low, but negative cross-price elasticity. As with other effects, the time horizon used for the analysis is critical. Short-term effects as calculated by Deschenes (2010) ignore a firm's innovation responses to higher energy prices (Popp, 2002; Popp et al., 2009), which may change the story dynamically over time; but literature for developing countries is neither available for static nor for dynamic effects. The other side of the coin, the creation of "green jobs" is often hailed as the ultimate win-win case of climate policy and green growth. There is little empirical evidence of this 
phenomenon, but existing studies shed serious doubt on the existence of a green job miracle, in particular for developing countries. In the case of climate policies, green jobs are mostly defined as jobs in the renewable energy industry. For developing countries, Dercon (2014) argues that the low-skilled-labor intensity of these industries will finally decide if the poor benefit from this development. Wei et al. (2010) argue that the renewable energy sector is more labor intensive and therefore creates more jobs than the fossil fuel using energy sector. This, however, appears to be a rather optimistic assessment since energy prices are also higher for renewables, use more inputs per energy unit, and it is not clear what the net employment effect finally is (Fankhauser et al., 2008). For industrialized countries with large scale support of renewable energies such as Germany, there are contradicting findings that the net job creation is either positive (Lehr et al., 2012) or negative (Frondel et al., 2010). In any case, it appears that the export of technologies is essential to achieve a potentially positive net employment effect. Currently, the large majority of renewable energy technologies are developed in rich countries and this is unlikely to change in the short- to medium-run. Therefore, a low carbon job miracle is unlikely to be a plausible scenario for poverty reduction and progressive distributional effects.

Sixth, all those effects are capitalized into the prices of assets. If climate policy affects the expected future returns from houses, land, or corporate stock, the owners or renters of these assets will be differently affected. For developing countries, important factors are e.g. the ownership of agricultural land or the geographical vulnerability of asset ownership to sea level rises. Apart from cross-country evidence reporting a high vulnerability of developing countries (Dasgupta et al., 2008; Mendelsohn et al., 2006), intra-country evidence is missing.

Eventually, in the case of raised revenue through taxes or permits, the reallocation of these revenues to households may change the net effect of all impact channels described above. Many studies find that redistribution can make any carbon tax reform progressive, although as Rausch et al. (2011) note, this may come at the cost of efficiency.

\subsection{Contribution to the literature}

Considering the various distributional effects that potentially result from climate policies, data limitations and methodological challenges do not allow me to investigate them empirically in one piece of analysis. This holds particularly for developing countries, where necessary data is even harder to come by. Despite the apparent difficulties to deliver analytical studies incorporating the variety of potential welfare effects, the immediate need for knowledge in this field demands urgent action in research. For developing countries there is some literature available for impacts on the uses side and some Computable General Equilibrium (CGE) 
studies including effects on the sources side.

The uses side literature is predominantly based on descriptive patterns of household energy expenditures as in Sterner (2011), with critical and untested assumptions of completely inelastic energy demand. This simplified approach has two important drawbacks: First, welfare effects are mismeasured when households deviate from the assumption of inelastic demand. Second, inelastic demand implies zero impact on the emission of GHGs. CGE studies on the other hand, dealing also with sources side effects, include demand elasticities. These models come with different problems however. Demand curves are often of a simplified linear form and of dubious empirical credibility as are other used functional forms and parameters. Additionally, energy expenditures are difficult to disaggregate on a single fuel level which misses much of the substitution between different fuels. Usually, the emission accounting is also production based, which ignores the actual effect from emissions contained in consumption goods. Last but not least, welfare assessments based on average households always miss out on heterogeneity between households, which can be critical in distributional assessments.

In this thesis I try to address all of these problems in a unified, theoretically consistent and empirically tested model structure. Thereby I focus on household expenditures and the uses-side effects in order to deliver short-run but reliable analyses of household welfare impacts resulting from energy and climate policies. The consumption perspective is also strictly maintained in assessing the GHG emission implications. As a novelty in the literature of energy and climate policies in developing countries, I introduce an emission accounting framework for households based on actual emitted GHG in consumption.

In all chapters I employ partial equilibrium models with a maximum of detail in terms of household heterogeneity and energy demand. Additional to purely descriptive components of household consumption patterns, these models incorporate estimated household demand responses to policy interventions. These detailed partial equilibrium models are not substitutes for more general CGE models but complements, which help to go beyond average effects and offer as much heterogeneity as possible. The disadvantages are naturally the lack of indirect effects through factor markets, the missing total, general equilibrium effects, and the strong short-term focus of the analysis. At least for policy guidance, the latter does not appear to be extremely harmful. The estimated and simulated effects are all effective immediately after the policy implementation, which facilitates the practical understanding of results. In general, the used household demand model, the Quadratic Almost Ideal Demand System (QUAIDS), is of neoclassical nature and can also be used as a demand module in a CGE model, which would reconcile this line of work with studies incorporating different impact channels such as sources-side effects at the same time. 
To lay the ground for the emission accounting from the demand side, the second chapter describes the calculation and analysis of household carbon footprints for Indian households. Estimates of household $\mathrm{CO}_{2}$ emissions caused by the direct use of energy or indirectly through the consumption of other goods are rare for developing countries. Addressing this research gap I apply an environmentally extended input-output analysis matched with Indian household expenditure data to estimate the carbon footprint for Indian households in the years 2004/05 and 2011/12. I analyze the consumption dynamics behind the growing carbon footprints in a structural demand model framework. Between the two surveys, $\mathrm{CO}_{2}$ emissions contained in household consumption grew slightly faster than consumption itself. The scale effect of higher consumption is therefore ruled out to be the only factor for emission growth from Indian consumers. By estimating the income elasticities of major groups of consumption items, I am able to investigate the effect of changes in household consumption patterns to identify the composition effect. Although the scale effect dominates, high income elasticities for carbon intensive consumption items are likely to accelerate future growth in household carbon footprints. Electricity and private transport are mainly responsible for this slightly nonlinear emission growth effect.

In the remaining chapters, I put the focus on distributional effects of climate mitigation policies. The third chapter starts out with a closer look at welfare effects of carbon taxes in Mexico. Mexico recently declared ambitious goals in reducing domestic $\mathrm{CO}_{2}$ emissions and introduced a carbon tax in 2014. Although negative effects on household welfare and related poverty measures are widely discussed as possible consequences, empirical evidence is missing. I try to fill this gap by simulating an input-output model coupled with household survey data to examine the welfare effects of different carbon tax rates over the income distribution. The currently effective tax rate is small and has negligible effects on household welfare. Higher simulated tax rates, maintaining the current tax base, show a slight progressivity but welfare losses remain moderate. Welfare losses, regressivity and poverty rise more with widening the tax base towards natural gas and other greenhouse gases $\left(\mathrm{CH}_{4}, \mathrm{~N}_{2} \mathrm{O}\right)$ through food price increases. For a complete analysis of the policy, I simulate a redistribution of calculated tax revenues and find that the resulting effects become highly progressive, also for high rates, wider tax bases and even in the absence of perfect targeting of social welfare programs.

Chapter 4 builds on chapter 3 but deals with the weaknesses of the modelling framework, which is incapable of estimating household responses to policy induced price changes. Therefore, I analyze not only the effects of environmental taxes on household welfare but also on carbon emissions at the household level for the case of Mexico. The integrated welfare-environmental analysis that is based on a censored energy consumer demand system 
extends previous work in two ways. First, the estimation of a full matrix of substitution elasticities allows testing the necessity of incorporating second-order effects into the welfare analysis. Second, the derived substitution elasticities from the demand system are used to estimate the short-run $\mathrm{CO}_{2}$ emission reduction potential. For the Mexican case, I find first-order approximations of welfare effects to provide reasonable estimates, in particular, for carbon taxes. Analog to evidence in other low- and middle-income countries, the taxation of all energy items is found to be regressive with the exception of motor fuels. The inclusion of $\mathrm{CH}_{4}$ and $\mathrm{N}_{2} \mathrm{O}$ in a carbon tax regime comes along with particularly regressive impacts because of its strong effects on food prices. The analysis of the emission implications of different tax scenarios indicates that the short-run emission reductions at the household level can be substantial - albeit the effects depend on how revenue is recycled. This effectiveness combined with moderate and manageable adverse distributional impacts renders the carbon tax a preferred mitigation instrument. Considering the large effect of food price increases on poverty and the limited additional emission saving potential, the inclusion of $\mathrm{CH}_{4}$ and $\mathrm{N}_{2} \mathrm{O}$ in a carbon tax regime is not advisable.

In the final chapter, using extended methodology from the other chapters in one piece of analysis, I put the spotlight on energy subsidies in Indonesia. Consumer energy prices in Indonesia have been regulated by the government for a long time with a recent change in subsidy policies, facilitated by dramatically falling oil prices. I study welfare, energy poverty, and $\mathrm{CO}_{2}$ emissions implications of energy price change scenarios. The analysis extends previous work of energy price and subsidy removal impacts at the household-level in several ways. First, by employing a household energy demand system (QUAIDS) the analysis shows considerable heterogeneity of welfare impacts. For gasoline and electricity, first-order calculations are overestimating welfare effects by 10-20 percent with price changes between 20 and 50 percent. This holds particularly for gasoline and for richer households, which have higher usage rates. Second, the results point at another source of impact heterogeneity due to the ownership of energy-processing durables. Poor households that own these goods may be hit particularly strong by energy price rises. Third, I extend the welfare analysis beyond the money metric utility effects and look at energy poverty understood as a condition of missing or imperfect access to reliable and clean modern energy services. By drawing on the estimated demand function and resulting price elasticities, I find substantial effects of price increases on energy poverty. Fourth, the analysis explicitly considers the emission effects of the energy price scenarios. Albeit these effects are estimated with some uncertainty it turns out that reduced household energy demand implies a substantial reduction in emissions. The analysis thus indicates that energy taxes may serve as an effective mitigation instrument, but 
are accompanied with important adverse welfare effects that can, however, be cushioned by appropriate compensation policies. 



\section{Chapter 2}

\section{The carbon footprint of Indian households}

\subsection{Introduction}

Household income in India has increased considerably in line with economic growth over the last decades with a clear acceleration since the early 1990s. Although aggregate economic growth rates of India may have not transformed into a magnitude of poverty reductions that was hoped for (Dreze and Sen, 2013), substantial reductions in the poverty rate of 35 percentage points have been achieved since the end of the 1950s until 2012 (Datt et al., 2016). ${ }^{1}$ With sustained economic growth and an increasing share of the population leaving extreme poverty, consumption and associated energy use are expected to grow rapidly as well. As positive as this development process is, energy used in the production of goods and energy used directly by households comes to a large extent from fossil sources (IEA, 2015). Current $\mathrm{CO}_{2}$ emission levels per capita are low in international comparison but the large population size of India makes the country the 3rd biggest total $\mathrm{CO}_{2}$ emitter in 2014 behind China and the USA (Olivier et al., 2015). India's growth rates in energy use and $\mathrm{CO}_{2}$ emissions - driven by increasing direct and indirect energy requirements of households - will thus have substantial effects on global climate mitigation efforts. Direct energy use for cooking is expected to increase due to a switch from traditional to modern fuels. Electricity for lighting is becoming more and more prevalent also in rural India. Occupational imperatives on the labor market and private preferences require and lead to increased mobility that causes significant growth in private motorized transport. Further, indirect energy and emissions embodied in the

\footnotetext{
${ }^{1}$ This result holds approximately for two poverty lines. The first is a domestic, nutritional food poverty line following Datt and Ravallion (2011) based on Planning Commission (1993), the second represents the international \$ 1.25 PPP poverty line.
} 
production of consumed goods have a growing importance as well. The relationship between aggregate income and $\mathrm{CO}_{2}$ emissions on the country level has been extensively analyzed within the Environmental Kuznets Curve (EKC) literature (Dinda, 2004; Heil and Selden, 2001; Holtz-Eakin and Selden, 1995; Stern, 2004). For $\mathrm{CO}_{2}$ and more general for greenhouse gas (GHG) emissions, there is no turning point observed with higher gross domestic products. On the household level, the effect of rising income on $\mathrm{CO}_{2}$ emissions from consumption has been less frequently analyzed, particularly for developing countries. We contribute to this literature by deriving marginal propensities to emit (MPE) on the household level based on income elasticities of demand and emissions related to the products and energy consumed. We apply an environmentally extended input-output (IO) analysis in combination with household expenditure survey data from India for the years 2004/05 and 2011/12. For the analysis we calculate the carbon footprint of households and identify the respective emission drivers. By definition, household consumption induced carbon emissions can be explained by the expenditure levels, the spending shares and the consumption items' carbon intensity of production. By estimating household preferences through a consumer demand system we can assess whether consumption item choices tend to become more carbon-intensive with rising income levels and how important these dynamics of consumptions patterns are compared to the scale effect of higher total household expenditure. The remainder of the paper is as follows. After the literature review we present the IO analysis and the calculation of carbon footprints. In the results section we present a descriptive analysis of the carbon footprints and determine the income dynamics behind the carbon footprints and carbon intensity of consumption. Eventually we discuss the implications of our findings in the conclusion.

\subsection{Literature review}

Although our particular focus is on India and developing countries, most studies on carbon footprints focus on developed countries. For surveys of the literature concerning input-output analysis and the carbon footprint, see also Minx et al. (2009) and Kok et al. (2006). Generally, carbon emissions, which are closely related to direct and indirect energy requirements of households, have been the subject of research since the 1970s. Herendeen and Tanaka (1976) use input-output and household expenditure data to calculate energy requirements of U.S. households. Additional to energy intensities, GHG intensities have been calculated by Lenzen (1998b) for Australian final consumption. Based on IO-analysis and including other GHGs than $\mathrm{CO}_{2}$ such as $\mathrm{CH}_{4}, \mathrm{~N}_{2} \mathrm{O}, \mathrm{CF}_{4}$ and $\mathrm{C}_{2} \mathrm{~F}_{6}$ it is found that most of the GHG emissions are ultimately caused by household purchases. One of the first studies calculating carbon footprints on a disaggregated household level, household expenditure data and IO derived carbon 
intensities have been used to calculate household carbon footprints for Australia (Lenzen, 1998a). Among the finding that per capita income is the main determinant of household energy and carbon requirements, it is found that rural households spend their income on more energy intensive commodities than households from metropolitan areas on average. Wier et al. (2001) analyze the carbon footprint of Danish households, identifying household characteristics with a significant influence on $\mathrm{CO}_{2}$ emissions. Kerkhof et al. (2009) quantify $\mathrm{CO}_{2}$ emissions of households in the Netherlands, UK, Sweden and Norway by combining a hybrid approach of process and input-output analysis with household expenditure data. Similar approaches are used by Bin and Dowlatabadi (2005) and Weber and Matthews (2008), both focusing on US households.

Drawing on a similar methodology for energy as Lenzen (1998b), Lenzen et al. (2006) focus on the role of income growth in a cross-country analysis. Their motivation is to characterise household consumption patterns with respect to their environmental implications and hereby search for evidence on the Environmental Kuznets Curve (EKC). Their findings support previous research in the EKC energy literature, as energy requirements increase monotonically with household expenditure but no turning point is observed. In general, the EKC literature describes the relationship of income and emissions with the marginal propensity to emit (MPE), which is usually found to be diminishing with income at slow rates (Holtz-Eakin and Selden, 1995; Ravallion et al., 2000). However, these cross-country studies have little to say about the relationship between emissions and income within countries, let alone dealing with demand side emissions. The argumentation behind the EKC is methodologically on a more aggregate level and the discussed mechanisms cannot be transferred to the household level. Although Ravallion et al. (2000) already emphasized the importance of consumer demand for non-linear effects of income of emissions, studies that deal explicitly with this question on the household level are rare. For transport related emissions Kahn (1998) and Cox et al. (2012) discuss the existence of an EKC on the household level but studies covering all direct and indirect household emissions are almost non-existent. As an exception, Golley and Meng (2012) calculate carbon footprints for urban Chinese households and find a slightly increasing MPE.

Carbon footprints for Indian households and earlier years have been calculated by Parikh et al. (1997) combining IO-data from 1989-90 and household data for the years 1987-88. Their paper presents differences in consumption patterns across income groups and their carbon dioxide implications. A main finding is that the rich have a more carbon intensive lifestyle with the urban emission levels being 15 times as high as those of the rural poor. Apart from carbon footprints, closely related energy requirements of Indian households have been calculated by Pachauri and Spreng (2011) for the years 1983-84, 1989-90 and 1993-94. 
Based on IO-analysis, they find that household energy requirements have significantly increased over time identifying growing income, population and increasing energy intensity in the food and agricultural sectors as the main drivers. Based on this analysis, Pachauri (2004) presents cross-sectional variations in total household energy requirements. Using household consumption expenditure data for 1993-1994 matched with energy intensities calculated by Pachauri and Spreng (2011), an econometric estimation reveals income levels as the main factor determining variation in energy requirements across households.

Hertwich and Peters (2009) analyze the carbon footprint of nations by applying IO analysis with data from the Global Trade Analysis Project. Therewith they construct a multiregional input-output model to estimate the carbon footprint based on four major GHGs measured in $\mathrm{CO}_{2}$ equivalents. The focus is on eight expenditure categories, such as food, clothing and mobility, and their contribution to the national carbon footprint. They find a per capita carbon footprint of about $1.8 \mathrm{t} \mathrm{CO}_{2}$ equivalents for India in 2001.They also find that $95 \%$ of Indian emissions are from final consumption of households. Since we only focus on $\mathrm{CO}_{2}$ emissions and different years, these results are hardly comparable to our results. The following analysis provides an update on carbon footprints in India and a detailed analysis of the relationship with consumption on the household level.

\subsection{Methodology}

\subsubsection{Deriving the carbon footprint}

We combine energy IO analysis with emission factors and household expenditures for goods and services to estimate the carbon footprint for Indian households. Therewith, we can trace the carbon content of each final consumption item back to its intermediates and account for the direct as well as indirect emissions from consumption. We focus on carbon emissions from fossil fuels since $\mathrm{CO}_{2}$ emissions represent the largest share of $\mathrm{GHG}$ emissions and other GHG emissions are not available on the used detailed sectoral level. The method which has been applied is based on Leontief (1970) and we follow the approach of Proops et al. (1993) and Lenzen (1998b) summarized in Munksgaard et al. (2009). In a first step we estimate the $\mathrm{CO}_{2}$ intensities (in local currency unit) of each sector of the Indian economy. We apply a single region IO model based on data from the Global Trade Analysis Project (GTAP). By using a single region IO model we account for direct and indirect emissions from goods produced and consumed in India as well as for emissions from imported goods.

IO tables for the year 2004 are from the Indian Central Statistical Organisation (CSO) which provide us with an $[j \times 1]$ vector of domestic output $x$ by $130 \operatorname{sectors} j, \mathrm{a}[j \times 1]$ 
vector of final demand $y$ by 130 sectors $j$ (which includes imports). ${ }^{2}$ The $A[j \times j]$ matrix of the technical coefficients $A$ reflect the input requirements of the $j$ th sector of intermediates from other sectors measured in monetary units. ${ }^{3}$ The domestic technology assumption is applied with the assumption that imported goods are produced with the same technology as local goods. We also assume that technology has not changed drastically between 2004 and 2011 since we use the same IO table to estimate the emission intensities of sectors for 2011. ${ }^{4}$ Depending on the fuel type the $\mathrm{CO}_{2}$ emissions per unit of fuel use are represented in the emission coefficient vector $c[m \times 1]$. The $[m \times j]$ energy use matrix $E_{\text {ind }}$ represents the quantitative energy demand of the 58 sectors per monetary unit of intermediate output from other sectors. The energy use matrix $E_{f d}$ represents the household's fuel quantitative use per monetary unit of final demand from 58 sectors. ${ }^{5}$ Total emissions from consumption $\mathrm{CO}_{2}$ would consist of direct $\mathrm{CO} 2_{f d}$ from final demand and indirect $\mathrm{CO} 2_{\text {ind }}$ emissions from energy use by each sector. In the first step we match the 130 sectors of our IO tables with the energy use data, which is aggregated to 58 sectors in order to get the energy intensity matrix $E$. Secondly, we match the 58 sector emission intensities with the corresponding expenditure categories from the household survey data. The data on household expenditure is rather disaggregated and we match all the approximately 340 expenditure categories with the corresponding emission intensities. Even though the IO tables contain information on monetary fossil fuel and electricity demand we still need to refer to the quantitative energy intensity data from GTAP to gain a more precise estimate on emissions per sector.

We analyze the sum of direct and indirect emissions from industrial sectors. Direct emissions from final demand can be characterized as follows:

$$
C O 2_{f d}=c^{\prime} E_{f d} y
$$

where $c^{\prime}$ represents the inverse emissions coefficient vector, $E_{f d}$ is the energy use matrix and $y$ is the final demand vector. Indirect emissions $C O 2_{\text {ind }}$, which are divided into emissions from domestic production for domestic final demand, emissions from imported intermediates and emissions from imported final demand. ${ }^{6}$ The emissions by sector can be estimated by multiplying the demand of each sector represented as vector $y$ with the transposed emissions coefficients vector $c$ and the industrial energy use matrix $E_{\text {ind }}$ as well as the with the domestic

\footnotetext{
${ }^{2}$ The 130 sectors include administration and defence.

${ }^{3}$ All values are in local currency units at 2004 producer prices.

${ }^{4}$ This assumption is confirmed by the emission intensities per sector from the World Input Output Database (WIOD), which did not change drastically in India for available years between 2004 and 2009

${ }^{5}$ The data by the GTAP energy volume data is disaggregated into 58 sectors, which were matched with the 130 sectors from the Indian IO tables.

${ }^{6}$ Exports are excluded.
} 
Leontief inverse $(I-A)^{-1}$ :

$$
\begin{aligned}
C O 2_{\text {ind }}= & c^{\prime} E_{\text {ind }}\left[(I-A)^{-1} y_{\neq \exp }+\left(\left(I-A_{\text {tot }}\right)^{-1}-(I-A)^{-1}\right) y_{\neq \exp }\right. \\
& +\left(I-A_{\text {tot }}\right)^{-1} y_{\text {imp }} \text { fexp }
\end{aligned}
$$

where $A_{\text {tot }}=A+A_{\text {imp }}, y_{\text {tot }}=y+y_{\text {imp }}$ and $y_{\neq \text {exp }}$ is domestic final demand, $I$ represents an identity matrix and $A$ is the technical coefficients matrix, which mirrors the contribution of the intermediates to one final output unit. Additional to these direct and indirect production emissions, households directly use fuels which are unaccounted for in the IO analysis. With observed quantities in the survey data, we calculate direct carbon intensities for kerosene, liquefied petroleum gas (LPG), petrol and diesel. ${ }^{7}$ Another correction is necessary for electricity emission intensities, due to the block-tariff nature of electricity expenditures. Since prices per kilowatt hour rise with the usage of electricity, we find no constant but household specific carbon intensities. Lower income households with small electricity demand have higher carbon intensities per currency unit than higher income households with large demand. The calculation is based on observed quantities of electricity demand. ${ }^{8}$

Direct emissions from fuel use $\mathrm{CO}_{f d}$ and direct and indirect production emissions $\mathrm{CO} 2_{\text {ind }}$ embedded in consumption (with the exception of electricity)can be estimated by:

$$
\begin{aligned}
C O 2= & c^{\prime}\left[E_{f d} y_{h h}+E_{\text {ind }}\left(\left(I-A_{\text {tot }}\right)^{-1} y_{\neq \exp }+\left(\left(I-A_{\text {tot }}\right)^{-1}-(I-A)^{-1}\right) y_{\neq \exp }\right.\right. \\
& \left.\left.+\left(I-A_{\text {tot }}\right)^{-1} y_{\text {imp }}\right)\right]
\end{aligned}
$$

In order to estimate the household carbon footprint we multiply the carbon intensity $\sigma=c^{\prime}\left[E_{f d}+E_{\text {ind }}(I-A)^{-1}\right]$ per local currency unit of each industrial sector with the household expenditure for the respective category and sum up over all consumption categories for each household. Therewith we gain the household carbon footprint $\mathrm{CO} 2_{h h}$ for each household in tonnes (t) of $\mathrm{CO} 2$.

$$
C O 2_{h h}=\sum_{j=1}^{n}\left(\sigma_{j} * \exp _{j}\right)
$$

where $i$ represents the household and $j$ the different expenditure category. The household expenditure data for the carbon footprint calculation is from the National Sample Survey Organisation (NSSO) India, with a sample size of approximately 125000 and 100000 house-

\footnotetext{
${ }^{7}$ Direct carbon contents are $0.00255 \mathrm{t} / 1$ (kerosene), $0.00159 \mathrm{t} / \mathrm{kg}(\mathrm{LPG}), 0.00231 \mathrm{t} / 1$ (petrol) and $0.00273 \mathrm{t} / 1$ (diesel).

${ }^{8}$ Electricity production carbon intensity is taken as $0.001003 \mathrm{t} / \mathrm{kwh}$ (IPCC, 2005)
} 
holds in 2004/05 (61st round) and 2011/12 (68th round) respectively. Household expenditures are disaggregated into around 346 consumption items which we aggregate to 19 expenditure groups (for a description of expenditure groups see table 2.1 and the matching scheme with CSO IO tables for 2011/12, see table A.1). ${ }^{9}$

\subsubsection{Income dynamics of the carbon footprint}

The relationship between economic development and the environment has been divided into three components by the economic literature (Copeland and Taylor, 2005; Grossman and Krueger, 1994). First, the scale effect is simply the increase in pollution with economic activity. Second, the technique effect describes the pollution intensity of production activities. Third, the composition effect deals with the mixture of economic operations. Originally invented to describe the aggregate relationship between economic growth and environmental pollution, this classification can also be used for economic activity on the household level. By definition (equation 2.4), the household carbon footprint depends entirely on the consumption of goods and the carbon intensity of consumption goods. The total consumption size reflects the scale effect and the carbon intensity the technique and composition effect. With just one estimate of the production carbon intensities and assumed constant values over time between our used surveys, we focus exclusively on the scale and composition effect. Alternatively, the relationship of carbon footprints and income and household specific characteristics could be analyzed in a cross-section regression framework as demonstrated by Wier et al. (2001) and Pachauri (2004) for household energy requirements. Levinson and O'Brien (2015) estimate a parametric function of household local pollutant footprints depending on income and several household characteristics. They name this approach the estimation of environmental Engel curves and find generally concave curves for local pollutants for US households but do not include $\mathrm{CO}_{2}$ emissions. However, this reduced form approach may has considerable drawbacks. The first originates from a theoretical standpoint. Households target their consumption at goods which fulfil their needs under the income constraint, while pollution represents an externality that is neither explicitly taken into account nor is it an aim to maximize or minimize the environmental footprint. Such an analysis is therefore more limited to an interpretation of correlations. Secondly, endogeneity can never be ruled out in this approach since the carbon footprint is explicitly defined as the sum of the product of group expenditures and carbon intensities. Total expenditures as a proxy for income are highly correlated with any other explanatory factor for carbon footprints including potential unobserved factors. The third drawback of this approach is the missing information about the

\footnotetext{
${ }^{9}$ The classification is very similar for 2004/05 and available upon request.
} 
consumption categories driving the change in household carbon footprint at different points of the income distribution. While the coefficient for income explains the carbon intensity of consumption when all other variables are held constant, we have no information which consumption items are responsible for this change. We expect some categories to drive the carbon footprint more than others, revealing valuable information for further energy and climate mitigation policies. To deal with these issues we employ a structural model by estimating a household demand system for various consumption items. Since we do not have price data available for the household expenditure items, we assume constant prices and estimate Engel curves only dependent on income and socioeconomic characteristics of the households. The model to be estimated is a simple extended version of Working (1943) and Leser (1963) with a squared income term and has the following form:

$$
w_{i j}=\alpha_{j}+\beta_{i j} \log \left(y_{j}\right)+\lambda_{i j}\left(\log \left(y_{j}\right)\right)^{2}+\varepsilon_{i j}
$$

The necessity of including squared logarithmic terms for some expenditure items has been demonstrated in a series of empirical studies (Banks et al., 1997; Blundell et al., 1993; Hausman et al., 1995; Lewbel, 1991). They account for a higher degree nonlinear relationship between budget shares and income than is allowed for in some popular specifications of demand models such as the Translog (Christensen et al., 1975) and the Almost Ideal Demand System (Deaton and Muellbauer, 1980). In equation 2.5, $w_{i j}$ represents the share of total expenditures allocated to the ith consumption category by the jth household, $\log y_{j}$ the income of household $\mathrm{j}$ in $\operatorname{logs}$ and the error term $\varepsilon_{i j}$. With no income information available in the survey, we use total expenditures per household as a proxy for income. Aggregating household expenditures into 19 categories (see section 2.4), we estimate this system of equations with a feasible generalized nonlinear least squares two-step estimator. The demographic demand shifters household size, age and education are included in the $\alpha_{i j}$ term.

As the budget shares are defined as $w_{i}=\frac{e x p_{i}}{y_{i}}$ it is convenient to obtain income elasticities relative to $\exp _{i}$ :

$$
e_{i}=\frac{\left(\beta_{i}+2 \lambda_{i} \log \left(y_{i}\right)\right)}{w_{i}}+1
$$

Deaton (1997) points to potential simultaneity bias, which is caused by richer households buying high quality products, which are more expensive. As households get richer they do not consume more of a certain good and cause more carbon emissions but they consume higher quality goods, which may not have to be related with higher carbon emissions than the lower quality items of the same consumption category. To partly account for this quality bias we split the sample for the analysis into rural and urban. Another problem is the occurrence 
of zero expenditures, which are less of an issue for daily requirement goods such as food but more so for education, medical and personal goods which are either infrequently purchased or never due to income constraints. We apply the correction procedure of Shonkwiler and Yen (1999), which is based on Heckman (1976, 1979). First, a household specific probit model is estimated with the outcome of 1 if the household consumes good $i$ and 0 otherwise. For each household, the standard normal probability density function (pdf) $\Phi\left(z_{i h}, w_{i}\right)$ and the cumulative distribution function (cdf) $\phi\left(z_{i h}, w_{i}\right)$ are calculated by regressing $w_{i}$ on a set of independent variables $z_{i h}$. Secondly, the pdf and the cdf are integrated into the system of equations as follows:

$$
w_{i}^{*}=\Phi w_{i}+\varphi_{i} \phi
$$

Based on (2.7), the new expenditure levels are calculated for each household in the sample. Accordingly, new footprints are calculated as:

$$
C O 2_{h h}^{s i m}=\sum_{j=1}^{19} \sigma_{j} \exp _{j}^{\text {sim }}
$$

The difference between the simulated and the baseline footprint following a 1 percent increase in income can be directly interpreted as the income elasticity of $\mathrm{CO}_{2}$ for the respective subsample. This elasticity can also be interpreted as a version of the marginal propensity to emit (MPE) on the household level. In order to understand the role of changing consumption patterns for the emission of $\mathrm{CO}_{2}$, we decompose the changes of the carbon footprint into the share each consumption category has in explaining the rise of the footprint. The MPE is therefore directly decomposable into consumption items.

\subsection{Results}

\subsubsection{Household $\mathrm{CO}_{2}$ requirements}

The average $\mathrm{CO}_{2}$ emission intensities for 2011/12 and for 19 aggregate consumption groups and items are displayed in Figure 2.1. Emission intensities vary strongly between the consumption categories with the highest emission intensity per currency unit for electricity, followed by kerosene and LPG. Further, toiletry, medical and clothing as well as transport items exhibit relatively high carbon intensities due to the manufacturing process of those goods or direct energy use in the case of transport. Animal protein, which accounts for dairy as well as any kind of meat products or fish, exhibits a low carbon intensity since we only account for emissions from fossil fuels and not for other greenhouse gases such as methane 
or nitrous oxide. The carbon intensity of the category vegetables $\&$ fruits, which includes all non-animal agricultural produce, is higher than of animal protein since there is more input from other emission intensive sectors. We observe low emission intensities for education and vegetables, which contains all the agricultural goods apart from meat, dairy or fish. Since $2004 / 05$, electricity is the only average carbon intensity which changed with a clear upward trend (Appendix Figure A.1). With a rising electrification rate, this is driven by relatively low electricity demand from lower income households and associated higher carbon intensities through the increasing block-tariff schedule.

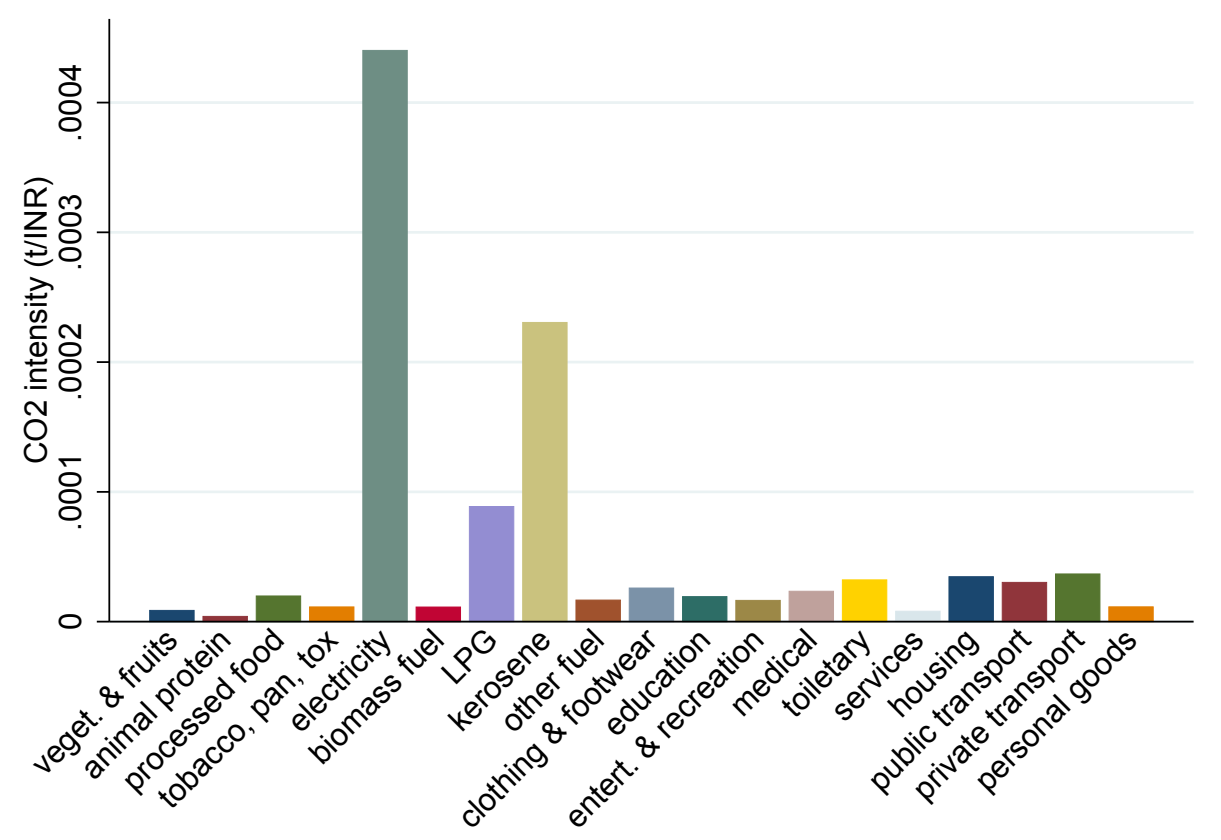

Fig. 2.1 Carbon intensities of expenditure Sub-Groups (2011/12)

Table 2.1 gives an overview on what households spent their income on in 2004/05 and 2011/12. The structure of the expenditure shares varies largely between rural and urban households. Rural households spent a larger fraction of their income on agricultural goods and a smaller share on housing (including rent) and transport than urban households. Table 2.1 also reveals that expenditure shares for vegetables and fruits were declining between the two time periods for both rural and urban households. Despite the increase in animal protein expenditures, total food budget shares decline with rising income as predicted by Engels law.

The resulting average per capita footprint is at $0.7 \mathrm{tCO}_{2}$ in $2011 / 12$, less than half the size of per capita $\mathrm{CO}_{2}$ production emissions which are at $1.7 \mathrm{t}$ in 2012. This difference is due to smaller reported survey expenditures and smaller indicated total population in the survey, measured as the sum of individual weights. Regarding the difference between survey 
and national accounts data, there are a variety of reasons discussed in the literature from selection issues to item nonresponse (Deaton, 2005) other conceptual issues. There is also the possibility that the national accounts data has serious quality issues since the consumption aggregate is determined residually and definitions of consumption is different from the survey data (Datt et al., 2016; Deaton, 2005; Sen, 2000). As we have no reliable information on the exact nature of the bias in the used national accounts and survey data, we refrain from scaling the survey data with a constant factor to make it comparable with the national accounts. Such a procedure would have little influence on the further analysis which mainly focuses on carbon footprint changes over the income distribution.

(a)

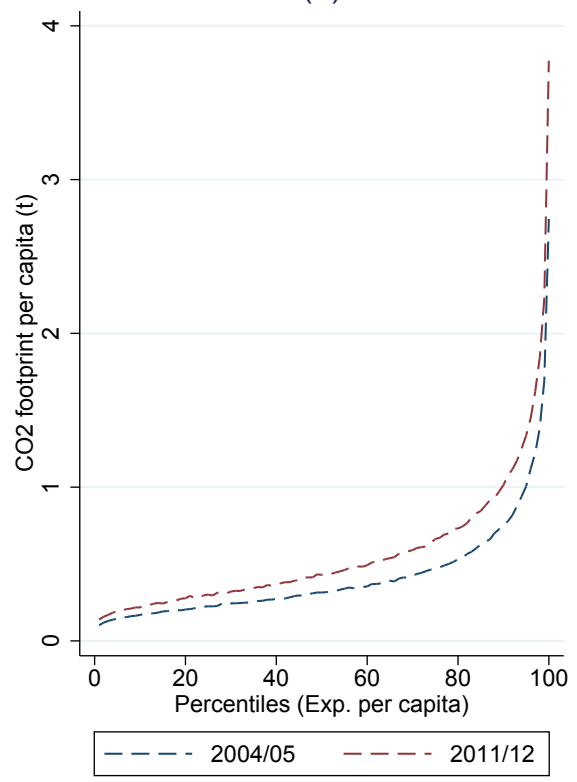

(b)

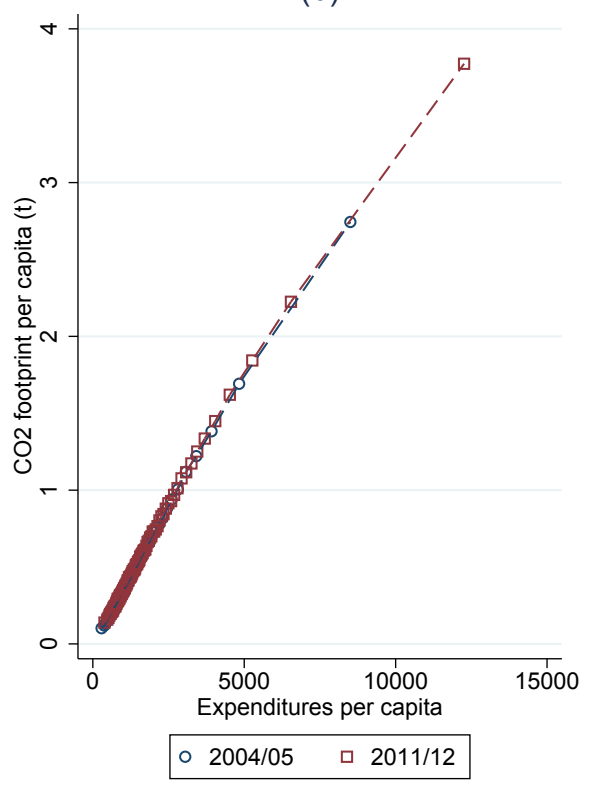

Fig. 2.2 Household carbon footprint per capita

We find large differences for carbon footprints over the income distribution as displayed in Figure 2.2. The 2011/12 average per capita carbon footprint of the 10 percent richest household is with $1.6 \mathrm{t} \mathrm{CO}_{2}$ about 11 times higher than the carbon footprint of the poorest 10 percent with $0.15 \mathrm{t} \mathrm{CO}_{2}$. An almost linear relationship between per capita footprints and average per capita income per percentile can be observed for the bottom 80 percent of the population (Figure 2.2a). Behind this threshold, a clear nonlinear increase of footprints over income percentiles can be observed. Opposed to the optical impression, it does not imply a general nonlinear relationship between carbon footprints and income. The top income percentiles are much more compressed since they have a much larger income variation than low and middle income percentiles. Income and carbon footprints are in fact almost linearly 
related, with a slight concave curvature, displayed in Figure 2.2b. Between 2004/05 and 2011/12 growth in per capita carbon footprints grow along the same almost linear curve (Figure 2.2b) at the same real income level (in 2011 prices). Although it can be inferred that richer households are responsible for larger increases in carbon footprints, these absolute figures hide an important fact about the dynamics of emission growth over the population and over time. Despite the fact that annual average expenditure per capita growth rates have been larger for middle and high income households (Figure 2.3a), the carbon footprint per capita growth rates have been larger for lower income households. In fact, the growth rate in mean for carbon footprints is larger than for expenditures, indicating an average $\mathrm{CO}_{2}$-expenditure elasticity larger than 1 .

(a)
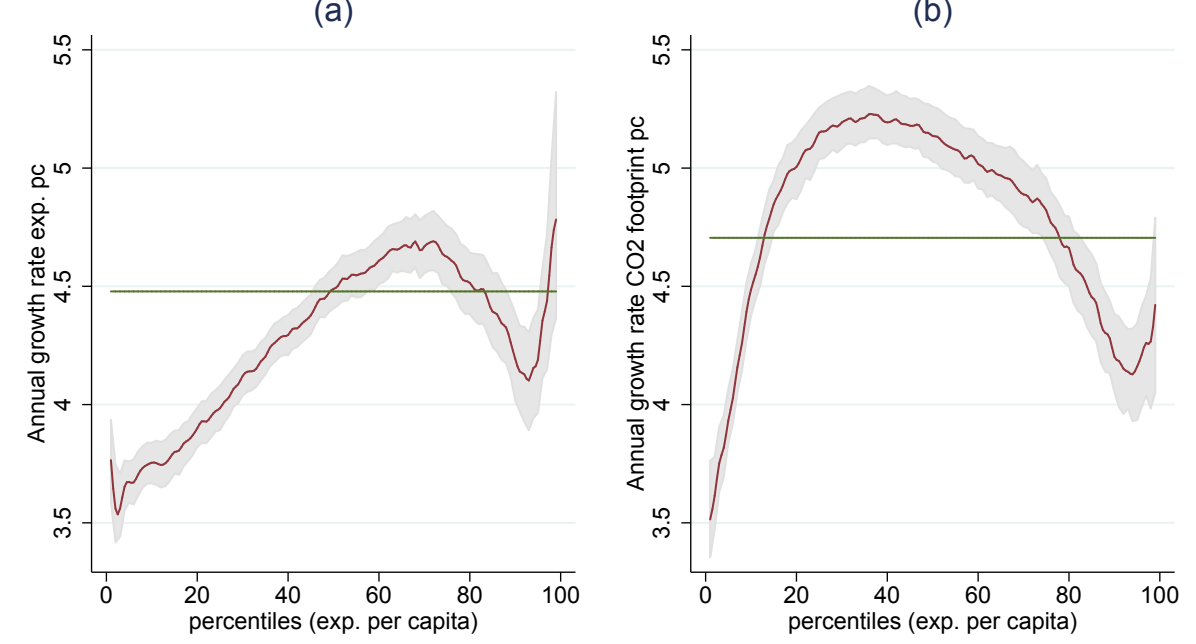

Upper $95 \%$ confidence bound/Lower $95 \%$ confidence bound Median spline

Growth rate in mean

Fig. 2.3 Expenditure and carbon footprint per capita growth incidence curves (2004/052011/12)

The carbon footprints have therefore risen more than proportional with expenditure growth, a fact that can be explained by consumption patterns and the associated carbon intensity of consumption. Over the expenditure distribution, the carbon intensity of consumption is increasing (Figure 2.4a) but has been growing stronger for the bottom 60 percent of the expenditure distribution over the last years (Figure 2.4b).

Responsible for this increase in the carbon intensity is a shift towards more carbon intensive consumption goods. Due to the high carbon intensity, particularly for low demand, rising electrification rates explain most of this increase. The carbon intensity of consumption 
(a)

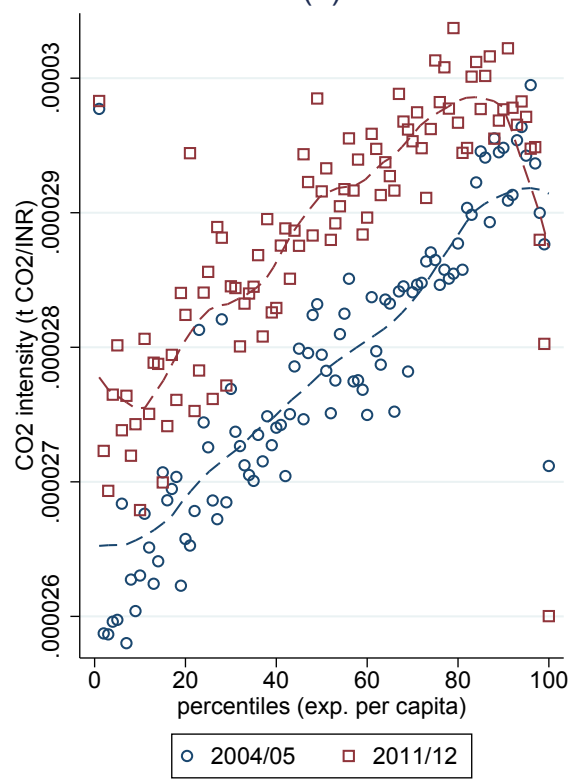

(b)

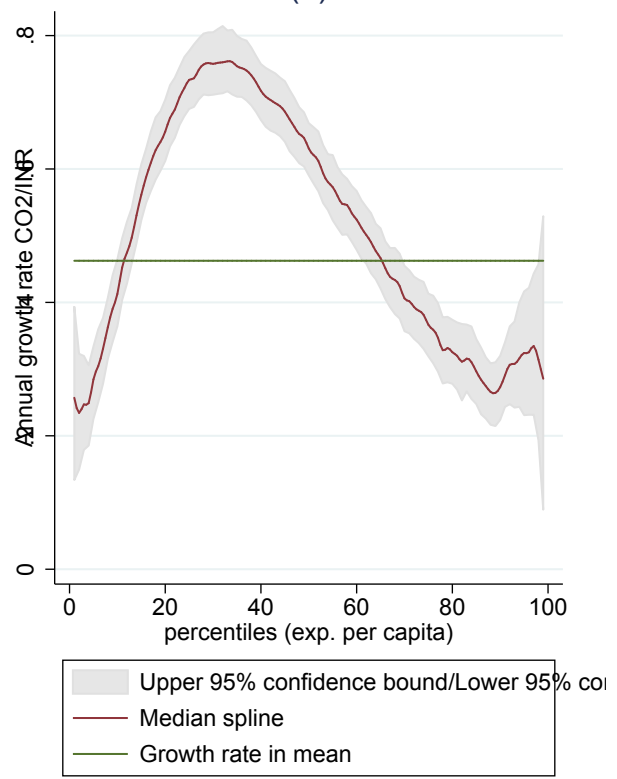

Fig. 2.4 Carbon intensity of consumption (2004/05 - 2011/12)

appears to have a certain income threshold when household shift their consumption towards less carbon intensive goods. Urban households appear to reduce the carbon intensity of consumption earlier than their rural counterparts. For a majority of the population however, it implies a more than proportional rise in carbon footprints when income increases. Beyond the size and composition of consumption varying with preferences at different income levels, other household characteristic may also be responsible for different carbon requirements. Urban households have on average a higher per capita footprint than rural households which also holds over the entire income distribution (Figure 2.5). ${ }^{10}$ Beyond the location of the household in urban or rural areas, other sociodemographic factors have been frequently used in trying to explain within country cross-sectional variation in regression analyzes of energy use and $\mathrm{CO}_{2}$ emissions (Pachauri, 2004; Wier et al., 2001). We opt for a nonparametric procedure and use kernel-weighted local polynomial smoothing to plot the carbon footprint per capita over income percentiles for different household characteristics (Figure 2.5). We observe a slightly higher pr capita footprint for households with older household heads above the 80th percentile. This might be due to higher direct energy needs of older households but the difference is small. Slightly higher footprints can also be observed for households with higher educated household heads, but differences are again negligible. Small but negligible

\footnotetext{
${ }^{10}$ Nonparametric distributional curves are calculated with kernel-weighted local polynomial smoothing using an epanechnikov kernel function with degree 0 and bandwith 1.15
} 
economies of scale in consumption and energy use are present when comparing different household sizes over the income distribution. These findings confirm earlier studies that sociodemographic (and sociocultural) information is of little importance for the determination of household energy and $\mathrm{CO}_{2}$ requirements (Pedersen, 2000; Stokes et al., 1994; Wier et al., 2001). Although available studies are from developed countries, there is little reason why demographic variables should play a larger role in developing countries as confirmed here. Despite the clear observed patterns, past trends of emissions embedded in consumption may not necessarily hold in the future. Particularly the electrification rate is projected to be close to 100 percent in the coming years, and initially large relative emission increases for lower income households may diminish. To provide an analytical tool how to evaluate the role of the different consumption items driving the carbon footprints, an Engel curve analysis is presented in the next section.
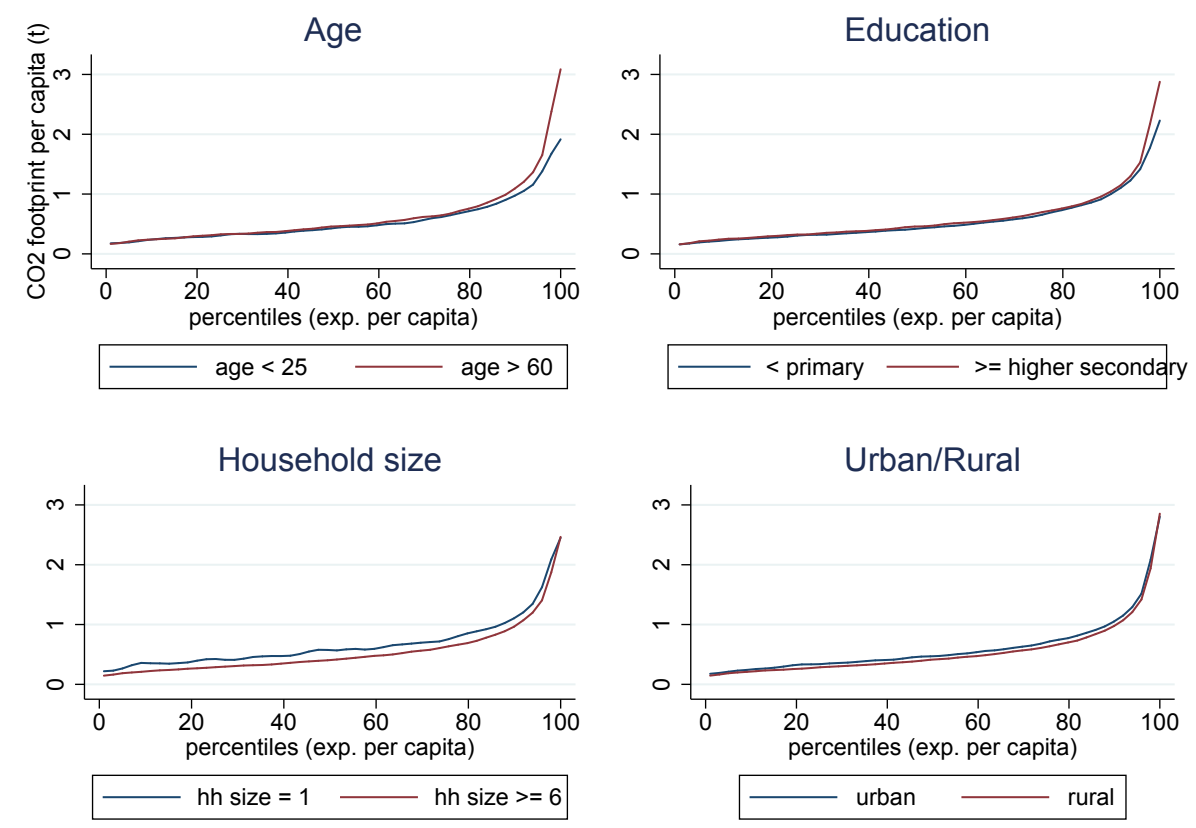

Fig. 2.5 Carbon footprints and sociodemographic factors (2011/12) 


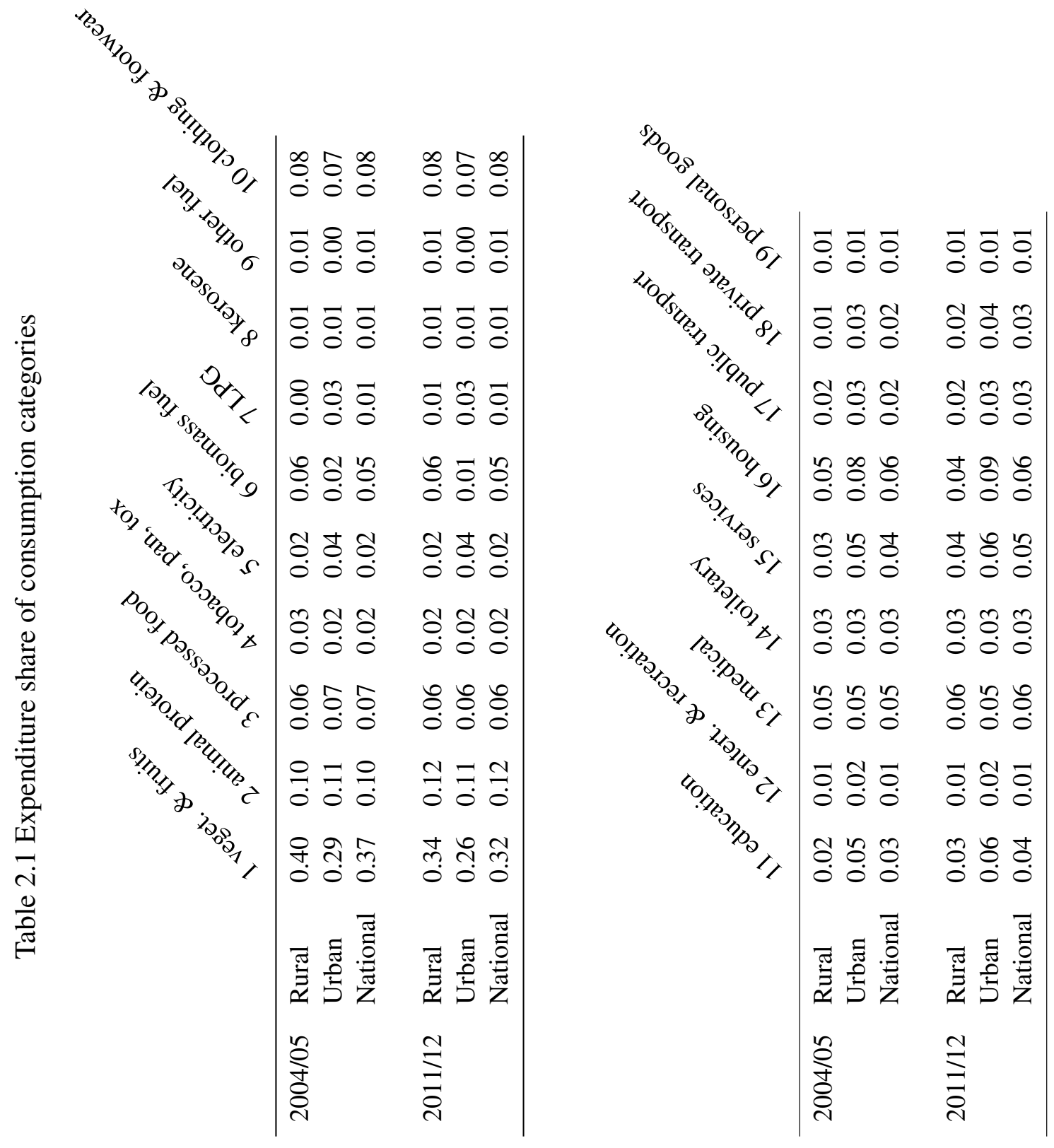




\subsubsection{Income and carbon elasticities of consumption}

Income elasticities for income quintiles and urban and rural populations separately are calculated based on coefficients from equation 2.5. We calculate elasticities individually for households and calculate average values for quintiles, divided into urban/rural and weighted by the household expenditure share of total sample expenditures in the respective category. Table 2.2 displays urban income elasticities, which widely differ depending on the income level. As expected, elasticities for agricultural products and animal protein decline with rising income. The income responses for the high carbon intensive consumption items differ significantly between the items and over the expenditure distribution. Electricity is almost a luxury good for the bottom quintile and the elasticity stays close to one with rising income. Other domestically used direct energy items are necessities, opposed to transport expenditures which are clearly luxury goods at all expenditure levels.

For rural households, estimated consumption responses for income changes reflect differing preferences (Table 2.3). Public transport is estimated to be an inferior good at all income levels whereas private transport is quite a popular luxury good. Electricity income elasticities are also close to one for most households but describe electricity to be more of a luxury good for the top quintile. Lower income rural households also buy relatively more LPG than their urban counterparts when income rises. Considering less carbon intensive products, expenditures for housing are a luxury for rural households but less so than for urban households despite the on average smaller housing spending shares. Besides the size of income effects, also sample sizes differ considerably between rural and urban income groups. Due to a large urban-rural income disparity, the bottom three urban quintile samples are small, the same holds for the top rural income quintile sample. Transport is found to be a luxury good for all households, which is particularly important due to its high carbon intensity. Households in India are expected to increase spending on transport across all income levels. For domestically used energy, rural households are still catching up in demand and exhibit income elasticities close to one.

To understand the implications for carbon emissions, we calculate carbon footprint changes resulting from a 1 percent income increase which results in income elasticities of carbon footprints or the marginal propensity to emit (MPE). For the different population groups, the resulting total elasticities are all close to 1 but differ to some extent depending on the income level and living in urban or rural areas (Tables 2.4 and 2.4). An income elasticity of the carbon footprint of 1 would rule out any change in the carbon intensity of consumption and income would be the only driver. The pattern we observe from the estimation of demand is that on average all urban households increase their carbon footprint elastically, exhibiting an MPE slightly above 1 . 
Table 2.2 Income elasticities (urban)

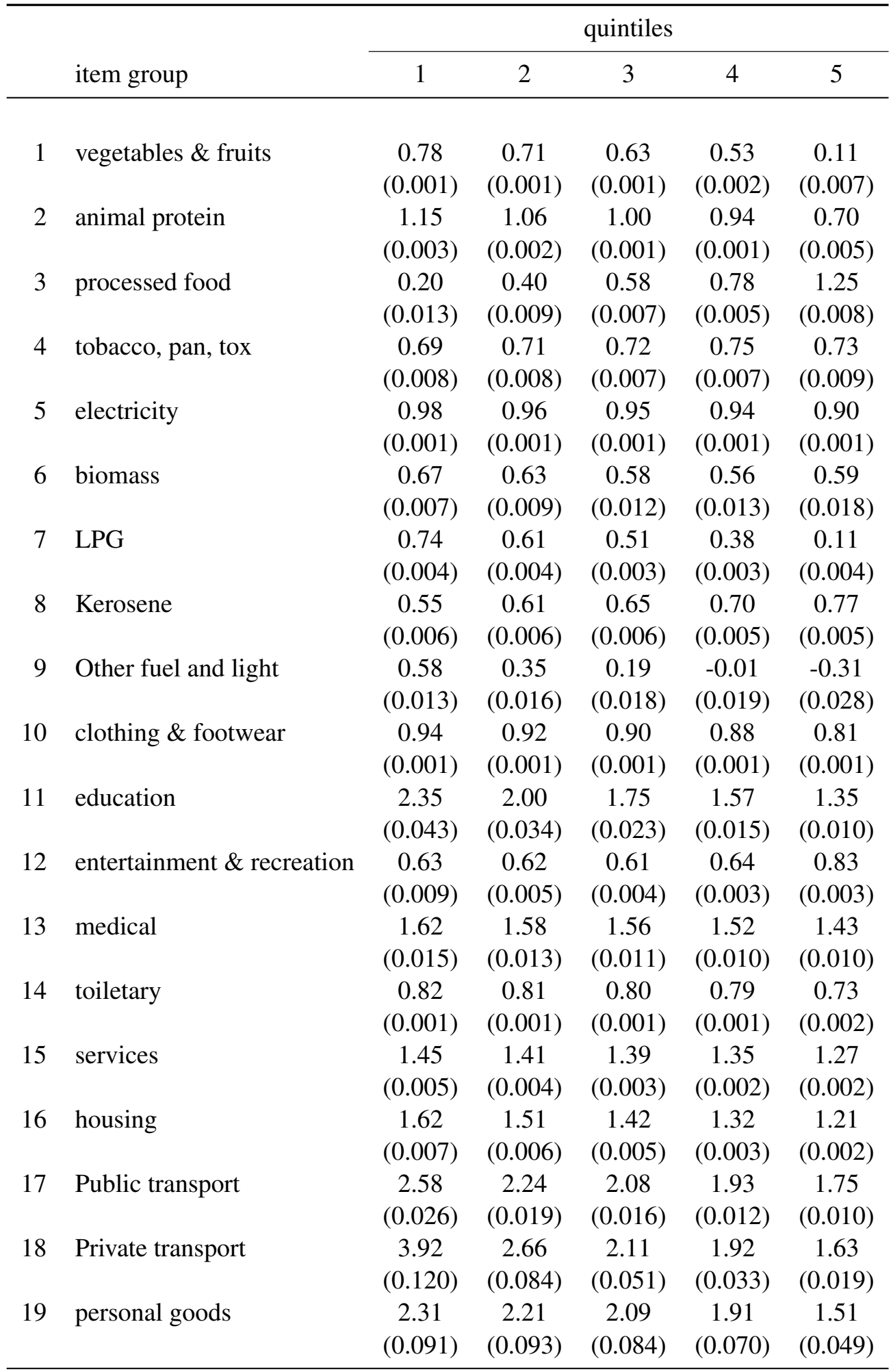

standard errors in parentheses 
Table 2.3 Income elasticities (Rural)

\begin{tabular}{|c|c|c|c|c|c|c|}
\hline & \multirow[b]{2}{*}{ item group } & \multicolumn{5}{|c|}{ quintiles } \\
\hline & & 1 & 2 & 3 & 4 & 5 \\
\hline 1 & vegetables \& fruits & $\begin{array}{c}0.71 \\
(0.001)\end{array}$ & $\begin{array}{c}0.63 \\
(0.001)\end{array}$ & $\begin{array}{c}0.56 \\
(0.001)\end{array}$ & $\begin{array}{c}0.43 \\
(0.002)\end{array}$ & $\begin{array}{c}0.03 \\
(0.011)\end{array}$ \\
\hline 2 & animal protein & $\begin{array}{c}1.31 \\
(0.003)\end{array}$ & $\begin{array}{c}1.19 \\
(0.002)\end{array}$ & $\begin{array}{c}1.13 \\
(0.001)\end{array}$ & $\begin{array}{c}1.08 \\
(0.001)\end{array}$ & $\begin{array}{c}0.92 \\
(0.005)\end{array}$ \\
\hline 3 & processed food & $\begin{array}{c}0.87 \\
(0.001)\end{array}$ & $\begin{array}{c}0.90 \\
(0.001)\end{array}$ & $\begin{array}{c}0.91 \\
(0.001)\end{array}$ & $\begin{array}{c}0.93 \\
(0.001)\end{array}$ & $\begin{array}{c}0.99 \\
(0.002)\end{array}$ \\
\hline 4 & tobacco, pan, tox & $\begin{array}{c}0.77 \\
(0.003)\end{array}$ & $\begin{array}{c}0.81 \\
(0.003)\end{array}$ & $\begin{array}{c}0.83 \\
(0.003)\end{array}$ & $\begin{array}{c}0.85 \\
(0.003)\end{array}$ & $\begin{array}{c}0.88 \\
(0.005)\end{array}$ \\
\hline 5 & electricity & $\begin{array}{c}0.89 \\
(0.001)\end{array}$ & $\begin{array}{c}0.89 \\
(0.001)\end{array}$ & $\begin{array}{c}0.90 \\
(0.001)\end{array}$ & $\begin{array}{c}0.92 \\
(0.001)\end{array}$ & $\begin{array}{c}1.01 \\
(0.003)\end{array}$ \\
\hline 6 & biomass & $\begin{array}{c}0.39 \\
(0.004)\end{array}$ & $\begin{array}{c}0.28 \\
(0.005)\end{array}$ & $\begin{array}{c}0.17 \\
(0.007)\end{array}$ & $\begin{array}{c}0.02 \\
(0.011)\end{array}$ & $\begin{array}{c}-0.24 \\
(0.023)\end{array}$ \\
\hline 7 & LPG & $\begin{array}{c}0.92 \\
(0.002)\end{array}$ & $\begin{array}{c}0.83 \\
(0.002)\end{array}$ & $\begin{array}{c}0.73 \\
(0.003)\end{array}$ & $\begin{array}{c}0.60 \\
(0.003)\end{array}$ & $\begin{array}{c}0.55 \\
(0.011)\end{array}$ \\
\hline 8 & Kerosene & $\begin{array}{c}0.41 \\
(0.003)\end{array}$ & $\begin{array}{c}0.38 \\
(0.004)\end{array}$ & $\begin{array}{c}0.40 \\
(0.004)\end{array}$ & $\begin{array}{c}0.43 \\
(0.006)\end{array}$ & $\begin{array}{c}0.68 \\
(0.012)\end{array}$ \\
\hline 9 & Other fuel and light & $\begin{array}{c}0.47 \\
(0.008)\end{array}$ & $\begin{array}{c}0.39 \\
(0.009)\end{array}$ & $\begin{array}{c}0.28 \\
(0.011)\end{array}$ & $\begin{array}{c}0.18 \\
(0.014)\end{array}$ & $\begin{array}{c}0.15 \\
(0.024)\end{array}$ \\
\hline 10 & clothing \& footwear & $\begin{array}{c}0.94 \\
(0.000)\end{array}$ & $\begin{array}{c}0.90 \\
(0.001)\end{array}$ & $\begin{array}{c}0.87 \\
(0.001)\end{array}$ & $\begin{array}{c}0.84 \\
(0.001)\end{array}$ & $\begin{array}{c}0.68 \\
(0.005)\end{array}$ \\
\hline 11 & education & $\begin{array}{c}2.44 \\
(0.028)\end{array}$ & $\begin{array}{c}1.96 \\
(0.020)\end{array}$ & $\begin{array}{c}1.67 \\
(0.015)\end{array}$ & $\begin{array}{c}1.44 \\
(0.012)\end{array}$ & $\begin{array}{c}1.24 \\
(0.015)\end{array}$ \\
\hline 12 & entertainment \& recreation & $\begin{array}{c}0.82 \\
(0.003)\end{array}$ & $\begin{array}{c}0.83 \\
(0.002)\end{array}$ & $\begin{array}{c}0.84 \\
(0.002)\end{array}$ & $\begin{array}{c}0.89 \\
(0.002)\end{array}$ & $\begin{array}{c}1.11 \\
(0.013)\end{array}$ \\
\hline 13 & medical & $\begin{array}{c}2.24 \\
(0.016)\end{array}$ & $\begin{array}{c}2.09 \\
(0.015)\end{array}$ & $\begin{array}{c}1.92 \\
(0.015)\end{array}$ & $\begin{array}{c}1.75 \\
(0.015)\end{array}$ & $\begin{array}{c}1.47 \\
(0.016)\end{array}$ \\
\hline 14 & toiletary & $\begin{array}{c}0.80 \\
(0.001)\end{array}$ & $\begin{array}{c}0.79 \\
(0.001)\end{array}$ & $\begin{array}{c}0.78 \\
(0.001)\end{array}$ & $\begin{array}{c}0.75 \\
(0.001)\end{array}$ & $\begin{array}{c}0.64 \\
(0.005)\end{array}$ \\
\hline 15 & services & $\begin{array}{c}1.36 \\
(0.003)\end{array}$ & $\begin{array}{c}1.28 \\
(0.002)\end{array}$ & $\begin{array}{c}1.24 \\
(0.002)\end{array}$ & $\begin{array}{c}1.20 \\
(0.001)\end{array}$ & $\begin{array}{c}1.12 \\
(0.002)\end{array}$ \\
\hline 16 & housing & $\begin{array}{c}1.26 \\
(0.002)\end{array}$ & $\begin{array}{c}1.29 \\
(0.002)\end{array}$ & $\begin{array}{c}1.29 \\
(0.002)\end{array}$ & $\begin{array}{c}1.28 \\
(0.003)\end{array}$ & $\begin{array}{c}1.29 \\
(0.007)\end{array}$ \\
\hline 17 & Public transport & $\begin{array}{c}-2.17 \\
(0.027)\end{array}$ & $\begin{array}{c}-1.60 \\
(0.023)\end{array}$ & $\begin{array}{c}-1.26 \\
(0.022)\end{array}$ & $\begin{array}{c}-1.03 \\
(0.025)\end{array}$ & $\begin{array}{r}-1.00 \\
(0.042)\end{array}$ \\
\hline 18 & Private transport & $\begin{array}{c}2.67 \\
(0.038)\end{array}$ & $\begin{array}{c}2.03 \\
(0.032)\end{array}$ & $\begin{array}{c}1.76 \\
(0.025)\end{array}$ & $\begin{array}{c}1.61 \\
(0.022)\end{array}$ & $\begin{array}{c}1.44 \\
(0.029)\end{array}$ \\
\hline 19 & personal goods & $\begin{array}{c}0.42 \\
(0.024)\end{array}$ & $\begin{array}{c}0.85 \\
(0.022)\end{array}$ & $\begin{array}{c}1.09 \\
(0.021)\end{array}$ & $\begin{array}{c}1.26 \\
(0.029)\end{array}$ & $\begin{array}{c}1.30 \\
(0.075)\end{array}$ \\
\hline
\end{tabular}

standard errors in parentheses 
Rural households have on average a MPE below 1, which is surprising considering the stronger growth in carbon footprints and carbon intensities due to higher electrification rates and direct energy use. While we expect a MPE above 1 particularly for low income households, the model has some limitations in correctly representing the discrete-continuous decision space for electricity and private transport demand. The MPE represents only continuous demand choices and the initial strong MPE rise through electrification is not incorporated. Despite this finding, the estimates for urban households, where electrification rates are fairly high, demonstrate how household carbon footprints and income is related. Once households have access to electricity, the MPE will unlikely to fall below 1 in the short- to medium-run in India.

Lower income household's carbon emissions stem to a large part from the agricultural sector. The MPE for vegetables and fruits is the second highest for these households, particularly in rural areas, but it is quickly declining with rising income. Urban households are increasingly buying processed food and do even more so with rising income at all income levels. Processed food contributes up to 6 percent of the rise in carbon footprints for urban households, an effect driven by very large income elasticities in this relatively low carbon intensive consumption category. The additional emissions from total food expenditures are continuously declining for all households in urban and rural areas down to 9 percent of the total increase. The largest item specific MPE can be found for electricity across all income levels and urban and rural areas. Up to 35 percent of the increase in footprints can be explained by higher direct energy use for electricity. As discussed above, urban households have higher MPEs than their urban counterparts, which directly results from higher electricity access rates. For all other domestically used energy, the item specific MPEs fall with rising income as LPG and kerosene demand does not rise infinitely. While emissions from food and domestic energy (except electricity) become less important with income growth, high elasticities drive emission growth from housing and particularly transport expenditures. The housing share of the total emission increase resulting from income growth increases from 10 to 15 percent for urban households from the first to the fifth quintile. Exceptionally strong is the MPE for private transport, driven by the luxury good character for all households. Rural households show relatively stronger footprint increases resulting from income growth. Up to 18 percent of the total emission rise can be explained by private transport demand. Urban households exhibit smaller MPEs for private transport but still major demand increases, reflecting their already higher consumption level. Emissions from direct energy use are sure to grow further for all income groups due to elastic income elasticities for electricity and transport with associated high carbon intensities. However, the growing share of direct energy use in carbon footprints growth does not imply that all other goods are becoming unimportant 
for emissions. Even for the top urban quintile, indirect emissions through the production of goods account for 50 percent of the emission increase. Although non-energy consumption items are less carbon intensive, they constitute the major share in total consumption and will continue to contribute significantly to rising carbon footprints. They are likely to contribute more when energy needs reach a saturation level where households do not need more energy for lighting, cooking, the operation of durables or transport. For domestically used energy such as LPG and Kerosene, this diminishing role can already be observed. Our derived estimates show that this saturation level might be in a very distant future for electricity and private transport, since both the urban and rural top quintiles show high income elasticities for these items.

Based on the estimation of consumer demand, the composition effect from the consumption side is not the most important factor, but is expected to play a role for current and future emission growth. On top of the scale effect, household demand for electricity and private transport is likely to let $\mathrm{CO}_{2}$ emissions rise more than proportional with income growth.

Table 2.4 MPE Engel curve estimates (urban)

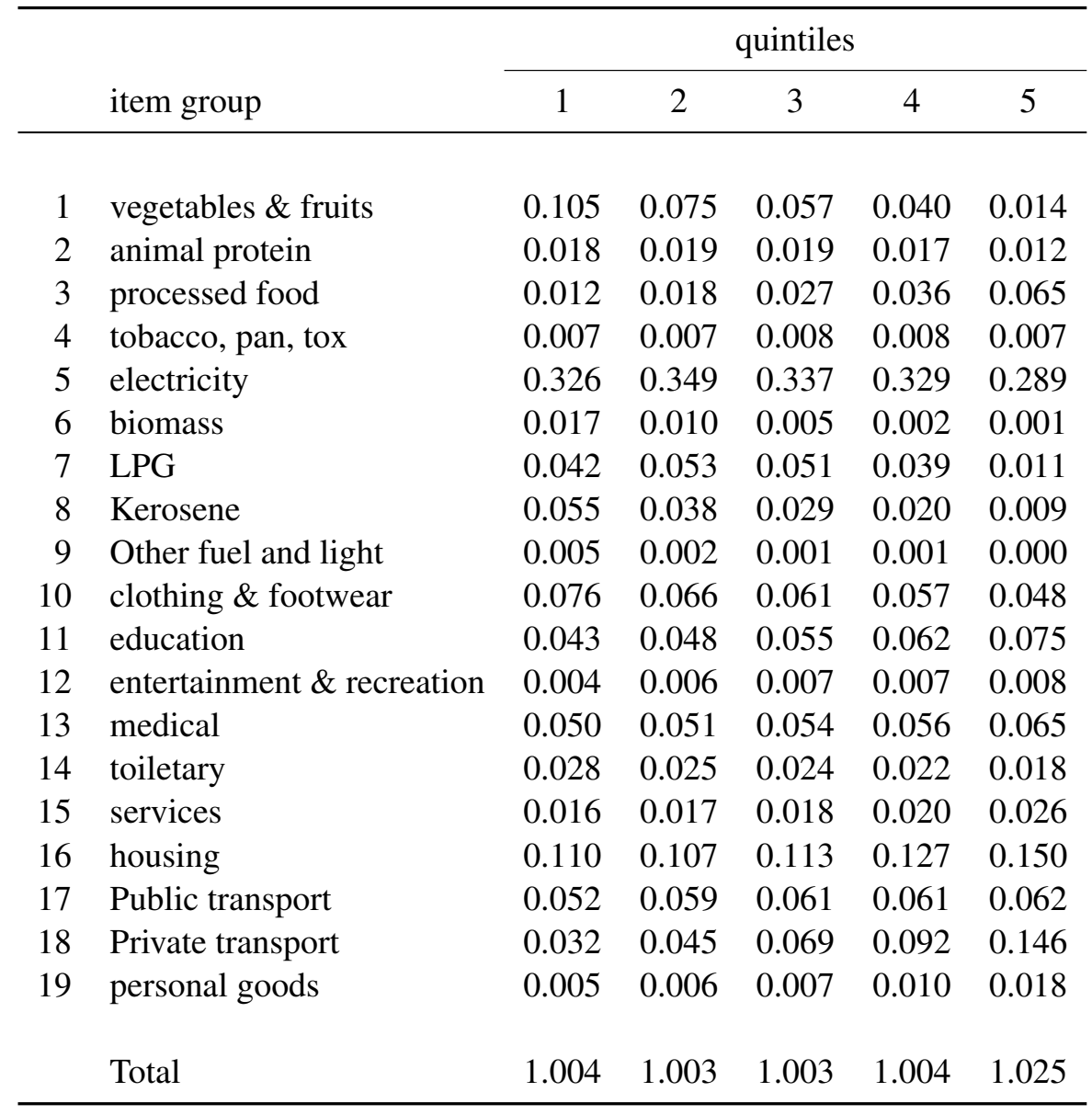


Table 2.5 MPE Engel curve estimates (rural)

\begin{tabular}{|c|c|c|c|c|c|c|}
\hline & \multirow[b]{2}{*}{ item group } & \multicolumn{5}{|c|}{ quintiles } \\
\hline & & 1 & 2 & 3 & 4 & 5 \\
\hline 1 & vegetables $\&$ fruits & 0.119 & 0.084 & 0.062 & 0.040 & 0.013 \\
\hline 2 & animal protein & 0.024 & 0.028 & 0.028 & 0.026 & 0.020 \\
\hline 3 & processed food & 0.047 & 0.046 & 0.042 & 0.041 & 0.046 \\
\hline 4 & tobacco, pan, tox & 0.012 & 0.012 & 0.012 & 0.012 & 0.012 \\
\hline 5 & electricity & 0.200 & 0.250 & 0.266 & 0.264 & 0.256 \\
\hline 6 & biomass & 0.017 & 0.009 & 0.005 & 0.002 & -0.001 \\
\hline 7 & LPG & 0.008 & 0.022 & 0.032 & 0.037 & 0.027 \\
\hline 8 & Kerosene & 0.055 & 0.031 & 0.023 & 0.014 & 0.010 \\
\hline 9 & Other fuel and light & 0.004 & 0.003 & 0.002 & 0.001 & 0.001 \\
\hline 10 & clothing \& footwear & 0.095 & 0.082 & 0.073 & 0.065 & 0.047 \\
\hline 11 & education & 0.037 & 0.041 & 0.044 & 0.053 & 0.057 \\
\hline 12 & entertainment \& recreation & 0.003 & 0.006 & 0.008 & 0.009 & 0.011 \\
\hline 13 & medical & 0.098 & 0.097 & 0.097 & 0.100 & 0.114 \\
\hline 14 & toiletary & 0.030 & 0.028 & 0.025 & 0.023 & 0.017 \\
\hline 15 & services & 0.020 & 0.020 & 0.020 & 0.020 & 0.021 \\
\hline 16 & housing & 0.080 & 0.081 & 0.084 & 0.090 & 0.108 \\
\hline 17 & Public transport & -0.060 & -0.057 & -0.049 & -0.042 & -0.036 \\
\hline 18 & Private transport & 0.034 & 0.053 & 0.076 & 0.115 & 0.183 \\
\hline \multirow[t]{2}{*}{19} & personal goods & 0.001 & 0.003 & 0.005 & 0.009 & 0.026 \\
\hline & Total & 0.825 & 0.838 & 0.855 & 0.879 & 0.930 \\
\hline
\end{tabular}

\subsection{Conclusion}

Based on input output analysis matched with expenditure data as well as consumer demand analysis, we have investigated the consumption dynamics behind the growing carbon footprints of Indian households between 2004/05 and 2011/12. By estimating the income elasticity of major groups of consumption items, we are able to analyze the effect of changes in the composition of household consumption. We find that the scale effect of total household income is the major driver of household emissions and dominates the composition effect of consumption shifts. Particularly urban households exhibit MPEs larger than 1 reflecting shifts in consumption patterns towards a higher carbon intensity of consumption. An important driver behind this shift is higher demand for electricity with income elasticities close to 1 for all urban income groups. Private transport is estimated to be a luxury good for both rural and urban households and adds to the rising carbon intensity of consumption. Indirect energy use remains an important factor in determining the size and growth of the 
carbon footprints in India. The fact that staple and processed foods contribute significantly to footprint increases for low income households is a reminder how many households in India are still poor despite all the improvements over the last decades. Additionally to the observed consumption dynamics, we find only minor differences in carbon footprints caused by sociodemographic characteristics of households. Households thus share very similar preferences and increase their consumption for all items with accelerated growth for direct energy use for cooking, lighting and transport. Considering that currently low income households use far less energy than high income households we expect convergence over time to occur. This, in turn, is likely to imply that the speed of $\mathrm{CO}_{2}$ emission growth and energy use may very well be accelerated in the near future. Calculating emission increases by assuming a unitary relationship between income and $\mathrm{CO}_{2}$ emissions is set to underestimate the emission growth that will come from the energy thirsty population. The relationship between income growth and carbon emissions is likely to be described by an elasticity around or even above 1 in the short- to medium-run, as electricity and private transport demands have not reached observable saturation levels. The demand for these energy intensive goods quickly increases with income as millions of Indians are striving to drive cars and use convenient household appliances for their homes. Our analysis thus clearly points to priority areas for serious mitigation efforts in India: The electricity and transport sectors. 


\section{Chapter 3}

\section{Poverty and Distributional Effects of a Carbon Tax in Mexico}

\subsection{Introduction}

Developing countries contribute a rising share to the worldwide emission of greenhouse gases. Mainly responsible for this growth in emissions are middle income countries with sustained economic growth rates while low income countries still exhibit relative small emissions per capita (Olivier et al., 2015). Among the group of middle income countries, Mexico, as an upper middle income and fairly advanced country, has become one of the most significant emitters of $\mathrm{CO}_{2}$ in absolute and per capita terms recently. In 2014, it was ranked the 15th biggest economy (World Bank, 2016) and the 12th biggest carbon emitter in the world with more economic growth and fossil fuel intensive energy use to be expected in the future. Mexico started to voluntarily commit itself to greenhouse gas emission reduction targets in 2010 at the Cancun Climate Change Conference. In 2013, the government launched additional and further reaching reforms to the Mexican energy markets and thus prepared the ground for a green fiscal reform (Metcalf, 2015). In October 2013, the Mexican Congress approved the Government's proposal of a tax on the sale and import of fossil fuels which came into effect on January 1, 2014, making Mexico the first non-developed country to adopt such a policy. The price of the proposed carbon tax was calculated by weighting the carbon price of various international markets and the carbon content of each fossil fuel sold in Mexico using emission factors of the combustion process. The Mexican Congress approved different tax rates for distinct fossil fuel types with prices ranging between 5.80 - 46.42 Mexican Pesos (MXN) per $\mathrm{tCO}_{2}$ (0.45 - 3.63 USD) (Belausteguigoitia, 2014). This implies a weighted average of MXN 43.10 per $\mathrm{tCO}_{2}$ (USD 3.37). However, the tax is not levied on all emissions 
but only on those generated by fossil fuels other than natural gas and jet fuel. The risks of introducing a carbon tax for Mexico are identified as rising poverty through higher consumer prices, competitiveness losses of the Mexican industry and associated negative effects on the economy, wages and unemployment. Although Mexico is a middle income country, the introduced carbon price is relatively low in international comparison. As a result, effects on the $\mathrm{CO}_{2}$ emission level and household welfare can generally be expected to be small. This however will not hold for expected higher future tax rates. In 2015, Mexico submitted its Intended Nationally Determined Contribution (INDC) to the UNFCCC in 2015 as the first developing country. Although the instruments to realize the planned emission savings are not explicitly mentioned, an increase in the carbon price appears as one highly suitable candidate. For Mexico, we do not find empirical evidence on the effects of a carbon tax in the literature. Gonzalez (2012) uses an analytical general equilibrium model to simulate a stylized carbon tax scenario for Mexico and finds that the direction of the effect is determined by the way the tax revenue is recycled. Redistribution towards food subsidies would lead to an overall progressive effect. We try to fill the gap in the literature by using an input-output model to calculate carbon intensities of various product categories and match the production side with consumption expenditure on the household level in order to determine the impact of carbon tax scenarios on household welfare. Besides calculating welfare effects for the current tax regime in place, we add scenarios including more $\mathrm{CO}_{2}$ emissions from natural gas, jet fuel and other greenhouse gas emissions from methane $\left(\mathrm{CH}_{4}\right)$ and nitrous oxide $\left(\mathrm{N}_{2} \mathrm{O}\right)$. We also include redistribution scenarios and check for welfare effects of border tax adjustments. The rest of the paper proceeds as follows. In section 3.2 we describe the methodology of the input-output model and the integration with the household consumption side used in the analysis. In section 3.3, general trends in emissions, energy use, consumption and poverty are supplied as background material for the analysis in section 3.4. We briefly discuss results and conclude in section 3.5.

\subsection{Methodology}

Our analysis consists of two steps, which have been applied in the previous literature on welfare effects of energy and climate policies (Labandeira and Labeaga, 1999, 2002). First, we calculate sector specific price changes following a taxation of $\mathrm{CO}_{2}$ emissions by drawing on an environmentally extended input-output model. In the second step the price changes are translated into welfare effects on the household level. 


\subsubsection{Input-output analysis and price changes per sector}

We obtain carbon intensities of 34 production sectors (table 3.1) by combining input-output tables with energy and emission data taken from the World Input Output Database (Timmer et al., 2015).

The resulting carbon intensities per production sector contain direct as well as indirect emissions from other sectors. ${ }^{1}$ By assumption, production is described by a Leontief production function which implies no substitution between sectors so that price increases are fully shifted towards consumers. The model is theoretically valid for small tax changes in the short-run but increases in uncertainty with time and the size of the tax. For calculating the carbon intensities we follow Proops et al. (1993) and distinguish between different fuel types as these naturally contain different amounts of $\mathrm{CO}_{2}$ per physical unit. ${ }^{2}$ Total fossil fuel use per energy carrier is represented by $F_{f}$, whereby $f$ indicates the type of fuel and represents an element of the vector $f$ showing the fuel quantities used in production per sector. The carbon content per physical unit of the respective fuel is $e_{f}$ and multiplying this vector by $f$ yields total production $\mathrm{CO}_{2}$ emissions $C_{\text {ind }}$ :

$$
e^{\prime} f=C_{\text {ind }}
$$

The intensity of fuel use in production $c_{i f}$ is defined as the ratio of the quantity of fuel type $f$ used in sector $i, F_{i f}$, and the sector's $i$ total output $X_{i}$ :

$$
c_{i f}=\frac{F_{i f}}{X_{i}}
$$

The product of the transposed fuel intensity matrix $C$ and the total demand $x$ gives the vector of production fossil fuel use $f$, i.e. $C^{\prime} x=f$. Multiplying both sides by the carbon content per fuel unit $e^{\prime}$ and recalling equation 3.1 then describes the components of production $\mathrm{CO}_{2}$ emissions:

$$
e^{\prime} C^{\prime} x=e^{\prime} f=C_{\text {ind }}
$$

The elements of $e^{\prime} C$ can be termed "direct carbon intensities" as they reveal how much $\mathrm{CO}_{2}$ is emitted per unit of total output by each sector. The inclusion of $\mathrm{CH}_{4}$ and $\mathrm{N}_{2} \mathrm{O}$ in the analysis provides us with intensities of carbon equivalents, reflecting the gases global

\footnotetext{
${ }^{1}$ The WIOD data contains 35 sectors, but we eliminate the 35th sector ("Private Households with Employed Persons") due to insignificant contribution to total production and energy use.

${ }^{2}$ Fossil fuels included are hard coal, brown coal, coke, diesel, gasoline, light fuel oil, fuel oil, naphtha, other petroleum and other gases excluding natural gas.
} 
Table 3.1 WIOD sector description

\begin{tabular}{ll}
\hline sector & sector description \\
\hline 1 & Agriculture, Hunting, Forestry and Fishing \\
2 & Mining and Quarrying \\
3 & Food, Beverages and Tobacco \\
4 & Textiles and Textile Products \\
5 & Leather and Footwear \\
6 & Wood and Products of Wood and Cork \\
7 & Pulp, Paper, Printing and Publishing \\
8 & Coke, Refined Petroleum and Nuclear Fuel \\
9 & Chemicals and Chemical Products \\
10 & Rubber and Plastics \\
11 & Other Non-Metallic Mineral \\
12 & Basic Metals and Fabricated Metal \\
13 & Machinery, Nec \\
14 & Electrical and Optical Equipment \\
15 & Transport Equipment \\
16 & Manufacturing, Nec; Recycling \\
17 & Electricity, Gas and Water Supply \\
18 & Construction \\
19 & Sale, Maintenance and Repair of Motor Vehicles and Motorcycles; Retail Sale of Fuel \\
20 & Wholesale Trade and Commission Trade, Except of Motor Vehicles and Motorcycles \\
21 & Retail Trade, Except of Motor Vehicles and Motorcycles; Repair of Household Goods \\
22 & Hotels and Restaurants \\
23 & Inland Transport \\
24 & Water Transport \\
25 & Air Transport \\
26 & Other Supporting and Auxiliary Transport Activities; Activities of Travel Agencies \\
27 & Post and Telecommunications \\
28 & Financial Intermediation \\
29 & Real Estate Activities \\
30 & Renting of M\&Eq and Other Business Activities \\
31 & Public Admin and Defence; Compulsory Social Security \\
32 & Education \\
33 & Health and Social Work \\
34 & Other Community, Social and Personal Services \\
\hline
\end{tabular}


warming potential. ${ }^{3}$ Since $\mathrm{CH}_{4}$ and $\mathrm{N}_{2} \mathrm{O}$ emissions are transformed to $\mathrm{CO}_{2}$ equivalent emissions, we continue to use the term carbon also when other gases are included. Finally, economic policy is more concerned with final demand and not exclusively with production $x$. Equation 3.3 has thus to be transformed in terms of final demand using the Leontief inverse $(I-A)^{1}$. Recalling total production $x=(I-A)^{1} y$ and substituting for $x$ into equation 3.3 gives:

$$
e^{\prime} C^{\prime}(I-A)^{-1} y=C_{\text {ind }}
$$

The multiplication of the direct carbon intensities $e^{\prime} C$ by the Leontief inverse $(I-A)^{1}$ then generates the indirect carbon intensities:

$$
C I_{\text {ind }}=e^{\prime} C^{\prime}(I-A)^{-1}
$$

Equation 3.5 provides us with a new vector of $\mathrm{CO}_{2}$ intensities which contains the direct carbon emissions, resulting from direct production emissions in the respective sector, plus the indirect carbon emissions, caused by the release of carbon emissions in the production of intermediate inputs in the production process of goods, per unit of final demand y. In order to determine the carbon content of each fuel, the WIOD data takes $\mathrm{CO}_{2}$ emission factors from the 2006 IPCC Guidelines for National Greenhouse Gas Inventories and from the United Nations Framework Convention on Climate Change (UNFCCC) emissions reporting, as especially the latter also report country specific emission factors. Additionally to production emissions, households have direct demand for fuels and associated direct emissions $C_{d i r}$ which are not captured in the input-output framework. Total emissions from household consumption is the sum of direct and indirect emissions from consumption and energy use:

$$
C=C_{d i r}+C_{\text {ind }}
$$

The carbon intensity of energy items with direct emissions such as fuels, could be calculated on the basis of observed quantities and physical emission factors. In the absence of observed quantities, we calculate these by using price per fuel unit data from the Instituto Nacional de Estadística y Geografía (INEGI), calculate direct emissions $C_{d i r}$ and obtain direct carbon intensities $\mathrm{CI}_{\text {dir }}\left(t \mathrm{CO}_{2} / \mathrm{MXN}\right)$. Total demand carbon intensities per sector are then:

$$
C I=C I_{d i r}+C I_{\text {ind }}
$$

\footnotetext{
${ }^{3}$ Global warming potential factors under the assumption of climate-carbon feedbacks and 100 year time horizons are 28 for $\mathrm{CH}_{4}$ and 265 for $\mathrm{N}_{2} \mathrm{O}$ (IPCC, 2013).
} 
For non-fuels, equation 3.7 simply reduces to $C I_{\text {ind }}$. Depending on the scenario, final demand can either exclude imports or include them in a border tax adjustment scenario. In the latter case, we assume imports exhibit the same carbon intensity in production and are taxed like domestic goods. In a next step, we receive a vector of sector specific carbon taxes by multiplying the general carbon tax rate $\mu$ with the sector specific $\mathrm{CO}_{2}$ intensity:

$$
t=\mu * C I
$$

Each sector specific ad valorem tax rate $t_{i}$ can be directly interpreted as the sector specific price change relative to the base price $p_{i 0}$ :

$$
\left(1+t_{i}\right) p_{i 0}=p_{i 1} \Leftrightarrow t_{i}=\frac{p_{i 1}}{p_{i 0}}-1
$$

We convert basic prices to consumer prices using data on the net tax rates per sector provided in WIOD's national supply and use tables. The most recently available tables are from 2011 for the IO and 2009 for the energy and emission data.

\subsubsection{Effects on household welfare}

The total effect on household welfare in our specification depends on the impact of sectoral price changes on expenditures. Household expenditures are taken from the 2014 Encuesta Nacional de Ingreso y Gasto de los Hogares (ENIGH) available from INEGI. To link the production with the consumption side, we assign all expenditure items to the 34 production sectors (table B.2 in Spanish language, Appendix). Matching is done on the basis of expenditures item names and assigned description from the questionnaire. In order to assess distributional implications we calculate first-order welfare effects relative to total expenditures per household. ${ }^{4}$ This is done by multiplying the consumption category specific carbon taxes with household expenditure shares:

$$
\Delta w_{h i}=w_{h i} * t_{i}
$$

to obtain the change in budget shares per consumption category. We use the sum of changes $\sum w_{h i}$ as the welfare loss, defined as the percentage share of total household expenditures. For the effects on poverty, we calculate absolute welfare effects and subtract them from household income, since domestic poverty lines are constructed with current income measures

\footnotetext{
${ }^{4}$ Second-order effects, including substitution away from and between goods, are naturally a superior measure of welfare effects but are hard to quantify here. Since our analysis is mostly concerned with the energy and carbon content of goods, estimating demand elasticities for a system of 34 sectors based on the IO classification would require extremely detailed price information which was unavailable to the authors.
} 
(CONEVAL, 2014). All absolute effect are calculated on a per capita basis to facilitate the analysis across different household sizes.

\subsubsection{Scenarios}

Apart from the expenditure shares on certain goods and the size of the tax, welfare effects finally depend on the tax base, which is the share of emissions covered by the tax regime. The current legislation taxes $\mathrm{CO}_{2}$ emissions from energy sources and excludes natural gas, jet fuel and non-energy emissions. The first scenario (A) reflects this current legislation scheme. Since natural gas is a major energy source in the electricity sector, we simulate the inclusion in the second scenario (B). Thirdly, reflecting the fact that climate change is a result of rising greenhouse gas emissions and not exclusively of energy $\mathrm{CO}_{2}$ emissions alone, we add methane $\left(\mathrm{CH}_{4}\right)$ and nitrous oxide $\left(\mathrm{N}_{2} \mathrm{O}\right)$ plus jet-fuel and non-energy $\mathrm{CO}_{2}$ emissions to the calculation. Besides the share of greenhouse gas emissions by a tax, the actual tax size is crucial in each scenario. Setting the tax rate to an amount that captures marginal damages resulting from climate change has created major dispute in the literature (Pindyck, 2013). Considering the problematic calculation of the social cost of carbon we offer lower and upper bound tax rates of 20 and 50 USD per ton $\mathrm{CO}_{2} / \mathrm{CO}_{2} \mathrm{e} .{ }^{5}{ }^{6}$ In the first scenario, we additionally simulate a simplified version of the actual "carbon tax" that was introduced in 2014. Instead of working with a number of single fuel taxes, we set a uniform carbon tax of $3.5 \mathrm{USD} / \mathrm{tCO}_{2}$ which is close to the implicit tax in place and facilitates comparisons with larger tax rates and other carbon tax regimes in the international context. ${ }^{7}$ The 20 USD tax can be seen as a short term interpretation of the carbon tax as a major policy tool to achieve Mexico's INDC. The upper bound of 50 USD adds to the understanding of how larger tax rates affect household welfare. We calculate total tax revenues on the basis of the carbon intensity vector and the scaled 2014 consumer expenditures. Our derived tax estimates are therefore a projection for 2014 and exclude the taxation of exports, which is in line with our model assumptions. ${ }^{8}$ Two redistribution scenarios are simulated, which includes a stylized lump-sum transfer per household over the entire population and a transfer of a share of the tax revenue to recipients of the social welfare program PROSPERA (formerly known as Oportunidades and rebranded as PROSPERA in late 2014).

\footnotetext{
${ }^{5}$ In the absence of clear scientific guidance on the exact social cost of carbon, these values will always be somewhat arbitrary.

${ }^{6}$ Annual average exchange rate 13.29 MXN/USD (International Monetary Fund, 2016).

${ }^{7}$ We also simulated the "real" carbon tax by calculating sector specific price changes based on the multiple of fuel taxes. As results do not differ significantly, we did not report them but they are available from the authors upon request.

${ }^{8}$ Official Mexican government estimates are slightly different due to differences in the calculation method, e.g. exports are taxed.
} 


\subsection{Emissions, consumption and poverty}

Total carbon emissions of the Mexican economy have been rising steadily over the last years (Figure 3.1). Since the beginning of the 1970s, emissions have increased by over 350 percent, reflecting both per capita economic and large population growth. On average, income per capita has increased by over 80 and carbon emissions per capita by over 100 percent. This unequal growth rates can be linked to the rising carbon intensity $\left(\mathrm{CO}_{2} / \mathrm{GDP}\right)$ of the economy until the 1990s; since then we observe a decline accompanied by more efficient energy use. Although the economy became less carbon intensive, energy efficiency improvements since 2000 have been small. If Mexico wants to change its growth path towards a low carbon pathway as discussed in its national climate strategy and its INDC pledges, a massive decarbonization of the energy system is the major challenge.
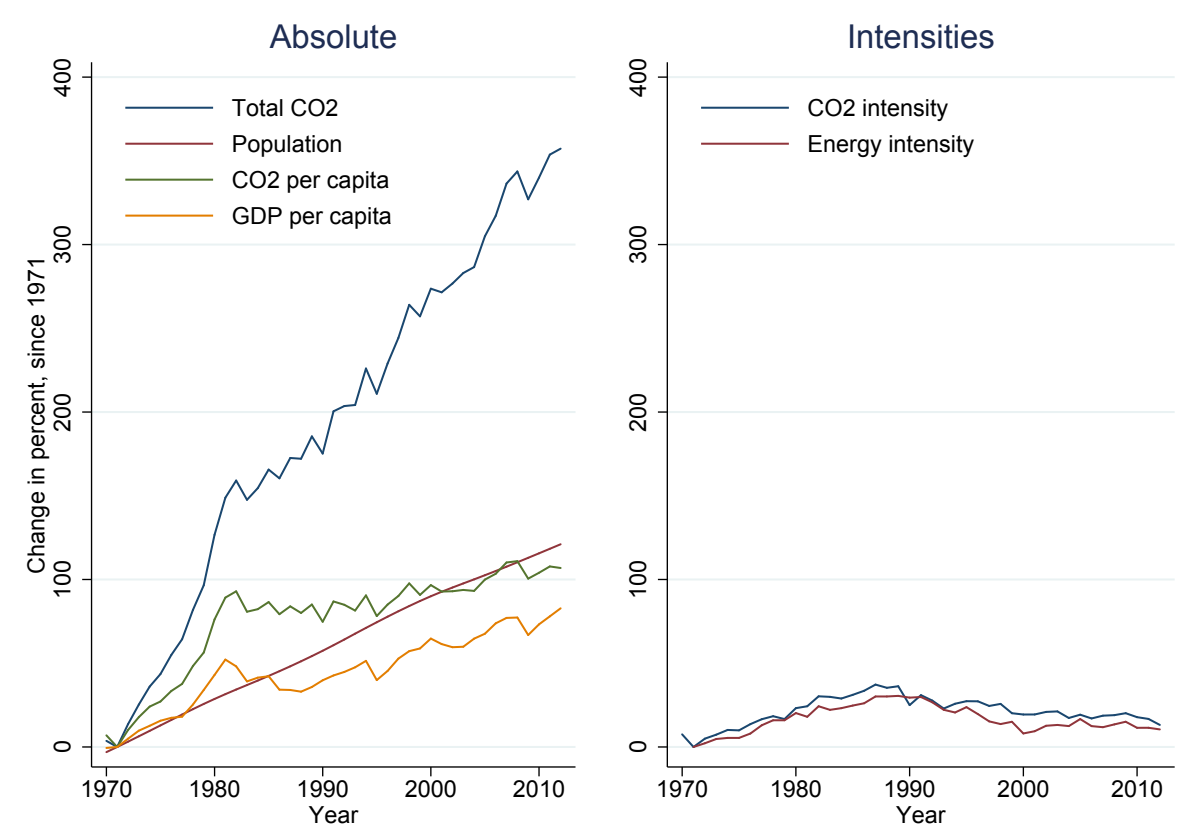

Fig. 3.1 $\mathrm{CO}_{2}$ emissions, GDP and $\mathrm{CO}_{2}$ intensities Mexico

Carbon emissions and intensities per production sector reveal more detailed dynamics in light of the overall slight decline (table 3.2). The utilities sector including electricity, gas and water supply has the highest emission total as well as emission intensity in 2009. Other sectors with high carbon intensities like water transport are less important in terms of direct emissions and even less so for household consumption. Inland and air transport play a bigger role but the latter is excluded from the current carbon tax legislation which implies zero price changes for households. 
Table 3.2 Sectoral $\mathrm{CO}_{2}$ production emissions and $\mathrm{CO}_{2}$ intensities (Scenario $\mathrm{B}$ )

\begin{tabular}{ccccccc}
\hline & & CO2 $(\mathrm{kt})$ & & \multicolumn{3}{c}{ CO2 intensity $(\mathrm{kt} / \mathrm{MXN})$} \\
\cline { 2 - 7 } sector & 2009 & change & \% change & 2009 & change & $\%$ change \\
& & $1995-2009$ & & & $1995-2009$ & \\
\hline 1 & 20829.2 & 3310.59 & 18.9 & 36.52 & 0.48 & 1.32 \\
2 & 28501.36 & 12996.07 & 83.82 & 26.17 & 1.65 & 6.74 \\
3 & 4742.34 & -986.9 & -17.23 & 17.48 & -5.39 & -23.58 \\
4 & 2654.53 & 70.84 & 2.74 & 24.26 & -0.15 & -0.62 \\
5 & 411.09 & -115.36 & -21.91 & 15.64 & -1.92 & -10.92 \\
6 & 442.26 & -275.22 & -38.36 & 23.52 & -6.81 & -22.45 \\
7 & 3102.72 & 636.81 & 25.82 & 24.03 & 1.57 & 6.97 \\
8 & 31112.55 & 5502.69 & 21.49 & 52.5 & -21.26 & -28.82 \\
9 & 9650.42 & -3377.63 & -25.93 & 27.93 & -8.52 & -23.37 \\
10 & 1481.2 & -83.21 & -5.32 & 23.39 & -4.6 & -16.44 \\
11 & 24279.19 & 7282.68 & 42.85 & 107.12 & 8.23 & 8.32 \\
12 & 14053.75 & -794.34 & -5.35 & 38.5 & -12.59 & -24.63 \\
13 & 816.03 & 101.63 & 14.23 & 15.35 & -3.44 & -18.3 \\
14 & 3068.47 & 729.92 & 31.21 & 11.23 & -1.56 & -12.19 \\
15 & 1721.49 & 395.03 & 29.78 & 10.1 & -1.55 & -13.33 \\
16 & 2955.43 & 850.44 & 40.4 & 23.87 & -2.15 & -8.25 \\
17 & 107813.29 & 32436.2 & 43.03 & 290.91 & -151.67 & -34.27 \\
18 & 11732 & 6325.56 & 117 & 20.33 & -3.34 & -14.12 \\
19 & 2118.31 & 737.27 & 53.39 & 17.25 & -0.46 & -2.58 \\
20 & 2800.13 & 960.17 & 52.18 & 7.63 & -1.14 & -12.99 \\
21 & 8708.97 & 3109.77 & 55.54 & 12.1 & -1.12 & -8.47 \\
22 & 6039.58 & 1313.3 & 27.79 & 24.78 & -2.83 & -10.24 \\
23 & 23689.76 & 8221.65 & 53.15 & 29.36 & -2.1 & -6.66 \\
24 & 2237.76 & 266.55 & 13.52 & 147.31 & -5.01 & -3.29 \\
25 & 8254.4 & 2006.94 & 32.12 & 86.15 & -45.9 & -34.76 \\
26 & 1965.47 & 523.14 & 36.27 & 18.45 & -4.58 & -19.87 \\
27 & 2074.73 & 569.84 & 37.87 & 8.23 & -2.38 & -22.44 \\
28 & 907.06 & 417.77 & 85.38 & 4.16 & 0.65 & 18.65 \\
29 & 826.02 & 344.42 & 71.52 & 3.59 & -0.62 & -14.69 \\
30 & 5427.32 & 3451.16 & 174.64 & 9.13 & -1.14 & -11.08 \\
31 & 5222.88 & 1301.03 & 33.17 & 15.48 & -5.24 & -25.27 \\
32 & 6886.26 & 1976.5 & 40.26 & 11.69 & -4.36 & -27.16 \\
33 & 2509.07 & 798.18 & 46.65 & 10.89 & -2.24 & -17.07 \\
34 & 2244.8 & 402.36 & 21.84 & 14.99 & -2.73 & -15.4 \\
\hline & & & & & &
\end{tabular}


(a) Percentiles

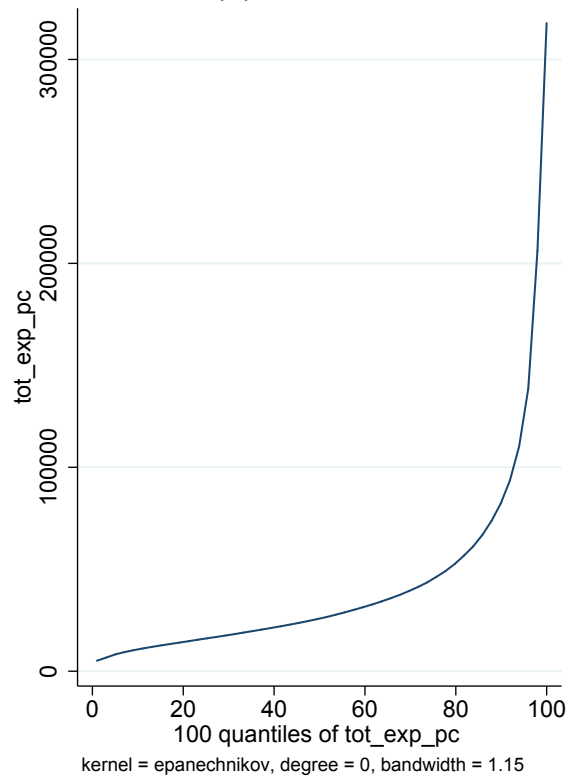

(b) Lorenz Curve

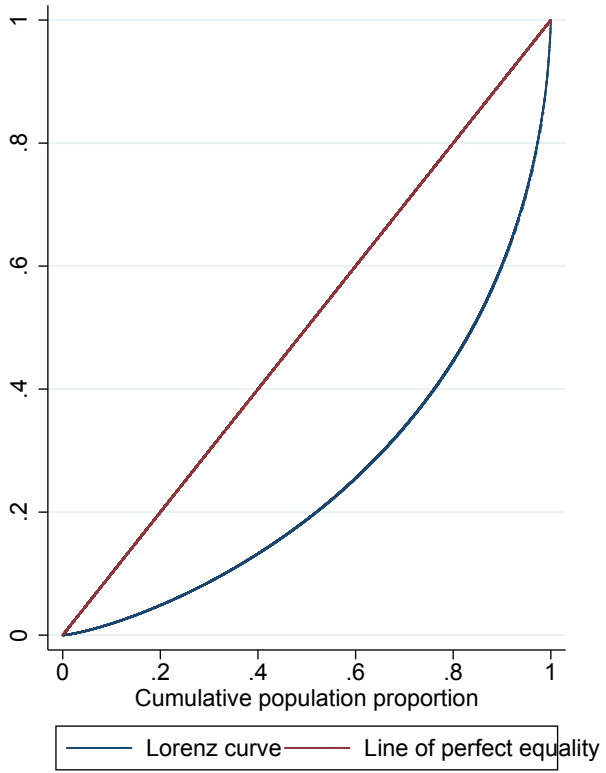

Fig. 3.2 Household per capita expenditures Mexico (2014=

(a) Carbon Intensity (kg CO2/MXN)

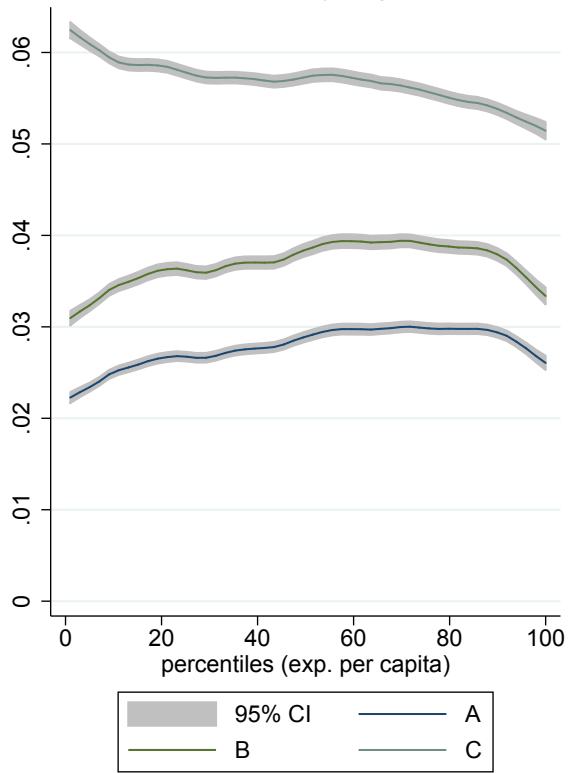

(b) Carbon Footprint (kg CO2)

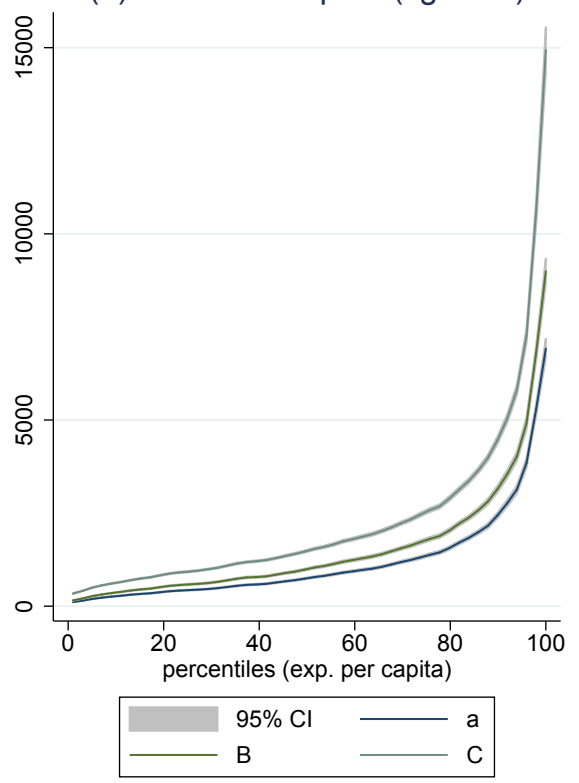

Fig. 3.3 $\mathrm{CO}_{2}$ intensity of expenditures and $\mathrm{CO}_{2}$ footprints Mexico (2014) 
The observed overall decline in the carbon intensity can mainly be ascribed to the utilities sector, which exhibits a large decrease in absolute terms and of 34 percent relatively from 1995 to 2009. This decline can be largely ascribed to a shift from oil to gas in the power sector. Based on the analysis of overall carbon intensities, we would not expect the carbon intensity to change by great amounts from 2009 to 2014 and use the 2009 carbon intensities, deflated to the 2014 price level, for further analysis. Finally, a decline in the carbon intensity is no guarantee for decreasing emissions as can be observed from table 3.2. However, total emissions would have been higher without reductions in the carbon intensity, which has mainly happened in the energy and manufacturing sectors. Although we observe changes in the carbon intensity per sector until 2009, and the used household survey data is from 2014 , we refrain from extrapolating an observed trend per sector to receive a vector of projected carbon intensities for 2014. Declines over time depend on the transformation towards more low carbon energy sources, information which is unavailable to the authors for recent years.

For the calculation of welfare effects relevant consumption expenditures are quite unequally distributed over the population. In 2014, total consumption expenditures of the top 10 percent of households are about 20 times higher than the bottom 10 percent expenditures (figure 3.2 a). We find that 50 percent of the population have less than a 20 percent share of total expenditures (figure $3.2 \mathrm{~b}$ ), over 60 percent of all expenditures can be accounted to just 10 percent of the population at the top of the expenditure distribution.

High expenditure inequality already provides an indication for distributional impacts of consumption taxes in absolute terms. In relative terms, tax payments grow in proportion to the carbon intensity of consumption. We check the latter by calculating household specific carbon footprints for our three scenarios and relate these to household expenditures. The carbon intensity of consumption increases until the 50th percentile when only $\mathrm{CO}_{2}$ emissions from energy use are taxed (Scenario A and B). ${ }^{9}$ It decreases again at the 90th percentile, reflecting a shift to more service and less energy intensive consumption items (figure $3.3 \mathrm{a}$ ). This decline is quite moderate and can't make up for the quantity increase in consumption, reflected in high carbon footprints for high expenditure households (figure $3.3 \mathrm{~b}$ ). Remarkably, the carbon intensity declines over the expenditure distribution when $\mathrm{CH}_{4}$ and $\mathrm{N}_{2} \mathrm{O}$ are taxed additionally to $\mathrm{CO}_{2}$ emission from energy. The importance of $\mathrm{CH}_{4}$ and $\mathrm{N}_{2} \mathrm{O}$ intensive goods such as food in the consumption basket declines with income.

Although the welfare effects in our model depend on expenditure patterns, poverty effects finally depend on the definition of poverty lines as well. We calculate Foster-Greer-Thorbecke (FGT) poverty indices on the basis of poverty lines provided by the Consejo Nacional de

\footnotetext{
${ }^{9}$ Nonparametric distributional curves are calculated with kernel-weighted local polynomial smoothing using an epanechnikov kernel function with degree 0 and bandwith 1.15
} 
Evaluacion de la Politica de Desarrollo Social (CONEVAL, 2014). Two distinct poverty lines are used. The first describes a minimum well-being standard of an individual which corresponds to the value of the food basket per person per month (Bienestar minimo - Canasta alimentaria). The population below this poverty line cannot afford enough food to ensure adequate nutrition. The second poverty line is equivalent to the total value of the food plus non-food basket per person per month and hence refers to a general well-being standard (Bienestar - Canasta alimentaria y no alimentaria). Both poverty lines are useful to calculate since each captures a different magnitude of poverty. Each poverty line is calculated for rural and urban individuals in monthly income per capita values in current prices which allows for a distinction between rural and urban poverty in the calculations. In the analysis, the average of the indicated monthly values over the year 2014 was used. The calculated poverty indices differ quite strongly over rural and urban areas, while the total value is dominated by the large urban population. The poverty headcount using the wellbeing poverty line is 45 percent overall while 54 and 42 percent in rural and urban areas respectively (table 3.3). ${ }^{10}$ The Gini coefficient is at a relatively high level of 0.52 in international comparison and lower within urban and rural areas.

Reliability of household survey data, as well as national accounts data, is heavily debated in the literature (Datt and Ravallion, 2011; Deaton, 2005). The usual problem is that household survey data aggregates are considerably smaller than calculated in national account data. With the data used in our analysis, we can confirm the huge spread between consumption in the micro household and in the input-output data. However, information on input-output data specific problems or survey issues such as item underreporting, sample selection issues etc. for Mexico are unavailable to the authors. We assume the IO data to be more reliable and correct the survey data with a general scaling factor representing the relationship between the IO and survey consumption aggregate. For relative welfare measures, this scaling procedure has no effect on results but absolute changes and redistribution effects are different. The consumption aggregate in the IO data for the most recent available year 2011 is 2.7 times greater than in the survey data for the year 2014, although economic growth rates have been around 2.5 percent on average from 2011 to 2014 (World Bank, 2016). If consumption by households grew with the same rate, the survey data covers only 35.5 percent of the IO consumption aggregate resulting in a scaling factor of 2.81 .

\footnotetext{
${ }^{10}$ Differences to poverty statistics published by CONEVAL are due to equivalence scales, which we do not use since our focus is on poverty changes trough different tax rates and not through family composition.
} 
Table 3.3 FGT poverty indices and Gini index (2014)

\begin{tabular}{ccccc}
\hline Poverty line & Index & National & Rural & Urban \\
\hline Minimum Wellbeing & FGT 0 & 0.14 & 0.23 & 0.11 \\
& FGT 1 & 0.04 & 0.08 & 0.03 \\
& FGT 2 & 0.02 & 0.04 & 0.01 \\
\hline Wellbeing & FGT 0 & 0.45 & 0.54 & 0.42 \\
& FGT 1 & 0.17 & 0.23 & 0.15 \\
& FGT 2 & 0.08 & 0.13 & 0.07 \\
\hline & Gini & 0.52 & 0.45 & 0.5 \\
\hline
\end{tabular}

\subsection{Results}

The different carbon tax rates and tax bases generate a wide variety of price changes for households. Reflecting the carbon intensity of the respective production sector, price increases can be expected to rise from Scenario A to C, although with differences in sectors. The carbon intensity for electricity and utilities, calculated by excluding natural gas, jet fuel and non-energy emissions in scenario A (table 3.4), is considerably smaller than in Scenario B (table 3.5). Resulting price changes are small for the current tax rate and moderate for higher tax rates. With a tax of 3.5 USD per ton $\mathrm{CO}_{2}$, the price change in the electricity sector is well below one percent and rises up to 10 percent with 50 USD per ton. The largest price change in the current tax regime can be expected from refined petroleum products such as gasoline. Including natural gas in the taxation of $\mathrm{CO}_{2}$ emissions (Scenario $\mathrm{B}$ ) naturally increases the price for electricity and since the emissions covered increase by almost 100 percent, the carbon intensity and associated price changes with a similar magnitude relative to Scenario A. Electricity price changes now dominate fuel price increases. For other sectors, the inclusion of natural gas slightly increases price changes. As expected, including $\mathrm{CH}_{4}$ and $\mathrm{N}_{2} \mathrm{O}$ in taxation (Scenario $\mathrm{C}$, table 3.6) lead to strong price increases for agricultural products and to a lesser extent for processed food reflected in larger carbon intensities for these sectors. Other sectors are less affected in Scenario $\mathrm{C}$ and show carbon intensities and price increases similar to Scenario B. Resulting welfare effects also increase with the coverage of emissions from Scenario A to $\mathrm{C}$ and with the tax rate. For the currently implemented tax rate close to 3.5 USD/ $\mathrm{t} \mathrm{CO}_{2}$ the welfare effects are generally slightly progressive and small below 0.2 percent of total expenditures for most households. Welfare effects increase to a maximum of 4.2 percent of total expenditures for the poorest households in Scenario C for a tax rate of 50 $\mathrm{USD} / \mathrm{t} \mathrm{CO}_{2}$. 
Table $3.4 \mathrm{CO}_{2}$ Intensities for final demand and price changes (Scenario A)

\begin{tabular}{|c|c|c|c|c|}
\hline \multirow[b]{2}{*}{$\begin{array}{c}\text { Sector } \\
\text { No }\end{array}$} & \multirow[b]{2}{*}{$\mathrm{CI}(\mathrm{t} / \mathrm{Mio} \mathrm{MXN})$} & \multicolumn{3}{|c|}{ price changes in $\%$ for carbon tax rates (in USD) } \\
\hline & & 3.5 & 20 & 50 \\
\hline 1 & 29.07 & $0.13 \%$ & $0.72 \%$ & $1.80 \%$ \\
\hline 2 & 3.57 & $0.02 \%$ & $0.09 \%$ & $0.22 \%$ \\
\hline 3 & 12.50 & $0.05 \%$ & $0.31 \%$ & $0.77 \%$ \\
\hline 4 & 12.75 & $0.06 \%$ & $0.32 \%$ & $0.79 \%$ \\
\hline 5 & 9.06 & $0.04 \%$ & $0.22 \%$ & $0.56 \%$ \\
\hline 6 & 14.06 & $0.06 \%$ & $0.35 \%$ & $0.87 \%$ \\
\hline 7 & 10.45 & $0.05 \%$ & $0.26 \%$ & $0.65 \%$ \\
\hline 8 & 202.26 & $0.88 \%$ & $5.01 \%$ & $12.52 \%$ \\
\hline 9 & 5.24 & $0.02 \%$ & $0.13 \%$ & $0.32 \%$ \\
\hline 10 & 7.20 & $0.03 \%$ & $0.18 \%$ & $0.45 \%$ \\
\hline 11 & 40.40 & $0.18 \%$ & $1.00 \%$ & $2.50 \%$ \\
\hline 12 & 8.79 & $0.04 \%$ & $0.22 \%$ & $0.54 \%$ \\
\hline 13 & 3.40 & $0.01 \%$ & $0.08 \%$ & $0.21 \%$ \\
\hline 14 & 4.67 & $0.02 \%$ & $0.12 \%$ & $0.29 \%$ \\
\hline 15 & 5.21 & $0.02 \%$ & $0.13 \%$ & $0.32 \%$ \\
\hline 16 & 12.85 & $0.06 \%$ & $0.32 \%$ & $0.80 \%$ \\
\hline 17 & 158.43 & $0.69 \%$ & $3.92 \%$ & $9.81 \%$ \\
\hline 18 & 13.04 & $0.06 \%$ & $0.32 \%$ & $0.81 \%$ \\
\hline 19 & 14.19 & $0.06 \%$ & $0.35 \%$ & $0.88 \%$ \\
\hline 20 & 5.54 & $0.02 \%$ & $0.14 \%$ & $0.34 \%$ \\
\hline 21 & 10.15 & $0.04 \%$ & $0.25 \%$ & $0.63 \%$ \\
\hline 22 & 19.43 & $0.08 \%$ & $0.48 \%$ & $1.20 \%$ \\
\hline 23 & 21.24 & $0.09 \%$ & $0.53 \%$ & $1.31 \%$ \\
\hline 24 & 143.45 & $0.62 \%$ & $3.55 \%$ & $8.88 \%$ \\
\hline 25 & 8.69 & $0.04 \%$ & $0.22 \%$ & $0.54 \%$ \\
\hline 26 & 15.97 & $0.07 \%$ & $0.40 \%$ & $0.99 \%$ \\
\hline 27 & 6.41 & $0.03 \%$ & $0.16 \%$ & $0.40 \%$ \\
\hline 28 & 3.01 & $0.01 \%$ & $0.07 \%$ & $0.19 \%$ \\
\hline 29 & 2.29 & $0.01 \%$ & $0.06 \%$ & $0.14 \%$ \\
\hline 30 & 7.08 & $0.03 \%$ & $0.18 \%$ & $0.44 \%$ \\
\hline 31 & 11.06 & $0.05 \%$ & $0.27 \%$ & $0.68 \%$ \\
\hline 32 & 10.37 & $0.04 \%$ & $0.26 \%$ & $0.64 \%$ \\
\hline 33 & 8.07 & $0.03 \%$ & $0.20 \%$ & $0.50 \%$ \\
\hline 34 & 10.18 & $0.04 \%$ & $0.25 \%$ & $0.63 \%$ \\
\hline
\end{tabular}


Table $3.5 \mathrm{CO}_{2}$ Intensities for final demand and price changes (Scenario $\mathrm{B}$ )

\begin{tabular}{|c|c|c|c|}
\hline \multirow[b]{2}{*}{$\begin{array}{l}\text { Sector } \\
\text { No }\end{array}$} & \multirow[b]{2}{*}{ CI (t/Mio MXN) } & \multicolumn{2}{|c|}{$\begin{array}{l}\text { price changes in } \% \text { for carbon tax rates } \\
\text { (in USD) }\end{array}$} \\
\hline & & 20 & 50 \\
\hline 1 & 32.52 & $0.80 \%$ & $2.00 \%$ \\
\hline 2 & 3.47 & $0.63 \%$ & $1.57 \%$ \\
\hline 3 & 12.80 & $0.41 \%$ & $1.02 \%$ \\
\hline 4 & 17.49 & $0.43 \%$ & $1.07 \%$ \\
\hline 5 & 10.74 & $0.32 \%$ & $0.80 \%$ \\
\hline 6 & 17.84 & $0.45 \%$ & $1.12 \%$ \\
\hline 7 & 13.17 & $0.46 \%$ & $1.15 \%$ \\
\hline 8 & 209.01 & $5.37 \%$ & $13.42 \%$ \\
\hline 9 & 7.96 & $0.34 \%$ & $0.86 \%$ \\
\hline 10 & 12.35 & $0.32 \%$ & $0.79 \%$ \\
\hline 11 & 44.01 & $1.38 \%$ & $3.45 \%$ \\
\hline 12 & 12.53 & $0.51 \%$ & $1.27 \%$ \\
\hline 13 & 9.07 & $0.13 \%$ & $0.33 \%$ \\
\hline 14 & 6.03 & $0.19 \%$ & $0.48 \%$ \\
\hline 15 & 6.14 & $0.20 \%$ & $0.49 \%$ \\
\hline 16 & 13.03 & $0.55 \%$ & $1.38 \%$ \\
\hline 17 & 158.31 & $7.18 \%$ & $17.95 \%$ \\
\hline 18 & 12.45 & $0.44 \%$ & $1.10 \%$ \\
\hline 19 & 13.87 & $0.43 \%$ & $1.07 \%$ \\
\hline 20 & 5.31 & $0.19 \%$ & $0.48 \%$ \\
\hline 21 & 9.94 & $0.30 \%$ & $0.76 \%$ \\
\hline 22 & 19.40 & $0.61 \%$ & $1.52 \%$ \\
\hline 23 & 20.94 & $0.73 \%$ & $1.82 \%$ \\
\hline 24 & 143.30 & $3.63 \%$ & $9.08 \%$ \\
\hline 25 & 9.83 & $0.32 \%$ & $0.79 \%$ \\
\hline 26 & 16.07 & $0.45 \%$ & $1.12 \%$ \\
\hline 27 & 6.31 & $0.20 \%$ & $0.51 \%$ \\
\hline 28 & 3.03 & $0.10 \%$ & $0.24 \%$ \\
\hline 29 & 2.25 & $0.09 \%$ & $0.22 \%$ \\
\hline 30 & 7.11 & $0.22 \%$ & $0.55 \%$ \\
\hline 31 & 11.43 & $0.36 \%$ & $0.91 \%$ \\
\hline 32 & 10.34 & $0.29 \%$ & $0.72 \%$ \\
\hline 33 & 7.75 & $0.27 \%$ & $0.68 \%$ \\
\hline 34 & 10.32 & $0.33 \%$ & $0.83 \%$ \\
\hline
\end{tabular}


Table 3.6 $\mathrm{CO}_{2}$ Intensities for final demand and price changes (Scenario C)

\begin{tabular}{|c|c|c|c|}
\hline \multirow[b]{2}{*}{$\begin{array}{l}\text { Sector } \\
\text { No }\end{array}$} & \multirow[b]{2}{*}{ CI (t/Mio MXN) } & \multicolumn{2}{|c|}{$\begin{array}{l}\text { price changes in \% for carbon tax rates } \\
\text { (in USD) }\end{array}$} \\
\hline & & 20 & 50 \\
\hline 1 & 172.93 & $4.28 \%$ & $10.70 \%$ \\
\hline 2 & 31.80 & $0.79 \%$ & $1.97 \%$ \\
\hline 3 & 43.72 & $1.08 \%$ & $2.71 \%$ \\
\hline 4 & 23.63 & $0.58 \%$ & $1.46 \%$ \\
\hline 5 & 19.44 & $0.48 \%$ & $1.20 \%$ \\
\hline 6 & 47.12 & $1.17 \%$ & $2.92 \%$ \\
\hline 7 & 20.03 & $0.50 \%$ & $1.24 \%$ \\
\hline 8 & 222.20 & $5.50 \%$ & $13.75 \%$ \\
\hline 9 & 21.57 & $0.53 \%$ & $1.33 \%$ \\
\hline 10 & 15.22 & $0.38 \%$ & $0.94 \%$ \\
\hline 11 & 100.26 & $2.48 \%$ & $6.21 \%$ \\
\hline 12 & 27.79 & $0.69 \%$ & $1.72 \%$ \\
\hline 13 & 6.28 & $0.16 \%$ & $0.39 \%$ \\
\hline 14 & 9.50 & $0.24 \%$ & $0.59 \%$ \\
\hline 15 & 9.58 & $0.24 \%$ & $0.59 \%$ \\
\hline 16 & 26.51 & $0.66 \%$ & $1.64 \%$ \\
\hline 17 & 296.62 & $7.34 \%$ & $18.36 \%$ \\
\hline 18 & 23.27 & $0.58 \%$ & $1.44 \%$ \\
\hline 19 & 18.92 & $0.47 \%$ & $1.17 \%$ \\
\hline 20 & 9.59 & $0.24 \%$ & $0.59 \%$ \\
\hline 21 & 13.95 & $0.35 \%$ & $0.86 \%$ \\
\hline 22 & 26.49 & $0.66 \%$ & $1.64 \%$ \\
\hline 23 & 31.21 & $0.77 \%$ & $1.93 \%$ \\
\hline 24 & 151.90 & $3.76 \%$ & $9.40 \%$ \\
\hline 25 & 74.78 & $1.85 \%$ & $4.63 \%$ \\
\hline 26 & 19.10 & $0.47 \%$ & $1.18 \%$ \\
\hline 27 & 9.23 & $0.23 \%$ & $0.57 \%$ \\
\hline 28 & 4.90 & $0.12 \%$ & $0.30 \%$ \\
\hline 29 & 3.82 & $0.09 \%$ & $0.24 \%$ \\
\hline 30 & 10.06 & $0.25 \%$ & $0.62 \%$ \\
\hline 31 & 15.96 & $0.40 \%$ & $0.99 \%$ \\
\hline 32 & 12.04 & $0.30 \%$ & $0.75 \%$ \\
\hline 33 & 12.83 & $0.32 \%$ & $0.79 \%$ \\
\hline 34 & 101.27 & $2.51 \%$ & $6.27 \%$ \\
\hline
\end{tabular}


(a) Relative

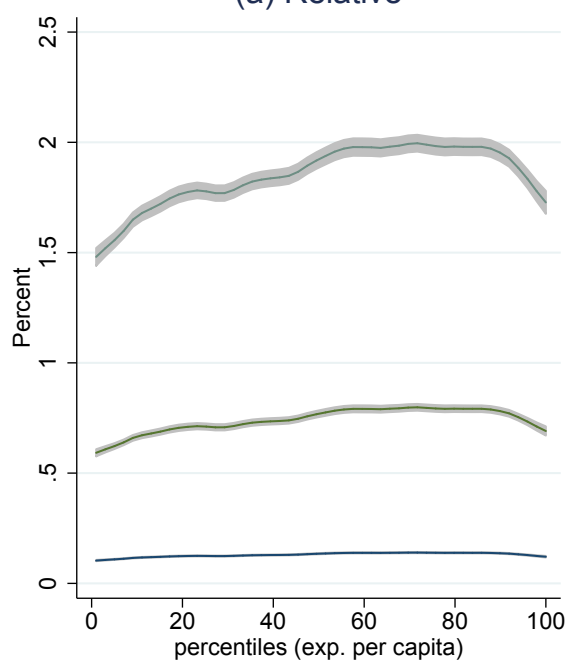

(b) Absolute

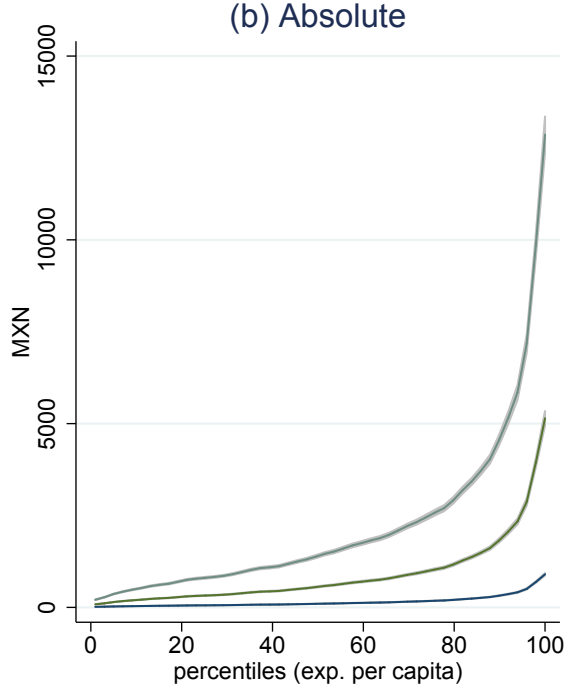

$95 \% \mathrm{Cl}$ USD 20

USD 3.5 USD 50

Fig. 3.4 Relative (a) and absolute (b) welfare effects Scenario A
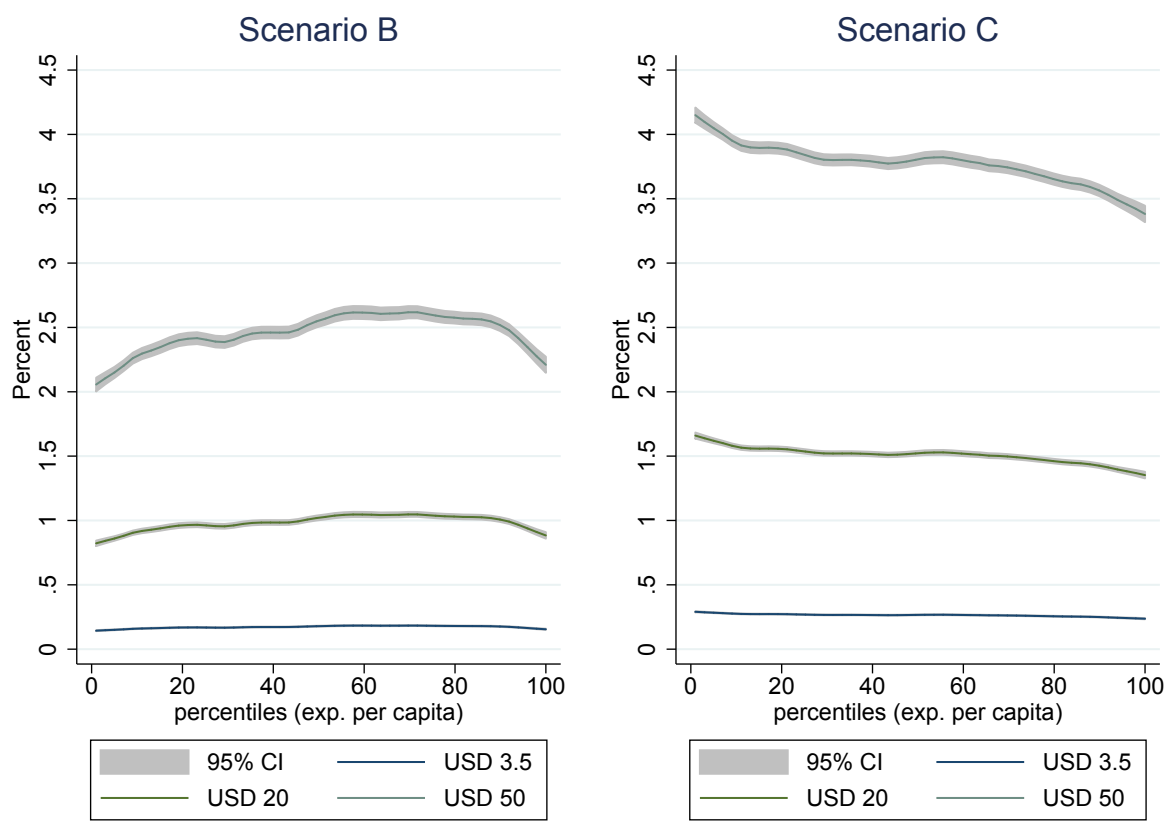

Fig. 3.5 Relative welfare effects scenario A and B 

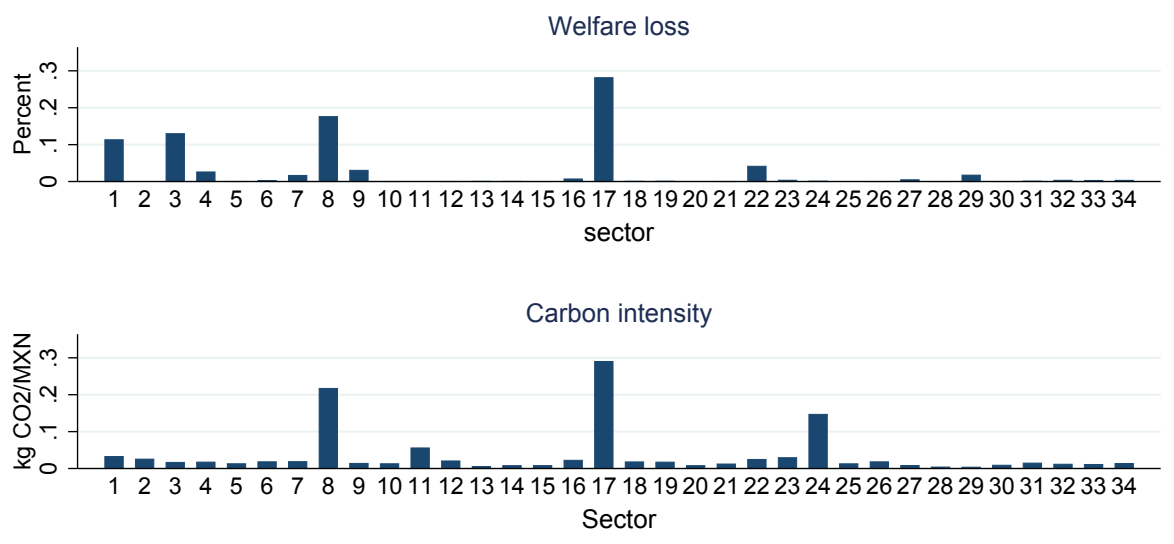

Expenditure share

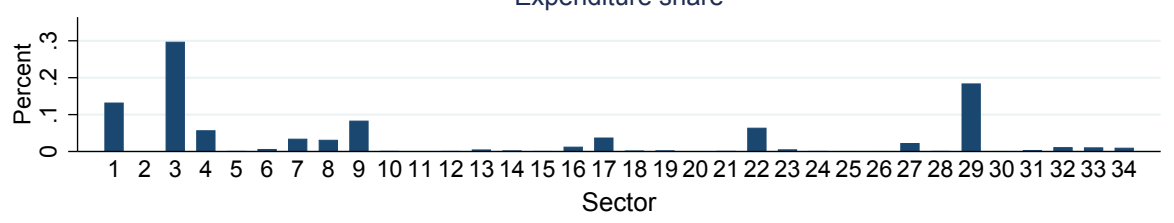

Fig. 3.6 Decomposition welfare loss, bottom 10 percent
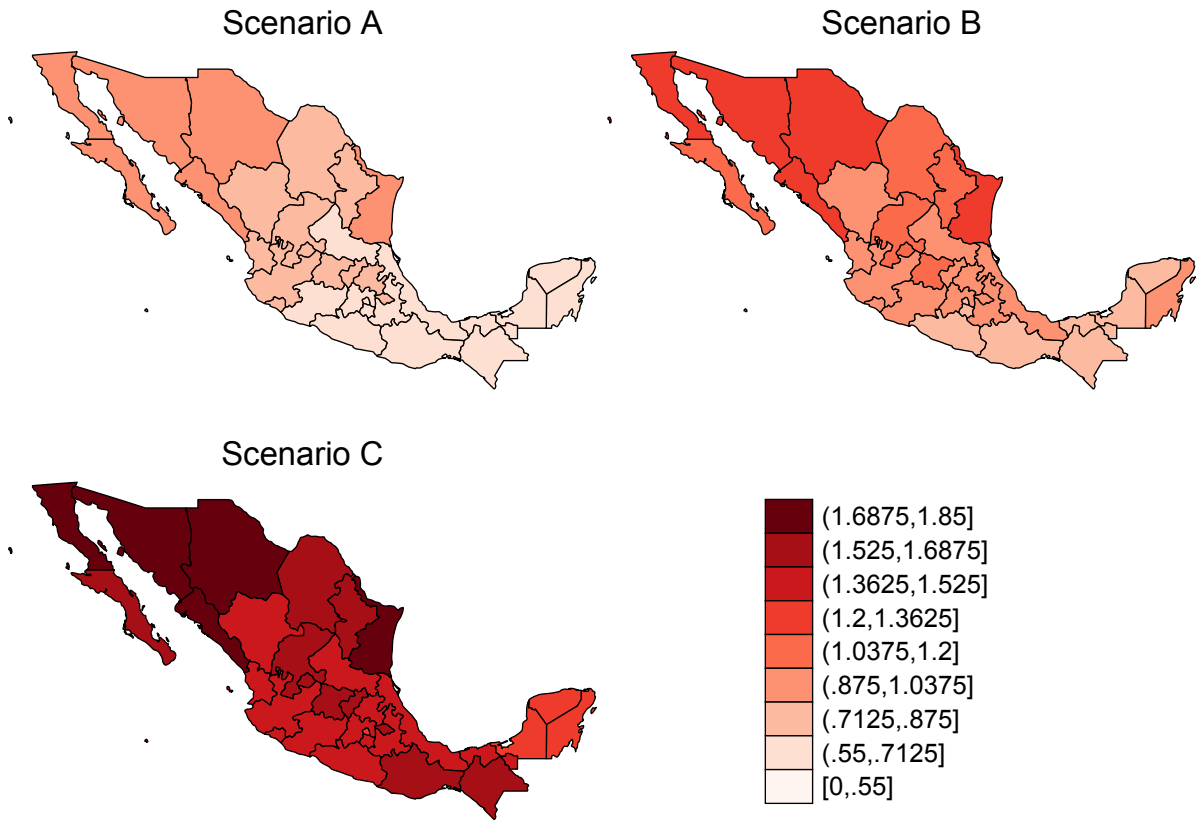

Fig. 3.7 Average relative welfare losses per federal state 
For Scenario A, relative welfare losses rise until the 60th percentile, stay constant until the 80th percentile and decline afterwards (figure 3.4). The absolute effect rises along the expenditure distribution as already indicated in the description of the expenditures and the carbon footprint. A more ambitious climate policy with higher tax rates of 20-50 USD/t $\mathrm{CO}_{2}$ would come with the same relative distributional pattern, although progressivity is more visible. With a larger tax rate of $50 \mathrm{USD} / \mathrm{CO}_{2}$, welfare losses are at 1.5 percent for the bottom part of the expenditure distribution. Poverty indices are hardly affected from the lower rates, whereas a 50 USD tax would increase the national minimum wellbeing and wellbeing poverty rates by 0.6 and 0.9 percentage points respectively (table 3.7 ), mainly driven by gasoline and electricity prices. For both poverty lines, rural poverty increases more than urban poverty.

Table 3.7 FGT poverty indices (in \%), changes from baseline (Scenario A)

\begin{tabular}{cccccccc}
\hline & \multicolumn{4}{c}{ Minimum Wellbeing } & \multicolumn{3}{c}{ Wellbeing } \\
\hline Scenario & FGT & National & Rural & Urban & National & Rural & Urban \\
\hline I (USD 3.5) & 0 & 0.064 & 0.000 & 0.082 & 0.081 & 0.024 & 0.097 \\
& 1 & 0.016 & 0.024 & 0.013 & 0.036 & 0.042 & 0.034 \\
& 2 & 0.008 & 0.015 & 0.006 & 0.023 & 0.030 & 0.021 \\
\hline II (USD 20) & 0 & 0.307 & 0.379 & 0.287 & 0.369 & 0.298 & 0.389 \\
& 1 & 0.090 & 0.140 & 0.076 & 0.205 & 0.243 & 0.194 \\
& 2 & 0.047 & 0.086 & 0.036 & 0.133 & 0.171 & 0.122 \\
\hline II (USD 20) & 0 & -0.336 & -0.465 & -0.300 & -0.228 & -0.480 & -0.157 \\
Lump-Sum & 1 & -0.138 & -0.333 & -0.084 & -0.214 & -0.450 & -0.147 \\
& 2 & -0.081 & -0.216 & -0.044 & -0.165 & -0.356 & -0.111 \\
\hline II (USD 20) & 0 & -0.732 & -1.975 & -0.383 & -0.355 & -1.960 & 0.096 \\
PROSPERA & 1 & -0.387 & -1.236 & -0.148 & -0.476 & -1.655 & -0.145 \\
& 2 & -0.233 & -0.790 & -0.076 & -0.408 & -1.321 & -0.152 \\
\hline III (USD 50) & 0 & 0.616 & 0.818 & 0.559 & 0.918 & 0.978 & 0.902 \\
& 1 & 0.231 & 0.358 & 0.195 & 0.519 & 0.616 & 0.492 \\
& 2 & 0.123 & 0.224 & 0.095 & 0.338 & 0.434 & 0.311 \\
\hline III (USD 50) & 0 & -0.703 & -1.279 & -0.542 & -0.580 & -1.276 & -0.385 \\
Lump-Sum & 1 & -0.334 & -0.809 & -0.200 & -0.526 & -1.104 & -0.364 \\
& 2 & -0.193 & -0.511 & -0.104 & -0.402 & -0.866 & -0.272 \\
\hline III (USD 50) & 0 & -1.706 & -4.942 & -0.798 & -0.820 & -4.583 & 0.237 \\
PROSPERA & 1 & -0.806 & -2.616 & -0.299 & -1.082 & -3.748 & -0.333 \\
& 2 & -0.439 & -1.522 & -0.135 & -0.876 & -2.844 & -0.324 \\
\hline
\end{tabular}


Table 3.8 FGT poverty indices (in \%), changes from baseline (Scenario B)

\begin{tabular}{cccccccc}
\hline & \multicolumn{4}{c}{ Minimum Wellbeing } & \multicolumn{3}{c}{ Wellbeing } \\
\hline Scenario & FGT & National & Rural & Urban & National & Rural & Urban \\
\hline I (USD 3.5) & 0 & 0.085 & 0.000 & 0.109 & 0.148 & 0.075 & 0.168 \\
& 1 & 0.021 & 0.032 & 0.018 & 0.048 & 0.056 & 0.046 \\
& 2 & 0.011 & 0.020 & 0.008 & 0.031 & 0.039 & 0.029 \\
\hline II (USD 20) & 0 & 0.372 & 0.495 & 0.338 & 0.499 & 0.448 & 0.513 \\
& 1 & 0.122 & 0.187 & 0.104 & 0.276 & 0.322 & 0.263 \\
& 2 & 0.064 & 0.115 & 0.050 & 0.179 & 0.227 & 0.166 \\
\hline II (USD 20) & 0 & -0.404 & -0.683 & -0.325 & -0.285 & -0.729 & -0.161 \\
Lump-Sum & 1 & -0.175 & -0.429 & -0.104 & -0.270 & -0.579 & -0.183 \\
& 2 & -0.103 & -0.276 & -0.054 & -0.208 & -0.458 & -0.138 \\
\hline II (USD 20) & 0 & -0.912 & -2.621 & -0.432 & -0.410 & -2.497 & 0.176 \\
PROSPERA & 1 & -0.482 & -1.555 & -0.182 & -0.599 & -2.106 & -0.176 \\
& 2 & -0.285 & -0.975 & -0.091 & -0.510 & -1.666 & -0.186 \\
\hline III (USD 50) & 0 & 0.833 & 1.049 & 0.773 & 1.237 & 1.203 & 1.246 \\
& 1 & 0.315 & 0.479 & 0.269 & 0.701 & 0.820 & 0.668 \\
& 2 & 0.169 & 0.303 & 0.132 & 0.459 & 0.580 & 0.425 \\
\hline III (USD 50) & 0 & -0.961 & -1.700 & -0.753 & -0.767 & -1.693 & -0.508 \\
Lump-Sum & 1 & -0.419 & -1.031 & -0.248 & -0.661 & -1.416 & -0.450 \\
& 2 & -0.241 & -0.644 & -0.127 & -0.504 & -1.106 & -0.335 \\
\hline III (USD 50) & 0 & -2.190 & -6.230 & -1.056 & -1.088 & -5.785 & 0.230 \\
PROSPERA & 1 & -0.941 & -3.101 & -0.335 & -1.319 & -4.638 & -0.388 \\
& 2 & -0.492 & -1.743 & -0.141 & -1.043 & -3.439 & -0.371 \\
\hline & & & & & & &
\end{tabular}

Including natural gas in the taxation of emissions (Scenario B), a 50 USD tax rate increases welfare losses up to 2.1 and 2.6 percent for low and high income households respectively (Figure 3.5). The currently implied tax rate of 3.5 USD would still create small welfare losses below 0.2 percent of total expenditures for all households. The maximum wellbeing poverty rate increase is 1.2 percentage points with a 50 USD tax (table 3.8). In this scenario, extremely poor rural households are hit worse than their urban counterparts. At the wellbeing poverty line, differences between urban and rural poverty impacts are less pronounced.

The story changes essentially with the inclusion of $\mathrm{CH}_{4}$ and $\mathrm{N}_{2} \mathrm{O}$ in the taxation of emissions (Scenario C). The price increase for agricultural and processed food products not just leads to higher welfare losses it also increases regressivity since poorer households spend relatively more on food products (figure 3.5). This is reflected in an increase in the minimum wellbeing poverty rate on the national level of 1.5 percentage points for a 50 USD 
Table 3.9 FGT poverty indices (in \%), changes from baseline (Scenario C)

\begin{tabular}{cccccccc}
\hline & \multicolumn{4}{c}{ Minimum Wellbeing } & \multicolumn{3}{c}{ Wellbeing } \\
\hline Scenario & FGT & National & Rural & Urban & National & Rural & Urban \\
\hline I (USD 3.5) & 0 & 0.131 & 0.178 & 0.118 & 0.169 & 0.080 & 0.194 \\
& 1 & 0.037 & 0.065 & 0.030 & 0.078 & 0.103 & 0.071 \\
& 2 & 0.020 & 0.042 & 0.014 & 0.052 & 0.076 & 0.046 \\
\hline II (USD 20) & 0 & 0.557 & 0.880 & 0.466 & 0.770 & 0.795 & 0.763 \\
& 1 & 0.219 & 0.382 & 0.173 & 0.452 & 0.596 & 0.411 \\
& 2 & 0.120 & 0.246 & 0.084 & 0.305 & 0.441 & 0.266 \\
\hline II (USD 20) & 0 & -0.523 & -0.773 & -0.452 & -0.444 & -1.035 & -0.278 \\
Lump-Sum & 1 & -0.229 & -0.546 & -0.140 & -0.369 & -0.759 & -0.260 \\
& 2 & -0.132 & -0.344 & -0.073 & -0.279 & -0.590 & -0.191 \\
\hline II (USD 20) & 0 & -1.333 & -3.684 & -0.673 & -0.567 & -3.494 & 0.255 \\
PROSPERA & 1 & -0.644 & -2.098 & -0.236 & -0.834 & -2.940 & -0.243 \\
& 2 & -0.364 & -1.262 & -0.112 & -0.690 & -2.270 & -0.247 \\
\hline III (USD 50) & 0 & 1.489 & 2.111 & 1.315 & 1.750 & 1.652 & 1.778 \\
& 1 & 0.573 & 0.996 & 0.454 & 1.154 & 1.520 & 1.052 \\
& 2 & 0.322 & 0.658 & 0.228 & 0.786 & 1.140 & 0.687 \\
\hline III (USD 50) & 0 & -1.319 & -2.388 & -1.019 & -1.072 & -2.037 & -0.800 \\
Lump-Sum & 1 & -0.535 & -1.281 & -0.326 & -0.898 & -1.839 & -0.634 \\
& 2 & -0.302 & -0.783 & -0.167 & -0.666 & -1.403 & -0.460 \\
\hline III (USD 50) & 0 & -2.723 & -8.246 & -1.172 & -1.547 & -8.292 & 0.346 \\
PROSPERA & 1 & -1.083 & -3.723 & -0.342 & -1.701 & -6.078 & -0.472 \\
& 2 & -0.518 & -1.943 & -0.119 & -1.273 & -4.302 & -0.424 \\
\hline
\end{tabular}

tax (table 3.9). More pronounced than in scenarios where only energy related emissions are taxed, is also the increase of poverty intensity and severity. With large food price changes, households above the poverty line will fall below the poverty line but also households below the poverty line face increasing difficulties to escape poverty. This holds particularly for rural households, which are already severely affected by price increases for energy items.

Reflecting the large rural urban income gap and despite the smaller poverty impacts, urban households face slightly higher welfare losses than rural households in scenario A and B when only energy emissions are taxed. Urban households spend relatively more on direct energy goods such as electricity. In Scenario C, rural low income households face higher welfare losses than their urban counterparts. For most socioeconomic groups, welfare effects lie within a 95 percent confidence interval of the average percentile consumption and are thus mostly statistically insignificant over the income distribution for all scenarios. We do not find any significant difference in welfare effects between female and male headed households 
and small differences due to family sizes. Age plays some role for consumption decisions, households with older household heads suffer slightly higher welfare losses. This finding can be explained by relatively higher expenditures for emission intensive utilities compared to households with younger household heads.

To understand the role of the single sectors in shaping welfare effects, we provide a graphical overview of sector specific carbon intensities, welfare effects and household expenditure shares for a USD 20 tax rate on $\mathrm{CO}_{2}$ emissions from energy use (Scenario B). For the bottom 10 percent of the expenditure distribution, agricultural products, processed food, refined petroleum and utilities make up the largest part of the welfare loss (figure 3.6). Agricultural products are not very energy intensive but households spend a large share of their income on processed foods. The carbon intensity for the utilities and refined petroleum products are the highest, which make them main contributors for the welfare loss despite a relatively low expenditure share. Expenditure patterns are different for the top 10 percent of the expenditure distribution, who spend relatively more on rent and service oriented goods such as hotels and restaurants (figure 3.6, appendix) but also on refined petroleum products such as gasoline. The latter becomes the consumption item causing the largest welfare loss and the main driver behind the progressive distributional effect in taxing $\mathrm{CO}_{2}$ emission from energy use.

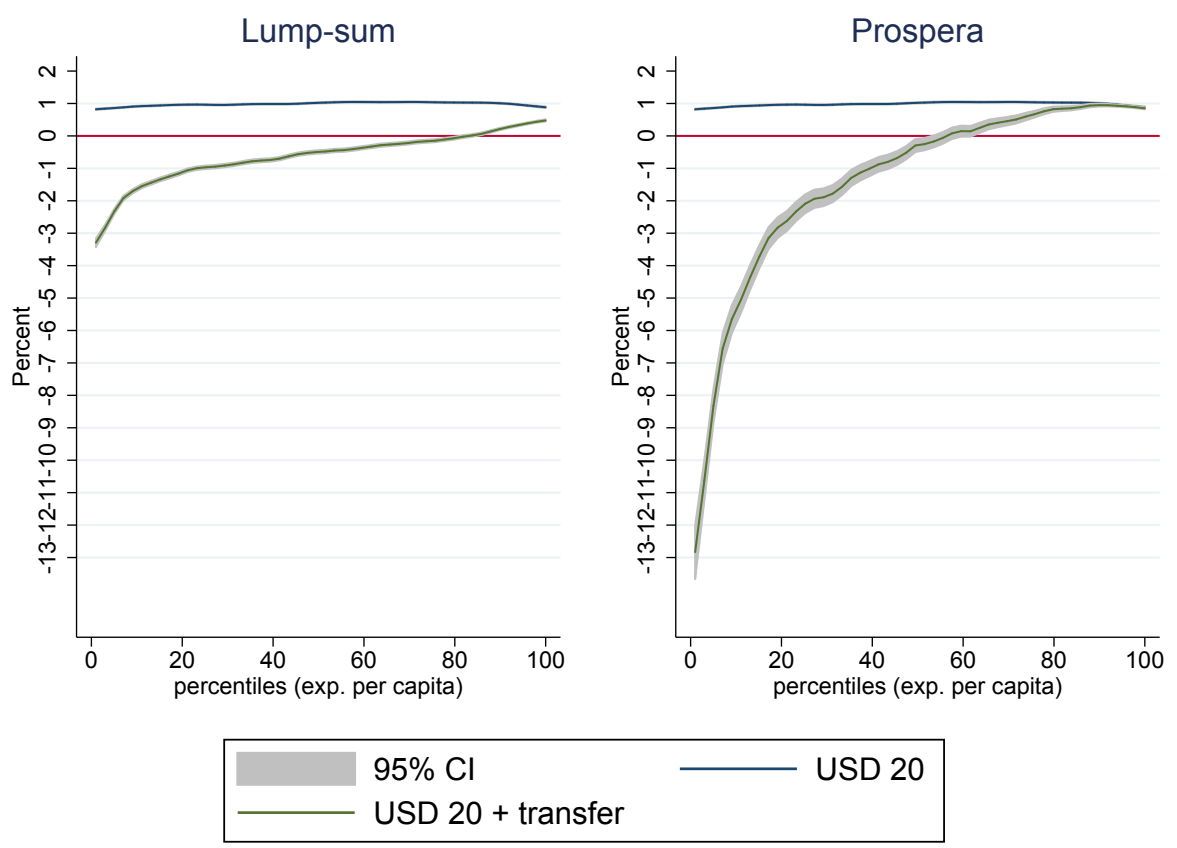

Fig. 3.8 Welfare effects lump-sum vs. PROSPERA redistribution Scenario B 
Additionally to finding differences in welfare effects across the expenditure distribution with different tax scenarios, we find spatial heterogeneity within the country. In line with our findings over the expenditure distribution, northern states, which generally exhibit above average expenditures per capita have higher average welfare losses in scenarios covering energy emissions only (Figure 3.7).

The reason can be found in higher budget shares for electricity and fuels in northern states. With $\mathrm{CH}_{4}$ and $\mathrm{N}_{2} \mathrm{O}$ emissions included, this spatial heterogeneity mostly vanishes since associated food price increases particularly lead to large welfare losses in southern states.

Finally, a redistribution simulation of projected tax revenues for our three scenarios is an elementary part for the analysis of distributional effects. Transferring total tax revenues in a lump-sum fashion per household in Scenario B with a 20 USD tax results in average welfare gains for the bottom 85 percent of the distribution (figure 3.8). Welfare gains for households at the lower end of the distribution are large with a magnitude of up to three times the effect of the counterfactual welfare loss. This large redistribution effect occurs despite the fact that low income households benefit less from the redistribution than high income households on a per capita basis due to larger family sizes. Poverty indicators decrease across all dimensions but more so for rural areas, where the combined tax and lump-sum redistribution scheme would lead to poverty rate declines of about half a percentage point at both poverty lines. Redistribution of full tax revenues via PROSPERA has the potential to generate huge welfare gains for PROSPERA recipients more than 10 percent of total household expenditures. Surprisingly, a nonsignificant share of households above the median income benefit from PROSPERA although they are not classified as poor. Poverty reductions are much stronger in this case, particularly at the minimum wellbeing poverty line and for rural households (table 3.8.

In all other simulated scenarios with redistribution, distributional patterns become even more progressive with higher tax revenues, particularly for PROSPERA scenarios. The urban poverty rate on the other hand remains either constant or increases slightly in all PROSPERA scenarios, which leads to moderate national poverty reductions despite massive improvements for rural households. Two reasons are behind this finding. First, PROSPERA is mainly targeted at very poor, particularly rural households. Urban households close to the wellbeing poverty line are less likely to be recipients of PROSPERA. Second, the urban wellbeing poverty line is significantly larger than the rural poverty line. Generally all redistribution simulations clearly reverse the regressive into a progressive overall effect.

Inequality indices such as the Gini Index hardly react to the magnitude of welfare effects caused by the different tax rates in our analysis (table B.1). The distributional effects of carbon taxes are not severe enough to create significant changes in the income distribution on 
the national level, not even with high tax rates and a broad tax base. However, redistribution of tax revenues via targeted cash transfer programs can decrease income inequality within rural areas or keep it constant when smaller shares of tax revenues are used for redistribution. If the tax is accompanied with border tax adjustments makes no significant difference, welfare effects remain largely unaffected. Although 9.5 percent of consumption goods get imported, these are mainly goods from less carbon intensive sectors such as the processed food and transport equipment sectors.

\subsection{Conclusion}

Our analysis offers a detailed view on potential welfare effects of different carbon tax scenarios for Mexico. The current rate of the carbon tax is small enough not to create much impact for household welfare. Although we are not able to calculate resulting emission reductions, the current effect can expected to be negligible with the currently implemented tax regime. Adding to it, natural gas remains tax exempt and makes up 25 percent of energy related $\mathrm{CO}_{2}$ emissions which renders the policy partly inefficient. As we show, including natural gas increases the welfare losses due to higher electricity prices. Although the inclusion of aviation fuels in the carbon tax would naturally increase efficiency, these effects are negligible since jet fuel emissions are only 2 percent of total energy related emissions. To have a measurable effect on national $\mathrm{CO}_{2}$ emissions, the necessary higher tax rates are projected to have negative effects on household welfare and related poverty outcomes. The exact magnitude and distributional outcome indeed depends on the tax rate but also on the share of taxed emissions. In the case of the highest simulated tax rate of $50 \mathrm{USD} / \mathrm{tCO}_{2} \mathrm{e}$ and including $\mathrm{CH}_{4}$ and $\mathrm{N}_{2} \mathrm{O}$ in the taxation, we find overall effects to be regressive with relative welfare losses at 4.2 and 3.4 percent of total expenditures for the poorest and richest households respectively. For carbon tax rates of $20 \mathrm{USD} / \mathrm{tCO}_{2}$ exclusively taxing $\mathrm{CO}_{2}$ from energy use, which might be more realistically expected in climate policies, welfare losses are progressive and around 1 percent of total expenditures for all households. Naturally, the reason for this progressivity is a rising carbon intensity of consumption over the expenditure distribution up to a certain income level, driven by transport fuels such as gasoline. In contrast, the top decile demands more service oriented, low carbon intensive goods which lessens the progressivity of carbon taxes to some extent. Nevertheless, absolute tax payments strictly rise with income. Although welfare effects are generally moderate for low tax rates, total tax revenues allow for relatively high transfers to low income households which render the policy clearly progressive. National poverty incidence is more sensitive at the wellbeing poverty line in scenarios covering only energy related $\mathrm{CO}_{2}$ emissions. Additionally, low 
income rural households are also at higher risk than their urban counterparts. In the case of food price increases through taxation of $\mathrm{CH}_{4}$ and $\mathrm{N}_{2} \mathrm{O}$, poverty is much stronger affected which demonstrates the importantance of a well thought through redistribution mechanism. Nevertheless, since distributional results are calculated on average per expenditure percentile, they hide an important fact. In scenarios with redistribution not every poor household benefits through the PROSPERA system. The share of PROSPERA recipients in the lowest percentile is about 70 percent and declines to 13 percent at the 50th percentile, resulting in a substantial number of households below the minimum wellbeing and other households close to the bienestar poverty line not covered, particularly in urban areas. Despite the on average promising redistribution outcome, targeting must be improved to achieve poverty reductions for the entire population. 



\section{Chapter 4}

\section{Household Welfare and $\mathrm{CO}_{2}$ Emission Impacts of Energy and Carbon Taxes in Mexico}

\subsection{Introduction}

Mexico has become a major emitter of greenhouse gas emissions over the last decades with both economic and population growth as driving forces. In response, the Mexican government committed itself to carbon dioxide emission reductions relative to a baseline scenario and passed a climate change law in 2012 with legally binding emission reduction goals (Vance, 2012). Additionally, substantial reform efforts in the energy sector have been made recently that may affect energy prices. The oil and gas industry was opened to competition in the up-, middle- and downstream sectors and Mexican households will be subjected to international gasoline prices by 2018. The Federal Electricity Commission (CFE) is planned to be reformed with the objective to form and regulate a competitive electricity market with incentives for private investment (The Atlantic Council, 2014). In the residential electricity market, large seasonal subsidies in warmer regions of Mexico continue to exist to cover for higher demand of air conditioning (Davis et al., 2014; Komives et al., 2009). While the effects of these (potential) reforms on energy consumer prices are uncertain in some cases (oil sector) or modest in others (gasoline price subsidies), ambitious climate policy implies increasing energy prices in a country with a fossil-fuel reliant energy system. Higher energy prices are thus likely to lead to welfare losses in the short-run that may not be equally distributed. In developed countries, poorer households tend to be more vulnerable to energy price increases, as energy goods usually represent a larger proportion of their total 
expenditure with some exceptions for transport fuels (Flues and Thomas, 2015; Speck, 1999). For developing countries, although there is less evidence on the distributional effects, it has been pointed out early by Shah and Whalley (1991) as well as Shah and Larsen (1992) that emerging distributional patterns are supposedly different. The recently growing literature on welfare effects of energy price changes or subsidy reform mainly focuses on fuel prices with some emphasis on gasoline. Various countries are covered in the volume of Sterner (2011) and in Arze del Granado et al. (2012). A general result is that high-income households capture significantly higher amounts of subsidies for fuels than low income households. A similar result is found by Datta (2010), who investigates the distributional welfare effects of a fuel tax in India. Gillingham et al. (2006) show that the direct (consumption losses via higher prices) and indirect (income effects) welfare impacts of fuel price increases (both domestic and transport fuels) are either regressive or distributional neutral in relative terms for a range of developing countries. Potentially large welfare losses due to higher energy prices are particularly critical for middle income countries with relatively high $\mathrm{CO}_{2}$ emissions and the need for further economic development, growth, and poverty reduction. Mexico is such a case where nearly half of the population still lives below the official poverty line (Consejo Nacional de Evaluación de la Política de Desarrollo Social (CONEVAL, 2014)). Against this background, the present study adds to the literature in two ways. First, we provide some evidence on the short-run poverty and distributional effects of energy price changes for Mexico. We calculate the welfare impacts of hypothetical price increases of electricity, motor fuels, gas and public transportation. Since these price changes can be interpreted as environmental taxes, we can also assess how tax revenues can be redistributed, for example by employing cash-transfers to households. Additional to price changes for energy items, we simulate the welfare impacts of scaling up the carbon tax that was initially introduced in 2014. By drawing on the demand estimates, we examine whether second-order effects need to be calculated for the welfare analysis in our context. By estimating a censored consumer demand system, we incorporate the discrete choice to use certain energy types and the exact pattern of substitution between them and other goods. Second, we calculate the short-run $\mathrm{CO}_{2}$ emission savings potential of consumer responses due to energy and carbon taxes. The rest of the paper proceeds as follows. First, we present the database on which the analysis is based upon with some descriptive statistics in section 4.2. In section 4.3 we describe the theory and the closely connected empirical strategy to measure welfare effects and household induced $\mathrm{CO}_{2}$ emissions. We present the results in section 4.4, conclude in section 4.5 and provide some policy recommendations. 


\subsection{Household energy use}

We use household expenditure data from ENIGH surveys conducted by INEGI, the national institute for geography and statistics in Mexico. The data are representative at both the national level as well as rural and urban areas. They contain information on item-wise expenditure for every household, as well as an extensive list of variables capturing household and sociodemographic characteristics. The expenditure categories used in the analysis are (1) electricity, (2) motor fuels (including low-/ and high-octane gasoline as well as diesel and gas), (3) gas (aggregate of natural gas and LPG), (4) public transportation, (5) food (excluding alcohol and tobacco) and (6) other goods. Figure 4.1 shows the distribution of energy expenditures over expenditure percentiles for 2014. ${ }^{1}$ Expenditures on the four energy goods relative to total expenditures range between 6 and 13 percent of total household expenditures. A clear reverse U-shaped curve can be observed for total energy budget shares over the total expenditure distribution.

(a) Budget shares

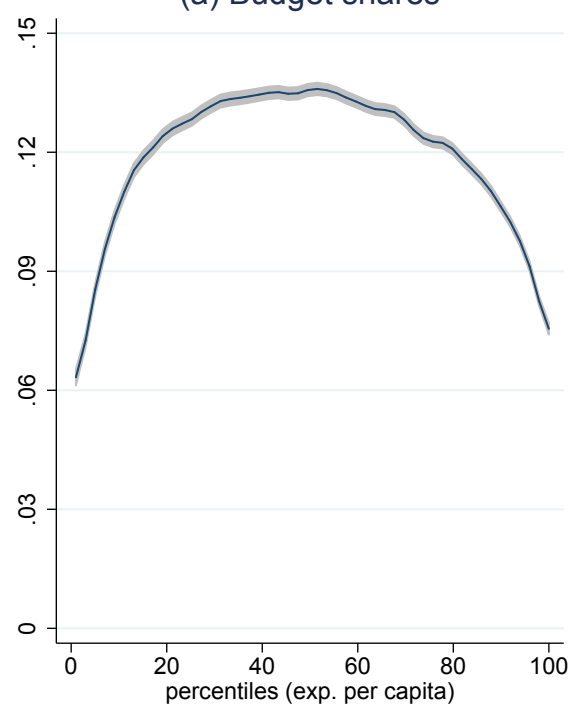

(b) Total Expenditures

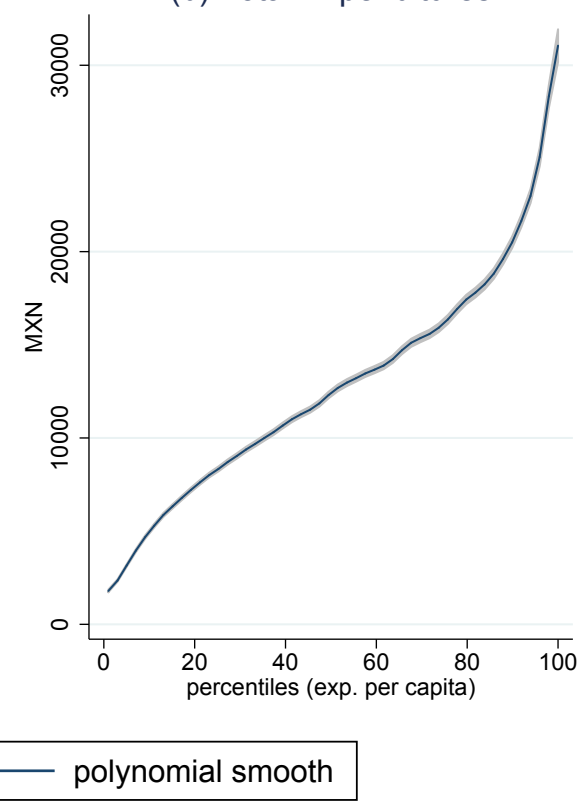

Fig. 4.1 Energy expenditures

Figure 4.2 plots the distributional incidence for the energy goods separately and also distinguishes between users and non-users. This distinction may matter for welfare analyses, as users of some energy good may not find it so easy to switch away from using it. Households

\footnotetext{
${ }^{1}$ Nonparametric distributional curves are calculated with kernel-weighted local polynomial smoothing using an epanechnikov kernel function with degree 0 and bandwith 1.15 .
} 
may own vehicles and other energy-processing durables that they do not want to (or cannot) put out of use. When considering all observations, the electricity consumption share is continuously decreasing over the expenditure distribution, but is exhibiting little variation across percentiles and lies at around 2.4 percent for the poorest households. The slightly declining budget shares over the income distribution pattern are not universally found in other countries, e.g. in Sri Lanka, Mali and Indonesia, richer households exhibit larger electricity budget shares (Gillingham et al., 2006) which is partly a result of the design of electricity tariffs. ${ }^{2}$ For motor fuels, the share is rising over the expenditure distribution, ranging from about 1.6 percent to 4.3 percent. Both gas and public transport exhibit an inverse U-shaped curve over the expenditure distribution, with gas being the least important energy good.

(a) Electricity

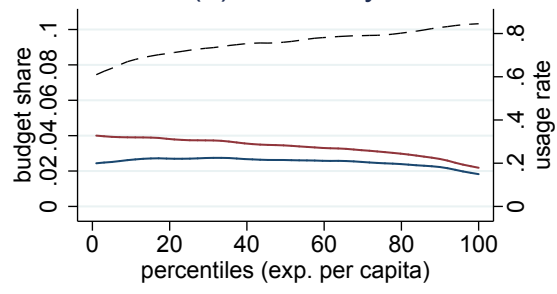

(c) Gas

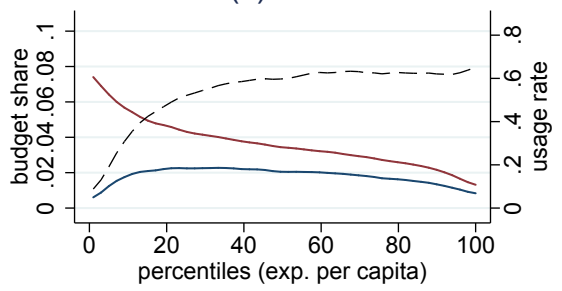

(b) Motor Fuels

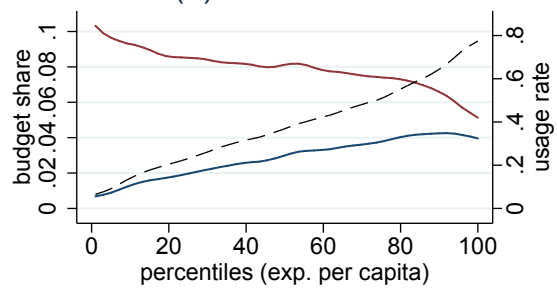

(d) Public Transport

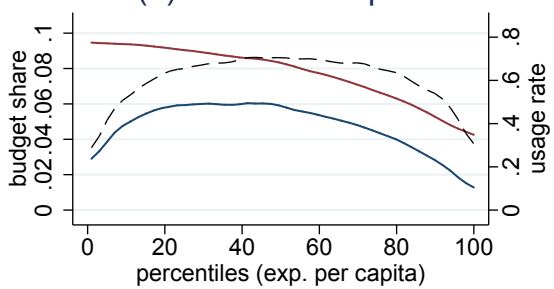
\begin{aligned} \hline full sample & users only \\ ----- usage rate & \end{aligned}

Fig. 4.2 Energy budget shares and usage rates

When only considering households with positive expenditures for the respective energy goods, budget shares continuously decrease with income for all energy types. The difference between user and non-users is most pronounced for motor fuel expenditures for the first decile, for which the mean share is just above 10 percent. Note that only around 16 percent of the households in the poorest decile own a vehicle compared to 73 percent in the richest decile. Poor households that use gas also have a larger expenditure share than rich ones. Public transport expenditure shares for users reach nearly 10 percent for the first deciles and decline

\footnotetext{
${ }^{2}$ Results for Indonesia can be found in chapter 5 .
} 
over the expenditure distribution. Only minor differences in electricity expenditure shares are detected. These findings indicate that the distributional incidence of relative expenditures depend heavily on the usage rate in the respective income groups. Poor households that depend on one of these energy goods might be disproportionately vulnerable when subjected to energy price increases. Our data indicate that motor fuel usage, i.e. the percentage of households consuming some motor fuel, increased from 4.5 percent in the poorest decile to 16 percent between 2002 and 2014. Poor households have thus become more vulnerable to motor fuel price increases. We find that rural households spend slightly less of their current income on electricity than urban households. For the other energy goods, the data shows no significant difference in consumption patterns between rural and urban households (results not reported).

\subsection{Methodology}

\subsubsection{Demand system}

We model the demand for electricity, motor fuels, gas, public transport, food and other non-durables based on household survey data with a microeconomic, partial equilibrium demand framework. For our analysis we use the Quadratic Almost Ideal Demand System (QUAIDS) framework (Banks et al., 1997) since observed Engel curves appear to be well approximated by a quadratic relationship between budget shares and logarithmic transformed expenditures. ${ }^{3}$ The estimation of a QUAIDS has been applied to the energy context by Brännlund and Nordström (2004) and Labandeira et al. (2006) for Sweden and Spain, but according to our knowledge, no demand system specification of this form has been applied to the energy context in low and middle income countries before. ${ }^{4}$

The QUAIDS as a rank three quadratic logarithmic budget share system has an indirect utility function of the following form:

$$
\ln V=\left\{\left[\frac{\ln x-\ln a(p)}{b(p)}\right]^{-1}+\lambda(p)\right\}^{-1}
$$

The price indexes $\ln a(p)$ and $b(p)$ are defined as:

\footnotetext{
${ }^{3}$ For higher observed nonlinearity, other systems such as the EASI from Lewbel and Pendakur (2009) would be more appropriate

${ }^{4}$ The Almost Ideal Demand System (AIDS) has been used in related contexts (Symons et al., 1994; West and Williams III, 2004)
} 


$$
\begin{aligned}
\ln a(p) & =\alpha_{0}+\sum_{i=1}^{n} \alpha_{i} \ln p_{i}+\frac{1}{2} \sum_{i=1}^{n} \sum_{j=1}^{n} \gamma_{i j} \ln p_{i} \ln p_{j} \\
b(p) & =\prod_{i=1}^{n} p_{i}^{\beta_{i}}
\end{aligned}
$$

The term $\lambda(p)$ in the indirect utility function is a differentiable, homogeneous function of degree zero of prices $p$ and defined as:

$$
\lambda(p)=\sum_{i=1}^{n} \lambda_{i} \ln p_{i}
$$

with $\sum_{i} \lambda_{i}=0$ the derived expenditure share system is:

$$
w_{i}=\alpha_{i}+\sum_{j=1}^{n} \gamma_{i j} \ln p_{j}+\beta_{i} \ln \left[\frac{x}{a(p)}\right]+\frac{\lambda_{i}}{b(p)}\left\{\ln \left[\frac{x}{a(p)}\right]\right\}^{2}
$$

where $w_{i}$ is the share of commodity (group) $\mathrm{i}$ of total expenditures $x$. To be consistent with utility maximization, the following restrictions need to hold:

Adding-up

$$
\sum_{i=1}^{n} \alpha_{i}=1 ; \quad \sum_{i=1}^{n} \gamma_{i j}=0 ; \quad \sum_{i=1}^{n} \beta_{i}=0 ; \quad \sum_{i=1}^{n} \lambda_{i}=0
$$

Homogeneity

$$
\sum_{j=1}^{n} \gamma_{i j}=0
$$

Symmetry

$$
\gamma_{i j}=\gamma_{j i}
$$

Budget elasticities can be derived from the share equation:

$$
e_{i}=\frac{\mu_{i}}{w_{i}}+1
$$

with

$$
\mu_{i}=\frac{\partial w_{i}}{\partial \ln x}=\beta_{i}+\frac{2 \lambda_{i}}{b(p)}\left\{\ln \left[\frac{x}{a(p)}\right]\right\}
$$


The uncompensated price elasticity is given by:

$$
e_{i j}^{u}=\frac{\mu_{i j}}{w_{i}}-\delta_{i j}
$$

with

$$
\mu_{i j}=\frac{\partial w_{i}}{\partial \ln p_{i}}=\gamma_{i j}-\mu_{i}\left(\alpha_{j}+\sum_{k}^{n} \gamma_{j k} \ln p_{k}\right)-\frac{\lambda_{i} \beta_{j}}{b(p)}\left\{\ln \left[\frac{x}{a(p)}\right]\right\}^{2}
$$

and $\delta_{i j}$ is the Kronecker delta. Compensated price elasticities are derived by the slutsky equation

$$
e_{i j}^{c}=e_{i j}^{u}+e_{i} w_{j}
$$

Demographic demand shifters including sex, age, education of the household head, household size and a rural area dummy influence preferences through $\alpha_{i}$ in equation 4.5. To account for zero expenditures, we follow Shonkwiler and Yen (1999) and obtain elasticity estimates in a censored system setting. In first step, a household specific probit model is estimated with the outcome of 1 if the household consumes good $i$ and 0 otherwise. For each household in the sample, the standard normal probability density function (pdf) $\varphi\left(z_{i h}, w_{i}\right)$ and the cumulative distribution function (cdf) $\Phi\left(z_{i h}, w_{i}\right)$ are calculated by regressing $w_{i}$ on a set of independent variables $z_{i h}$. In a second step, the pdf and the cdf are integrated into the system of equations:

$$
w_{i}^{*}=\Phi w_{i}+\varphi_{i} \phi
$$

Opposed to Heckman (1979), this approach is based on the full sample in both steps of the estimation process. The elasticities change as:

Expenditure elasticity

$$
e_{i}^{*}=\frac{\Phi\left(\mu_{i}\right)}{w_{i}}+1
$$

Price elasticity

$$
e_{i j}^{*}=\frac{\Phi\left(\mu_{i}\right)}{w_{i}}+\phi \tau_{i j}\left(1-\frac{\varphi_{i}}{w_{i}}\right)-\delta_{i j}
$$

Since we use prices as dependent variables in the first stage estimation, $\tau_{i j}$ is the coefficient of price $j$ from equation $i$ from the probit model. The respective expenditure and price elasticities, $e_{i}$ and $e_{i j}$ are derived under the modified system (4.14). Explanatory variables used in the probit estimation are listed in table 4.2. This two-step methodology has been extensively applied in agricultural demand contexts (see for example Ecker and Qaim (2011); 
Shonkwiler and Yen (1999); Yen et al. (2002)) but not yet for energy demand. The censored system is estimated for the full system and therefore loses the adding-up restriction, which is why we calculate approximate second-order welfare effects based on equation (20). We use a two-step feasible generalized nonlinear least squares (FGNLS) estimator for the estimation of equation (17). Identification of price elasticities is enabled through cross-sectional (spatial) and time variation. We select eight years for the demand system estimation: 2002, 2004, 2005, 2006, 2008, 2010, 2012 and 2014. Additional to this considerable variation in time, spatial variation comes from CPI data on the city level. The price data consist of indices that are available from INEGI for 46 cities throughout Mexico and every state is represented by at least one city. Households not residing in one of the 46 cities are assigned to the city that is located in their state. When more than one city lies in the respective state, an unweighted average of the price indices is calculated. The price indices are disaggregated for the categories food, gasoline, electricity, gas (aggregated index for both LPG and natural gas) and public transport (inter alia). For other goods, we use the general price index. For motor fuels, we use the aggregated index of low- and high-octane gasoline. To correct for city specific effects, we incorporate city fixed effects in the $\alpha_{i}$ term in equation 4.5.

\subsubsection{Simulation and welfare effects}

We simulate price changes for different scenarios, where the price change per good $i$ is simply:

$$
\frac{\Delta p_{i}}{p_{i}^{0}}=\frac{p_{i}^{1}-p_{i}^{0}}{p_{i}^{0}}
$$

and the new price level after the tax change is:

$$
p_{i}^{1}=\left(1+\frac{\Delta p_{i}}{p_{i}^{0}}\right) p_{i}^{0}
$$

$\ln a(p)$ and $b(p)$ (equation 4.14) get adjusted accordingly with new price levels and we obtain simulated budget shares for good $i$ and each household according to:

$$
\begin{aligned}
w_{i}^{1}= & \Phi\left(\widehat{\alpha}_{i}+\sum_{j=1}^{n} \widehat{\gamma_{i j}} \ln p_{j}^{1}+\widehat{\beta}_{i} \ln \left[\frac{x^{0}}{a\left(p^{1}\right)}\right]+\frac{\widehat{\lambda}_{i}}{b\left(p^{1}\right)}\left\{\ln \left[\frac{x^{0}}{a\left(p^{1}\right)}\right]\right\}^{2}\right) \\
& +\varphi_{i} \phi+\widehat{\varepsilon}_{i}^{0}
\end{aligned}
$$


The "hats" are estimated coefficients from equation 4.14 and the superscripts denote the periods of reference. Household characteristics in the $\alpha$ term remain unchanged in all scenarios. Since the demand system does not predict household expenditures perfectly, the redidual term $\varepsilon_{i}$ containing household specific unexplained effects is included. ${ }^{5}$

The literature on the welfare impacts of energy price increases and subsidy reforms focuses to a large extent on first-order effects as in Sterner (2011). These first-order effects, based on work of Feldstein (1972) and Stern (1987) only require the observed demand and no additional information on substitution behavior due to price changes. First order welfare losses relative to income (total expenditures are used as a proxy) are calculated as:

$$
F O=\sum_{i=1}^{n} w_{i}\left(\frac{\Delta p_{i}}{p_{i}^{0}}\right)
$$

With estimated coefficients at hand, we calculate a second-order approximation to the Compensating Variation (CV), which is the amount of money the household needs to be compensated with to attain the utility level $u^{0}$ prior to the price changes, again relative to total household expenditures: ${ }^{6}$

$$
C V=\sum_{i=1}^{n} w_{i}\left(\frac{\Delta p_{i}}{p_{i}^{0}}\right)+\frac{1}{2} \sum_{i=1}^{n} \sum_{j=1}^{n} w_{i} e_{i j}\left(\frac{\Delta p_{i}}{p_{i}^{0}}\right)\left(\frac{\Delta p_{j}}{p_{j}^{0}}\right)
$$

The CV is compared to the first-order effect to clarify the necessity of estimating a demand system in our context. The price change in equation (4.17) can also be interpreted as an ad valorem tax rate $t_{i}$. Tax payments per household are then calculated as:

$$
T=\sum_{i=1}^{n} \frac{\Delta p_{i}}{p_{i}^{0}}\left(p_{i}^{0} * q_{i}^{1}\right)=\sum_{i=1}^{n} t_{i} \frac{\exp _{i}^{1}}{1+\frac{\Delta p_{i}}{p_{i}^{0}}}
$$

which are multiplied with household weights and summed over all households to obtain the total tax revenue. With household substitution already incorporated, simulated expenditures based on equation 4.19 are used for the tax calculation and deflated to the base period. When tax revenues are redistributed to households in the form of direct cash transfers, we assume

\footnotetext{
${ }^{5}$ Additionally, with the missing adding up restriction, budget shares do not sum perfectly to 1 . We find this error to be very small in the range of $0.03-0.3$ percentage point deviation from 1 in our simulations

${ }^{6}$ The approximation is based on a second-order Taylor series expansion of the expenditure function (Banks et al., 1996; Deaton and Muellbauer, 1980b; Friedman and Levinsohn, 2002)
} 
the additional income is completely spent on non-durable consumption and the new budget shares are:

$$
\begin{aligned}
w_{i}^{1, t r}= & \Phi\left(\widehat{\alpha}_{i}+\sum_{j=1}^{n} \widehat{\gamma_{i j}} \ln p_{j}^{1}+\widehat{\beta}_{i} \ln \left[\frac{x^{1}}{a\left(p^{1}\right)}\right]+\frac{\widehat{\lambda}_{i}}{b\left(p^{1}\right)}\left\{\ln \left[\frac{x^{1}}{a\left(p^{1}\right)}\right]\right\}^{2}\right) \\
& +\varphi_{i} \phi+\widehat{\varepsilon}_{i}^{0}
\end{aligned}
$$

\subsection{3 $\mathrm{CO}_{2}$ emissions}

In our analytical framework, $\mathrm{CO}_{2}$ emissions $(C)$ are calculated from a demand side perspective. The carbon content of the goods in our analysis may come from three different sources. First, fuels have a direct $\mathrm{CO}_{2}$ content per physical unit $\left(C_{d i r}\right){ }^{7}$ Second, goods are produced with energy which leads to the emission of $\mathrm{CO}_{2}$, the direct production emissions. Third, other goods used in the production process are responsible for the indirect production emissions. We term production emissions from direct and indirect energy use as indirect emissions $C_{\text {ind }}$. Total emissions $C$ are simply the sum of direct and indirect emissions:

$$
C=C_{\text {dir }}+C_{\text {ind }}
$$

Where applicable, as in the case of fuels, $C_{d i r}$ can be calculated based on the expenditure data. The indirect emissions $C_{\text {ind }}$ are calculated with an environmentally extended inputoutput model based on data from the World Input-Output Database (Timmer et al., 2015) as:

$$
C_{\text {ind }}=C I^{\prime} x=C I^{\prime}(I-A)^{-1} y
$$

where $\mathrm{CI}$ is the direct carbon intensity of production, $(I-A)^{-1}$ the Leontief inverse and $C I^{\prime}(I-A)^{-1}$ the indirect carbon intensities containing all direct and indirect production emissions. ${ }^{8}$ These $\mathrm{CO}_{2}$ emissions embedded in household consumption, the carbon footprints,

\footnotetext{
${ }^{7}$ For motor fuels we assume the $\mathrm{CO}_{2}$ content of gasoline: $2.31 \mathrm{~kg} \mathrm{CO}_{2} /$. Gas/LPG: $1.5 \mathrm{~kg} \mathrm{CO} / \mathrm{kg}$. These physical units are transformed to $\mathrm{CO}_{2}$ intensities per monetary unit by assuming prices of MXN 13 per 1 motor fuel and MXN 13 per kg of gas. Although this procedure is not precise due to different prices for households over space and fuel choice, it corrects for the otherwise missing direct carbon content on consumption in the absence of quantity information

${ }^{8}$ For details on the calculation of carbon intensities and matching with household expenditures for Mexico, see chapter 3 . How we matched the 34 sector production classification to our 6 good demand classification is described in table C.1
} 
are derived by multiplying expenditures per good with the respective carbon intensity $C I_{k}$ $\left(\mathrm{tCO}_{2} / \mathrm{MXN}\right)$ :

$$
C O_{2}^{0}=\sum_{i=1}^{n}\left(\exp _{i}^{0} * C I_{i}\right)
$$

In each scenario, new expenditure levels $\exp _{i}^{1}$ per good $\mathrm{i}$ and each household are derived from new budget shares $w_{i}^{1}$. New carbon emissions are then calculated as:

$$
C O_{2}^{1}=\sum_{i=1}^{n}\left(\frac{\exp _{i}^{1}}{1+\frac{\Delta p_{i}}{p_{i}^{0}}} * C I_{i}\right)
$$

For the calculation of tax revenue, the simulated expenditures are real expenditures at base prices. They isolate the unobserved quantity effect from the nominal expenditure change. Aggregating over households by using household weights, we obtain total carbon emissions resulting from domestic household demand. The difference to the baseline value is then exclusively explained by consumer substitution. Substitution effects are also taken into account in redistribution scenarios when total expenditures increase through cash transfers. New expenditure levels $\exp _{i}^{1, t r}$ based on equation 4.23 are expected to be higher with normal goods and reduce the emission saving potential determined by the size of $\beta$ and $\lambda$ through the budget elasticity.

\subsection{Poverty, welfare and $\mathrm{CO}_{2}$ emissions}

In order to understand the implications of energy price changes for household welfare and carbon footprints, we simulate stylized scenarios with price changes for each fuel separately and one scenario with price changes for all energy types simultaneously. In a second step, we take a closer look at potential future policy interventions in the form of different carbon tax rates. Along the way, we check upon the importance of calculating second-order effects for welfare analysis in this context. For the effects on poverty, we calculate absolute welfare effects and subtract them from household income, since domestic poverty lines are constructed with household income per capita (CONEVAL, 2014). We calculate FGT poverty indices on the basis of poverty lines for Mexico provided by the National Council for the Evaluation of Social Development Policy CONEVAL (Consejo Nacional de Evaluacion de la Politica de Desarrollo Social). CONEVAL indicates two different poverty lines. One refers to extreme poverty illustrated by the minimum wellbeing standard of an individual which corresponds to the value of the food basket per person per month (Bienestar minimo - 
Canasta alimentaria). The population below this poverty line cannot aquire enough food to ensure adequate nutrition. The second poverty line is equivalent to the total value of the food plus non-food basket per person per month and hence refers to a general wellbeing standard (Bienestar - Canasta alimentaria y no alimentaria). We provide results for both poverty lines to distinguish between effects on extreme and moderate poverty.

\subsubsection{Energy price changes}

Since the direct interpretation of the coefficients is difficult, we report elasticities in table 4.1. Following Banks et al. (1997), we calculate elasticities for each household individually and construct a weighted average, with the weights generated as the household's share of total sample expenditure for the relevant good. The estimated budget elasticities suggest that on average, households perceive motor fuels as a luxury good and electricity, gas and public transport as necessities. For the latter three energy items, income elasticities are fairly close to 1 which indicates quickly rising energy demand with income growth. Income plays a more nuanced role for the discrete energy use decision. With a very high electrification rate, income is no important determinant for using electricity at all. In the case of motor fuel, income plays a major role for the determination of private transport vehicle ownership. The probability of public transport use on the other hand is only slightly affected by rising incomes but more so by the necessity and convenience of this transportation mode, reflected in a large effect of the rural dummy.

Uncompensated own-price elasticities all show the expected negative signs and reflect inelastic household responses to price changes with the exception of electricity and motor fuels. Cross-price elasticities between energy items show the expected pattern, e.g. the domestically used electricity and gas and transport expenditures motor fuel and public transport are substitutes although fairly inelastic. Compensated price elasticities for energy items, used in the calculation of welfare effects, do not differ significantly since expenditure elasticities are all close to 1. For food and other goods, the elasticities become indistinguishable from 0 . Based on the observance of energy price elasticities, we would not expect large differences between the first- and second-order welfare effects except for electricity price changes.

The descriptive analysis of budget shares has already revealed the potential distributional patterns of price changes for the respective energy types. Reflecting these expenditure patterns, the magnitude of a stylized price change of 20 percent per energy good separately is displayed in figure 4.3. We find almost no difference between first- and second-order welfare losses. Overall, the calculated own-price elasticities imply a smaller second- relative to the first-order effect on average. However, the use of 95 percent confidence intervals in the calculation of average welfare effects per percentile reveals no statistically signifi- 
Table 4.1 Demand elasticities

Uncompensated Price Elasticities

Price

\begin{tabular}{cccccccc} 
& & Electricity & Motor fuels & Gas & Publ Trans & Food & Other \\
\cline { 2 - 7 } & Electricity & -1.49 & -0.16 & 0.14 & 0.03 & 0.03 & 0.28 \\
& $(0.002)$ & $(0.001)$ & $(0.001)$ & $(0.000)$ & $(0.000)$ & $(0.001)$ \\
\multirow{4}{*}{ Demand fuels } & -0.09 & -1.03 & 0.02 & 0.10 & 0.26 & -0.45 \\
& & $(0.000)$ & $(0.000)$ & $(0.000)$ & $(0.001)$ & $(0.001)$ & $(0.002)$ \\
& \multirow{4}{*}{ Gas } & 0.18 & 0.04 & -0.69 & -0.16 & -0.29 & 0.11 \\
& & $(0.001)$ & $(0.000)$ & $(0.001)$ & $(0.001)$ & $(0.002)$ & $(0.000)$ \\
& \multirow{6}{*}{ Publ Trans } & 0.01 & 0.10 & -0.06 & -0.65 & -0.74 & 0.63 \\
& & $(0.000)$ & $(0.001)$ & $(0.001)$ & $(0.002)$ & $(0.004)$ & $(0.004)$ \\
& \multirow{4}{*}{ Food } & 0.01 & 0.06 & -0.02 & -0.15 & -0.10 & -0.50 \\
& & $(0.000)$ & $(0.000)$ & $(0.000)$ & $(0.000)$ & $(0.003)$ & $(0.001)$ \\
& \multirow{4}{*}{ Other } & 0.01 & -0.03 & 0.00 & 0.05 & -0.43 & -0.73 \\
& & $(0.000)$ & $(0.000)$ & $(0.000)$ & $(0.000)$ & $(0.000)$ & $(0.000)$ \\
\hline
\end{tabular}

Compensated Price Elasticities

Price

\begin{tabular}{cccccccc} 
& & Electricity & Motor fuels & Gas & Publ Trans & Food & Other \\
\cline { 2 - 7 } & Electricity & -1.43 & -0.12 & 0.16 & 0.06 & 0.30 & 0.82 \\
& $(0.002)$ & $(0.001)$ & $(0.001)$ & $(0.000)$ & $(0.000)$ & $(0.001)$ \\
\multirow{4}{*}{ Demand fuels } & -0.06 & -0.92 & 0.03 & 0.12 & 0.56 & 0.28 \\
& & $(0.000)$ & $(0.000)$ & $(0.000)$ & $(0.001)$ & $(0.001)$ & $(0.001)$ \\
& \multirow{4}{*}{ Gas } & 0.20 & 0.07 & -0.66 & -0.13 & -0.04 & 0.58 \\
& & $(0.001)$ & $(0.000)$ & $(0.001)$ & $(0.001)$ & $(0.002)$ & $(0.001)$ \\
& \multirow{4}{*}{ Publ Trans } & 0.03 & 0.11 & -0.05 & -0.53 & -0.44 & 1.00 \\
& & $(0.000)$ & $(0.001)$ & $(0.001)$ & $(0.002)$ & $(0.004)$ & $(0.003)$ \\
& \multirow{4}{*}{ Food } & 0.02 & 0.08 & -0.01 & -0.12 & 0.16 & -0.24 \\
& & $(0.000)$ & $(0.000)$ & $(0.000)$ & $(0.000)$ & $(0.003)$ & $(0.003)$ \\
& \multirow{4}{*}{ Other } & 0.04 & 0.01 & 0.02 & 0.09 & -0.12 & 0.04 \\
& & $(0.000)$ & $(0.000)$ & $(0.000)$ & $(0.000)$ & $(0.000)$ & $(0.000)$ \\
\hline
\end{tabular}

Expenditure Elasticities

\begin{tabular}{cccccc}
0.96 & 1.22 & 0.84 & 0.85 & 0.60 & 1.20 \\
$(0.001)$ & $(0.001)$ & $(0.001)$ & $(0.003)$ & $(0.002)$ & $(0.000)$ \\
\hline
\end{tabular}

Standard errors in parentheses 
Table 4.2 Probit energy demand (marginal effects)

\begin{tabular}{|c|c|c|c|c|}
\hline VARIABLES & $\begin{array}{c}\text { (1) } \\
\text { electricity }\end{array}$ & $\begin{array}{l}\text { (2) } \\
\text { motor fuels }\end{array}$ & $\begin{array}{l}\text { (3) } \\
\text { gas }\end{array}$ & $\begin{array}{c}(4) \\
\text { public transp }\end{array}$ \\
\hline $\operatorname{lnp} 1$ & $\begin{array}{c}-0.00634 * * * \\
(0.00127)\end{array}$ & $\begin{array}{l}-0.134 * * * \\
(0.00596)\end{array}$ & $\begin{array}{l}0.241^{* * *} * \\
(0.00664)\end{array}$ & $\begin{array}{l}0.160 * * * \\
(0.00684)\end{array}$ \\
\hline $\operatorname{lnp} 2$ & $\begin{array}{c}0.0485 * * * \\
(0.00614)\end{array}$ & $\begin{array}{c}-0.369 * * * \\
(0.0237)\end{array}$ & $\begin{array}{c}0.0204 \\
(0.0269)\end{array}$ & $\begin{array}{c}0.415^{* * * *} \\
(0.0275)\end{array}$ \\
\hline $\operatorname{lnp} 3$ & $\begin{array}{c}-0.0108 * * * \\
(0.00226)\end{array}$ & $\begin{array}{c}0.150 * * * \\
(0.0117)\end{array}$ & $\begin{array}{c}0.0558 * * * \\
(0.0133)\end{array}$ & $\begin{array}{c}-0.106 * * * \\
(0.0135)\end{array}$ \\
\hline $\operatorname{lnp} 4$ & $\begin{array}{l}0.00653^{*} \\
(0.00347)\end{array}$ & $\begin{array}{c}-0.322 * * * \\
(0.0171)\end{array}$ & $\begin{array}{c}0.242 * * * \\
(0.0193)\end{array}$ & $\begin{array}{c}0.332 * * * \\
(0.0197)\end{array}$ \\
\hline $\operatorname{lnp5}$ & $\begin{array}{c}-0.0281 * * * * \\
(0.0103)\end{array}$ & $\begin{array}{c}0.794 * * * \\
(0.0508)\end{array}$ & $\begin{array}{l}0.117 * * \\
(0.0570)\end{array}$ & $\begin{array}{c}-1.051 * * * \\
(0.0582)\end{array}$ \\
\hline $\operatorname{lnp} 6$ & $\begin{array}{c}-0.00596 \\
(0.0151)\end{array}$ & $\begin{array}{c}-0.335 * * * \\
(0.0739)\end{array}$ & $\begin{array}{c}-0.998 * * * \\
(0.0825)\end{array}$ & $\begin{array}{c}0.418 * * * \\
(0.0846)\end{array}$ \\
\hline $\ln (x)$ & $\begin{array}{c}0.00627 * * * \\
(0.000456)\end{array}$ & $\begin{array}{l}0.317 * * * \\
(0.00178)\end{array}$ & $\begin{array}{l}0.177 * * * \\
(0.00216)\end{array}$ & $\begin{array}{c}0.0305^{* * *} \\
(0.00224)\end{array}$ \\
\hline male & $\begin{array}{c}-0.00233^{* * * *} \\
(0.000647)\end{array}$ & $\begin{array}{l}0.156^{* * * *} \\
(0.00286)\end{array}$ & $\begin{array}{c}-0.000476 \\
(0.00327)\end{array}$ & $\begin{array}{c}-0.0829 * * * \\
(0.00336)\end{array}$ \\
\hline age & $\begin{array}{c}0.000299 * * * \\
(1.94 \mathrm{e}-05)\end{array}$ & $\begin{array}{c}0.000955^{* * * *} \\
(8.32 \mathrm{e}-05)\end{array}$ & $\begin{array}{c}0.00189 * * * \\
(9.24 \mathrm{e}-05)\end{array}$ & $\begin{array}{c}-0.00212 * * * \\
(9.37 \mathrm{e}-05)\end{array}$ \\
\hline education & $\begin{array}{l}0.00103^{* *} \\
(0.000482)\end{array}$ & $\begin{array}{c}0.0758 * * * \\
(0.00211)\end{array}$ & $\begin{array}{c}-0.0159 * * * \\
(0.00246)\end{array}$ & $\begin{array}{c}-0.0707 * * * \\
(0.00247)\end{array}$ \\
\hline household size & $\begin{array}{c}0.000599 * * * \\
(0.000142)\end{array}$ & $\begin{array}{c}-0.00687 * * * \\
(0.000654)\end{array}$ & $\begin{array}{c}0.00843 * * * \\
(0.000754)\end{array}$ & $\begin{array}{l}0.0289 * * * \\
(0.000770)\end{array}$ \\
\hline rural & $\begin{array}{c}-0.00331 * * * \\
(0.000553)\end{array}$ & $\begin{array}{c}0.0754 * * * \\
(0.00307)\end{array}$ & $\begin{array}{l}-0.136 * * * \\
(0.00336)\end{array}$ & $\begin{array}{l}-0.143 * * * \\
(0.00343)\end{array}$ \\
\hline Observations & 117,656 & 117,656 & 117,656 & 117,656 \\
\hline
\end{tabular}

cant difference with the exception of electricity. Electricity price changes have a slightly regressive effect as opposed to motor fuel price changes, which are clearly progressive. Welfare losses for gas and public transport price increases rise with expenditures until the 20th percentile and start falling from the 50th percentile. As expected from the descriptive analysis in section II, price changes for public transport have the potential to create the largest welfare losses for low and middle income households. Absolute welfare losses are strictly rising with expenditures for all energy goods. Simultaneous price increases for all energy related expenditures lead to an inverse U-shaped distributional impacts curve (figure 4.4). The magnitude of welfare losses is more distributional neutral and smaller in magnitude than 
welfare losses from food price increases, which are strongly regressive. With multiple price changes, the necessity of calculating second-order welfare effects is visible between the 20th and 90th percentile. First-order effects overestimate the welfare loss up to 10 percent for middle income households.
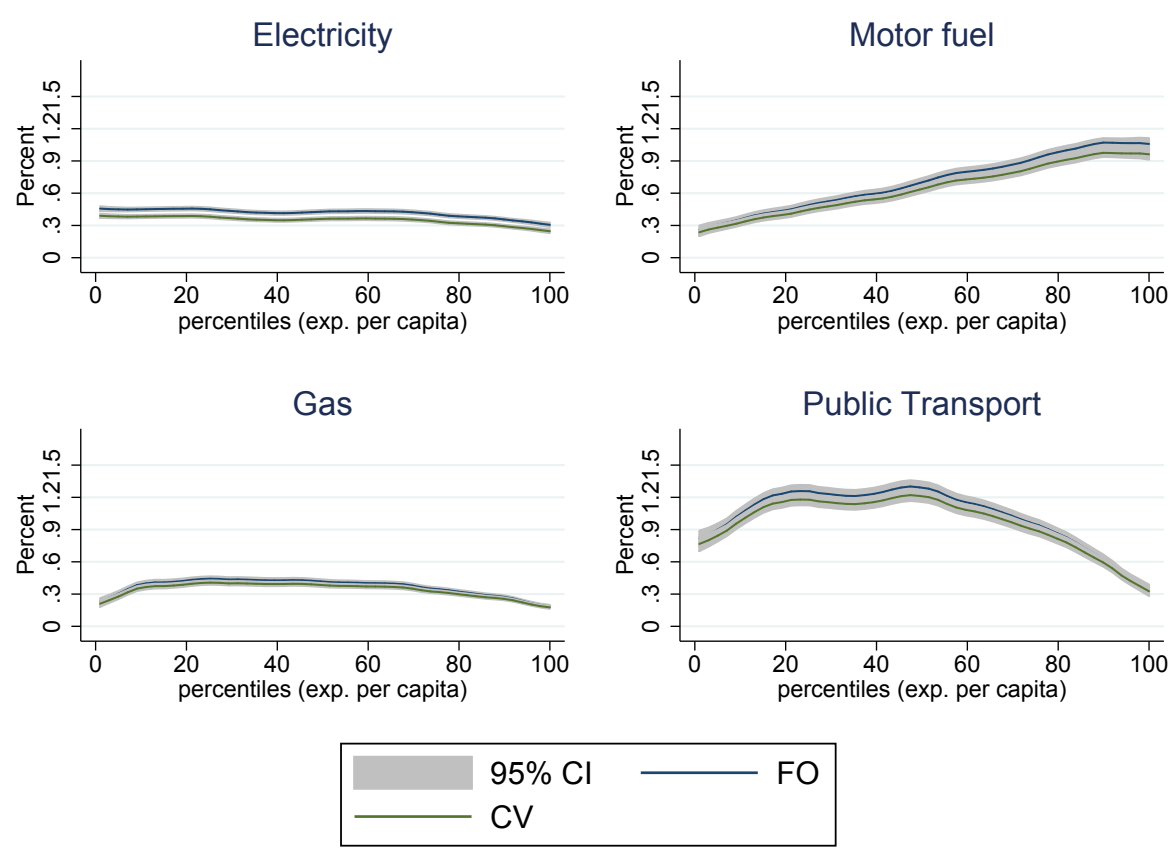

Fig. 4.3 Welfare effects first- and second-order (CV), energy items

As expected from the descriptive analysis of users vs non-users of energy types, distributional results differ significantly for the average user with strictly positive demand for the respective energy good (figure 4.5). While we see almost no difference for electricity, price increases for all other energy items are clearly regressive for the user part of the population. Taking motor fuel as an example, the population average progressive effects can be explained by low car ownership rates of the lower part of the expenditure distribution. For public transport, a major share of rural low income households appears not as dependent on public transport and therefore we find smaller welfare losses than for the rest of the population. Although these differences between users and non-users shed light on heterogeneity in welfare effects within the same income group, the share of the population affected around the poverty lines is more relevant for poverty incidence. Price increases for each energy type separately have quite modest impacts on the wellbeing poverty rate, with differences for each energy good (figure 4.6). We calculate welfare losses for first- and second order effects to assess the importance of taking into account substitution behavior for poverty incidence. Price increases of up to 50 percent for the single energy items produce nearly identical poverty rate 


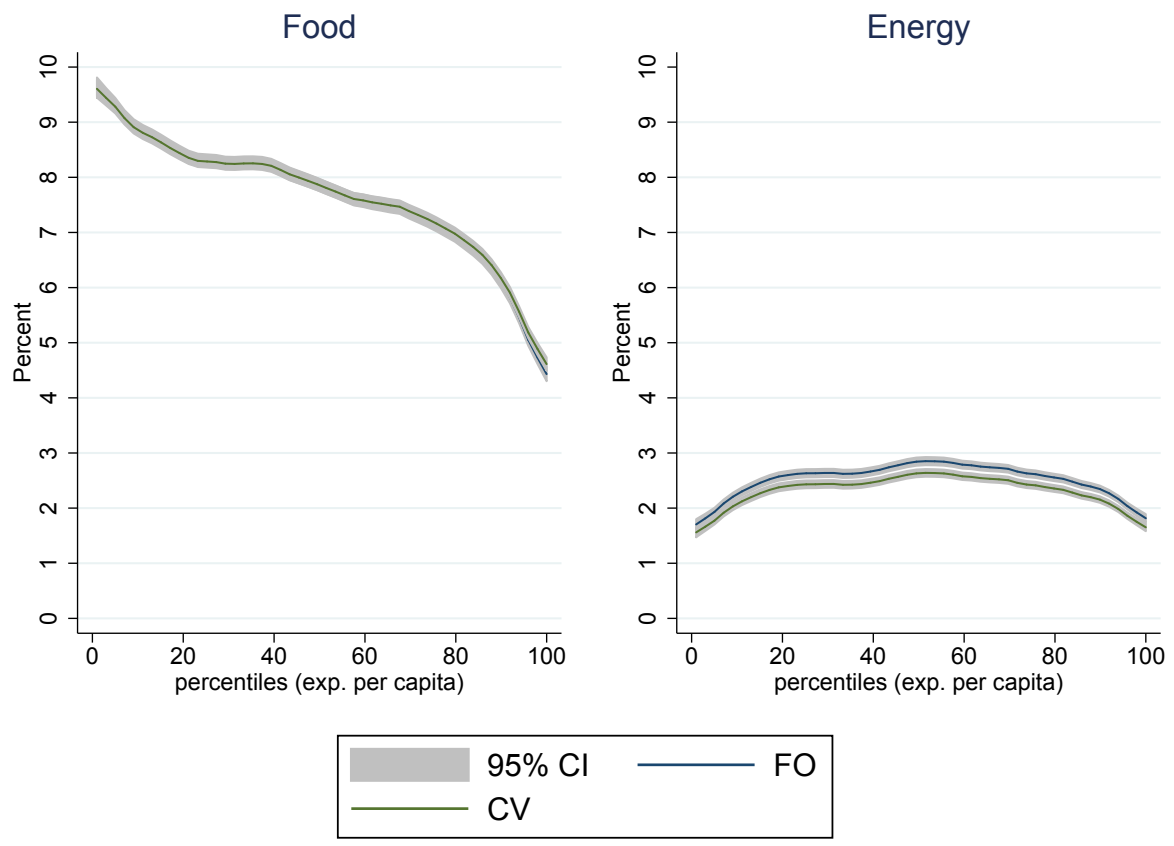

Fig. 4.4 Welfare effects first- and second-order (CV), energy and food

outcomes for first- and second-order effects. Only beyond this range, differences become significant. For joint price increases for all energy goods, the difference between first- and second-order effects starts earlier and is more pronounced. The domestically used energy electricity and gas both show little sensitivity towards price increases with respect to the poverty rate. An electricity price rise of 50 percent would increase the wellbeing poverty rate by 0.5 percentage points maximum. Domestic energy prices for consumers in Mexico are relatively low in international comparison.

Energy price increases in general have less impact on poverty than food price increases, reflected in a steeper gradient in figure 4.6. Nevertheless, at the wellbeing poverty line, a 20 percent price increase on energy has substantial effects on poverty with an increase of 1.4 percentage points in the poverty rate (table 4.4). The on average higher budget shares and associated welfare effects for middle income households also lead to higher increases of the wellbeing poverty rate for all energy goods and for food compared to the minimum wellbeing poverty rate (table 4.3). Additionally to changes in poverty, middle income households close to the poverty line would be disproportionally affected by higher energy prices although technically not defined as poor after the price change.

For each price increase we calculate resulting changes in the household carbon footprint (energy related $\mathrm{CO}_{2}$ emissions and $\mathrm{CO}_{2}$ equivalent emissions including $\mathrm{CH}_{4}$ and $\mathrm{N}_{2} \mathrm{O}$ ), displayed in table 4.5. Although motor fuel does not have the highest carbon intensity, 
Table 4.3 FGT poverty indices (in \%), changes from baseline, minimum wellbeing poverty line

\begin{tabular}{lccccccc}
\hline & FGT & Electricity & $\begin{array}{c}\text { Motor } \\
\text { fuels }\end{array}$ & Gas & $\begin{array}{c}\text { Public } \\
\text { Transport }\end{array}$ & Energy & Food \\
\hline price change & 0 & 0.143 & 0.099 & 0.169 & 0.373 & 0.785 & 3.077 \\
& 1 & 0.041 & 0.043 & 0.043 & 0.124 & 0.259 & 1.299 \\
& 2 & 0.019 & 0.022 & 0.019 & 0.057 & 0.122 & 0.692 \\
+ lum-sum & 0 & -0.091 & -0.481 & -0.081 & -0.215 & -0.775 & -1.307 \\
& 1 & -0.030 & -0.159 & -0.046 & -0.096 & -0.323 & -0.540 \\
& 2 & -0.018 & -0.084 & -0.027 & -0.058 & -0.180 & -0.293 \\
+ PROSPERA & 0 & -0.213 & -0.821 & -0.308 & -0.601 & -1.820 & -2.581 \\
& 1 & -0.115 & -0.377 & -0.151 & -0.330 & -0.745 & -0.622 \\
& 2 & -0.067 & -0.200 & -0.088 & -0.183 & -0.357 & -0.193 \\
\hline
\end{tabular}

Table 4.4 FGT poverty indices (in \%), changes from baseline, wellbeing poverty line

\begin{tabular}{lccccccc}
\hline & FGT & Electricity & $\begin{array}{c}\text { Motor } \\
\text { fuels }\end{array}$ & Gas & $\begin{array}{c}\text { Public } \\
\text { Transport }\end{array}$ & Energy & Food \\
\hline price change & 0 & 0.192 & 0.316 & 0.184 & 0.710 & 1.440 & 4.414 \\
& 1 & 0.097 & 0.127 & 0.123 & 0.356 & 0.720 & 2.687 \\
& 2 & 0.061 & 0.074 & 0.075 & 0.216 & 0.438 & 1.808 \\
+ lum-sum & 0 & -0.015 & -0.311 & 0.003 & -0.043 & -0.598 & -0.925 \\
& 1 & -0.043 & -0.285 & -0.056 & -0.088 & -0.475 & -0.934 \\
& 2 & -0.035 & -0.205 & -0.047 & -0.086 & -0.371 & -0.688 \\
+ PROSPERA & 0 & -0.046 & -0.440 & -0.117 & -0.046 & -0.647 & -1.647 \\
& 1 & -0.135 & -0.531 & -0.170 & -0.352 & -1.043 & -1.571 \\
& 2 & -0.118 & -0.423 & -0.151 & -0.318 & -0.816 & -0.972 \\
\hline
\end{tabular}



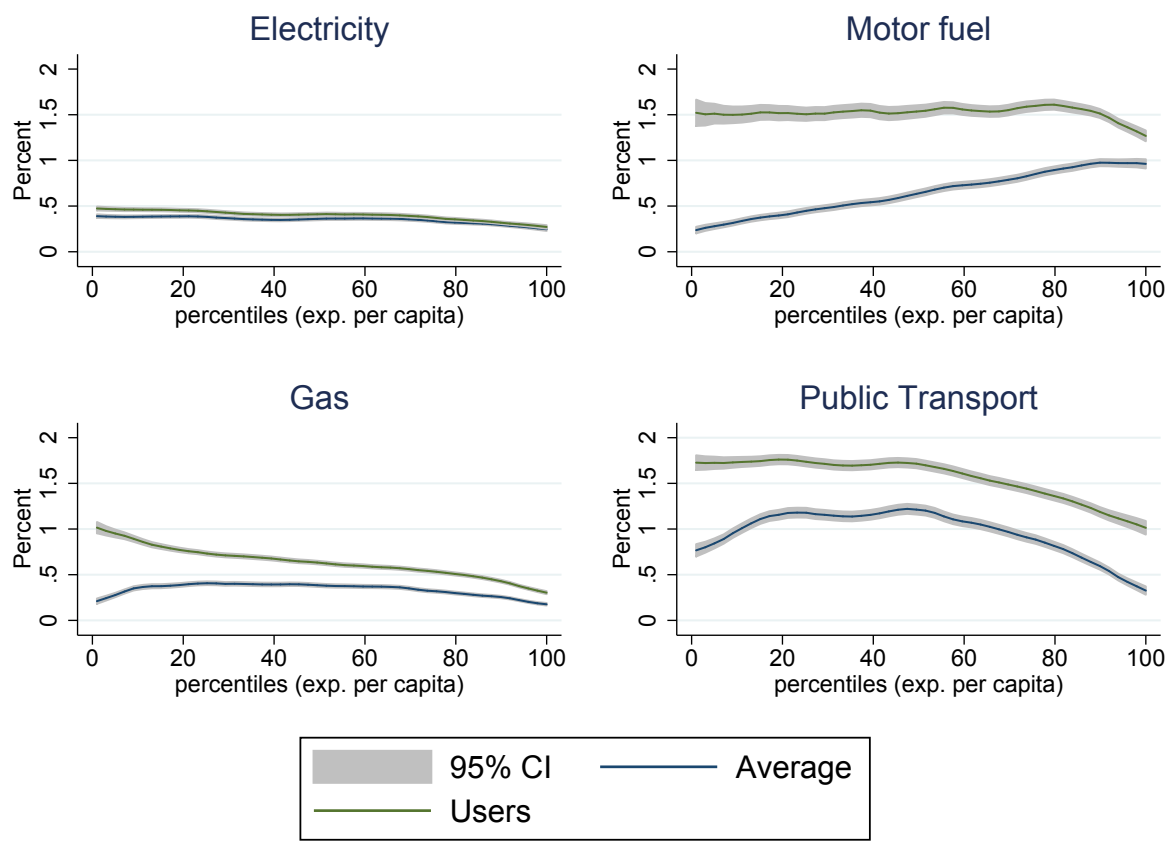

Fig. 4.5 Welfare effects first- and second-order (CV), users vs. average

a motor fuel price increase/tax would create the largest emission reductions, driven by relatively large budget shares. Emission reductions through electricity price changes would also be large, determined by high price elasticities despite relatively small budget shares. Remarkably, taxing gas alone has no observable effect on $\mathrm{CO}_{2}$ emissions. This seemingly counter intuitive result can be explained by positive cross-price elasticities with electricity. As a clear substitute and with higher carbon intensity, increased electricity demand turns the emission saving from reduced gas use into a small net emission increase. A similar finding can be observed for a tax on public transport, which results in zero emission savings due to substitution with motorized private transport. These findings demonstrate the importance of obtaining a full range of own- and cross-price effects to simulate integrated welfareenvironmental models. Multiple price changes for all energy related goods may lead to very strong emission reductions from household demand. Food price increases have, as discussed above, large effects on poverty, and also a significant impact on energy related $\mathrm{CO}_{2}$ emissions. As households are estimated to have close to zero own-price elasticities for food, the complementary character of gas, public transport and other goods accounts for the energy related emission reduction.

Redistribution of tax revenues leads to moderate progressive welfare effects when lumpsum transfers are used (figure 4.7). Mostly, net taxes are paid by the rich households with the exception of public transport where the middle class pays the bill. When redistributing all 

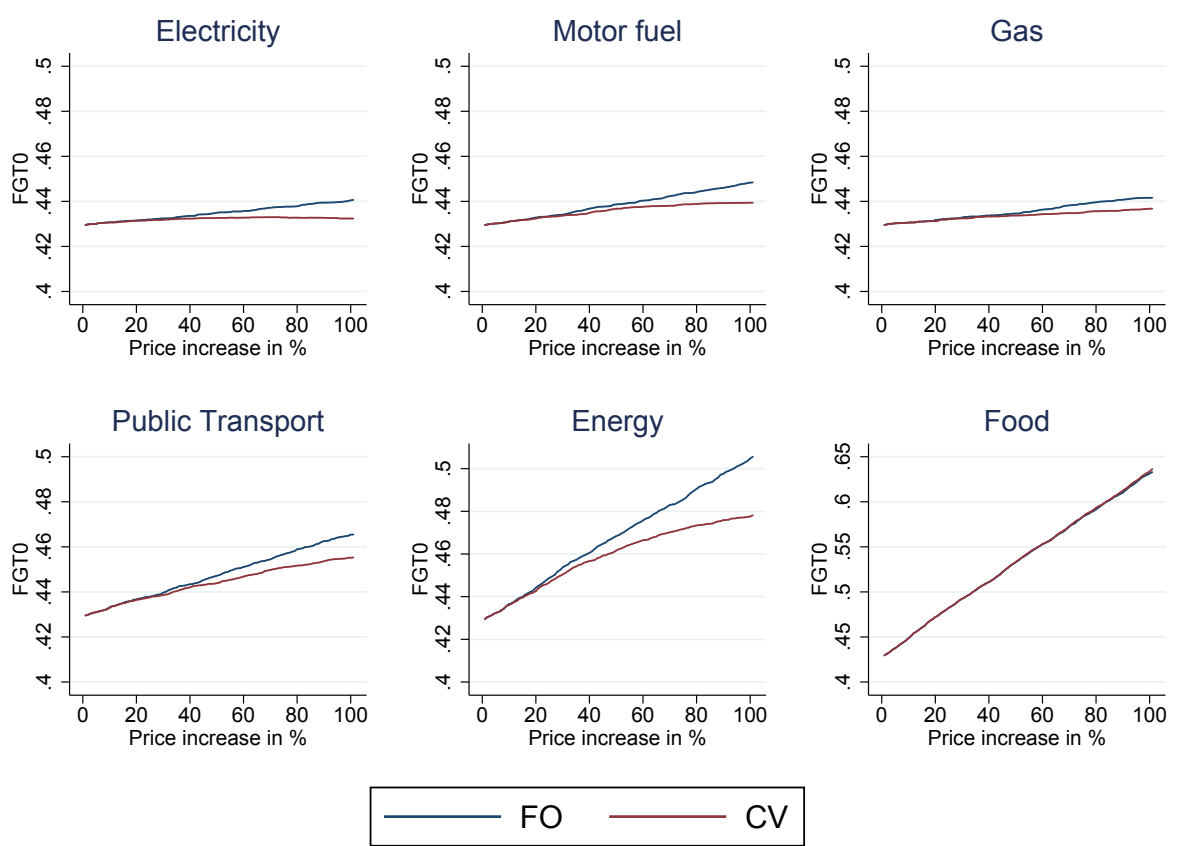

Fig. 4.6 Poverty rate (FGT0, wellbeing poverty line) and price increases

tax revenues solely to PROSPERA recipients, progressivity becomes very strong with large welfare gains around 11 percent of expenditures for the poorest households in the case of motor fuel or public transport taxes. Compared to the pure lump-sum scheme, households are less well compensated starting at the 50th percentile which is also above the moderate poverty line. As a result, the poverty rate decreases by 0.65 percentage points at the wellbeing poverty line in the case of a simultaneous tax of 20 percent on all four energy goods and redistribution via PROSPERA. On the other hand, poverty measured at the minimum wellbeing poverty line reacts more sensitively to redistribution trough the relatively large compensation amounts. In this case and redistribution via PROSPERA, we find a reduction in the poverty rate of 1.8 percent. $\mathrm{CO}_{2}$ reductions are slightly larger when redistribution takes place via PROSPERA than via universal lump-sum transfers, but differences are small. When taxing all energy related goods with a 20 percent tax rate and tax revenue is fully redistributed via PROSPERA, household $\mathrm{CO}_{2}$ emissions are calculated to be 9.5 percent smaller than in the baseline and 1.5 percent less than without redistribution. On the other hand, a tax on food with a simultaneous redistribution of tax revenues has positive effects on household $\mathrm{CO}_{2}$ emissions. Driven by increased demand for direct energy and other goods, the positive income effect from the relatively large redistribution amount has a strong effect on direct energy demand despite the negative cross-price effects with energy goods such as electricity. 
Table $4.5 \mathrm{CO}_{2}$ (e) emission impacts energy price changes (20\%)

\begin{tabular}{llcccccc}
\hline & Electricity & $\begin{array}{c}\text { Motor } \\
\text { fuel }\end{array}$ & Gas & $\begin{array}{c}\text { Public } \\
\text { Transport }\end{array}$ & Energy & Food \\
\hline price change & $\mathrm{CO}_{2}$ & $-4.7 \%$ & $-5.9 \%$ & $0.0 \%$ & $0.0 \%$ & $-10.8 \%$ & $-2.1 \%$ \\
& $\mathrm{CO}_{2} \mathrm{e}$ & $-2.8 \%$ & $-3.1 \%$ & $-0.1 \%$ & $-1.2 \%$ & $-7.3 \%$ & $-3.1 \%$ \\
+ + lum-sum & & & & & & & \\
& $\mathrm{CO}_{2}$ & $-4.5 \%$ & $-5.3 \%$ & $0.3 \%$ & $0.7 \%$ & $-9.1 \%$ & $3.5 \%$ \\
& $\mathrm{CO}_{2} \mathrm{e}$ & $-2.6 \%$ & $-2.5 \%$ & $0.2 \%$ & $-0.5 \%$ & $-5.5 \%$ & $2.4 \%$ \\
+ PROSPERA & $\mathrm{CO}_{2}$ & $-4.5 \%$ & $-5.4 \%$ & $0.3 \%$ & $0.6 \%$ & $-9.3 \%$ & $2.5 \%$ \\
& $\mathrm{CO}_{2} \mathrm{e}$ & $-2.6 \%$ & $-2.5 \%$ & $0.2 \%$ & $-0.5 \%$ & $-5.6 \%$ & $2.0 \%$ \\
\hline
\end{tabular}
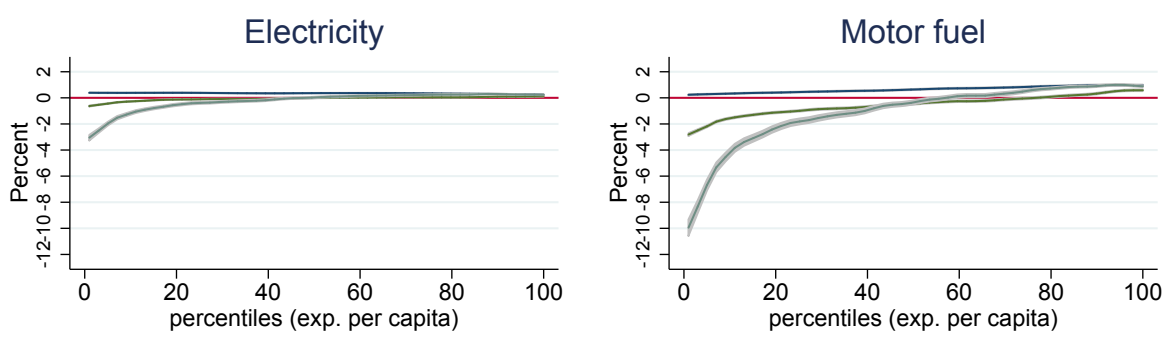

Gas
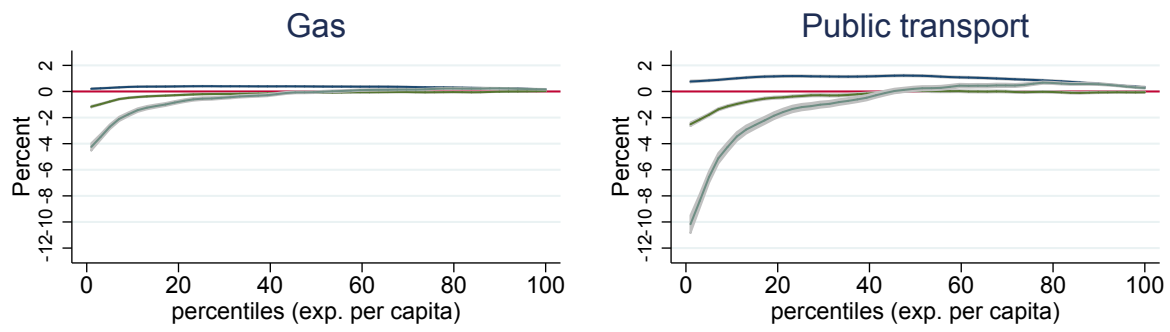

$95 \% \mathrm{Cl}$

CV

$\mathrm{CV}+$ lump-sum

$\mathrm{CV}+$ Prospera

Fig. 4.7 Welfare effects redistribution scenarios

\subsubsection{Carbon tax}

The first-order welfare and poverty effects of a carbon tax in Mexico have been analyzed in chapter 3 . We take calculated sector specific price changes from chapter 3 and apply it to our product categorization to check upon the validity to use first-order effects and calculate the short run $\mathrm{CO}_{2}$ emissions reduction potential when price increases are fully shifted to consumers. ${ }^{9}$ Approximate price increases for a $25 \mathrm{USD} / \mathrm{tCO}_{2}$ tax and for two different tax

\footnotetext{
${ }^{9}$ See table C.1 for the aggregation scheme.
} 
bases are displayed in table 4.6. Considering that the tax rate in 2014 was at $3.5 \mathrm{USD} / \mathrm{tCO}_{2}$, we focus on $25 \mathrm{USD} / \mathrm{tCO}_{2}$ scenario as an upper bound of potential tax increases in the short term. Price changes for households are most severe for electricity, followed by motor fuel and gas. Public transport and food items are less affected by taxing energy related $\mathrm{CO}_{2}$ emissions. Food prices are clearly more sensitive to taxing $\mathrm{N}_{2} \mathrm{O}$ and $\mathrm{CH}_{4}$ while direct energy items are hardly affected. Generally, carbon tax induced price changes are smaller than discussed in the previous section on energy and food price changes, although the simulated tax rate can be considered non-marginal.

Table 4.6 $\mathrm{CO}_{2}$ intensities and price changes carbon tax

\begin{tabular}{cccccc}
\hline & & \multicolumn{2}{c}{$\mathrm{CI}(\mathrm{kg} / \mathrm{MXN})$} & \multicolumn{2}{c}{ Price Change $(\mathrm{t}=$} \\
& & \multicolumn{3}{c}{ 25 USD $)$} \\
\cline { 3 - 6 } & item & $\mathrm{CO}_{2}$ & $\mathrm{CO}_{2} \mathrm{e}$ & $\mathrm{CO}_{2}$ & $\mathrm{CO}_{2} \mathrm{e}$ \\
\hline 1 & Electricity & 0.290 & 0.297 & $9.0 \%$ & $9.2 \%$ \\
2 & Motor Fuel & 0.217 & 0.222 & $6.7 \%$ & $6.9 \%$ \\
3 & Gas & 0.140 & 0.140 & $4.3 \%$ & $4.3 \%$ \\
4 & Public Transport & 0.029 & 0.031 & $0.9 \%$ & $1.0 \%$ \\
5 & Food & 0.020 & 0.070 & $0.6 \%$ & $2.2 \%$ \\
6 & Other & 0.013 & 0.022 & $0.4 \%$ & $0.7 \%$ \\
\hline
\end{tabular}

The first- and second order effects are plotted in figure 4.8 and we observe that their 95 percent confidence intervals in the calculation of average welfare effects per percentile clearly overlap. This result holds despite the fact that electricity prices are a major channel of carbon tax induced welfare losses and the finding of a large estimated own-price elasticity. The magnitude of electricity price changes in the range of 9 percent does not necessarily require the estimation of demand elasticities. In Scenario I, taxing only energy related $\mathrm{CO}_{2}$ emissions, welfare effects are slightly progressive in the range of 0.9 and 1.1 percent for lower and higher income households respectively.

When incorporating $\mathrm{CH}_{4}$ and $\mathrm{N}_{2} \mathrm{O}$ in the tax scheme, welfare effects are overall regressive and particularly severe for low income households at 2 percent of total expenditures. The much higher welfare effects are mostly caused by food price increases. Considering the inability of households to substitute away from food expenditures, this scenario has larger welfare and poverty effects. These are generally rising with the tax base with a 1.1 percentage points increase in the wellbeing poverty rate (table 4.7). As in the case of energy price increases, the moderate wellbeing poverty rate is more affected than the minimum wellbeing poverty rate. Redistribution via lump-sum transfers or PROSPERA can turn the welfare effects clearly progressive, poverty indicators even improve over all dimensions. 
The short-run emission reduction potential through consumer substitution is at 5.6/3.5 $\left(\mathrm{CO}_{2} / \mathrm{CO}_{2} \mathrm{e}\right)$ percent of total household induced $\mathrm{CO}_{2} / \mathrm{CO}_{2} \mathrm{e}$ emissions and rises up to $6 / 4$ $\left(\mathrm{CO}_{2} / \mathrm{CO}_{2} \mathrm{e}\right)$ percent in Scenario II. The taxation of $\mathrm{CH}_{4}$ and $\mathrm{N}_{2} \mathrm{O}$ does not only lead to adverse poverty effects, the additional short-run $\mathrm{CO}_{2} \mathrm{e}$ emission saving potential is also very limited.

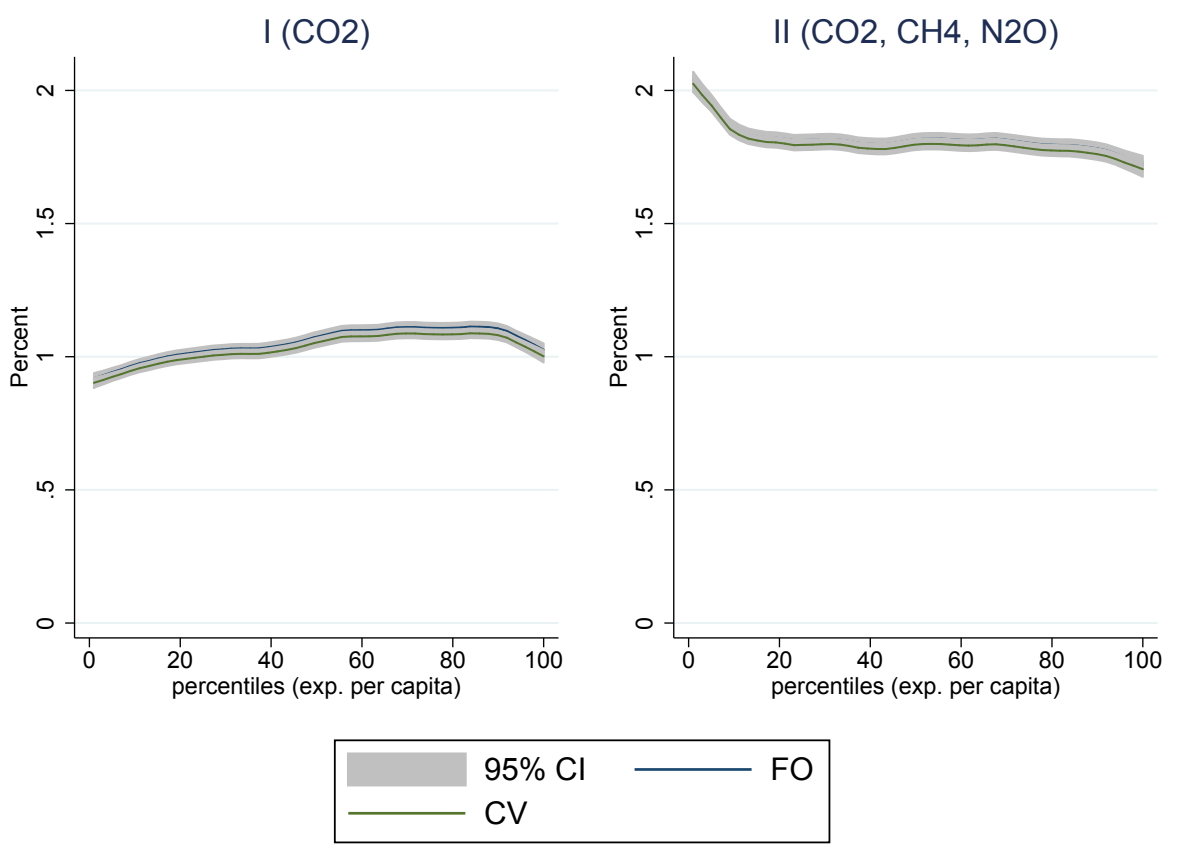

Fig. 4.8 Welfare effects of carbon taxes

It is important to consider however, that these simulated emission reductions are relative to a baseline with zero income growth and tax revenues are completely reinvested carbon free. Additional to expected income growth, redistribution of tax revenues to households in the form of cash transfers, tax rebates or the increased use of public goods inevitably leads to the use of goods produced with fossil fuels if the energy system remains untransformed. In the case of direct cash transfers to households, the $\mathrm{CO}_{2}$ emission saving potential can shrink to 83 percent of the reductions achieved in scenarios without redistribution. Taking into account $\mathrm{CH}_{4}$ and $\mathrm{N}_{2} \mathrm{O}$, the wider tax base generates large tax revenues and lump-sum transfers which in turn lead to large income effects and smaller $\mathrm{CO}_{2}$ and $\mathrm{CO}_{2}$ e savings which are reduced to 75 and 62 percent respectively. Redistribution via PROSPERA leads to slightly larger $\mathrm{CO}_{2}$ emission reductions as already observed in the case of energy price changes. Considering the problematic link of taxing $\mathrm{CH}_{4}$ and $\mathrm{N}_{2} \mathrm{O}$ with food prices, taxing $\mathrm{CO}_{2}$ alone provides an option for an ambitious short-run climate policy with moderate welfare effects that could be turned into welfare gains with proper redistribution schemes. 
Table 4.7 FGT changes carbon tax

\begin{tabular}{lccccc}
\hline & & \multicolumn{2}{c}{ Minimum wellbeing } \\
\cline { 3 - 6 } & & \multicolumn{4}{c}{ Tax Scenario } \\
\cline { 3 - 6 } & FGT & $\mathrm{I}\left(\mathrm{CO}_{2}\right)$ & $\mathrm{II}\left(\mathrm{CO}_{2}, \mathrm{CH}_{4}\right.$, & $\mathrm{I}\left(\mathrm{CO}_{2}\right)$ & $\mathrm{II}\left(\mathrm{CO}_{2}, \mathrm{CH}_{4}\right.$, \\
$\left.\mathrm{N}_{2} \mathrm{O}\right)$ & & $\left.\mathrm{N}_{2} \mathrm{O}\right)$ \\
\hline Carbon Tax & 0 & 0.399 & 0.755 & 0.723 & 1.186 \\
& 1 & 0.140 & 0.264 & 0.392 & 0.651 \\
& 2 & 0.066 & 0.130 & 0.233 & 0.406 \\
& & & & & -0.301 \\
& & -0.407 & -0.607 & -0.061 & -0.347 \\
& 1 & -0.147 & -0.228 & -0.189 & -0.272 \\
& 2 & -0.083 & -0.126 & -0.161 & -0.493 \\
+ Lump-sum & & & & & -0.854 \\
& 0 & -0.407 & -1.505 & -0.292 & -0.686 \\
\hline
\end{tabular}

Table $4.8 \mathrm{CO}_{2}(\mathrm{e})$ emission impacts (USD 25/t $\mathrm{CO}_{2}(\mathrm{e})$ )

\begin{tabular}{|c|c|c|c|}
\hline & & \multicolumn{2}{|c|}{ Tax Scenario } \\
\hline & & $\mathrm{I}\left(\mathrm{CO}_{2}\right)$ & $\begin{array}{c}\mathrm{II}\left(\mathrm{CO}_{2},\right. \\
\left.\mathrm{CH}_{4}, \mathrm{~N}_{2} \mathrm{O}\right)\end{array}$ \\
\hline \multirow[t]{2}{*}{ Carbon Tax } & $\mathrm{CO}_{2}$ & $-5.6 \%$ & $-6.0 \%$ \\
\hline & $\mathrm{CO}_{2} \mathrm{e}$ & $-3.5 \%$ & $-4.0 \%$ \\
\hline \multirow[t]{2}{*}{ + Lump-sum } & $\mathrm{CO}_{2}$ & $-4.7 \%$ & $-4.5 \%$ \\
\hline & $\mathrm{CO}_{2} \mathrm{e}$ & $-2.6 \%$ & $-2.5 \%$ \\
\hline \multirow[t]{2}{*}{ + PROSPERA } & $\mathrm{CO}_{2}$ & $-4.9 \%$ & $-4.7 \%$ \\
\hline & $\mathrm{CO}_{2} \mathrm{e}$ & $-2.6 \%$ & $-2.4 \%$ \\
\hline
\end{tabular}




\subsection{Discussion and conclusion}

We simulate the short-run poverty and distributional effects of energy price changes and carbon taxes in a partial equilibrium framework. We estimate a full matrix of substitution elasticities, test first- versus second-order welfare effects and find the latter are only slightly different than the former as in the case of electricity but differ with multiple price changes. Despite this finding, two practical reasons speak against the abandonment of demand estimation in our context. First of all, checking on the validity of using first-order effects is preferable over assuming it. Secondly, without estimated substitution elasticities we are unable to calculate the $\mathrm{CO}_{2}$ emission saving potential that comes from household consumption. The latter is usually lacking in prior literature.

By simulating stylized price increase scenarios, we find only motor fuels to unfold progressive effects. Taxing electricity, gas and public transport is regressive, although in the latter case the middle class is most affected. Important to consider is also the heterogeneity within income percentiles. For actual users with positive demand for energy items, price increases are regressive. To put energy price changes into perspective, we find that food price increases have significantly larger welfare effects. Households spend a larger fraction on food products than on energy and show small sensitivity to prices reflected in a close to zero own-price elasticity. Middle income households close to the wellbeing poverty line would be more affected by higher energy prices than low income households. Although the smaller effects on extreme poverty are welcome from a development perspective, the political economy behind this pattern could be problematic. The progressive distribution pattern of welfare effects resulting from a carbon tax is largely driven by private motorized transport. Though the absolute monetary losses are small for households, the public opinion on environmental policy reforms appears to be quite sensible to gasoline price changes.

We also simulate a carbon tax at USD 25 per $\mathrm{C}_{2}$ and find slightly progressive welfare effects and substantial emissions reductions. The additional taxation of $\mathrm{CH}_{4}$ and $\mathrm{N}_{2} \mathrm{O}$ has the potential to create large price changes in the agricultural sector which makes their incorporation into a carbon tax regime an unsuitable candidate for creating poverty and environmental synergies in short-run climate policies. Considering the problematic link of taxing $\mathrm{CH}_{4}$ and $\mathrm{N}_{2} \mathrm{O}$ with food prices, taxing $\mathrm{CO}_{2}$ alone provides an option for an ambitious short-run climate policy with moderate welfare effects that could be turned into welfare gains with proper redistribution schemes. The calculated emission reductions through energy and carbon taxes must be understood as household consumption induced emission reductions relative to a baseline with no income growth. Emission reductions through substitution by households can be quite substantial even in the case of small price changes. Income 
and related consumption growth on the other hand reduce the emission saving potential. Taking into account the latter through redistribution via cash transfers, the initially large numbers become significantly smaller but remain substantial. Unsurprisingly, redistribution of simulated tax revenue can turn any regressive outcome progressive and reduce poverty. A targeted transfer through a social welfare program (PROSPERA) proofs to be preferable in terms of poverty and emission outcomes. Since compensation amounts are relatively large for lower income households, poverty reduction through redistribution is clearly more visible at the lower, minimum poverty line and also creates less additional consumption effects and associated emission increases. 



\section{Chapter 5}

\section{The effects of energy price changes: Heterogeneous welfare impacts, energy poverty and $\mathrm{CO}_{2}$ emissions in Indonesia}

\subsection{Introduction}

Fuel and energy prices are typically subject to heavy government intervention in many countries. Energy is subsidized to make it affordable and to shield domestic prices from international price fluctuations. In addition, transport fuels are heavily taxed in a number of countries because of negative externalities they create. These subsidies and taxes can constitute a heavy burden on government budgets or alternatively a reliable source of tax revenue. In recent years, climate change mitigation policies have been adding to the reasons to regulate energy prices. With regard to energy pricing, one particular policy option, abolishing fuel subsidies in developing countries, is often seen as a win-win policy, as it reduces distortions, internalizes negative climate externalities, and, on top of that, is progressive as it hurts richer, fuel-consuming households more than poorer households (Arze del Granado et al., 2012; Clements et al., 2013; Sterner, 2011). This paper adds to the literature that examines the latter assertion. The direct welfare effects of energy price changes for households depend on the magnitude of the price change, the relative importance of energy items in the basket of commodities and finally on the ability and willingness to substitute the more expensive good to deal with price shocks. In addition, indirect (general equilibrium) effects are triggered by changing production costs and hence the prices of other goods (and intermediate inputs). These changes will eventually affect labor demand and wages. Such effects are taken into account by general equilibrium modelling exercises. In this paper, we 
analyze the welfare impacts of energy price changes using a partial equilibrium approach based on a detailed empirical model of household energy demand in Indonesia. Since the majority of energy subsidies are in the form of fixed prices for consumers, indirect effects through wages and employment are unlikely to be of major importance. Additionally, the use of a CGE would come with a high demand for empirically unavailable parameter values and a higher energy item aggregation than needed in our case. Previous partial equilibrium studies on the impact of fuel subsidies in low and middle income countries have typically come to the conclusion that fuel subsidy (tax) cuts (increases) tend to be progressive.

We improve on and add to existing work in three ways: First, we model behavioral responses to price changes, i.e. we capture second order effects that are typically not accounted for in previous work. Second, we explore in detail the heterogeneity of impacts caused by the ownership of energy-processing durables, such as private transport vehicles, electric appliances or cooking stoves. These durables are acquired by households according to the amount of services the household needs and some of them are not easily substituted, particularly transport vessels. While it is true that low income households have lower ownership rates of many energy processing durables, a considerable share among the poor has high service needs due to occupational or geographical circumstances. It is these households that may be strongly affected by certain fuel price changes. Third, we also examine the quality and quantity effects of price changes on energy services, which may have a significant impact on individual wellbeing. Thereby, we extend the welfare analysis beyond the money metric utility effects and look at energy poverty understood as a condition of missing or imperfect access to reliable and clean modern energy services. Without affordable alternative technological solutions to the use of fossil fuels, rising energy prices may seriously affect the amount of energy services that households continue to use for basic living requirements.

In Indonesia, consumer energy prices have been regulated by the government for a long time with a recent change in subsidy policies, facilitated by dramatically falling oil prices. This makes the country an ideal place to study the welfare implications of energy price changes. In addition, our work is likely to remain highly relevant to the country's policymakers: When oil prices rise again in the future and current government policies continue to phase out subsidies with flexible pricing mechanisms close to market levels, the price of energy will rise for households. We analyze this scenario of rising energy prices for a set of commercial energy items used by households and estimate the impact on household welfare, energy poverty and demand related carbon emissions.

The rest of the paper proceeds as follows. We first describe the current situation of consumer energy prices and the energy subsidy scheme for consumers in Indonesia (section 5.2). We then provide an overview of the literature related to energy price changes with a 
focus on low and middle income countries (section 5.3). Section 5.4 presents the price and survey data as well as some descriptive statistics. In section 5.5 we describe the theoretical and empirical models underpinning our welfare analysis. The results are presented in section 5.6 and we conclude in section 5.7 with some policy recommendations.

\subsection{Consumer energy prices and subsidies in Indonesia}

Energy prices for households in Indonesia have traditionally been set by the government below international market price levels. These subsidies are argued to make access to energy affordable to the poor. In fossil fuel rich countries, like Indonesia, this policy is also motivated by the idea of sharing natural resource wealth with its citizens. Subsidies have been the dominating domestic energy policy instrument for decades but the high costs have put considerable pressure on public finances in recent years, and much more so since 2009 when the country became a net oil importer and left the OPEC. Today, the country is more oil-dependent than ever before, as from 2000 to 2013, total final energy consumption and the per capita final energy consumption increased by over 80 percent and 55 percent respectively (MEMR, 2014). ${ }^{1}$ Very likely, this increased oil-dependence can be partly ascribed to fuel subsidies. As a reaction to the fiscal pressure, the government implemented significant subsidy reductions in 2005, 2008 and 2013, i.e. during a time when rising oil prices pushed up fuel subsidy expenditures that could no longer be sustained. Figure 5.1 shows nominal energy prices for electricity, gasoline, kerosene, and LPG, respectively, from 2008 onwards. ${ }^{2}$ All three subsidy reforms were accompanied by compensation programs, which helped to gain public acceptance. At the end of 2012, Indonesia had the lowest fuel prices of any net-oil consuming nation worldwide and fuel subsidy expenditures increased up to 21.2 percent of total central government spending (World Bank, 2013). In June 2013, the government decided to increase prices on gasoline and diesel up by 44 and 22 percent, respectively. Public protests did not spread too far and subsidy cuts were accompanied with two compensation packages, including short-term unconditional cash transfers, increased food distribution and additional spending in infrastructure programs. In late 2014, the newly elected government announced a complete phase-out of fuel subsidies in the coming years. As a result of this policy and low world oil prices, the price for automotive fuels decreased with subsequent rises in March 2015. The government's concern about the social implications of fuel subsidy reform led it to treat several fuel items differently. Subsidies on kerosene, today a less used fuel for lighting and cooking source for the rural poor, have not been trimmed down as much

\footnotetext{
${ }^{1}$ Population growth in the same period has been around 17 percent.

${ }^{2}$ Data on general energy prices are from the Ministry of Energy and Mineral Resources.
} 
as those on gasoline and diesel. ${ }^{3}$ Recent subsidy reform has also made a distinction on the purchasing side, when subsidies on both kerosene and gasoline have been completely abolished for industrial consumers. When international oil prices are low, gasoline subsidies may be completely phased out for the time being. However, when oil prices start to rise again and subsidies are abolished as politically communicated, households will face non-marginal price increases that, depending on the scenario for international markets could raise prices by 100 percent and more. We focus explicitly on the main energy items that households use, including electricity and fuels such as gasoline, kerosene and LPG. Traditional fuels, i.e. firewood and biomass, are widely used as well, particularly in rural areas. However, we have no information on prices for these fuels, neither in the survey data nor from external sources. For electricity demand, price discrimination between different users is established through a progressive block tariff schedule that results in higher prices per kwh with higher installed power capacity and demand. Households pay the lowest price on average compared to industry and business (figure 5.1) and also face the smallest price increases over the last years. With an estimated production price of 1200 IDR per kwh ( about 0.07 Euro at 2015 exchange rates), only few customers pay an unsubsidized price and tariffs for households as low as 150 IDR reveal the dimension of subsidies paid in this sector. For transport fuels, different products with varying octane qualities exist but low quality gasoil, mainly used for motorcycles, dominates the market. While the higher quality gasoline fuels (92 and 95 octane) have been closer to international market prices, the price of lower quality gasoline and diesel has been fixed by the government at comparatively low levels with recent price fluctuations towards international price levels. There are differences between the official retail price and measured prices at the consumer level, particularly in rural areas where transport costs and additional trading margins in informal market add to the official price. Kerosene, a multi-purpose fuel for cooking and lighting, has not seen a change in retail prices since 2008 but rural consumer nevertheless pay an increasingly higher price over the last years. The increasingly used fuel for cooking, LPG, comes in different bottle sizes and the prices are regulated accordingly. The smallest size is $3 \mathrm{~kg}$ with the lowest price and no change over the last years. Prices for $12 \mathrm{~kg}$ bottles increased recently while the $50 \mathrm{~kg}$ bottles move with market prices. Like transport fuels, LPG is more expensive in rural than in urban areas on average.

\footnotetext{
${ }^{3}$ In 2007 the government launched a kerosene-to-LPG transition program that included the disbursement of more than 48 million free LPG start-up packages and subsidized the price for small LPG tanks $(3 \mathrm{~kg})$.
} 

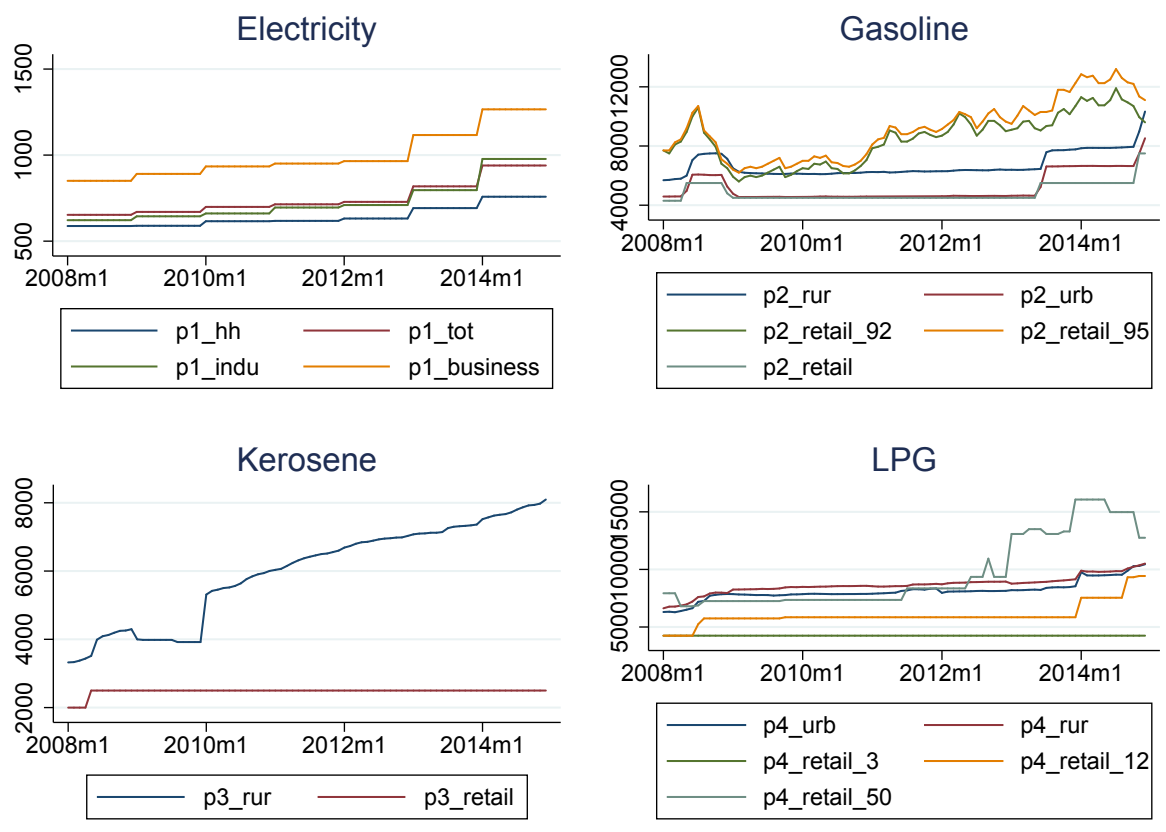

Fig. 5.1 Nominal energy prices over time

\subsection{Literature review}

Shah and Whalley (1991) and Shah and Larsen (1992) were among the first to warn of applying conventional wisdom in assessing the incidence of environmental taxes for developing countries. They hinted at the fact that, with lower shares of energy expenditures in the consumption basket of the poor, distributional effects of energy related taxes in developing countries can generally be expected to be progressive. Earlier work on Indonesia by Pitt (1985) finds that kerosene subsidies benefited the urban and wealthy households the most. In addition, they cannot support the notion that kerosene subsidies would help to address deforestation externalities. Olivia and Gibson (2008) estimate a five good household energy demand system for Indonesia with a correction procedure for quality effects suggested by Deaton (1988). Based on a marginal tax reform approach by Ahmad and Stern (1984), increasing taxes on energy is found to be desirable from both an efficiency and equity perspective. Other work on energy prices and subsidies for Indonesia predominantly use Computable General Equilibrium (CGE) models. Clements et al. (2013), for example, simulate the effects of a price increase for petroleum products and find a decline in aggregate household consumption with high income urban households suffering the highest losses. Another CGE analysis with a highly disaggregated household sector by Yusuf and Resosu- 
darmo (2008) - in a similar scenario with rising fuel prices -, also find progressive effects for transport fuels, but regressive effects of higher Kerosene prices. Dartanto (2013) uses a CGE model with a disaggregated household sector to explicitly look at the effects of fuel subsidy reductions on the poverty rate. He finds a slight increase in the poverty headcount with no recycling of revenues. Yet, a complete removal of fuel subsidies and a partial reallocation to other government spending items and transfers has the potential to slightly reduce poverty. Durand-Lasserve et al. (2015) also use a CGE to assess the distributional impacts of energy subsidy reforms and find subsidy removals to be generally regressive. They simulate different redistribution schemes and find lump-sum transfers to change the distributional impacts towards progressivity. For other low and middle income countries, there is some evidence for a progressive (regressive) impact of fuel taxes (subsidies). Sterner (2011) presents a collection of mostly first-order, partial equilibrium studies on the impact of transport fuel taxes on the poor in Mexico, Costa Rica, China, India, Ethopia, Ghana, Kenya, Tanzania and the impact of reducing transport fuel subsidies in Iran. The general result is that poor households face a lower tax burden relative to their income as richer households, leading to a progressive income distribution effect in all cases. The main reason is that poorer households tend to spend relatively little on transport fuels. Recently there is also an increasing interest in energy subsidy reforms as reflected by a growing literature for low and middle income countries. Arze del Granado et al. (2012) provide a review of fuel subsidies for 20 countries and find that the top income quintile receives as much as six times more in subsidy payments than the bottom quintile. In general, there appears to be no disagreement that - in developing countries - transport fuel subsidies benefit the rich more than the poor. Yet, there is no work on energy subsidies in general, i.e. subsidies on electricity and cooking fuels are typically ignored. While the heterogeneity of impacts of price changes across the income distribution has been scrutinized in most empirical work, other possible sources of impact heterogeneity have received less attention. The presence of certain energy-related household needs, for example the need for transport in remote areas, may have important implications for welfare impacts of price changes. Specifically, some households, and more so poorer ones, do spend a higher than average share of their budgets on energy and this may introduce substantial impact heterogeneity. Additionally, the issue of energy poverty is virtually absent from the discussion on fuel taxes and subsidies.

\subsection{Household energy use and energy poverty}

We use household expenditure data from the Indonesian Survei Sosial Ekonomi Nasional (SUSENAS), a cross-section survey collected annually by Badan Pusat Statistik (BPS) In- 
donesia. ${ }^{4}$ Drawing on the survey data, the poverty rate in Indonesia was at 12 percent in 2013 using the national poverty lines provided by BPS Indonesia with the majority of the poor living in rural areas (see also table 5.1). ${ }^{5}$ The SUSENAS survey has a detailed expenditure module with reported expenditures and quantities on electricity (in kwh), gasoline (in l), kerosene (in 1) and liquefied petroleum gas LPG (in kg). In addition, other expenditures for transport are reported, including spending on public transport, airfares, and marine transport. Based on these data, Figure 5.2 shows the patterns for all energy (electricity, gasoline, kerosene, LPG, other transport and firewood), modern energy (electricity, gasoline, kerosene and LPG; used in the later analysis), transport energy (gasoline and other transport) and domestic energy (electricity, kerosene, LPG and firewood) expenditures over the income distribution, divided into percentiles of total household per capita expenditure. ${ }^{6}$ Due to the discrete decision to obtain major energy-consuming durables, we distinguish between the average user in the sample including zero demand (demand $>=0$ ) and the average user with strictly positive demand (demand $>0$ ). This is a simple approximation to the abovementioned heterogeneity in energy spending patterns between households that, in contrast, may be similar in terms of household per capita income. In the case of aggregated energy expenditures, this hardly makes a difference but it is very relevant in the analysis of single energy items. In general, energy expenditures rise over the expenditure distribution which appears to be driven by transport expenditures. Modern domestic energy use is only absent for some households below the 20th percentile, and the share of households relying solely on traditional energy sources for cooking and lighting is below 10 percent among this group. A more detailed look into the expenditure patterns of single energy items for rural (figure 5.3) and urban (figure 5.4) households provides some interesting insights here. For gasoline demand, the following pattern emerges: the budget shares for gasoline of the richest households is about twice as high as the average poor household's budget share. Yet, those households in the lower part of the income distribution who actually use gasoline have a similar budget share as the rich. This shows that the sole look at averages even within income groups is not sufficient, in particular if policy makers are interested in identifying potential losers. 30 percent of the poorest households use gasoline, most of them as an input to motorcycle transport. This differentiation is not necessary for electricity demand, as, according to the

\footnotetext{
${ }^{4}$ For descriptive purposes and the welfare analysis we use the March 2013 data. For the estimation we use a pooled dataset for the years 2009-2013. Data provision by Badan Pusat Statistik (BPS) is gratefully acknowledged.

${ }^{5}$ The national poverty line is relatively low. In 2010, a year for which poverty rates for both international and national poverty rates are reported by the World Bank, the poverty rate was 11.3 using the national and 15.9 using the Int. $\$ 1.9$ poverty line.

${ }^{6}$ Nonparametric distributional curves are calculated with kernel-weighted local polynomial smoothing using an epanechnikov kernel function with degree 0 and bandwith 1.15 .
} 
survey data, about 90 percent of the population have non-zero electricity demand. This reflects relatively high grid access in Indonesia, reported to be around 76 percent in 2012 (IEA, 2014). The difference can be explained by electricity coming from local power supply and diesel generators. Electricity budget shares are generally rising with income and differ between rural and urban areas. The average urban household spends 1 percentage point more of his income on electricity than the average rural household. While Kerosene is a multi-purpose fuel, LPG and firewood are mostly used for cooking. Over time, kerosene has become the least popular fuel in Indonesia with only 30 percent of households exhibiting positive demand. It is still more used in rural areas and, somewhat surprisingly, not just by low income households but with slightly higher budget shares by middle and higher income households. LPG and firewood might be close substitutes in general, but, as expected, low income rural households still depend heavily on firewood and LPG is becoming the dominant cooking fuel for urban households - now used by 51 percent of the population.

In contrast to regular consumption goods, energy use is typically a two-step decision process with the first step being a discrete decision to own a durable which converts energy into some usable form to enjoy the desired energy service. A case in point is of course private transport. Not surprisingly, demand for gasoline can be well explained by the ownership of private transport vehicles, dominated by motorbikes in Indonesia. Once households own a motorbike, they tend to spend a similar share of their income on gasoline - irrespective of their income levels. This is illustrated in Table 5.1 that combines poverty status, ownership of private transport means, and gasoline expenditure shares. The national ownership rate of private transport means stands at 65 percent in our dataset. The rate in urban areas is 74 percent and significantly lower but still considerable with 58.2 percent in rural areas. Among the poor, still 37.1 percent own a vehicle, typically a motorbike. For these income poor motorbike owners, the average budget share for gasoline is 5.2 percent, only 0.1 percentage points less than the share of the non-poor. Note also that urban poor vehicle owners spend an even higher budget share on gasoline than the urban non-poor. Maybe somewhat contrary to expectations, we do not find major differences in transport-related energy demand between rural and urban households. Note that the residual category includes diverse transport modes such as local public transport as well as air travel. The latter is likely to be the main reason why budget shares increase with higher incomes and rich rural households with positive demand have higher budget shares than their urban counterparts. For lower income households, the share of public transport might be higher in this category, but we are unable to further distinguish between transport modes. Other minor transport energy items are motor oils and diesel, with the latter likely to be relevant to prices of public transport. The direct use of diesel by households is negligible in Indonesia. Opposed to transport, expenditures for 
firewood (also includes other undefined fuels) decline with rising incomes and the usage rate declines steeply (figure 5.5). Rural households clearly use more firewood than urban households, reflected in higher usage rates and budget shares.

Our analysis of energy demand patterns reveals interesting insights into an often overlooked dimension in the distributional analysis of energy price changes: energy poverty. The International Energy Association defines energy poverty as "the lack of access to modern energy services. These services are defined as household access to electricity and clean cooking facilities [e.g. fuels and stoves that do not cause air pollution in houses]" (IEA, 2014). ${ }^{7}$ We therefore focus on the domestically used energy items electricity, kerosene and LPG, for which expenditure information is available in the household survey. The used quantities are transformed to physical, normalized units (kilograms oil equivalent, kgoe) and summed up to household energy use per capita. Two different energy poverty approaches are subsequently defined and will help us to understand the sensitivity of the chosen poverty lines. First, we define poverty cut-offs at 50 kgoe (kilogram of oil equivalent) of final energy per capita and year in the form of modern fuels used for cooking and a minimum amount of electricity resulting in the energy poverty Line (EPL) 1, similar as in Modi, Vijay et al. (2005). Since quantity information for firewood is missing, we calculate household energy use per capita exclusively based on modern fuels. Therefore, energy poverty is strictly defined as a lack of use of modern energy and not as total energy use which would include biomass.

Table 5.1 Gasoline demand, vehicle ownership and poverty

\begin{tabular}{lccccc}
\hline & pop \% & $\mathrm{w}(\mathrm{d}>=0)^{\mathrm{a}}$ & $\mathrm{w}(\mathrm{d}>0)^{\mathrm{b}}$ & $\mathrm{priv} \mathrm{tr}^{\mathrm{c}}$ & Moto $^{\mathrm{d}}$ \\
\hline & & & & & \\
All & 1 & 0.035 & 0.053 & 0.65 & 0.636 \\
Urban & 0.426 & 0.038 & 0.051 & 0.74 & 0.727 \\
Rural & 0.574 & 0.032 & 0.055 & 0.582 & 0.568 \\
Poor & 0.117 & 0.019 & 0.052 & 0.371 & 0.365 \\
Nonpoor & 0.883 & 0.037 & 0.053 & 0.686 & 0.672 \\
Urban poor & 0.039 & 0.025 & 0.053 & 0.462 & 0.459 \\
Urban nonpoor & 0.387 & 0.039 & 0.051 & 0.768 & 0.754 \\
Rural poor & 0.078 & 0.017 & 0.051 & 0.326 & 0.318 \\
Rural nonpoor & 0.497 & 0.035 & 0.056 & 0.623 & 0.607 \\
\hline a Average budget share over population including zero demand \\
b Average budget share over population excluding zero demand \\
c Ownership rate for private transport vehicle(s) \\
d Ownership rate for motorcycle(s
\end{tabular}

\footnotetext{
${ }^{7} \mathrm{~A}$ wider definition of energy poverty could also include transport related energy or the quality and performance of the energy use as discussed in Angelou et al. (2013) but this is beyond the scope of our study.
} 

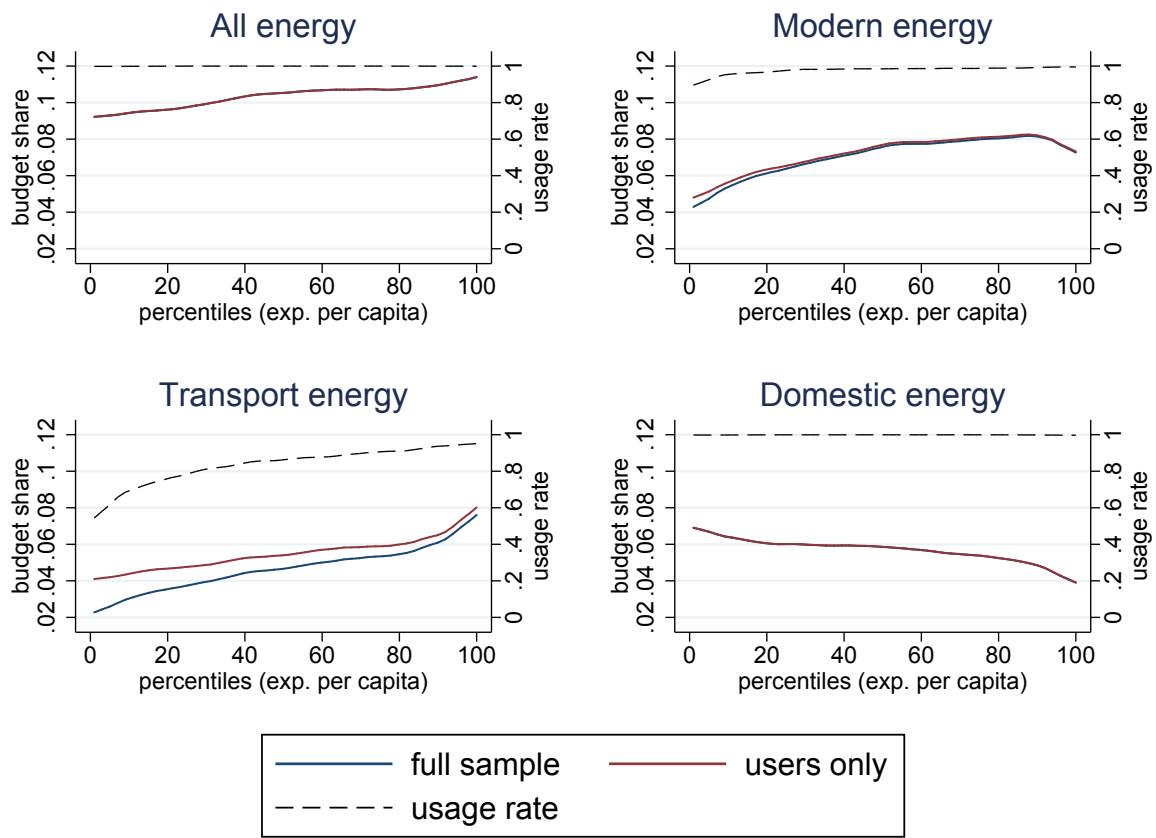

Fig. 5.2 Energy expenditure shares

(a) Electricity

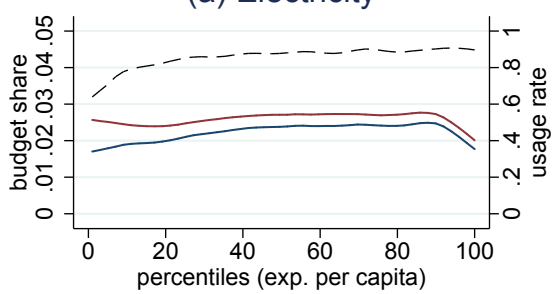

(c) Kerosene

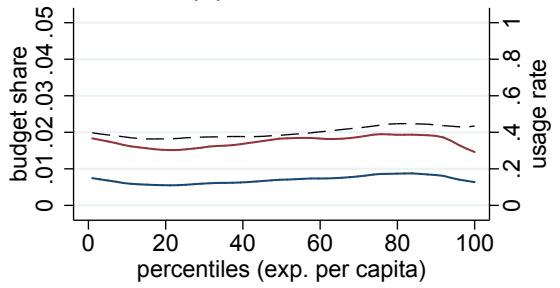

full sample usage rate

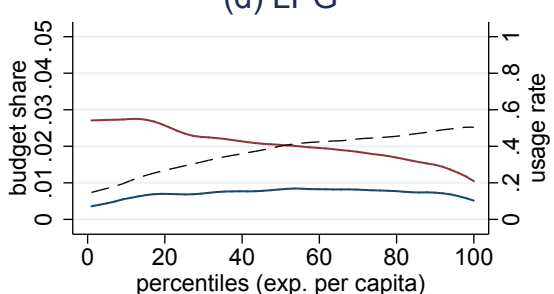

(b) Gasoline

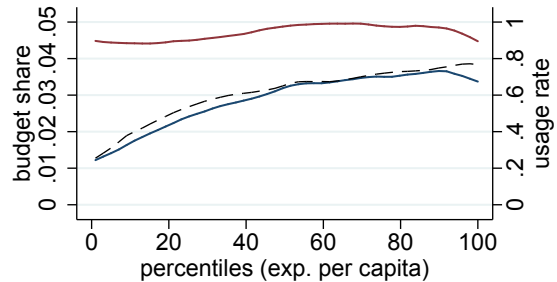

(d) LPG

users only

Fig. 5.3 Rural energy expenditure shares and usage rates 
(a) Electricity

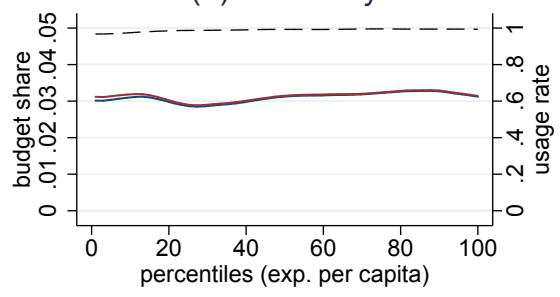

(c) Kerosene

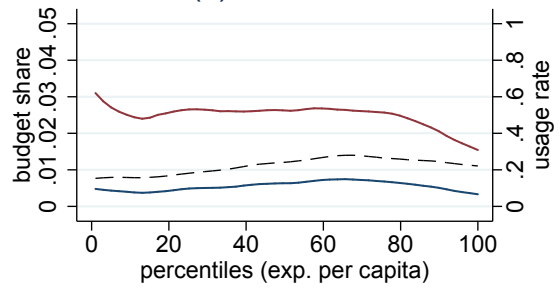

full sample usage rate (b) Gasoline

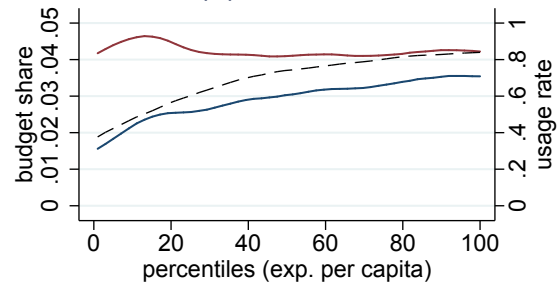

(d) LPG

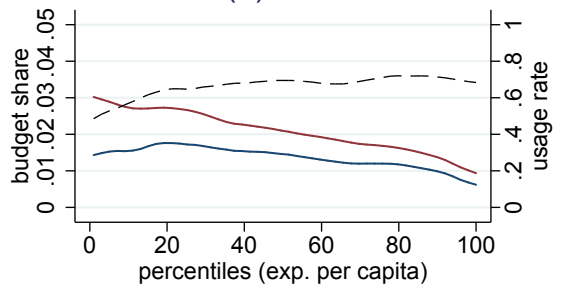

users only

Fig. 5.4 Urban energy expenditure shares and usage rates

Rural

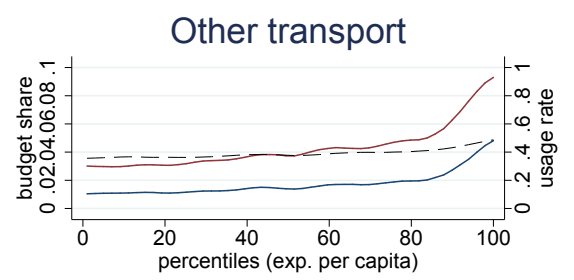

Firewood

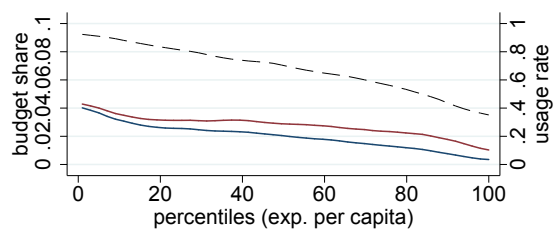

Urban

Other transport

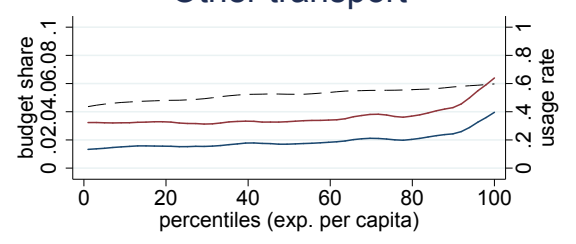

Firewood
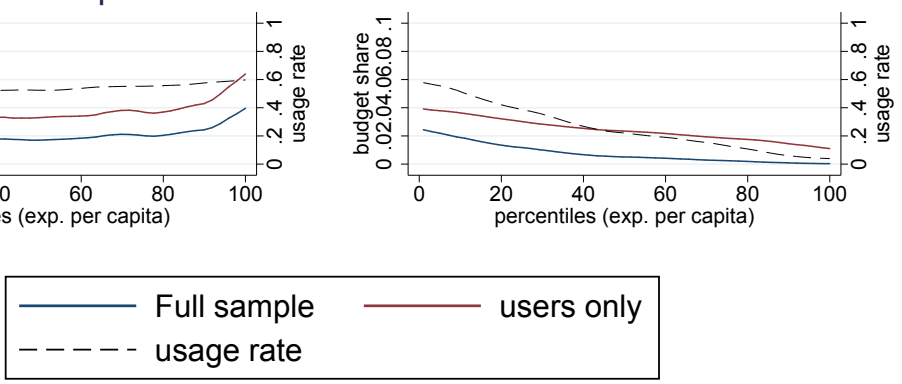

Fig. 5.5 Urban and rural energy expenditure shares and usage rates 
Secondly, we define an alternative energy poverty line (EPL 2) at the expenditure poverty line inspired by Foster et al. (2000). We do this by transforming demanded quantities of all "modern" energy items into kgoe and perform a nonparametric kernel-weighted local polynomial regression of the quantity used per energy item on total household expenditures per capita for the reference year 2013. ${ }^{8}$ The calculated value at the per capita expenditure poverty line can then be directly interpreted as our energy poverty line at which we calculate FGT energy poverty indices. We refrain from calculating a "transport poverty line" because of conceptual and empirical issues, such as the difficult comparability between urban and rural energy needs and the missing public transport data. Table 5.2 displays the calculated FGT energy indices and the per capita energy poverty line EPL 2 which is considerably smaller than EPL 1 at around $22 \mathrm{kgoe}$. Although this poverty line is at a relatively low level, the national energy poverty rate is close to 30 percent, dominated by the rural energy poverty rate of 43 percent. To be clear, there are many households not defined as income poor but do not use more modern energy than the average household at the poverty line. Based on EPL 1, the national energy poverty rate is above 60 percent. Since many, particularly rural households use firewood for cooking and we excluded it from the analysis, the magnitude is not particularly surprising.

Table 5.2 Energy poverty

\begin{tabular}{lcccccccccc}
\hline & \multicolumn{1}{c}{ FGT } \\
\cline { 2 - 11 } & \multicolumn{3}{c}{ National } & \multicolumn{3}{c}{ Rural } & \multicolumn{3}{c}{ Urban } \\
\cline { 2 - 11 } & 0 & 1 & 2 & 0 & 1 & 2 & 0 & 1 & 2 \\
\hline EPL 1 & 0.61 & 0.32 & 0.22 & 0.75 & 0.44 & 0.31 & 0.43 & 0.16 & 0.09 \\
EPL 2 & 0.29 & 0.14 & 0.09 & 0.43 & 0.22 & 0.15 & 0.11 & 0.04 & 0.02 \\
\hline EPL 2 poverty line: 21.82 kgoe & & & & & &
\end{tabular}

\subsection{Welfare measurement, demand estimation and $\mathrm{CO}_{2}$ Emis- sions}

\subsubsection{Demand system}

There is an extensive literature on the estimation of demand functions based on economic theory. Since the seminal work of Stone (1954), a significant amount of research has been produced, with Deaton and Muellbauer's (1980b) Almost Ideal Demand System (AIDS)

\footnotetext{
${ }^{8}$ See Fan and Gijbels (1996) for further information on kernel-weighted local polynomial regression.
} 
(Deaton and Muellbauer, 1980a) and the quadratic extension of the AIDS, the QUAIDS by Banks et al. (1997) among the more prominent ones. The estimation of QUAIDS has been applied to the energy context by West and Williams III (2004), Labandeira et al. (2006), Nikodinoska and Schröder (2016) and Tiezzi and Verde (2016). According to our knowledge, no demand system specification of this form has been applied to the energy context in low and middle income countries before. For India, Gundimeda and Köhlin (2008) estimate an LAAIDS differentiated by income for rural and urban households separately. They report a full range of substitution elasticities for a four good energy demand system but no welfare effects. More recent developments in the field are towards even higher nonlinearity in parametric systems (Lewbel and Pendakur, 2009). For our analysis we use the well-established QUAIDS framework since observed Engel curves appear to be well approximated by a quadratic relationship between budget shares and logarithmic transformed expenditures. Rank three quadratic logarithmic budget share systems have an indirect utility function of the following form:

$$
\ln V=\left\{\left[\frac{\ln x-\ln a(p)}{b(p)}\right]^{-1}+\lambda(p)\right\}^{-1}
$$

The price indexes $\log [a(p)]$ and $b(p)$ are defined as:

$$
\begin{gathered}
\ln a(p)=\alpha_{0}+\sum_{i=1}^{n} \alpha_{i} \ln p_{i}+\frac{1}{2} \sum_{i=1}^{n} \sum_{j=1}^{n} \gamma_{i j} \ln p_{i} \ln p_{j} \\
b(p)=\prod_{i=1}^{n} p_{i}^{\beta_{i}}
\end{gathered}
$$

The term $\lambda(p)$ in the indirect utility function is a differentiable, homogeneous function of degree zero of prices $\mathrm{p}$ and defined as:

$$
\lambda(p)=\sum_{i=1}^{n} \lambda_{i} \ln p_{i}
$$

With $\sum_{i} \lambda_{i}=0$. The derived expenditure share system is:

$$
w_{i}=\alpha_{i}+\sum_{j=1}^{n} \gamma_{i j} \ln p_{j}+\beta_{i} \ln \left[\frac{x}{a(p)}\right]+\frac{\lambda_{i}}{b(p)}\left\{\ln \left[\frac{x}{a(p)}\right]\right\}^{2}
$$

Where $w_{i}$ is the share of commodity (group) $\mathrm{i}$ of total non-durable expenditures $\mathrm{x}$. To be consistent with utility maximization, the following restrictions need to hold: 
Adding-up

$$
\sum_{i=1}^{n} \alpha_{i}=1 ; \quad \sum_{i=1}^{n} \gamma_{i j}=0 ; \quad \sum_{i=1}^{n} \beta_{i}=0 ; \quad \sum_{i=1}^{n} \lambda_{i}=0
$$

Homogeneity

$$
\sum_{j=1}^{n} \gamma_{i j}=0
$$

Symmetry

$$
\gamma_{i j}=\gamma_{j i}
$$

Income /Expenditure elasticities can be derived from the share equation:

$$
e_{i}=\frac{\mu_{i}}{w_{i}}+1
$$

with

$$
\mu_{i}=\frac{\partial w_{i}}{\partial \ln x}=\beta_{i}+\frac{2 \lambda_{i}}{b(p)}\left\{\ln \left[\frac{x}{a(p)}\right]\right\}
$$

The uncompensated price elasticity is given by:

$$
e_{i j}^{u}=\frac{\mu_{i j}}{w_{i}}-\delta_{i j}
$$

with

$$
\mu_{i j}=\frac{\partial w_{i}}{\partial \ln p_{i}}=\gamma_{i j}-\mu_{i}\left(\alpha_{j}+\sum_{k}^{n} \gamma_{j k} \ln p_{k}\right)-\frac{\lambda_{i} \beta_{j}}{b(p)}\left\{\ln \left[\frac{x}{a(p)}\right]\right\}^{2}
$$

and $\delta_{i j}$ is the Kronecker delta. Compensated price elasticities are derived by the slutsky equation:

$$
e_{i j}^{c}=e_{i j}^{u}+e_{i} w_{j}
$$

In household expenditure data, recorded zero expenditures are a common problem. The possible reasons, infrequency of purchase or corner solutions are hard to distinguish empirically however. The literature usually identifies this data issue as "censored", although censoring may only be a special case of the underlying data generating process. We stick to this discussion and use "censored" as a synonym for zero observations in budget share data. Apart from the recent use of Full Information Maximum Likelihood (FIML) estimation (Chen and Yen, 2005), the suggested solutions in the literature are based on Heckman's two step 
approach (Heckman, 1979). Heien and Wessells (1990) applied the two step approach to the demand context, but attracted criticism for being inconsistent in later work. Shonkwiler and Yen (1999) prove this inconsistency, showing the statistical correct way to obtain elasticity estimates in censored system settings. First, a household specific probit model is estimated with the outcome of 1 if the household consumes good $i$ and 0 otherwise. For each household, the standard normal probability density function (pdf) $\phi$ and the cumulative distribution function (cdf) $\Phi$ are calculated by regressing $w_{i}$ on a set of independent variables $z_{i}$. Secondly, the pdf and the cdf are integrated into the system of equations as follows:

$$
w_{i}^{*}=\Phi w_{i}+\varphi_{i} \phi
$$

In contrast to Heckman (1979), this approach makes use of the full sample in both steps of the estimation process. According to Shonkwiler and Yen (1999) the estimation of a censored system requires a procedure that uses the whole sample since each dependent variable may have a different pattern of censoring. The elasticity formulas (relative to quantities) for the QUAIDS change as:

Expenditure elasticity

$$
e_{i}^{*}=\frac{\Phi\left(\mu_{i}\right)}{w_{i}}+1
$$

Price elasticity

$$
e_{i j}^{*}=\frac{\Phi\left(\mu_{i}\right)}{w_{i}}+\phi \tau_{i j}\left(1-\frac{\varphi_{i}}{w_{i}}\right)-\delta_{i j}
$$

The respective expenditure and price elasticities, $e_{i}$ and $e_{i j}$ are derived under the modified system (13). This two-step methodology has been applied in food demand contexts by Yen et al. (2002) and Ecker and Qaim (2011) amongst others but not yet for energy demand.

\subsubsection{Welfare effects}

Since the literature on the welfare impacts of subsidy reforms focuses on first-order effects as in Sterner (2011), we are interested in the necessity of calculating second-order effects taking into account demand substitution. The first-order effects (FO) only require the observed demand and no additional information on substitution behavior due to price changes (Deaton and Muellbauer, 1980b; Feldstein, 1972; Stern, 1987):

$$
F O=\sum_{i=1}^{n} w_{i} \frac{\Delta p_{i}}{p_{i}^{0}}
$$


More exact welfare measures, incorporating substitution effects, have been proposed early by Hicks (1939) with the compensating and equivalent variation measures. The difference between first-order welfare measures, approximated by the budget share and more exact second-order approximations incorporating household demand responses are well documented in Banks et al. (1996). As they demonstrate, the difference between first and second-order or "exact" welfare measures can be quite substantial when price changes are non-marginal. They point to another main difference which is created by the distribution of substitution elasticities, which may change the welfare effects considerably if elasticities differ over the income distribution. To account for heterogeneous preferences, we obtain ownand cross price elasticities $\left(e_{i} j\right)$ on the household level following Banks et al. (1997) which are used in a cost of living experiment with the second order welfare loss approximated by a second-order taylor series expansion of the cost function (Deaton and Muellbauer, 1980b):

$$
C V=\sum_{i=1}^{n} w_{i}\left(\frac{\Delta p_{i}}{p_{i}^{0}}\right)+\frac{1}{2} \sum_{i=1}^{n} \sum_{j=1}^{n} w_{i} e_{i j}\left(\frac{\Delta p_{i}}{p_{i}^{0}}\right)\left(\frac{\Delta p_{j}}{p_{j}^{0}}\right)
$$

\subsubsection{Household $\mathrm{CO}_{2}$ emissions}

$\mathrm{CO}_{2}$ emissions embodied in household consumption (carbon footprints) could easily be calculated with direct carbon intensities measured in available physical energy units (e.g. $2.4 \mathrm{~kg} \mathrm{CO} 2$ per liter gasoline). However, the direct carbon content is not accounting for emissions in the production process (e.g. refining gasoline) and for electricity and the residual other goods category we would not be able to provide carbon contents. Therefore, in our analytical framework, carbon emissions are calculated from a demand side perspective by employing an input-output (IO) model. These carbon footprints are derived by calculating carbon intensities of the Indonesian production sectors and a subsequent matching with household consumption. The underlying database is the national $\mathrm{IO}$ table and $\mathrm{CO}_{2}$ emissions per industrial sector from the World Input Output Database (Timmer et al., 2015). ${ }^{9}$ Total production emissions $C_{\text {ind }}$ are simply a product of the matrix of sector specific direct carbon intensities $C I$ and total production vector $x$ :

$$
C I^{\prime} x=C_{\text {ind }}
$$

\footnotetext{
${ }^{9}$ The matching between WIOD sectors and the SUSENAS cinsumption classfication is documented in table D.1, Appendix.
} 
Since our analysis has a focus on final demand y, direct carbon intensities are not of interest and we transform equation (5.19) with the Leontief inverse $(I-A)^{-1}$. Recalling total production

$$
x=(I-A)^{-1} y
$$

and substituting (5.20) for $x$ in (5.19) gives us total production emissions from a demand side perspective:

$$
C I^{\prime}(I-A)^{-1} y=C_{\text {ind }}
$$

The multiplication of the direct carbon intensities $e^{\prime} C$ by the Leontief inverse $(I-A)^{-1}$ then generates the indirect carbon intensities $C I_{\text {ind }}$ :

$$
C I_{\text {ind }}=C I^{\prime}(I-A)^{-1}
$$

which we use in the further analysis. For the fuels gasoline, kerosene and LPG we have to additionally add these production based emissions to the direct carbon content emitted in the combustion process. ${ }^{10}$ These direct carbon contents are transformed to household specific expenditure based carbon intensities by calculating direct carbon emissions (quantities multiplied with carbon contents) and dividing through the respective fuel expenditures. Household specific carbon footprints are then calculated by multiplying expenditures per good with the respective carbon intensity $\mathrm{CI}_{k}\left(\mathrm{tCO}_{2} / \mathrm{MXN}\right)$ :

$$
C O_{2 i}=\sum_{k=1}^{5}\left(\exp _{i k} * C I_{k}\right)
$$

After price changes take place, new expenditure levels $\exp _{i}^{1}$ per household are derived from the simulated budget shares $w_{i}^{1}$ :

$$
w_{i}^{1}=\Phi\left(\widehat{\alpha}_{i}+\sum_{j=1}^{n} \widehat{\gamma_{i j}} \ln p_{j}^{1}+\widehat{\beta}_{i} \ln \left[\frac{x^{0}}{a\left(p^{1}\right)}\right]+\frac{\widehat{\lambda}_{i}}{b\left(p^{1}\right)}\left\{\ln \left[\frac{x^{0}}{a\left(p^{1}\right)}\right]\right\}^{2}\right)+\varphi_{i} \phi+\widehat{\varepsilon}_{i}^{0}
$$

The carbon emissions per household are then calculated as:

$$
C O_{2}^{1}=\sum_{i=1}^{n}\left(\frac{\exp _{i}^{1}}{1+\frac{\Delta p_{i}}{p_{i}^{0}}} * C I_{i}\right)
$$

\footnotetext{
${ }^{10}$ Gasoline: $2.31 \mathrm{~kg} \mathrm{CO}_{2} / 1$, Kerosene: $2.55 \mathrm{~kg} \mathrm{CO} / \mathrm{l}$, LPG: $1.5 \mathrm{~kg} \mathrm{CO}_{2} / \mathrm{kg}$
} 
where the simulated expenditures are deflated to the baseline level in period 0 to avoid upward biased projected emission levels. Additionally, to account for consumption growth effects through redistribution via social programs, we simulate new expenditures and resulting carbon emissions after income changes occur.

\subsection{Energy price changes, poverty, welfare effects and $\mathrm{CO}_{2}$ emissions}

We simulate the welfare and energy poverty impact for two stylized scenarios (20 and 50 percent price increase) and obtain results for single and multiple simultaneous price changes. Based on the current low international oil prices, scenarios with even higher price increases up to 100 percent and above are indeed possible for the coming years considering past trends. Yet, price changes of this magnitude imply that we would have to forecast completely out of sample. As mentioned before, the survey data offers price information for electricity, gasoline, kerosene and LPG. Unfortunately we neither have price information for other transport nor firewood expenditures and have to exclude them from further analysis. In addition to these scenarios with energy price increases, we also simulate a scenario that interprets the price change as an ad valorem tax rate and redistributes collected tax revenues via lump-sum cash transfers to households. We assume similarity between consumers' responses of price changes through market mechanisms and taxes, although there is increasing evidence questioning this assumption (Rivers and Schaufele, 2015; Tiezzi and Verde, 2016). Since this difference is most likely to play out in the long-run, our analysis still offers valid results in the short-run.

\subsubsection{Estimation results}

The first stage estimation generates results from the probit model specification. Marginal effects, evaluated at the sample means are displayed in table 5.3. All energy-price coefficients have close to zero magnitude which implies that energy prices appear not to be a major determinant of energy use decisions. Income on the other hand is an important factor, particularly for private motorized transport. In the next step, the full demand system is estimated. Due to the difficult economic interpreation of model coefficients, we report expenditure elasticities in table 5.4 and price elasticities in table 5.5. Following Banks et al. (1997), we calculate elasticities for each household individually and construct a weighted average, with the weights generated as the household's share of total sample expenditure for the relevant good.

With rising income, the willingness to spend more on electricity increases, turning from a 
necessity to a luxury good at the 90th percentile. We observe high income responses towards gasoline use, with slightly rising budget elasticities over the expenditure distribution all above one. Gasoline is clearly a luxury good for households of all incomes. Kerosene also exhibits budget elasticities close to 1, particularly for lower income households. LPG is also estimated to be a necessity for all households, although as in the case of kerosene, the tendency to demand more quantity declines with rising income.

Table 5.3 First stage probit model (marginal effects at means)

\begin{tabular}{|c|c|c|c|c|}
\hline VARIABLES & $\begin{array}{c}(1) \\
\text { Electricity } \\
\text { y1 }\end{array}$ & $\begin{array}{c}(2) \\
\text { Gasoline } \\
\text { y1 }\end{array}$ & $\begin{array}{c}(3) \\
\text { Kerosene } \\
\text { y1 }\end{array}$ & $\begin{array}{c}(4) \\
\text { LPG } \\
\text { y1 }\end{array}$ \\
\hline $\mathrm{p} 1$ & $\begin{array}{c}1.23 \mathrm{e}-05^{* * *} \\
(7.67 \mathrm{e}-07)\end{array}$ & $\begin{array}{c}-8.05 \mathrm{e}-06^{* * * *} \\
(1.25 \mathrm{e}-06)\end{array}$ & $\begin{array}{c}2.39 \mathrm{e}-05^{* * *} \\
(1.25 \mathrm{e}-06)\end{array}$ & $\begin{array}{c}-4.53 \mathrm{e}-06^{* * *} \\
(1.31 \mathrm{e}-06)\end{array}$ \\
\hline $\mathrm{p} 2$ & $\begin{array}{c}-2.79 \mathrm{e}-05^{* * * *} \\
(5.44 \mathrm{e}-07)\end{array}$ & $\begin{array}{c}-3.23 \mathrm{e}-05^{* * *} \\
(9.96 \mathrm{e}-07)\end{array}$ & $\begin{array}{c}6.73 \mathrm{e}-05^{* * * *} \\
(9.90 \mathrm{e}-07)\end{array}$ & $\begin{array}{c}-6.21 \mathrm{e}-05^{* * *} \\
(1.15 \mathrm{e}-06)\end{array}$ \\
\hline p3 & $\begin{array}{c}-2.72 \mathrm{e}-05^{* * *} \\
(2.40 \mathrm{e}-07)\end{array}$ & $\begin{array}{c}-6.28 \mathrm{e}-06^{* * * *} \\
(3.89 \mathrm{e}-07)\end{array}$ & $\begin{array}{c}-5.01 \mathrm{e}-05^{* * * *} \\
(3.88 \mathrm{e}-07)\end{array}$ & $\begin{array}{c}3.20 \mathrm{e}-05^{* * *} \\
(3.79 \mathrm{e}-07)\end{array}$ \\
\hline $\mathrm{p} 4$ & $\begin{array}{c}-1.13 \mathrm{e}-05^{* * * *} \\
(6.69 \mathrm{e}-08)\end{array}$ & $\begin{array}{c}-4.12 \mathrm{e}-06^{* * * *} \\
(7.27 \mathrm{e}-08)\end{array}$ & $\begin{array}{c}2.46 \mathrm{e}-06 * * * \\
(7.94 \mathrm{e}-08)\end{array}$ & $\begin{array}{c}-5.05 \mathrm{e}-06 * * * \\
(9.61 \mathrm{e}-08)\end{array}$ \\
\hline p5 & $\begin{array}{c}0.000723 * * * \\
(6.88 \mathrm{e}-05)\end{array}$ & $\begin{array}{c}0.00583 * * * \\
(0.000113)\end{array}$ & $\begin{array}{l}-0.0177 * * * \\
(0.000122)\end{array}$ & $\begin{array}{c}0.00184 * * * \\
(0.000115)\end{array}$ \\
\hline $\ln (\mathrm{x})$ & $\begin{array}{l}0.0851 * * * \\
(0.000777)\end{array}$ & $\begin{array}{l}0.486 * * * \\
(0.00146)\end{array}$ & $\begin{array}{c}-0.0436 * * * \\
(0.00131)\end{array}$ & $\begin{array}{l}0.286 * * * \\
(0.00131)\end{array}$ \\
\hline male & $\begin{array}{c}-0.0115^{* * *} \\
(0.00120)\end{array}$ & $\begin{array}{l}0.147 * * * \\
(0.00209)\end{array}$ & $\begin{array}{c}-0.0316 * * * \\
(0.00216)\end{array}$ & $\begin{array}{c}-0.0158^{* * *} \\
(0.00203)\end{array}$ \\
\hline age & $\begin{array}{c}0.000638^{* * *} \\
(3.05 \mathrm{e}-05)\end{array}$ & $\begin{array}{c}-0.00385^{* * *} \\
(5.05 \mathrm{e}-05)\end{array}$ & $\begin{array}{c}0.000719 * * * \\
(5.22 \mathrm{e}-05)\end{array}$ & $\begin{array}{c}-0.000950 * * * \\
(4.86 \mathrm{e}-05)\end{array}$ \\
\hline hhsize $=2$ & $\begin{array}{c}0.00387^{* *} \\
(0.00178)\end{array}$ & $\begin{array}{l}0.109 * * * \\
(0.00360)\end{array}$ & $\begin{array}{c}0.0550 * * * \\
(0.00318)\end{array}$ & $\begin{array}{l}0.107 * * * \\
(0.00284)\end{array}$ \\
\hline hhsize $=3$ & $\begin{array}{l}0.000562 \\
(0.00176)\end{array}$ & $\begin{array}{l}0.175 * * * \\
(0.00343)\end{array}$ & $\begin{array}{c}0.0617 * * * \\
(0.00312)\end{array}$ & $\begin{array}{l}0.118 * * * \\
(0.00273)\end{array}$ \\
\hline hhsize $=4$ & $\begin{array}{c}-0.00580 * * * \\
(0.00180)\end{array}$ & $\begin{array}{l}0.169 * * * \\
(0.00346)\end{array}$ & $\begin{array}{c}0.0566^{* * * *} \\
(0.00316)\end{array}$ & $\begin{array}{l}0.118 * * * \\
(0.00277)\end{array}$ \\
\hline hhsize $=5$ & $\begin{array}{c}-0.0144 * * * \\
(0.00193)\end{array}$ & $\begin{array}{l}0.143 * * * \\
(0.00363)\end{array}$ & $\begin{array}{c}0.0663 * * * \\
(0.00335)\end{array}$ & $\begin{array}{c}0.0834 * * * \\
(0.00294)\end{array}$ \\
\hline hhsize $=6$ & $\begin{array}{c}-0.0332 * * * \\
(0.00204)\end{array}$ & $\begin{array}{c}0.0824 * * * \\
(0.00375)\end{array}$ & $\begin{array}{c}0.0945 * * * \\
(0.00346)\end{array}$ & $\begin{array}{c}0.0211^{* * * *} \\
(0.00295)\end{array}$ \\
\hline Observations & 761,624 & 761,624 & 761,624 & 761,624 \\
\hline
\end{tabular}

Standard errors in parentheses

*** $\mathrm{p}<0.01, * * \mathrm{p}<0.05, * \mathrm{p}<0.1$ 
Households with different income respond quite similarly to price changes for all energy items, which is why we show only one price elasticity matrices for the first, fifth and tenth expenditure per capita decile. In general, households react strongly to price changes for all energy items. Most own-price elasticities are close to -1 with the strongest response observed for gasoline. Based on the estimations, we expect to find differences between first and second order welfare effects particularly for electricity and gasoline price changes when high usage rates meet relatively large own-price elasticities.

Table 5.4 Budget elasticities

\begin{tabular}{cccccc}
\hline Deciles & Electricity & Gasoline & Kerosene & LPG & Other \\
\hline 1 & 0.877 & 1.341 & 0.933 & 0.824 & 0.984 \\
& $(0.002)$ & $(0.008)$ & $(0.003)$ & $(0.005)$ & $(0.000)$ \\
2 & 0.890 & 1.391 & 0.905 & 0.810 & 0.984 \\
& $(0.890)$ & $(1.391)$ & $(0.905)$ & $(0.810)$ & $(0.984)$ \\
3 & 0.905 & 1.407 & 0.895 & 0.804 & 0.984 \\
& $(0.001)$ & $(0.005)$ & $(0.004)$ & $(0.003)$ & $(0.000)$ \\
4 & 0.916 & 1.435 & 0.893 & 0.784 & 0.985 \\
& $(0.001)$ & $(0.005)$ & $(0.004)$ & $(0.003)$ & $(0.000)$ \\
5 & 0.935 & 1.448 & 0.890 & 0.771 & 0.985 \\
& $(0.001)$ & $(0.005)$ & $(0.004)$ & $(0.003)$ & $(0.000)$ \\
6 & 0.950 & 1.446 & 0.886 & 0.754 & 0.985 \\
& $(0.001)$ & $(0.005)$ & $(0.003)$ & $(0.003)$ & $(0.000)$ \\
7 & 0.966 & 1.437 & 0.880 & 0.737 & 0.985 \\
& $(0.001)$ & $(0.004)$ & $(0.003)$ & $(0.003)$ & $(0.000)$ \\
8 & 0.986 & 1.435 & 0.870 & 0.721 & 0.986 \\
& $(0.001)$ & $(0.004)$ & $(0.003)$ & $(0.003)$ & $(0.000)$ \\
9 & 1.014 & 1.429 & 0.856 & 0.701 & 0.986 \\
& $(0.001)$ & $(0.004)$ & $(0.003)$ & $(0.003)$ & $(0.000)$ \\
10 & 1.083 & 1.361 & 0.780 & 0.623 & 0.988 \\
& $(0.002)$ & $(0.004)$ & $(0.007)$ & $(0.003)$ & $(0.000)$ \\
\hline
\end{tabular}

Standard errors in parentheses

The evaluation of cross-price elasticities reveals that not all modern domestic energy items are complements. Electricity and kerosene are weak substitutes while electricity and LPG are weak complements, more so for households with higher income. The cross-price elasticities between LPG and kerosene are zero, which clearly shows an unimportant role of energy prices for the politically supported conversion from kerosene to LPG. Substitution between private transport in the form of gasoline demand and domestic energy has no general pattern either. Kerosene and LPG are weak substitutes and complements with gasoline respectively while gasoline and electricity-gasoline cross-price elasticities are close to zero. 
Table 5.5 Price elasticities

\begin{tabular}{|c|c|c|c|c|c|c|}
\hline \multirow[t]{2}{*}{ decile } & \multirow[t]{2}{*}{ item } & \multicolumn{5}{|c|}{ price } \\
\hline & & Electricity & Gasoline & Kerosene & LPG & Other \\
\hline \multirow[t]{10}{*}{1} & Electricity & -0.83 & 0.03 & 0.01 & -0.05 & 0.85 \\
\hline & & $(0.002)$ & (0.001) & $(0.001)$ & $(0.002)$ & $(0.001)$ \\
\hline & Gasoline & 0.03 & -1.01 & 0.02 & -0.03 & 0.96 \\
\hline & & (0.001) & (0.003) & $(0.001)$ & (0.002) & $(0.003)$ \\
\hline & Kerosene & 0.03 & 0.05 & -0.95 & 0.00 & 0.78 \\
\hline & & $(0.001)$ & (0.004) & $(0.001)$ & (0.000) & (0.004) \\
\hline & LPG & -0.10 & -0.08 & 0.00 & -0.99 & 1.20 \\
\hline & & (0.004) & (0.005) & $(0.000)$ & $(0.001)$ & (0.008) \\
\hline & Other & 0.02 & 0.01 & 0.01 & 0.01 & -0.02 \\
\hline & & $(0.000)$ & $(0.000)$ & $(0.000)$ & $(0.000)$ & $(0.001)$ \\
\hline \multirow[t]{10}{*}{5} & Electricity & -0.82 & 0.04 & 0.01 & -0.09 & 0.83 \\
\hline & & $(0.001)$ & $(0.000)$ & $(0.000)$ & $(0.002)$ & $(0.001)$ \\
\hline & Gasoline & 0.03 & -1.03 & 0.03 & -0.08 & 0.97 \\
\hline & & $(0.000)$ & $(0.002)$ & $(0.001)$ & $(0.002)$ & $(0.002)$ \\
\hline & Kerosene & 0.04 & 0.14 & -0.95 & 0.00 & 0.77 \\
\hline & & (0.001) & $(0.005)$ & $(0.001)$ & (0.000) & $(0.004)$ \\
\hline & LPG & -0.16 & -0.20 & 0.00 & -1.01 & 1.33 \\
\hline & & $(0.002)$ & (0.004) & $(0.000)$ & $(0.001)$ & $(0.006)$ \\
\hline & Other & 0.02 & 0.03 & 0.00 & 0.02 & -0.05 \\
\hline & & $(0.000)$ & $(0.000)$ & $(0.000)$ & (0.000) & $(0.000)$ \\
\hline \multirow[t]{10}{*}{10} & Electricity & -0.80 & 0.01 & 0.01 & -0.13 & 0.83 \\
\hline & & $(0.001)$ & $(0.001)$ & $(0.000)$ & $(0.002)$ & $(0.001)$ \\
\hline & Gasoline & 0.01 & -0.97 & 0.04 & -0.17 & 0.96 \\
\hline & & $(0.001)$ & $(0.001)$ & $(0.001)$ & (0.003) & (0.002) \\
\hline & Kerosene & 0.04 & 0.21 & -0.94 & 0.00 & 0.76 \\
\hline & & $(0.000)$ & (0.006) & $(0.001)$ & (0.000) & $(0.004)$ \\
\hline & LPG & -0.45 & -0.75 & 0.00 & -1.05 & 2.09 \\
\hline & & $(0.005)$ & $(0.010)$ & (0.000) & (0.001) & $(0.013)$ \\
\hline & Other & 0.03 & 0.04 & 0.00 & 0.02 & -0.05 \\
\hline & & (0.000) & $(0.000)$ & $(0.000)$ & (0.000) & (0.000) \\
\hline
\end{tabular}

Standard errors in parentheses 
For other countries, the substitutability of energy items appears to be very context specific as finding in the empirical literature demonstrate. Tiezzi and Verde (2016) find complementarity between electricity and gasoline for the US while Nikodinoska and Schröder (2016)) find the opposite for Germany.

Since this is a critical step in the further analysis, we test for the potential bias of different prices through the geographical location of the household by including province fixed effects and find no significant difference. ${ }^{11}$

\subsubsection{Welfare and poverty effects}

A relatively moderate 20 percent price increase for all four energy items under consideration and averaging over all households per expenditure percentile is displayed in figure 5.6. As expected, electricity and gasoline make up the biggest part of the welfare losses with a progressive pattern in both cases. The relative welfare losses for a uniform 20 percent electricity price increase are between 0.4 and 0.6 percent of total expenditures for the poorest and richest households respectively. For gasoline, these relative welfare losses are larger in particular for richer households, between 0.4 and 0.7 percent. Smaller welfare effects for Kerosene and LPG reflect their relatively low usage rates and budget shares. For the domestically used LPG, a price increase would be slightly regressive, but the magnitude is small due to still low usage rates. This however could change when more and more households use LPG instead of firewood also in rural areas. The difference between the upper bound first order and the lower bound second order effects is relatively small at this magnitude of price effects. First order estimates of welfare losses in the first scenario are on average 10 percent higher. It becomes more pronounced in the second scenario of a 50 percent price increase, where the difference increases to over 20 percent for electricity and gasoline with again small observed differences for kerosene and LPG (figure 5.7). In particular for gasoline, second order effects are slightly less progressive. Responsible for this effect is not a variation of demand responses with rising expenditures but the increase in the usage rate. A larger fraction of households with actual gasoline demand also implies a larger substitution potential. Low income households which are close to the poverty line and dependent on the use of modern energy are less well represented in these average effects.

\footnotetext{
${ }^{11}$ Households in more remote locations face higher prices for all modern energy items and also have smaller demand.
} 


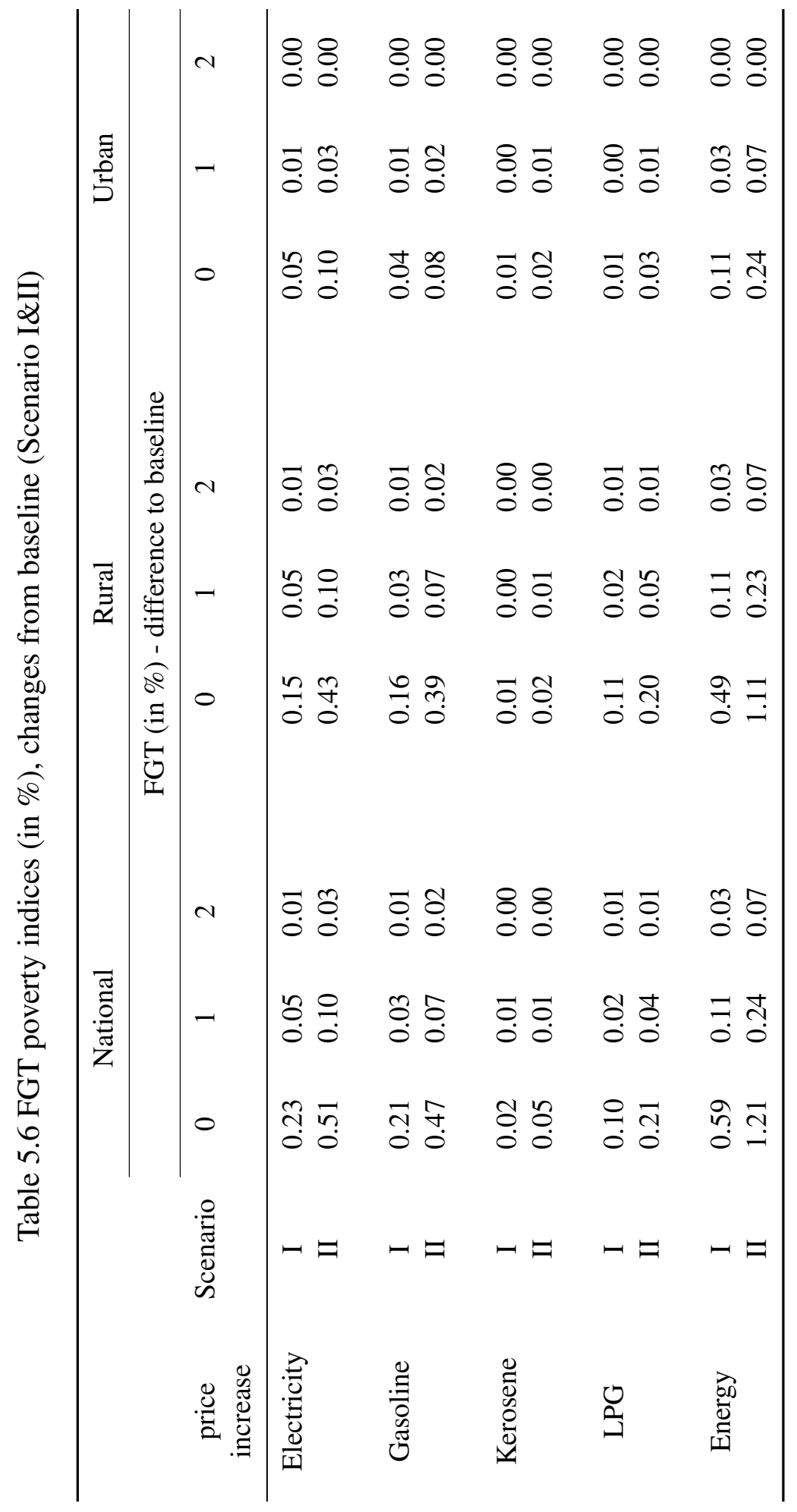




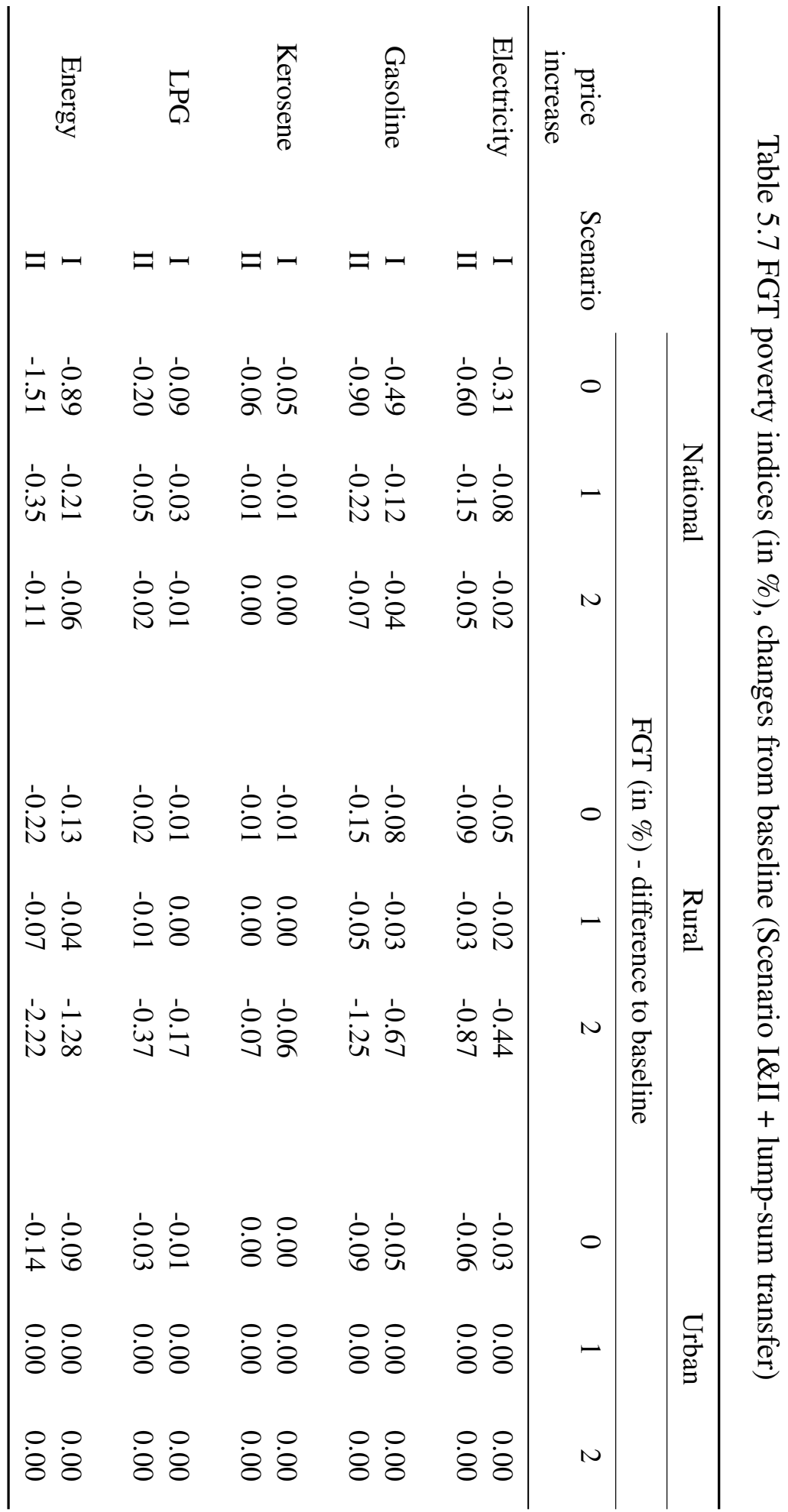


In this regard, the poverty indicators in table 5.6 do not show a large increase, but absolute numbers are important to consider. ${ }^{12}$ The moderate electricity price increases in Scenario I raise the national poverty rate by 0.23 percent, which appears to be very small but absolutely about half a million people will be additionally classified as poor, most of them in rural areas. For gasoline price increases, we observe a similar magnitude. Although the poverty effects are relatively small due to low usage rates and budget shares of modern energy, there is a significant and growing number of households which are negatively affected by price increases. Most of these households are living in urban areas but with more rural households using modern energy items and private transport vehicles this finding is unlikely to be stable over time. Non-negligible effects can also be found for LPG price increases, which demonstrates its importance as the new major cooking fuel for Indonesian households.

In the multiple price change scenario, changing prices for all four energy items simultaneously, we observe a general progressive pattern, dominated by electricity and in particular gasoline (Figure 5.8). Nevertheless, multiple price changes for the energy items under consideration would result in serious welfare losses for poor households of close to 1.5 and 3 percent of total expenditures for scenario I and II respectively. In particular for Scenario II, higher usage rates and associated substitution options for higher income households turn the distributional effect less progressive. On the other hand, it also means there is less need to redistribute tax revenue to higher income households since they are capable of dealing with price increases. In Scenario II, poverty effects are quite strong with increases of 0.6 and 1.2 percentage points in the poverty rate for Scenario I and II respectively.

To shed some light on potential effects through redistribution if energy taxes of 20 percent are the drivers behind the price increases, we simulate a full redistribution of tax revenues via lump-sum transfers to households. For all four energy items, redistribution of tax revenue leads to welfare gains for low income households (figure 5.9). Electricity and gasoline taxes raise substantial revenue that could lead to quite large welfare gains for the majority of the population if proper redistribution schemes can be identified. Welfare gains are also reflected in poverty indicators, which improve for all scenarios (table 5.7). As much as urban households are disproportionately hit by energy price hikes, there are also more urban households which benefit from transfer payments. Since universal lump-sum transfers are unlikely to be implemented, more realistic redistribution schemes would rely on social welfare programs, which directly target the poor. ${ }^{13}$

\footnotetext{
${ }^{12}$ Second-order welfare effects are used in the computation of post-reform poverty indices.

${ }^{13}$ The survey data does offer information on social welfare programs but unfortunately their coverage is low and therefore unsuitable for a large scale redistribution scheme.
} 

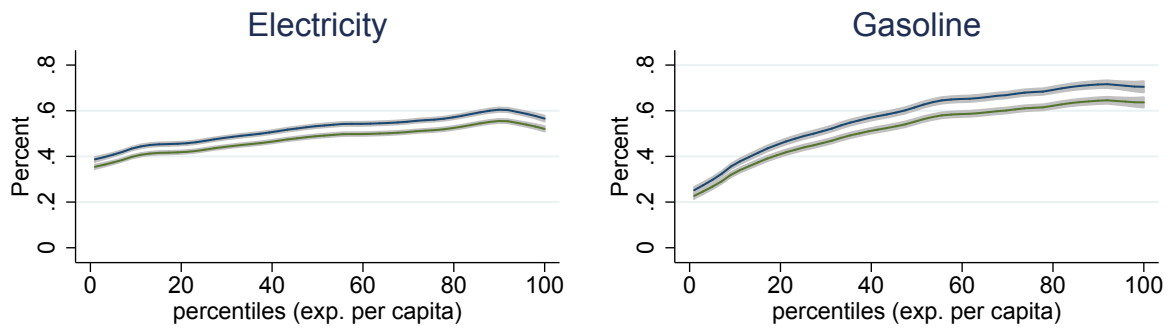

Kerosene

LPG
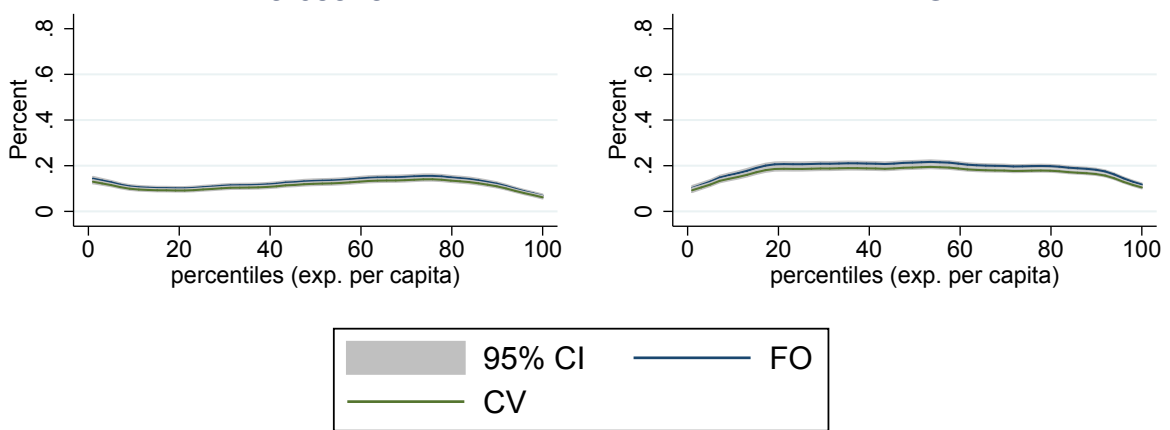

Fig. 5.6 Welfare effects Scenario I
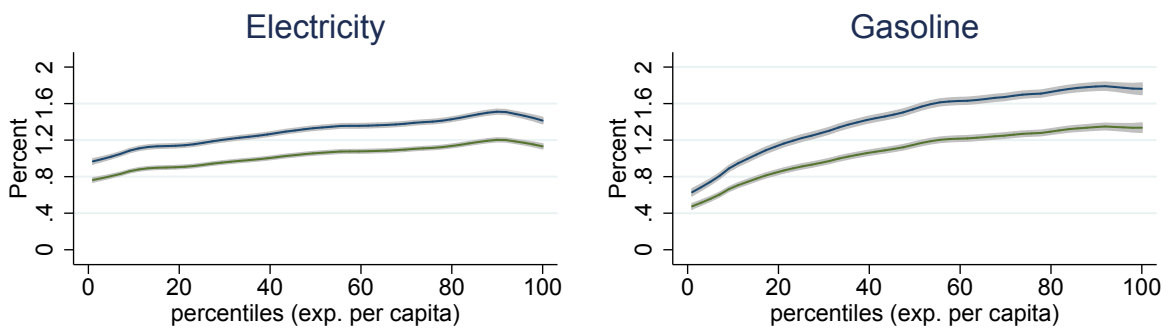

Kerosene

\section{LPG}
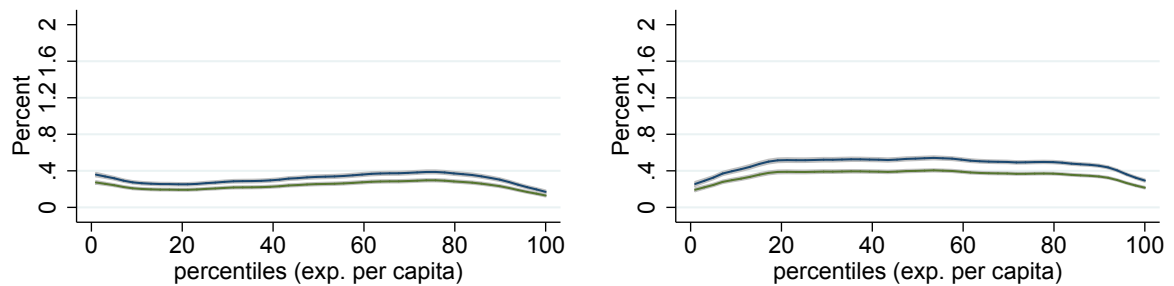

$95 \% \mathrm{Cl}$

FO

CV

Fig. 5.7 Welfare effects Scenario II 


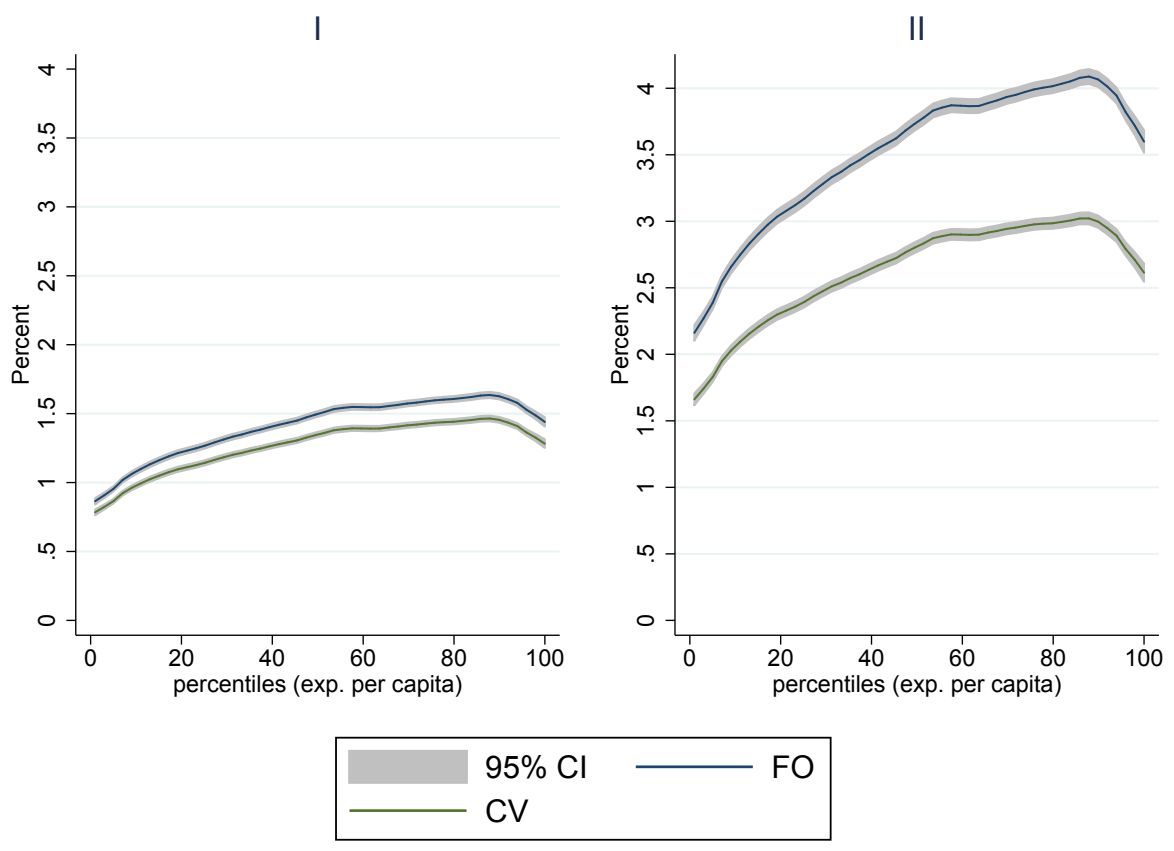

Fig. 5.8 Welfare effects simultaneous increase Scenarios I \& II
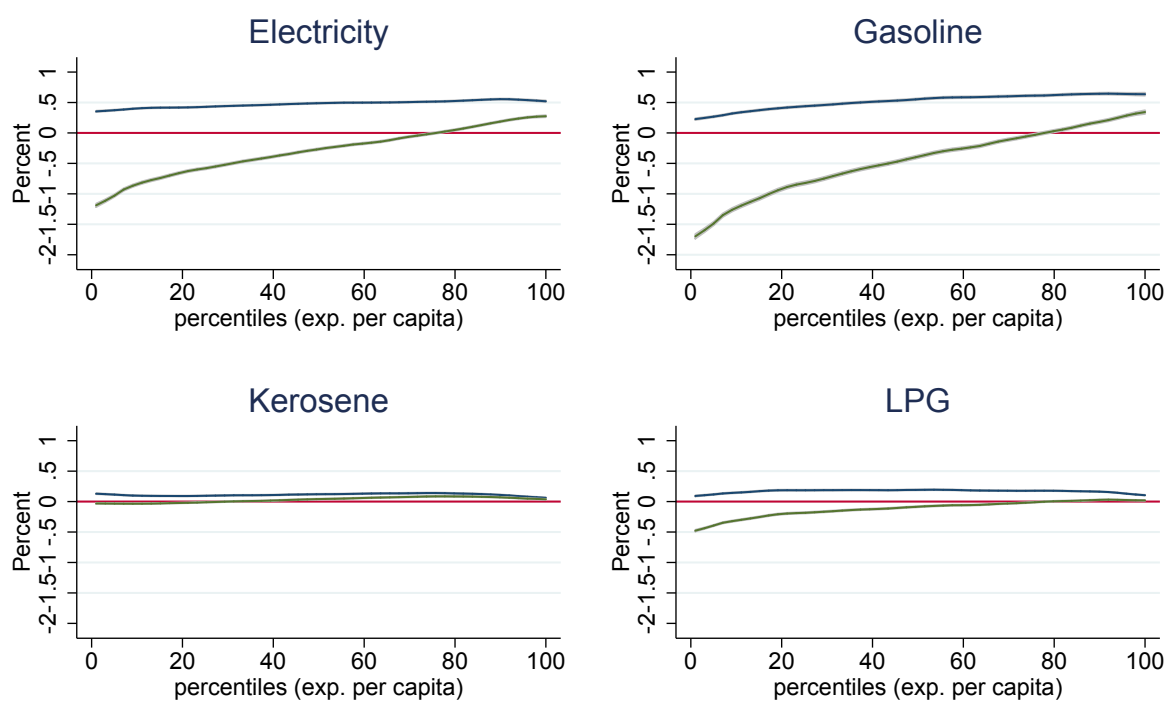

$95 \% \mathrm{Cl}$

CV

CV + lump-sum

Fig. 5.9 Welfare effects with lump-sum transfers Scenario I 


\subsubsection{Energy poverty}

Based on the estimated price elasticity matrices, we calculate the quantities households reduce per capita in response to price increases for the respective scenarios. Based on these behavioral responses, we calculate the FGT class of indices for both scenarios and energy poverty lines and find significant effects on energy poverty resulting from lower energy use. Table 5.8 displays the change in FGT indicators for the two simulated scenarios. We find considerable effects of price increases on the poverty rate with particularly tremendous effects of electricity and LPG price increases. LPG price increases result in higher energy poverty levels than kerosene price increases, the latter with the expected smallest effects. For all modern fuels, the increase in energy poverty is larger in rural areas despite the higher urban usage rates. As discussed in the interpretation of estimated price elasticities, complementarity between LPG and gasoline implies reduced domestic energy use also in the case of gasoline price increases. Energy poverty increases due to gasoline price changes are about 25 percent of LPG price increase induced energy poverty, a value close to the estimated cross-price elasticity. Redistribution of tax revenues does not change energy poverty significantly since households are projected to spend most of the extra income on other goods than energy. ${ }^{14}$

These findings reflect the downside of consumer responses and associated smaller calculated welfare effects through substitution. While the microeconomic welfare metric tells us only about utility based monetary effects, other welfare dimensions such as energy poverty are not directly addressed in a standard welfare assessment. Although one could argue that households take energy requirements into account in consumption decisions, they are also likely to substitute modern for traditional fuels when prices rise. Additionally, they may not internalize all associated external costs such as health issues caused by air pollution. Unfortunately, our data does not permit us to quantify the exact nature of substitution between modern and traditional fuels when prices change. However, a simple estimation of firewood demand in a Working-Leser form (Leser, 1963; Working, 1943), depending on prices of modern energy, household total expenditures $x$ and household characteristics $H$ sheds some light on this issue:

$$
w_{f w d}=\alpha_{f w d}+\sum_{j=1}^{n} \gamma_{i j} \ln p_{j}+\ln (x)+H
$$

Due to a significant share of zero firewood budget shares, equation (5.26) is estimated as a heckman selection model with additional variables reflecting lighting and cooking fuel choice

\footnotetext{
${ }^{14}$ Results are almost identical to the scenario without redistribution and therefore not reported.
} 


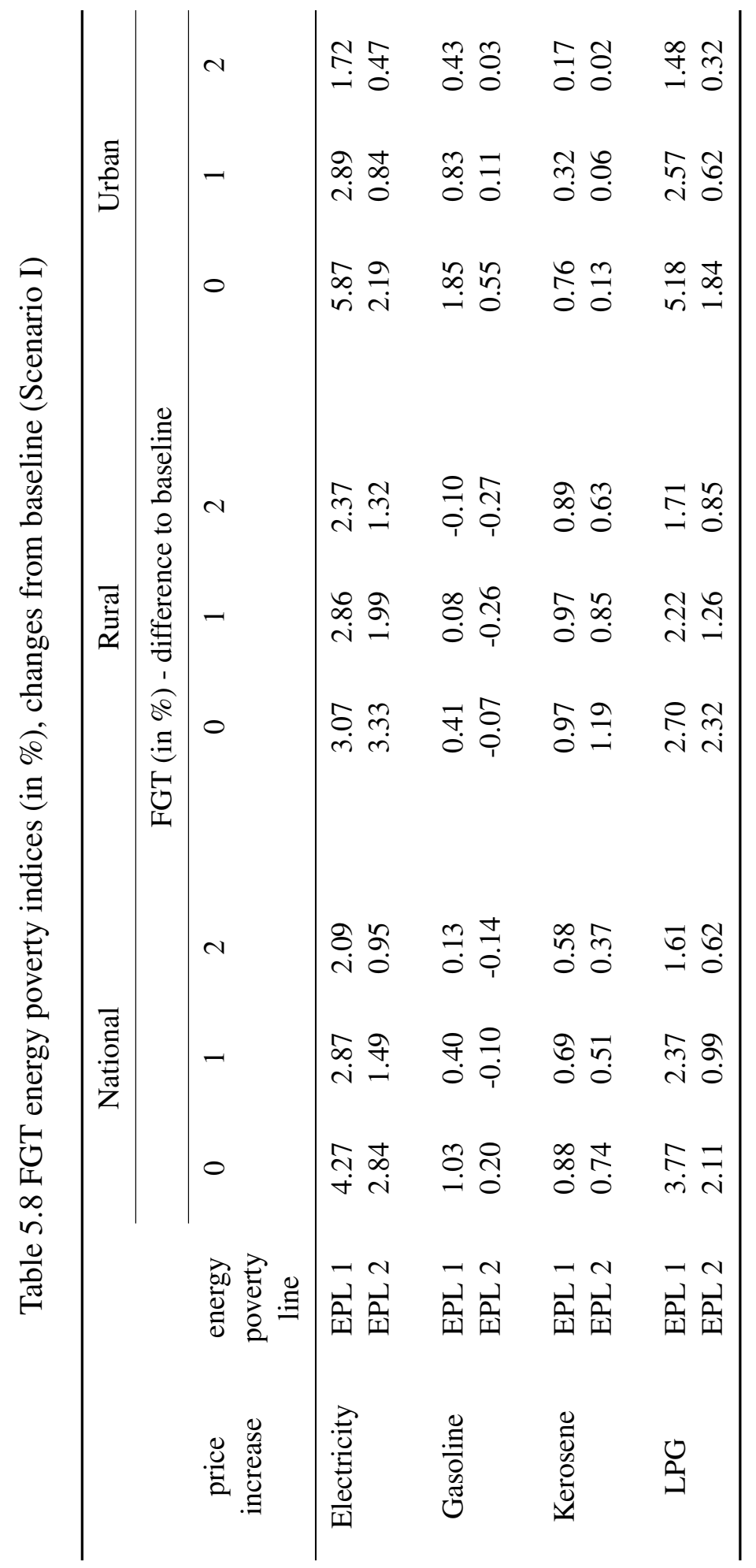




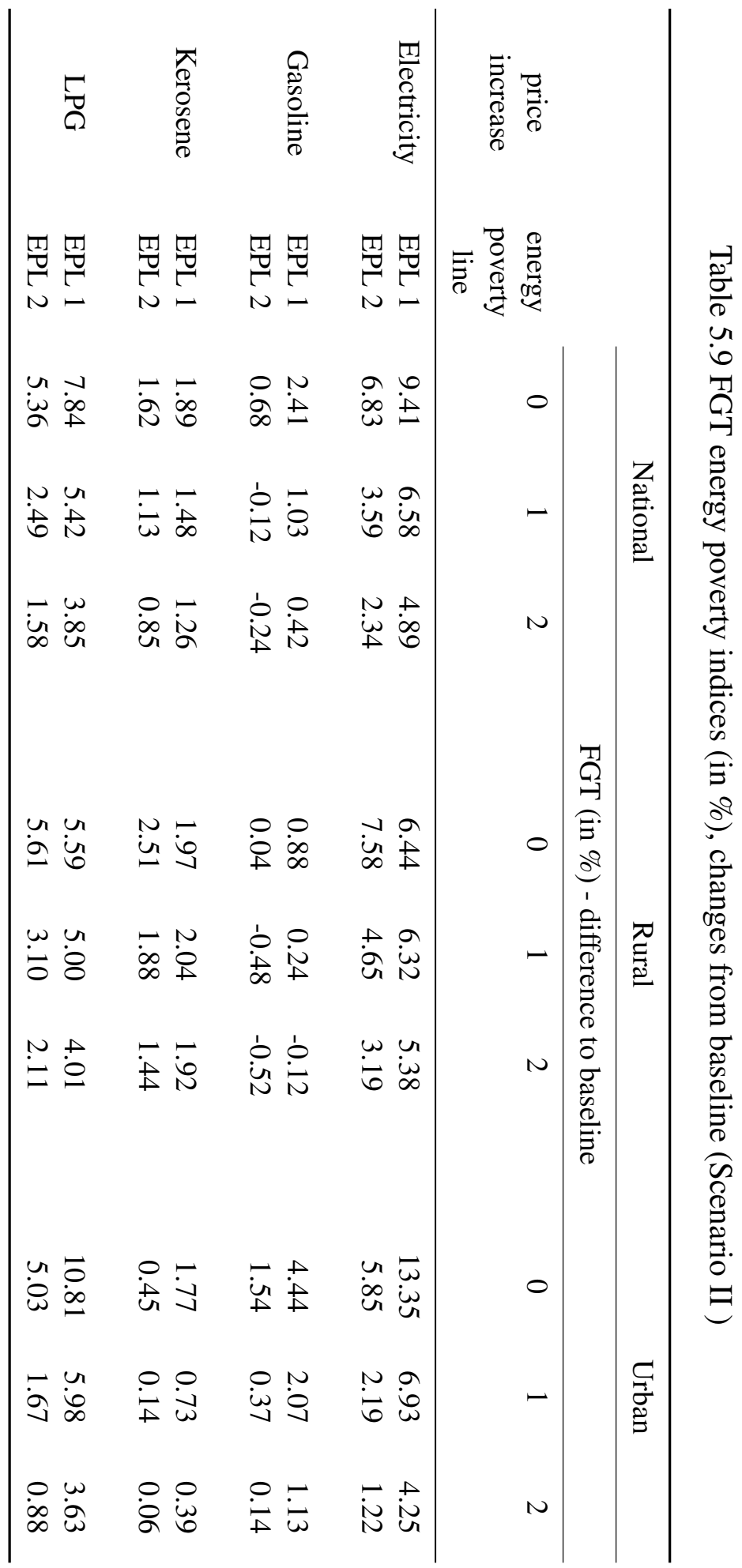


in the identifying equation. ${ }^{15}$ The estimated firewood cross-price elasticities (table 5.10) exhibit an expected substitutability between other domestically used energy items electricity, kerosene, LPG and firewood. This serves as some evidence, although not integrated into the rest of the analysis due to data constraints, that households are very likely to increase the use of traditional fuels when prices of modern, domestically used energy items rise. Households may not reduce domestically used energy as strong as energy poverty indices suggest, but instead move towards traditional fuels.

Table 5.10 Firewood cross-price elasticities

\begin{tabular}{lcccc}
\hline & \multicolumn{4}{c}{ prices } \\
\cline { 2 - 5 } & Electricity & Gasoline & Kerosene & LPG \\
\hline firewood & 0.11 & -2.29 & 0.41 & 0.28 \\
\hline
\end{tabular}

\subsection{4 $\mathrm{CO}_{2}$ emission effects}

Since households respond to price changes, the effect on household related carbon emissions are expected to be negative with the estimated price elasticities. How large this effect is for the single energy items can be seen in table 5.11. The elasticity of household carbon emissions relative to price changes is the highest for electricity and gasoline due to the high carbon intensity of electricity and high budget shares for gasoline. Moderate price changes of 20 percent for electricity and gasoline lead to already substantial emission reductions at the order of 4.7 and 5.4 percent of household carbon emissions. Redistribution of tax revenues does not change this picture tremendously with on average 10 percent lower reductions, although absolute reductions will decline with the size of the price change and redistributive transfers.

Although these emission reductions appear to be rather large, they have to be put into perspective. They cannot be readily compared to domestic production based emissions, which are about 25 percent larger as demand side emissions. ${ }^{16}$ Household emissions are in turn only 65 percent of demand side emissions, which includes imported emissions under the domestic technology assumption. ${ }^{17}$ Relative to total production $\mathrm{CO}_{2}$ emissions, households

\footnotetext{
${ }^{15} \mathrm{As}$ in the case of demand system coefficients we do not report results due to the difficult economic interpretation and report elasticities instead.

${ }^{16}$ Domestic demand emissions (including imports) are only 80 percent of domestic production emissions, the rest gets exported.

${ }^{17}$ Demand side emissions include expenditures from households, government, gross fixed capital formation and changes in inventories and valuables.
} 
are responsible for about 50 percent. Additionally, the household survey covers only about 50 percent of demand emissions calculated with the IO data. How to finally interpret the emission reductions is a question of how to deal with the large disparity between survey and IO data. If the survey data is scaled up to match the total aggregate consumption in the IO tables, the calculated relative reductions of household emissions remain identical. Relative to total domestic, production based $\mathrm{CO}_{2}$ emissions, the estimated reductions need to be adjusted downwards by 50 percent if the survey data is scaled or 75 percent when it remains unscaled.

Table 5.11 Household $\mathrm{CO}_{2}$-price elasticities

\begin{tabular}{cccccc} 
Scenario & electricity & gasoline & kerosene & LPG & energy \\
\hline price increase & -0.238 & -0.272 & 0.022 & -0.141 & -0.612 \\
price increase + lump-sum & -0.214 & -0.243 & 0.024 & -0.133 & -0.555
\end{tabular}

\subsection{Conclusion}

Consumer energy price increases affect richer households more in relative and consequentially also in absolute terms. On the one hand, our findings confirm prior studies, which are based on observed demand and the assumption of zero substitution between goods, on the progressive direction of this effect for electricity and gasoline. On the other hand, we find neutral effects for Kerosene and LPG and smaller welfare losses for electricity and gasoline by employing second-order welfare estimates. The calculated first-order effects for electricity and gasoline are on average 10 and 20 percent larger in Scenario I and II, which may seem small in relative terms but are substantial differences in absolute terms. First-order effects particularly overestimate welfare losses for the upper part of the income distribution where small percentage changes in relative terms translate into large absolute monetary amounts. For redistribution this has important consequences, since richer households are estimated to be capable of dealing with increasing energy prices and therefore need less compensation. This holds particularly for gasoline, which is at the center of the subsidy debate and a major fuel used by households. Due to lower usage rates for low income households, also the poverty impacts are moderate when prices change by small amounts. Despite these supposedly small relative changes, a non-marginal number of low income households are actually highly affected by energy price changes. Additionally, there is a large and growing number of households who are vulnerable to large energy price increases, which appear to be quite possible when energy subsidies are completely abolished.

Eventually, redistribution of taxes or saved subsidies is crucial of turning this story around into welfare gains and poverty reduction. Although the simulated lump-sum transfers are 
already quite effective in absorbing large welfare shocks, more targeted transfers are certainly desirable from an equity and fiscal perspective. Although the estimation of a demand system proves to be already useful for calculating welfare effects, the consideration of energy poverty and household related carbon emissions makes it additionally valuable. Without changes in quantities demanded, energy poverty would not change in our expenditure based definition of energy poverty. Additionally to welfare losses from energy price increases, households also suffer from a lack of modern energy items which could trigger additional negative impacts such as adverse health effects through the shift to traditional sources of energy. By simulating energy item quantities, we find substantial effects of price increases for energy used domestically on energy poverty. Somewhat surprisingly, this also holds for gasoline since the estimation reveals a complementary relationship to LPG. Particularly problematic for energy poverty is this complementarity for low income households, for which these energy goods have much more of a necessity character than for high income households. The resulting divergence of relatively small estimated second order welfare effects and large impacts on energy poverty reflects a weakness of standard welfare metrics which assumes complete information and the absence of negative externalities. Also redistribution of tax revenue is only partially able to deal with rising energy poverty in our model since households spend most of the transfer income on other goods than modern energy. The resulting increased use of traditional biomass fuels such as firewood is certainly critical from both a health perspective through indoor air pollution and $\mathrm{CO}_{2}$ emission perspective through deforestation.

The reduction of carbon emissions embodied in household consumption is the flip side of the coin to energy poverty increases and welfare losses. The pricing of direct energy use by households leads to substantial emissions reductions at the order of 0.28 percent for each percent increase in prices for gasoline or electricity. Analog to the results for energy poverty, where households only partially increase their energy use due to redistributive transfers, the adverse emission effect of redistribution is very limited with 10 percent smaller reductions. These emission reductions are, as is the nature of our data and model, exclusively embodied in household consumption. When comparing to production based $\mathrm{CO}_{2}$ emissions, which are usually referred to in other studies, the effects are about half of what is estimated. For all simulated effects, we have to keep in mind that households can only reduce energy use to a certain minimum level. This and the nature of our modeling framework restricts the interpretation of results to the very short run perspective. 



\section{References}

Ahmad, E. and Stern, N. (1984). The theory of reform and indian indirect taxes. Journal of Public Economics, 25(3):259-298.

Akimoto, K., Sano, F., Homma, T., Oda, J., Nagashima, M., and Kii, M. (2010). Estimates of GHG emission reduction potential by country, sector, and cost. Energy Policy, 38(7):33843393.

Althor, G., Watson, J. E. M., and Fuller, R. A. (2016). Global mismatch between greenhouse gas emissions and the burden of climate change. Scientific Reports, 6:20281.

Angelou, N., Elizondo Azuela, G., Portale, E., Jaques Goldenberg, I., Bhatia, M., Banerjee, S. G., Bushueva, I., Inon, J. G., and Sarkar, A. (2013). Global tracking framework. Technical Report 77889, The World Bank.

Arze del Granado, F. J., Coady, D., and Gillingham, R. (2012). The Unequal Benefits of Fuel Subsidies: A Review of Evidence for Developing Countries. World Development, 40(11):2234-2248.

Banks, J., Blundell, R., and Lewbel, A. (1996). Tax Reform and Welfare Measurement: Do We Need Demand System Estimation? The Economic Journal, 106(438):1227-1241.

Banks, J., Blundell, R., and Lewbel, A. (1997). Quadratic Engel Curves and Consumer Demand. Review of Economics and Statistics, 79(4):527-539.

Belausteguigoitia, J. C. (2014). Economic Analyses to Support the Environmental Fiscal Reform. Technical report, Centro Mario Molina.

Bin, S. and Dowlatabadi, H. (2005). Consumer lifestyle approach to US energy use and the related CO2 emissions. Energy Policy, 33(2):197-208.

Bovenberg, A. L. (1999). Green tax reforms and the double dividend: an updated reader's guide. International Tax and Public Finance, 6(3):421-443.

Bowen, A. and Hepburn, C. (2014). Green growth: an assessment. Oxford Review of Economic Policy, 30(3):407-422.

Brännlund, R. and Nordström, J. (2004). Carbon tax simulations using a household demand model. European Economic Review, 48(1):211-233.

Bull, N., Hassett, K. A., and Metcalf, G. E. (1994). Who Pays Broad-Based Energy Taxes? Computing Lifetime and Regional Incidence. The Energy Journal, 15(3):145-164. 
Carraro, C., Favero, A., and Massetti, E. (2012). Investments and public finance in a green, low carbon, economy. Energy Economics, 34:S15-S28.

Chen, Z. and Yen, S. T. (2005). On bias correction in the multivariate sample-selection model. Applied Economics, 37(21):2459-2468.

Clements, M. B. J., Coady, D., Fabrizio, M. S., Gupta, M. S., Alleyne, M. T. S. C., and Sdralevich, M. C. A. (2013). Energy Subsidy Reform: Lessons and Implications. International Monetary Fund.

Cole, D. H. (2015). Advantages of a polycentric approach to climate change policy. Nature Climate Change, 5(2):114-118.

Collier, P. and Venables, A. J. (2012). Greening Africa? Technologies, endowments and the latecomer effect. Energy Economics, 34, Supplement 1:S75-S84.

CONEVAL (2014). Informe de Pobreza en México. Technical report, Consejo Nacional de Evaluación de la Política de Desarrollo Social (CONEVAL).

Copeland, B. R. and Taylor, M. S. (2005). Trade and the environment: Theory and evidence. Princeton University Press.

Cox, A., Collins, A., Woods, L., and Ferguson, N. (2012). A household level environmental Kuznets curve? Some recent evidence on transport emissions and income. Economics Letters, 115(2):187-189.

Dartanto, T. (2013). Reducing fuel subsidies and the implication on fiscal balance and poverty in Indonesia: A simulation analysis. Energy Policy, 58:117-134.

Dasgupta, S., Laplante, B., Meisner, C., Wheeler, D., and Yan, J. (2008). The impact of sea level rise on developing countries: a comparative analysis. Climatic Change, 93(3-4):379-388.

Datt, G. and Ravallion, M. (2011). Has India's Economic Growth Become More Pro-Poor in the Wake of Economic Reforms? The World Bank Economic Review, 25(2):157-189.

Datt, G., Ravallion, M., and Murgai, R. (2016). Growth, Urbanization and Poverty Reduction in India. Working Paper 21983, National Bureau of Economic Research.

Datta, A. (2010). The incidence of fuel taxation in India. Energy Economics, 32, Supplement $1:$ S26-S33.

Davis, L. W., Fuchs, A., and Gertler, P. (2014). Cash for Coolers: Evaluating a Large-Scale Appliance Replacement Program in Mexico. American Economic Journal: Economic Policy, 6(4):207-38.

Deaton, A. (1988). Quality, Quantity, and Spatial Variation of Price. The American Economic Review, 78(3):418-430.

Deaton, A. (1997). The analysis of household surveys: a microeconometric approach to development policy. World Bank Publications. 
Deaton, A. (2005). Measuring Poverty in a Growing World (or Measuring Growth in a Poor World). Review of Economics and Statistics, 87(1):1-19.

Deaton, A. and Muellbauer, J. (1980a). An Almost Ideal Demand System. The American Economic Review, 70(3):312-326.

Deaton, A. and Muellbauer, J. (1980b). Economics and consumer behavior. Cambridge University Press.

Dell, M., Jones, B. F., and Olken, B. A. (2009). Temperature and Income: Reconciling New Cross-Sectional and Panel Estimates. American Economic Review, 99(2):198-204.

Dercon, S. (2014). Is Green Growth Good for the Poor? The World Bank Research Observer, 29(2):163-185.

Deschenes, O. (2010). Climate Policy and Labor Markets. Working Paper 16111, National Bureau of Economic Research.

Dinan, T. M. and Rogers, D. L. (2002). Distributional Effects of Carbon Allowance Trading: How Government Decisions Determine Winners and Losers. National Tax Journal, 55(2):199-221.

Dinda, S. (2004). Environmental Kuznets Curve Hypothesis: A Survey. Ecological Economics, 49(4):431-455.

Dollar, D., Kleineberg, T., and Kraay, A. (2016). Growth still is good for the poor. European Economic Review.

Dollar, D. and Kraay, A. (2002). Growth is Good for the Poor. Journal of Economic Growth, 7(3):195-225.

Dreze, J. and Sen, A. (2013). An Uncertain Glory: India and its Contradictions. Penguin UK.

Durand-Lasserve, O., Campagnolo, L., Chateau, J., and Dellink, R. (2015). Modelling of distributional impacts of energy subsidy reforms. OECD Environment Working Papers, Organisation for Economic Co-operation and Development, Paris.

Ecker, O. and Qaim, M. (2011). Analyzing Nutritional Impacts of Policies: An Empirical Study for Malawi. World Development, 39(3):412-428.

Edmonds, J., Calvin, K., Clarke, L., Kyle, P., and Wise, M. (2012). Energy and technology lessons since rio. Energy Economics, 34:S7-S14.

Elzen, M. G. J. d., Olivier, J. G. J., Höhne, N., and Janssens-Maenhout, G. (2013). Countries' contributions to climate change: effect of accounting for all greenhouse gases, recent trends, basic needs and technological progress. Climatic Change, 121(2):397-412.

Fan, J. and Gijbels, I. (1996). Local Polynomial Modelling and Its Applications: Monographs on Statistics and Applied Probability 66. CRC Press.

Fankhauser, S., Sehlleier, F., and Stern, N. (2008). Climate change, innovation and jobs. Climate Policy, 8(4):421-429. 
Feldstein, M. S. (1972). Distributional Equity and the Optimal Structure of Public Prices. The American Economic Review, 62(1/2):32-36.

Flues, F. and Thomas, A. (2015). The distributional effects of energy taxes. OECD Taxation Working Papers.

Fomby, T., Ikeda, Y., and Loayza, N. V. (2013). The Growth Aftermath of Natural Disasters. Journal of Applied Econometrics, 28(3):412-434.

Foster, V., Tre, Jean-Philippe, and Wodon, Quentin (2000). Energy Prices, Energy Efficiency, and Fuel Poverty. Technical report, World Bank.

Friedman, J. and Levinsohn, J. (2002). The Distributional Impacts of Indonesia's Financial Crisis on Household Welfare: A "Rapid Response" Methodology. The World Bank Economic Review, 16(3):397-423.

Frondel, M., Ritter, N., Schmidt, C. M., and Vance, C. (2010). Economic impacts from the promotion of renewable energy technologies: The German experience. Energy Policy, 38(8):4048-4056.

Fullerton, D. (2008). Distributional Effects of Environmental and Energy Policy: An Introduction. Working Paper 14241, National Bureau of Economic Research.

Fullerton, D. (2011). Six Distributional Effects of Environmental Policy. Working Paper 16703, National Bureau of Economic Research.

Fullerton, D. and Heutel, G. (2007). The general equilibrium incidence of environmental taxes. Journal of Public Economics, 91(3-4):571-591.

Fullerton, D. and Heutel, G. (2011). Analytical General Equilibrium Effects of Energy Policy on Output and Factor Prices. The B.E. Journal of Economic Analysis \& Policy, 10(2).

Fullerton, D. and Monti, H. (2013). Can pollution tax rebates protect low-wage earners? Journal of Environmental Economics and Management, 66(3):539-553.

Garbaccio, R. F., Ho, M. S., and Jorgenson, D. W. (2000). The Health Effects of Controlling Carbon Emission in China. In Ancillary Benefits and Costs of Greenhouse Gas Mitigation. Organisation for Economic Co-operation and Development, Paris.

Gillingham, R., Newhouse, D. L., Coady, D., Kpodar, K., El-Said, M., and Medas, P. A. (2006). The Magnitude and Distribution of Fuel Subsidies; Evidence From Bolivia, Ghana, Jordan, Mali, and Sri Lanka. IMF Working Paper 06/247, International Monetary Fund.

Golley, J. and Meng, X. (2012). Income inequality and carbon dioxide emissions: The case of Chinese urban households. Energy Economics, 34(6):1864-1872.

Gonzalez, F. (2012). Distributional effects of carbon taxes: The case of Mexico. Energy Economics, 34(6):2102-2115.

Goulder, L. H. (1995). Environmental taxation and the double dividend: a reader's guide. International tax and public finance, 2(2):157-183. 
Grainger, C. A. and Kolstad, C. D. (2010). Who Pays a Price on Carbon? Environmental and Resource Economics, 46(3):359-376.

Grossman, G. M. and Krueger, A. B. (1994). Economic growth and the environment. Working Paper 4634, National Bureau of Economic Research.

Gundimeda, H. and Köhlin, G. (2008). Fuel demand elasticities for energy and environmental policies: Indian sample survey evidence. Energy Economics, 30(2):517-546.

Hallegatte, S., Heal, G., Fay, M., and Treguer, D. (2011). From Growth to Green Growth-A Framework. Policy Research Working Papers. The World Bank.

Heckman, J. J. (1976). The Common Structure of Statistical Models of Truncation, Sample Selection and Limited Dependent Variables and a Simple Estimator for Such Models, volume 5 of Annals of Economic and Social Measurement, pages 475-492. NBER.

Heckman, J. J. (1979). Sample Selection Bias as a Specification Error. Econometrica, 47(1):153-161.

Heerden, J. v., Gerlagh, R., Blignaut, J., Horridge, M., Hess, S., Mabugu, R., and Mabugu, M. (2006). Searching for Triple Dividends in South Africa: Fighting CO2 pollution and poverty while promoting growth. The Energy Journal, 27(2):113-141.

Heien, D. and Wessells, C. R. (1990). Demand Systems Estimation with Microdata: A Censored Regression Approach. Journal of Business \& Economic Statistics, 8(3):365-371.

Heil, M. T. and Selden, T. M. (2001). Carbon emissions and economic development: future trajectories based on historical experience. Environment and Development Economics, 6(1):63-83.

Herendeen, R. and Tanaka, J. (1976). Energy cost of living. Energy, 1(2):165-178.

Hertwich, E. G. and Peters, G. P. (2009). Carbon Footprint of Nations: A Global, TradeLinked Analysis. Environmental science \& technology, 43(16):6414-6420.

Hicks, J. (1939). Value and Capital. Clarendon Press, Oxford.

Holtz-Eakin, D. and Selden, T. M. (1995). Stoking the fires? CO2 emissions and economic growth. Journal of Public Economics, 57(1):85-101.

IEA (2011). World Energy Outlook 2011. International Energy Agency.

IEA (2014). World Energy Outlook 2014. Organisation for Economic Co-operation and Development, Paris.

IEA (2015). India Energy Outlook - Special Report. Technical report, International Energy Agency.

International Monetary Fund (2016). International Financial Statistics.

IPCC (2005). Safeguarding the ozone layer and the global climate system: Issues related to hydrofluorocarbons and perfluorocarbons. IPCC Special Report. 
IPCC (2013). Anthropogenic and Natural Radiative Forcing., pages 73-79. Cambridge University Press, Cambridge, United Kingdom and New York, NY, USA.

IPCC (2013). Summary for Policymakers. In Climate change 2013: The Physical Science Basis. Contribution of working group I to the Fifth Assessment Report of the Intergovernmnetal Panel on climate Change. IPCC.

IPCC (2014). Climate Change 2014: Impacts, Adaptation, and Vulnerability. Part B: Regional Aspects., page 688. Cambridge University Press, Cambridge, United Kingdom and New York, NY, USA,.

IRENA (2015). Renewable Power Generation Costs in 2014. Technical report, International Renewable Energy Agency.

Jakob, M., Steckel, J. C., Flachsland, C., and Baumstark, L. (2015). Climate finance for developing country mitigation: blessing or curse? Climate and Development, 7(1):1-15.

Jakob, M., Steckel, J. C., Klasen, S., Lay, J., Grunewald, N., Martínez-Zarzoso, I., Renner, S., and Edenhofer, O. (2014). Feasible mitigation actions in developing countries. Nature Climate Change, 4(11):961-968.

Jorgenson, D. W., Goettle, R. J., Ho, M. S., and Wilcoxen, P. J. (2013). Double Dividend: Environmental Taxes and Fiscal Reform in the United States. MIT Press.

Kahn, M. E. (1998). A household level environmental Kuznets curve. Economics Letters, 59(2):269-273

Kerkhof, A. C., Nonhebel, S., and Moll, H. C. (2009). Relating the environmental impact of consumption to household expenditures: An input-output analysis. Ecological Economics, 68(4):1160-1170.

Kesicki, F. and Ekins, P. (2012). Marginal abatement cost curves: a call for caution. Climate Policy, 12(2):219-236.

Knutti, R., Rogelj, J., Sedláček, J., and Fischer, E. M. (2016). A scientific critique of the two-degree climate change target. Nature Geoscience, 9(1):13-18.

Kok, R., Benders, R. M. J., and Moll, H. C. (2006). Measuring the environmental load of household consumption using some methods based on input-output energy analysis: A comparison of methods and a discussion of results. Energy Policy, 34(17):2744-2761.

Komives, K., Johnson, T. M., Halpern, J. D., Luis, J. A., and Scott, J. R. (2009). Residential electricity subsidies in Mexico : exploring options for reform and for enhancing the impact on the poor. Technical Report 47107, The World Bank.

Labandeira, X. and Labeaga, J. (1999). Combining input-output analysis and microsimulation to assess the effects of carbon taxation on Spanish households. Fiscal Studies, 20(3):305-320.

Labandeira, X. and Labeaga, J. M. (2002). Estimation and control of Spanish energy-related CO2 emissions: an input-output approach. Energy Policy, 30(7):597-611. 
Labandeira, X., Labeaga, J. M., and Rodríguez, M. (2006). A Residential Energy Demand System for Spain. Energy Journal, 27(2):87-111.

Lehr, U., Lutz, C., and Edler, D. (2012). Green jobs? Economic impacts of renewable energy in Germany. Energy Policy, 47:358-364.

Lenzen, M. (1998a). Energy and greenhouse gas cost of living for Australia during 1993/94. Energy, 23(6):497-516.

Lenzen, M. (1998b). Primary energy and greenhouse gases embodied in Australian final consumption: an input-output analysis. Energy Policy, 26(6):495-506.

Lenzen, M., Wier, M., Cohen, C., Hayami, H., Pachauri, S., and Schaeffer, R. (2006). A comparative multivariate analysis of household energy requirements in Australia, Brazil, Denmark, India and Japan. Energy, 31(2-3):181-207.

Leontief, W. (1970). Environmental repercussions and the economic structure: an inputoutput approach. The review of economics and statistics, pages 262-271.

Leser, C. E. V. (1963). Forms of Engel Functions. Econometrica, 31(4):694-703.

Levinson, A. and O'Brien, J. (2015). Environmental Engel Curves. Working Paper 20914, National Bureau of Economic Research.

Lewbel, A. and Pendakur, K. (2009). Tricks with Hicks: The EASI Demand System. American Economic Review, 99(3):827-63.

Markandya, A., Armstrong, B. G., Hales, S., Chiabai, A., Criqui, P., Mima, S., Tonne, C., and Wilkinson, P. (2009). Public health benefits of strategies to reduce greenhouse-gas emissions: low-carbon electricity generation. The Lancet, 374(9706):2006-2015.

Mathur, A. and Morris, A. C. (2014). Distributional effects of a carbon tax in broader U.S. fiscal reform. Energy Policy, 66:326-334.

MEMR (2014). Handbook of Energy \& Economic Statistics of Indonesia 2014. Ministry of Energy and Mineral Resources, Jakarta.

Mendelsohn, R., Dinar, A., and Williams, L. (2006). The distributional impact of climate change on rich and poor countries. Environment and Development Economics, null(02):159-178.

Metcalf, G. (2015). A Conceptual Framework for Measuring the Effectiveness of Green Fiscal Reforms. GGKP Working Paper, 7.

Metcalf, G. E. (1999). A Distributional Analysis of Green Tax Reforms. National Tax Journal, 52:655-681.

Minx, J., Wiedmann, T., Wood, R., Peters, G., Lenzen, M., Owen, A., Scott, K., Barrett, J., Hubacek, K., Baiocchi, G., Paul, A., Dawkins, E., Briggs, J., Guan, D., Suh, S., and Ackerman, F. (2009). Input-Output Analysis and Carbon Footprinting: an Overview of Applications. Economic Systems Research, 21(3):187-216. 
Modi, Vijay, Lallement, Dominique, and Saghir, Jamal (2005). Energy Services for the Millennium Development Goals. Technical report, Energy Sector Management Assistance Programme, United Nations Development Programme, UN Millenium Project, and World Bank, New York.

Nauclér, T. and Enkvist, P.-A. (2009). Pathways to a low-carbon economy: Version 2 of the global greenhouse gas abatement cost curve. McKinsey \& Company, 192.

Nikodinoska, D. and Schröder, C. (2016). On the emissions-inequality and emissions-welfare trade-offs in energy taxation: Evidence on the German car fuels tax. Resource and Energy Economics, 44:206-233.

OECD (2011). Towards Green Growth. Organisation for Economic Co-operation and Development, Paris.

OECD (2015). Revisiting the Green Growth Strategy. In OECD Green Growth Studies, pages 46-71. Organisation for Economic Co-operation and Development.

Olivia, S. and Gibson, J. (2008). Household Energy Demand and the Equity and Efficiency Aspects of Subsidy Reform in Indonesia. The Energy Journal, 29(1):21-39.

Olivier, J. G., Janssens-Maenhout, G., Muntean, M., and Peters, J. A. (2015). Trends in Global CO2 Emissions: 2015 Report. Technical report, PBL Netherlands Environmental Assessment Agency.

Ostrom, E. (2010). Polycentric systems for coping with collective action and global environmental change. Global Environmental Change, 20(4):550-557.

Pachauri, S. (2004). An analysis of cross-sectional variations in total household energy requirements in India using micro survey data. Energy Policy, 32(15):1723-1735.

Pachauri, S. and Spreng, D. (2011). Measuring and monitoring energy poverty. Energy Policy, 39(12):7497-7504.

Parikh, J. K., Panda, M. K., and Murthy, N. (1997). Consumption patterns by income groups and carbon dioxide implications for india: 1990-2010. International Journal of Global Energy Issues, 9(4-6):237-255.

Parry, I. W. H. (2003). Fiscal Interactions and the Case for Carbon Taxes Over Grandfathered Carbon Permits. Oxford Review of Economic Policy, 19(3):385-399.

Pedersen, L. H. (2000). The dynamics of green consumption: a matter of visibility? Journal of Environmental Policy and Planning, 2(3):193-210.

Pereira, A. M., Pereira, R. M., and Rodrigues, P. G. (2016). A new carbon tax in Portugal: A missed opportunity to achieve the triple dividend? Energy Policy, 93:110-118.

Peters, G. P., Minx, J. C., Weber, C. L., and Edenhofer, O. (2011). Growth in emission transfers via international trade from 1990 to 2008. Proceedings of the National Academy of Sciences, 108(21):8903-8908.

Pindyck, R. S. (2013). Climate Change Policy: What Do the Models Tell Us? Journal of Economic Literature, 51(3):860-72. 
Pitt, M. M. (1985). Equity, externalities and energy subsidies The case of kerosine in Indonesia. Journal of Development Economics, 17(3):201-217.

Popp, D. (2002). Induced Innovation and Energy Prices. The American Economic Review, 92(1):160-180.

Popp, D., Newell, R. G., and Jaffe, A. B. (2009). Energy, the Environment, and Technological Change. Working Paper 14832, National Bureau of Economic Research.

Proops, J. L. R., Faber, M., and Wagenhals, G. (1993). Reducing CO2 Emissions. Springer Berlin Heidelberg.

Raddatz, C. (2009). The wrath of God : macroeconomic costs of natural disasters. Technical Report WPS5039, The World Bank.

Rausch, S., Metcalf, G. E., and Reilly, J. M. (2011). Distributional impacts of carbon pricing: A general equilibrium approach with micro-data for households. Energy Economics, 33, Supplement 1:S20-S33.

Rausch, S., Metcalf, G. E., Reilly, J. M., and Paltsev, S. (2010). Distributional Implications of Alternative U.S. Greenhouse Gas Control Measures. The B.E. Journal of Economic Analysis \& Policy, 10(2).

Ravallion, M. and Datt, G. (1996). How Important to India's Poor Is the Sectoral Composition of Economic Growth? The World Bank Economic Review, 10(1):1-25.

Ravallion, M., Heil, M., and Jalan, J. (2000). Carbon emissions and income inequality. Oxford Economic Papers, 52(4):651-669.

Rivers, N. and Schaufele, B. (2015). Salience of carbon taxes in the gasoline market. Journal of Environmental Economics and Management, 74:23-36.

Sanchez, L. F. and Stern, D. I. (2016). Drivers of industrial and non-industrial greenhouse gas emissions. Ecological Economics, 124:17-24.

Schmalensee, R. (2012). From "Green Growth" to sound policies: An overview. Energy Economics, 34, Supplement 1:S2-S6.

Sen, A. (2000). Estimates of Consumer Expenditure and Its Distribution: Statistical Priorities after NSS 55th Round. Economic and Political Weekly, 35(51):4499-4518.

Shafiee, S. and Topal, E. (2009). When will fossil fuel reserves be diminished? Energy policy, 37(1):181-189.

Shah, A. and Larsen, B. (1992). Carbon taxes, the greenhouse effect, and developing countries. Policy Research Working Paper Series 957, The World Bank.

Shah, A. and Whalley, J. (1991). Tax Incidence Analysis of Developing Countries: An Alternative View. The World Bank Economic Review, 5(3):535-552.

Shaw, J. (2014). Time to Tax Carbon. Harvard Magazine. 
Shonkwiler, J. S. and Yen, S. T. (1999). Two-Step Estimation of a Censored System of Equations. American Journal of Agricultural Economics, 81(4):972-982.

Speck, S. (1999). Energy and carbon taxes and their distributional implications. Energy Policy, 27(11):659-667.

Steckel, J. C., Brecha, R. J., Jakob, M., Strefler, J., and Luderer, G. (2013). Development without energy? Assessing future scenarios of energy consumption in developing countries. Ecological Economics, 90:53-67.

Steinberger, J. K. and Roberts, J. T. (2010). From constraint to sufficiency: The decoupling of energy and carbon from human needs, 1975-2005. Ecological Economics, 70(2):425-433.

Stern, D. I. (2004). The Rise and Fall of the Environmental Kuznets Curve. World Development, 32(8):1419-1439.

Stern, N. (1987). The theory of optimal commodity and income taxation. In The Theory of Taxation for Developing Countries. Oxford University Press.

Sterner, T., editor (2011). Fuel Taxes and the Poor: The Distributional Effects of Gasoline Taxation and Their Implications for Climate Policy. RFF Press, New York.

Stokes, D., Linsay, A., Marinopoulos, J., Treloar, A., and Wescott, G. (1994). Household Carbon Dioxide Production in Relation to the Greenhouse Effect. Journal of Environmental Management, 40(3):197-211.

Symons, E., Proops, J., and Gay, P. (1994). Carbon Taxes, Consumer Demand and Carbon Dioxide Emissions: A Simulation Analysis for the UK. Fiscal Studies, 15(2):19-43.

The Atlantic Council (2014). Mexico's Energy Reform: Mexico "Ready to Launch" Predicts Large Foreign Investment and Boost in Manufacturing from Cheaper Electricity. Technical report.

Tiezzi, S. and Verde, S. F. (2016). Differential demand response to gasoline taxes and gasoline prices in the U.S. Resource and Energy Economics, 44:71-91.

Timmer, M. P., Dietzenbacher, E., Los, B., Stehrer, R., and de Vries, G. J. (2015). An Illustrated User Guide to the World Input-Output Database: the Case of Global Automotive Production. Review of International Economics, 23(3):575-605.

UNEP (2011). Towards a Green Economy: Pathways to Sustainable Development and Poverty Eradication - A Synthesis for Policy Makers.

van der Ploeg, F. (2011). Natural Resources: Curse or Blessing? Journal of Economic Literature, 49(2):366-420.

van Vuuren, D. P., Hoogwijk, M., Barker, T., Riahi, K., Boeters, S., Chateau, J., Scrieciu, S., van Vliet, J., Masui, T., Blok, K., Blomen, E., and Kram, T. (2009). Comparison of top-down and bottom-up estimates of sectoral and regional greenhouse gas emission reduction potentials. Energy Policy, 37(12):5125-5139.

Vance, E. (2012). Mexico passes climate-change law. Nature. 
Weber, C. L. and Matthews, H. S. (2008). Quantifying the global and distributional aspects of American household carbon footprint. Ecological Economics, 66(2-3):379-391.

Wei, M., Patadia, S., and Kammen, D. M. (2010). Putting renewables and energy efficiency to work: How many jobs can the clean energy industry generate in the US? Energy Policy, 38(2):919-931.

West, S. E. and Williams III, R. C. (2004). Estimates from a consumer demand system: implications for the incidence of environmental taxes. Journal of Environmental Economics and Management, 47(3):535-558.

Wier, M., Lenzen, M., Munksgaard, J., and Smed, S. (2001). Effects of Household Consumption Patterns on CO 2 Requirements. Economic Systems Research, 13:259-274.

Working, H. (1943). Statistical Laws of Family Expenditure. Journal of the American Statistical Association, 38(221):43-56.

World Bank (2013). Indonesia Economic Quartely. Indonesia Economic Quartely. World Bank Indonesia, Jakarta.

World Bank (2014). Turn Down the Heat: Confronting the New Climate Normal. World Bank Publications.

World Bank (2016). World development indicators.

WRI (2014). Climate Analysis Indicator Tool: WRI's Climate Data Explorer.

Yen, S. T., Kan, K., and Su, S.-J. (2002). Household demand for fats and oils: two-step estimation of a censored demand system. Applied Economics, 34(14):1799-1806.

Yusuf, A. A. and Resosudarmo, B. P. (2008). Mitigating Distributional Impact of Fuel Pricing Reform: The Indonesian Experience. ASEAN Economic Bulletin, 25(1):32-47. 



\section{Appendix A}

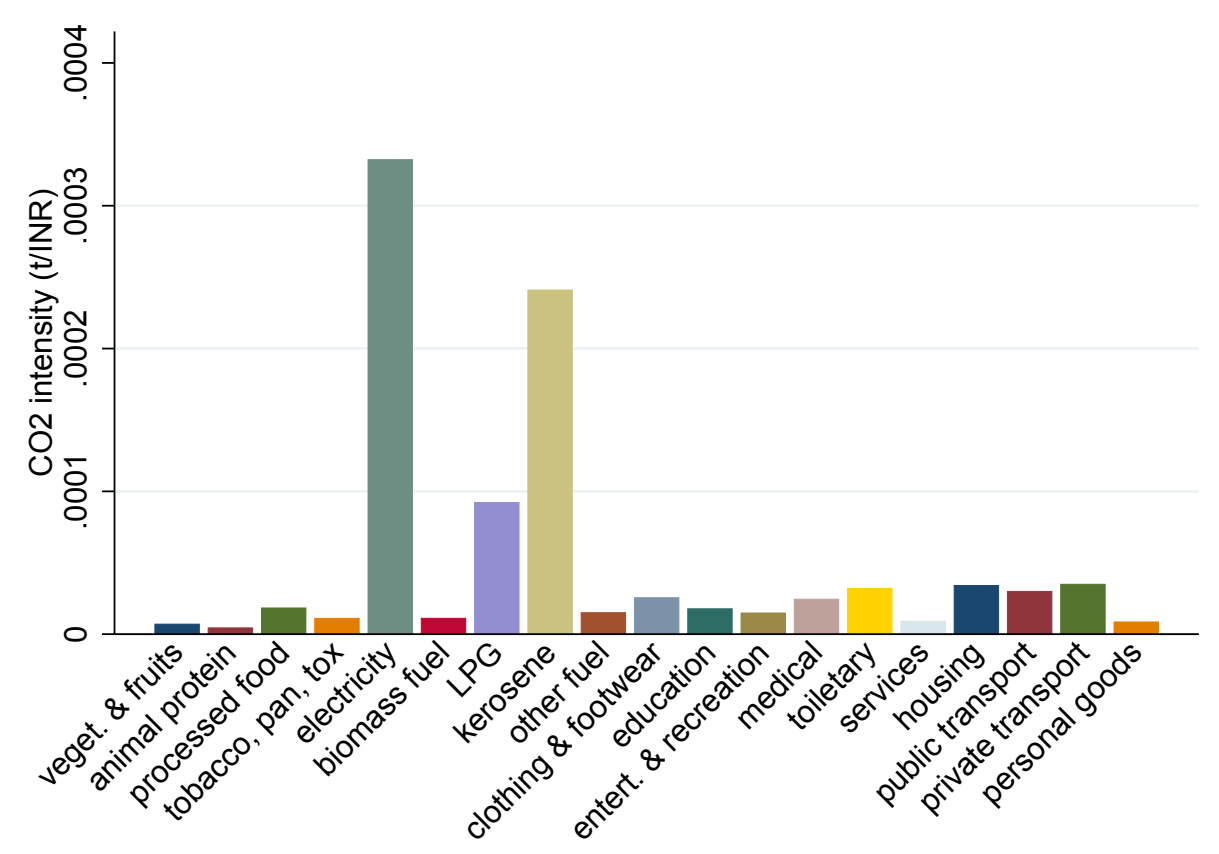

Fig. A.1 Emission Intensities of Expenditure Sub-Groups (2004/05) 
Table A.1 NSS-CSO Matching 2011/12

\begin{tabular}{|c|c|c|c|}
\hline NSS code & NSS description & IO code & Exp group code \\
\hline 101 & rice - PDS & 1 & 1 \\
\hline 102 & rice - other sources & 1 & 1 \\
\hline 103 & chira & 1 & 1 \\
\hline 104 & khoi, lawa & 1 & 1 \\
\hline 105 & muri & 1 & 1 \\
\hline 106 & other rice products & 1 & 1 \\
\hline 107 & wheat/atta - PDS & 2 & 1 \\
\hline 108 & wheat/ atta - other sources & 2 & 1 \\
\hline 110 & maida & 2 & 1 \\
\hline 111 & suji, rawa & 2 & 1 \\
\hline 112 & sewai, noodles & 1 & 1 \\
\hline 113 & bread (bakery) & 2 & 1 \\
\hline 114 & other wheat products & 2 & 1 \\
\hline 115 & jowar \& its products & 3 & 1 \\
\hline 116 & bajra $\&$ its products & 4 & 1 \\
\hline 117 & maize \& products & 5 & 1 \\
\hline 118 & barley \& its products & 2 & 1 \\
\hline 120 & small millets \& their products & 4 & 1 \\
\hline 121 & ragi \& its products & 7 & 1 \\
\hline 122 & other cereals & 20 & 1 \\
\hline 129 & cereal: sub-total $(101-122)$ & & \\
\hline 139 & cereal substitutes: tapioca, etc. & 20 & 1 \\
\hline 140 & arhar, tur & 6 & 1 \\
\hline 141 & gram: split & 6 & 1 \\
\hline 142 & gram: whole & 6 & 1 \\
\hline 143 & moong & 6 & 1 \\
\hline 144 & masur & 6 & 1 \\
\hline 145 & urd & 6 & 1 \\
\hline 146 & peas & 6 & 1 \\
\hline 147 & khesari & 7 & 1 \\
\hline 148 & other pulses & 7 & 1 \\
\hline 150 & gram products & 6 & 1 \\
\hline 151 & besan & 6 & 1 \\
\hline 152 & other pulse products & 7 & 1 \\
\hline 159 & pulses \& pulse products: s.t. $(140-152)$ & & \\
\hline 160 & milk: liquid (litre) & 21 & 2 \\
\hline 161 & baby food & 21 & 2 \\
\hline 162 & milk: condensed/ powder & 21 & 2 \\
\hline 163 & curd & 21 & 2 \\
\hline 164 & ghee & 21 & 2 \\
\hline
\end{tabular}




\begin{tabular}{|c|c|c|c|}
\hline NSS code & NSS description & IO code & Exp group code \\
\hline 165 & butter & 21 & 2 \\
\hline 166 & ice-cream & 21 & 2 \\
\hline 167 & other milk products & 21 & 2 \\
\hline 169 & milk \& milk products: s.t.(160-167) & & \\
\hline 170 & salt & 37 & 1 \\
\hline 171 & sugar - PDS & 38 & 1 \\
\hline 172 & sugar - other sources & 38 & 1 \\
\hline 173 & gur & 8 & 1 \\
\hline 174 & candy, misri & 39 & 1 \\
\hline 175 & honey & 38 & 1 \\
\hline 179 & sugar \& salt: s.t. (170-175) & & \\
\hline 180 & vanaspati, margarine & 40 & 1 \\
\hline 181 & mustard oil & 11 & 1 \\
\hline 182 & groundnut oil & 9 & 1 \\
\hline 183 & coconut oil & 10 & 1 \\
\hline 184 & refined oil & 10 & 1 \\
\hline 185 & soyabean, saffola, etc.] & 41 & 1 \\
\hline 189 & edible oil: s.t. (180-185) & & \\
\hline 190 & eggs (no.) & 23 & 2 \\
\hline 191 & fish, prawn & 26 & 2 \\
\hline 192 & goat meat/mutton & 22 & 2 \\
\hline 193 & beef/ buffalo meat & 22 & 2 \\
\hline 194 & pork & 22 & 2 \\
\hline 195 & chicken & 23 & 2 \\
\hline 196 & others: birds, crab, oyster, tortoise, etc. & 23 & 2 \\
\hline 199 & egg, fish \& meat: s.t. (190-199) & & \\
\hline 200 & potato & 19 & 1 \\
\hline 201 & onion & 19 & 1 \\
\hline 202 & tomato & 19 & 1 \\
\hline 203 & brinjal & 19 & 1 \\
\hline 204 & radish & 19 & 1 \\
\hline 205 & carrot & 19 & 1 \\
\hline 206 & palak/other leafy vegetables & 19 & 1 \\
\hline 207 & chillis: green & 19 & 1 \\
\hline 208 & lady's finger & 19 & 1 \\
\hline 210 & parwal, patal & 19 & 1 \\
\hline 211 & cauliflower & 19 & 1 \\
\hline 212 & cabbage & 19 & 1 \\
\hline 213 & pumpkin & 19 & 1 \\
\hline 214 & peas & 19 & 1 \\
\hline 215 & french beans, barbati & 19 & 1 \\
\hline 216 & lemon (no.) & 18 & 1 \\
\hline
\end{tabular}




\begin{tabular}{|c|c|c|c|}
\hline NSS code & NSS description & IO code & Exp group code \\
\hline 217 & other vegetables & 19 & 1 \\
\hline 219 & vegetables: s.t. (200-217) & & \\
\hline 220 & banana (no.) & 18 & 1 \\
\hline 221 & jackfruit & 18 & 1 \\
\hline 222 & watermelon & 18 & 1 \\
\hline 223 & pineapple (no.) & 18 & 1 \\
\hline 224 & coconut (no.) & 18 & 1 \\
\hline 225 & coconut green (no.) & 18 & 1 \\
\hline 226 & guava & 18 & 1 \\
\hline 227 & singara & 18 & 1 \\
\hline 228 & orange, mausami (no.) & 18 & 1 \\
\hline 230 & papaya & 18 & 1 \\
\hline 231 & mango & 18 & 1 \\
\hline 232 & kharbooza & 18 & 1 \\
\hline 233 & pears/naspati & 18 & 1 \\
\hline 234 & berries & 18 & 1 \\
\hline 235 & leechi & 18 & 1 \\
\hline 236 & apple & 18 & 1 \\
\hline 237 & grapes & 18 & 1 \\
\hline 238 & other fresh fruits & 18 & 1 \\
\hline 239 & fruits (fresh): s.t.(250-268) & & \\
\hline 240 & coconut: copra & 10 & 1 \\
\hline 241 & groundnut & 9 & 1 \\
\hline 242 & dates & 18 & 1 \\
\hline 243 & cashewnut & 9 & 1 \\
\hline 244 & walnut & 9 & 1 \\
\hline 245 & other nuts & 9 & 1 \\
\hline 246 & raisin, kishmish, monacca, etc. & 18 & 1 \\
\hline 247 & other dry fruits & 18 & 1 \\
\hline 249 & fruits (dry): s.t. (270-277) & & \\
\hline 250 & ginger $(\mathrm{gm})$ & 20 & 1 \\
\hline 251 & garlic (gm) & 20 & 1 \\
\hline 252 & jeera $(\mathrm{gm})$ & 20 & 1 \\
\hline 253 & dhania (gm) & 20 & 1 \\
\hline 254 & turmeric $(\mathrm{gm})$ & 20 & 1 \\
\hline 255 & black pepper (gm) & 20 & 1 \\
\hline 256 & dry chillies (gm) & 20 & 1 \\
\hline 257 & tamarind $(\mathrm{gm})$ & 20 & 1 \\
\hline 258 & curry powder (gm) & 20 & 1 \\
\hline 260 & oilseeds (gm) & 20 & 1 \\
\hline 261 & other spices (gm) & 20 & 1 \\
\hline 269 & spices: s.t. (250-269) & & \\
\hline
\end{tabular}




\begin{tabular}{|c|c|c|c|}
\hline NSS code & NSS description & IO code & Exp group code \\
\hline 270 & tea : cups (no.) & 42 & 3 \\
\hline 271 & tea : leaf $(\mathrm{gm})$ & 14 & 3 \\
\hline 272 & coffee : cups (no.) & 42 & 3 \\
\hline 273 & coffee: powder (gm) & 15 & 3 \\
\hline 274 & mineral water (litre) & 44 & 3 \\
\hline 275 & cold beverages: bottled/canned (litre) & 44 & 3 \\
\hline 276 & fruit juice and shake (litre) & 44 & 3 \\
\hline 277 & other beverages: cocoa, chocolate, etc. & 44 & 3 \\
\hline 279 & beverages: sub-total (270-279) & & \\
\hline 280 & cooked meals purchased (no.) & 43 & 3 \\
\hline 281 & cooked meals received free in workplace** (no.) & 43 & 3 \\
\hline 282 & cooked meals received as assistance $* *$ (no.) & 43 & 3 \\
\hline 283 & cooked snacks purchased & 43 & 3 \\
\hline 284 & other served processed food & 43 & 3 \\
\hline 289 & served processed food.: sub-total $(280-284)$ & & \\
\hline 290 & prepared sweets & 43 & 3 \\
\hline 291 & biscuits & 43 & 3 \\
\hline 292 & papad, bhujia, namkeen, mixture, & 43 & 3 \\
\hline 293 & chips (gm) & 43 & 3 \\
\hline 294 & pickles $(\mathrm{gm})$ & 43 & 3 \\
\hline 295 & sauce, jam, jelly (gm) & 43 & 3 \\
\hline 296 & other packaged processed food & & \\
\hline 299 & packaged processed food: sub-total (290-296) & & \\
\hline 300 & pan: leaf (no.) & 17 & 4 \\
\hline 301 & pan: finished (no.) & 45 & 4 \\
\hline 302 & ingredients for pan (gm) & 45 & 4 \\
\hline 309 & pan: s.t. $(300-302)$ & & \\
\hline 310 & bidi (no.) & 45 & 4 \\
\hline 311 & cigarettes (no.) & 45 & 4 \\
\hline 312 & leaf tobacco $(\mathrm{gm})$ & 17 & 4 \\
\hline 313 & snuff $(\mathrm{gm})$ & 45 & 4 \\
\hline 314 & hookah tobacco (gm) & 45 & 4 \\
\hline 315 & cheroot (no.) & 45 & 4 \\
\hline 316 & zarda, kimam, surti (gm) & 45 & 4 \\
\hline 317 & other tobacco products & 45 & 4 \\
\hline 319 & tobacco: s.t. $(310-317)$ & & \\
\hline 320 & ganja (gm) & 44 & 4 \\
\hline 321 & toddy (litre) & 44 & 4 \\
\hline 322 & country liquor (litre) & 44 & 4 \\
\hline 323 & beer (litre) & 44 & 4 \\
\hline 324 & foreign/refined liquor or wine (litre) & 44 & 4 \\
\hline 325 & other intoxicants & 44 & 4 \\
\hline
\end{tabular}




\begin{tabular}{|c|c|c|c|}
\hline NSS code & NSS description & IO code & Exp group code \\
\hline 329 & intoxicants: s.t. (320-325) & & \\
\hline 330 & coke & 64 & 9 \\
\hline 331 & firewood and chips & 56 & 6 \\
\hline 332 & electricity (std. unit) & 107 & 5 \\
\hline 333 & dung cake & 24 & 6 \\
\hline 334 & kerosene - PDS (litre) & 63 & 8 \\
\hline 335 & kerosene - other sources (litre) & 63 & 8 \\
\hline 336 & matches (box) & 56 & 9 \\
\hline 337 & coal & 64 & 9 \\
\hline 338 & LPG [excl. conveyance] & 63 & 7 \\
\hline 340 & charcoal & 64 & 9 \\
\hline 341 & candle (no.) & 73 & 9 \\
\hline 342 & gobar gas & 28 & 6 \\
\hline 343 & petrol (litre) [excl. conveyance] & 63 & 9 \\
\hline 344 & diesel (litre) [excl. conveyance] & 63 & 9 \\
\hline 345 & other fuel & 63 & 9 \\
\hline 349 & fuel and light: s.t. (330-345) & & \\
\hline 350 & dhoti (no.) & 54 & 10 \\
\hline 351 & sari (no.) & 54 & 10 \\
\hline 352 & cloth for shirt, pyjama, salwar, etc. (metre) & 54 & 10 \\
\hline 353 & cloth for coat, trousers, overcoat, etc. (metre) & 54 & 10 \\
\hline 354 & chaddar, dupatta, shawl, etc. (no.) & 54 & 10 \\
\hline 355 & lungi (no.) & 54 & 10 \\
\hline 356 & school/college uniform: boys & 54 & 10 \\
\hline 357 & school/college uniform: girls & 54 & 10 \\
\hline 358 & kurta-pajama suits: males (no.) & 54 & 10 \\
\hline 360 & kurta-pajama suits: females (no.) & 54 & 10 \\
\hline 361 & kurta, kameez (no.) & 54 & 10 \\
\hline 362 & pajamas, salwar (no.) & 54 & 10 \\
\hline 363 & shirts, T-shirts (no.) & 54 & 10 \\
\hline 364 & shorts, trousers, bermudas (no.) & 54 & 10 \\
\hline 365 & frocks, skirts, etc. (no.) & 54 & 10 \\
\hline 366 & blouse, dupatta, scarf, muffler (no.) & 54 & 10 \\
\hline 367 & lungi (no.) & 54 & 10 \\
\hline 368 & other casual wear* & 54 & 10 \\
\hline 370 & $\begin{array}{l}\text { baniyan, socks, other hosiery and undergarments, etc. } \\
\text { (no.) }\end{array}$ & 54 & 10 \\
\hline 371 & gamchha, towel, handkerchief (no.) & 54 & 10 \\
\hline 372 & infant clothing & 54 & 10 \\
\hline 373 & headwear, belts, ties (no.) & 54 & 10 \\
\hline 374 & knitting wool (gm) & 54 & 10 \\
\hline 375 & clothing (first-hand): other & 54 & 10 \\
\hline
\end{tabular}




\begin{tabular}{|c|c|c|c|}
\hline NSS code & NSS description & IO code & Exp group code \\
\hline 376 & clothing: second-hand & 54 & 10 \\
\hline 379 & clothing: sub-total $(350-376)$ & & \\
\hline 380 & bed sheet, bed cover (no.) & 54 & 16 \\
\hline 381 & rug, blanket (no.) & 52 & 16 \\
\hline 382 & pillow, quilt, mattress (no.) & 54 & 16 \\
\hline 383 & cloth for upholstery, curtains, tablecloth, etc. (metre) & 54 & 16 \\
\hline 384 & mosquito net (no.) & 54 & 16 \\
\hline 385 & bedding: others & 54 & 16 \\
\hline 389 & bedding, etc.: s.t. (380-385) & & \\
\hline 390 & leather boots, shoes & 59 & 10 \\
\hline 391 & leather sandals, chappals, etc. & 59 & 10 \\
\hline 392 & other leather footwear & 59 & 10 \\
\hline 393 & rubber / PVC footwear & 61 & 10 \\
\hline 394 & other footwear & 59 & 10 \\
\hline 395 & footwear: second-hand & 59 & 10 \\
\hline 399 & footwear: sub-total (390-395) & & \\
\hline 400 & books, journals: first hand & 58 & 11 \\
\hline 401 & books, journals, etc.: second hand & 58 & 11 \\
\hline 402 & newspapers, periodicals & 57 & 11 \\
\hline 403 & library charges & 121 & 11 \\
\hline 404 & stationery, photocopying charges & 123 & 11 \\
\hline 405 & tuition and other fees (school, college, etc.) & 121 & 11 \\
\hline 406 & private tutor/ coaching centre & 121 & 11 \\
\hline 407 & educational CD & 121 & 11 \\
\hline 408 & other educational expenses & 121 & 11 \\
\hline 409 & education: s.t. (400-408) & & \\
\hline 410 & medicine & 70 & 13 \\
\hline 411 & X-ray, ECG, pathological test, etc. & 122 & 13 \\
\hline 412 & doctor's/surgeon's fee & 122 & 13 \\
\hline 413 & hospital \& nursing home charges & 122 & 13 \\
\hline 414 & other medical expenses & 122 & 13 \\
\hline 419 & medical - institutional: s.t. (410-414) & & \\
\hline 420 & medicine & 70 & 13 \\
\hline 421 & X-ray, ECG, pathological test, etc. & 122 & 13 \\
\hline 422 & doctor's/ surgeon's fee & 122 & 13 \\
\hline 423 & family planning appliances & 122 & 13 \\
\hline 424 & other medical expenses & 122 & 13 \\
\hline 429 & medical - non-institutional: sub-total $(420-424)$ & & \\
\hline 430 & cinema, theatre & 129 & 12 \\
\hline 431 & mela, fair, picnic & 129 & 12 \\
\hline 432 & sports goods, toys, etc. & 105 & 12 \\
\hline 433 & club fees & 129 & 12 \\
\hline
\end{tabular}




\begin{tabular}{|c|c|c|c|}
\hline NSS code & NSS description & IO code & Exp group code \\
\hline 434 & goods for recreation and hobbies & 105 & 12 \\
\hline 435 & photography & 94 & 12 \\
\hline 436 & VCD/ DVD hire (incl. instrument) & 94 & 12 \\
\hline 437 & cable TV & 94 & 12 \\
\hline 438 & other entertainment & 129 & 12 \\
\hline 439 & entertainment: sub-total $(430-438)$ & & \\
\hline 440 & spectacles & 105 & 19 \\
\hline 441 & torch & 105 & 19 \\
\hline 442 & lock & 105 & 19 \\
\hline 443 & umbrella, raincoat & 105 & 19 \\
\hline 444 & lighter (bidi/ cigarette/ gas stove) & 105 & 19 \\
\hline 445 & other minor durable-type goods & 105 & 19 \\
\hline 449 & minor durable-type goods: sub-total $(440-445)$ & & \\
\hline 450 & toilet soap & 71 & 14 \\
\hline 451 & toothpaste, toothbrush, comb, etc. & 62 & 14 \\
\hline 452 & powder, snow, cream, lotion and perfume & 71 & 14 \\
\hline 453 & hair oil, shampoo, hair cream & 71 & 14 \\
\hline 454 & shaving blades, shaving stick, razor & 82 & 14 \\
\hline 455 & shaving cream, aftershave lotion & 71 & 14 \\
\hline 456 & sanitary napkins & 57 & 14 \\
\hline 457 & other toilet articles & 71 & 14 \\
\hline 459 & toilet articles: sub-total $(450-457)$ & & \\
\hline 460 & electric bulb, tubelight & 91 & 16 \\
\hline 461 & electric batteries & 90 & 16 \\
\hline 462 & other non-durable electric goods & 91 & 16 \\
\hline 463 & earthenware & 76 & 16 \\
\hline 464 & glassware & 76 & 16 \\
\hline 465 & bucket, water bottle/ feeding bottle \& other plastic goods & 62 & 16 \\
\hline 466 & coir, rope, etc. & 53 & 16 \\
\hline 467 & washing soap/soda/powder & 71 & 16 \\
\hline 468 & other washing requisites & 71 & 16 \\
\hline 470 & incense (agarbatti), room freshener & 71 & 16 \\
\hline 471 & flower (fresh): all purposes & 20 & 16 \\
\hline 472 & mosquito repellent, insecticide, acid etc. & 68 & 16 \\
\hline 473 & other petty articles & 76 & 16 \\
\hline 479 & other household consumables: sub-total $(460-473)$ & & \\
\hline 480 & domestic servant/cook & 123 & 15 \\
\hline 481 & attendant & 123 & 15 \\
\hline 482 & sweeper & 123 & 15 \\
\hline 483 & barber, beautician, etc. & 123 & 15 \\
\hline 484 & washerman, laundry, ironing & 123 & 15 \\
\hline 485 & tailor & 123 & 15 \\
\hline
\end{tabular}




\begin{tabular}{|c|c|c|c|}
\hline NSS code & NSS description & IO code & Exp group code \\
\hline 486 & grinding charges & 128 & 15 \\
\hline 487 & telephone charges: landline* & 128 & 15 \\
\hline 488 & telephone charges: mobile & 128 & 15 \\
\hline 490 & postage \& telegram & 128 & 15 \\
\hline 491 & miscellaneous expenses & 129 & 15 \\
\hline 492 & priest & 128 & 15 \\
\hline 493 & legal expenses & 125 & 15 \\
\hline 494 & repair charges for non-durables & 129 & 15 \\
\hline 495 & pet animals (incl. birds, fish) & 129 & 15 \\
\hline 496 & internet expenses & 128 & 15 \\
\hline 497 & other consumer services excluding conveyance & 129 & 15 \\
\hline 499 & $\begin{array}{l}\text { consumer services excluding conveyance: sub-total } \\
(480-496)\end{array}$ & & \\
\hline 500 & air fare & 112 & 18 \\
\hline 501 & railway fare & 109 & 17 \\
\hline 502 & bus/tram fare & 97 & 17 \\
\hline 503 & taxi, auto-rickshaw fare & 97 & 17 \\
\hline 504 & steamer, boat fare & 111 & 17 \\
\hline 505 & rickshaw (hand drawn \& cycle) fare & 99 & 17 \\
\hline 506 & horse cart fare & 22 & 17 \\
\hline 507 & porter charges & 128 & 17 \\
\hline 508 & petrol for vehicle & 29 & 18 \\
\hline 510 & diesel for vehicle & 29 & 18 \\
\hline 511 & lubricants \& other fuels for vehicle & 29 & 18 \\
\hline 512 & school bus, van, etc. & 97 & 17 \\
\hline 513 & other conveyance expenses & 98 & 17 \\
\hline 519 & conveyance: sub-total $(\mathbf{5 0 0 - 5 1 3 )}$ & & \\
\hline 520 & house rent, garage rent (actual) & 120 & 16 \\
\hline 521 & hotel lodging charges & 117 & 16 \\
\hline 522 & residential land rent & 120 & 16 \\
\hline 523 & other consumer rent & 120 & 16 \\
\hline 529 & rent: sub-total $(520-523)$ & & \\
\hline 539 & house rent, garage rent (imputed- urban only) & 120 & 16 \\
\hline 540 & water charges & 108 & 16 \\
\hline 541 & other consumer taxes $\&$ cesses & 130 & 15 \\
\hline 549 & consumer taxes and cesses: sub-total $(540-541)$ & & \\
\hline 550 & bedstead & 54 & 16 \\
\hline 551 & almirah, dressing table & 54 & 16 \\
\hline 552 & chair, stool, bench, table & 55 & 16 \\
\hline 553 & suitcase, trunk, box, handbag and other travel goods & 63 & 16 \\
\hline 554 & foam, rubber cushion & 61 & 16 \\
\hline 555 & carpet, daree \& other floor mattings & 52 & 16 \\
\hline
\end{tabular}




\begin{tabular}{|c|c|c|c|}
\hline NSS code & NSS description & IO code & Exp group code \\
\hline 556 & paintings, drawings, engravings, etc. & 69 & 16 \\
\hline 557 & other furniture \& fixtures (couch, sofa, etc.) & 55 & 16 \\
\hline 559 & furniture \& fixtures: sub-total $(550-557)$ & & \\
\hline 560 & radio, 2 -in-1 & 94 & 12 \\
\hline 561 & television & 94 & 12 \\
\hline 562 & VCR/VCD/DVD player & 94 & 12 \\
\hline 563 & camera \& photographic equipment & 94 & 12 \\
\hline 564 & $\mathrm{CD}, \mathrm{DVD}$, audio/video cassette, etc & 94 & 12 \\
\hline 565 & musical instruments & 105 & 12 \\
\hline 566 & other goods for recreation & 105 & 12 \\
\hline 569 & goods for recreation: sub-total $(560-566)$ & & \\
\hline 570 & stainless steel utensils & 82 & 16 \\
\hline 571 & other metal utensils & 82 & 16 \\
\hline 572 & casseroles, thermos, thermoware & 82 & 16 \\
\hline 573 & other crockery \& utensils & 82 & 16 \\
\hline 579 & crockery \& utensils: sub-total $(570-573)$ & & \\
\hline 580 & electric fan & 91 & 16 \\
\hline 581 & air conditioner, air cooler & 91 & 16 \\
\hline 582 & inverter & 91 & 16 \\
\hline 583 & lantern, lamp, electric lampshade & 91 & 16 \\
\hline 584 & sewing machine & 91 & 16 \\
\hline 585 & washing machine & 91 & 16 \\
\hline 586 & stove & 91 & 16 \\
\hline 587 & pressure cooker/ pressure pan & 91 & 16 \\
\hline 588 & refrigerator & 91 & 16 \\
\hline 590 & water purifier & 91 & 16 \\
\hline 591 & $\begin{array}{l}\text { electric iron, heater, toaster, oven \& other electric heating } \\
\text { appliances }\end{array}$ & 91 & 16 \\
\hline 592 & other cooking/ household appliances & 91 & 16 \\
\hline 599 & $\begin{array}{l}\text { cooking \& other household appliances: sub-total } \\
(580-592)\end{array}$ & & \\
\hline 600 & bicycle & 99 & 18 \\
\hline 601 & motor cycle, scooter & 98 & 18 \\
\hline 602 & motor car, jeep & 97 & 18 \\
\hline 603 & tyres \& tubes & 61 & 18 \\
\hline 604 & other transport equipment & 100 & 18 \\
\hline 609 & personal transport equipment: sub-total (600-604) & & \\
\hline 610 & contact lenses, hearing aids \& orthopaedic equipment & 102 & 13 \\
\hline 611 & other medical equipment & 102 & 13 \\
\hline 619 & therapeutic appliances: sub-total (610-611) & & \\
\hline 620 & clock, watch & 101 & 19 \\
\hline 621 & other machines for household work & 91 & 19 \\
\hline
\end{tabular}




\begin{tabular}{llcc}
\hline NSS code & NSS description & IO code & Exp group code \\
\hline 622 & PC/ Laptop/ other peripherals incl. software & 92 & 19 \\
623 & mobile handset & 92 & 19 \\
624 & telephone instrument (landline) & 92 & 19 \\
625 & any other personal goods & 93 & 19 \\
$\mathbf{6 2 9}$ & other personal goods: sub-total (620-625) & 87 & \\
630 & bathroom and sanitary equipment & 89 & 16 \\
631 & plugs, switches \& other electrical fittings & 129 & 16 \\
632 & residential building \& land (cost of repairs only) & 105 & 16 \\
633 & other durables (specify) & & \\
$\mathbf{6 3 9}$ & residential building, land and other durables: & 103 & 19 \\
& sub-total (630-633) & 103 & 19 \\
640 & gold ornaments & 103 & 19 \\
641 & silver ornaments & 103 & 19 \\
642 & jewels, pearls & & \\
643 & other ornaments & & \\
$\mathbf{6 4 9}$ & jewellery \& ornaments: sub-total (640-643) & & \\
$\mathbf{6 5 9}$ & durable goods: total & & \\
& (559+569+579+599+609+619+629+639+649) & & \\
\hline
\end{tabular}





\section{Appendix B}
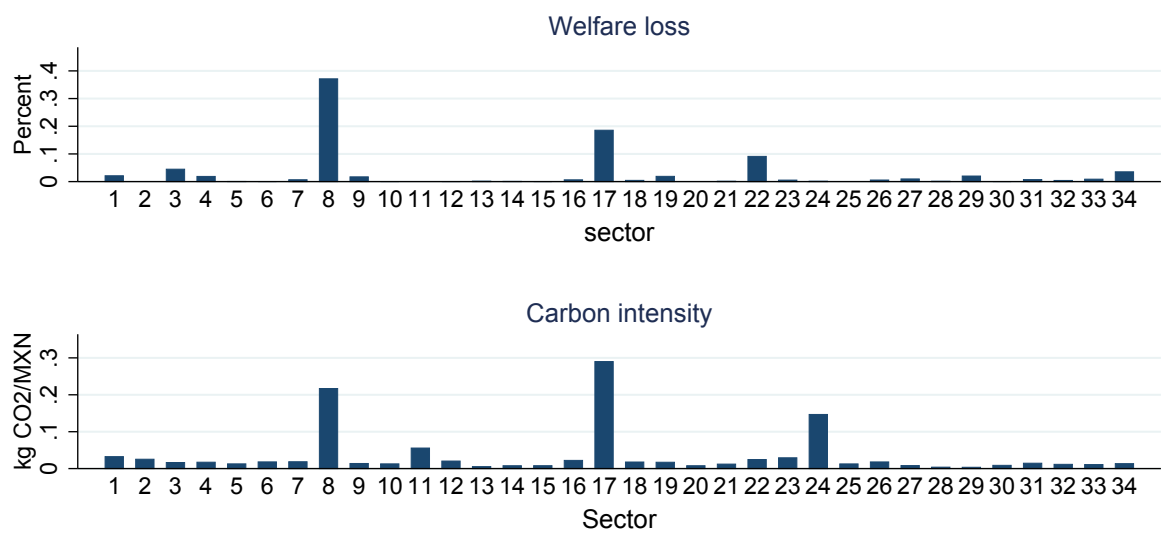

Expenditure share

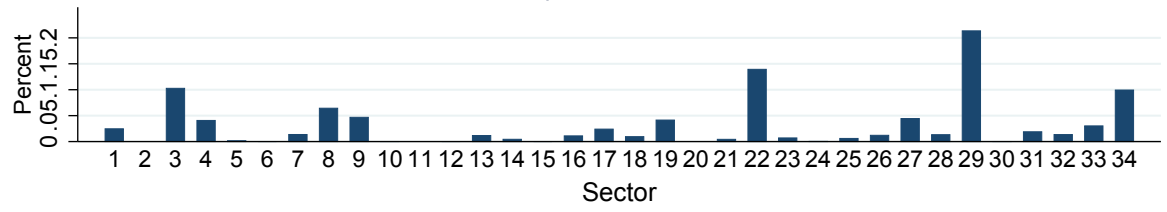

Fig. B.1 Decomposition welfare loss, top 10 percent 
Table B.1 Inequality effects (Gini Index)

\begin{tabular}{cccc}
\hline Scenario & National & Rural & Urban \\
\hline Baseline & 0.518 & 0.452 & 0.505 \\
A & & & \\
I (USD 3.5) & 0.518 & 0.452 & 0.505 \\
II (USD 20) & 0.519 & 0.452 & 0.505 \\
II (USD 20) + lump-sum & 0.516 & 0.449 & 0.503 \\
II (USD 20) + PROSPERA & 0.514 & 0.440 & 0.503 \\
III (USD 50) & 0.519 & 0.453 & 0.506 \\
III (USD 50) + lump-sum & 0.514 & 0.444 & 0.501 \\
III (USD 50) + PROSPERA & 0.509 & 0.425 & 0.501 \\
\hline B & & & \\
I (USD 3.5) & 0.518 & 0.452 & 0.505 \\
II (USD 20) & 0.519 & 0.452 & 0.505 \\
II (USD 20) + lump-sum & 0.516 & 0.448 & 0.503 \\
II (USD 20) + PROSPERA & 0.513 & 0.436 & 0.503 \\
III (USD 50) & 0.520 & 0.453 & 0.507 \\
III (USD 50) + lump-sum & 0.513 & 0.442 & 0.500 \\
III (USD 50) + PROSPERA & 0.507 & 0.419 & 0.500 \\
\hline C & & & \\
I (USD 3.5) & 0.518 & 0.452 & 0.505 \\
II (USD 20) & 0.519 & 0.454 & 0.506 \\
II (USD 20) + lump-sum & 0.515 & 0.447 & 0.502 \\
II (USD 20) + PROSPERA & 0.511 & 0.431 & 0.502 \\
III (USD 50) & 0.521 & 0.457 & 0.508 \\
III (USD 50) + lump-sum & 0.510 & 0.440 & 0.498 \\
III (USD 50) + PROSPERA & 0.502 & 0.410 & 0.498 \\
\hline & & &
\end{tabular}

Table B.2 ENIGH-WIOD Matching 2014

\begin{tabular}{llc}
\hline ENIGH code & ENIGH description & WIOD sector \\
\hline A001 & Maíz en grano & 1 \\
A002 & Harina de maíz & 3 \\
A003 & Masa de maíz & 3 \\
A004 & Tortilla de maíz & 3 \\
A005 & Tostadas & 3 \\
A006 & Otros productos de maíz & 3 \\
A007 & Harina de trigo & 3 \\
A008 & Tortilla de harina & 3 \\
A009 & Pasta para sopa & 3 \\
A010 & Galletas dulces & 3 \\
A011 & Galletas saladas & 3
\end{tabular}




\begin{tabular}{|c|c|c|}
\hline ENIGH code & ENIGH description & WIOD sector \\
\hline $\mathrm{A} 012$ & Pan blanco: bolillo, telera, baguete, etcétera & 3 \\
\hline A013 & Pan dulce en piezas & 3 \\
\hline A014 & Pan dulce empaquetado & 3 \\
\hline A015 & Pan para sándwich, hamburguesa, hot-dog y tostado & 3 \\
\hline A016 & Pasteles y pastelillos en piezas o a granel & 3 \\
\hline A017 & Pasteles y pastelillos empaquetados & 3 \\
\hline A018 & Otros productos de trigo & 3 \\
\hline A019 & Arroz en grano & 1 \\
\hline A020 & Otros productos de arroz & 3 \\
\hline A021 & Cereal de maíz, de trigo, de arroz, de avena, de granola, etcétera & 1 \\
\hline A022 & Botanas: frituras, palomitas, cheetos, doritos etcétera (excepto papas) & 3 \\
\hline A023 & Sopas instantáneas & 3 \\
\hline $\mathrm{A} 024$ & Otros cereales & 1 \\
\hline A025 & Bistec de res (de cualquier parte que se saque) & 3 \\
\hline A026 & Arrachera, filete & 3 \\
\hline A027 & Milanesa de res & 3 \\
\hline A028 & Chamorro de res & 3 \\
\hline A029 & Chuleta de costilla de res & 3 \\
\hline A030 & $\begin{array}{l}\text { Agujas, aldilla, chambarete, diezmillo, espinazo, fajilla de res para asar, } \\
\text { retazo, tampiqueña }\end{array}$ & 3 \\
\hline A031 & Cocido de res & 3 \\
\hline A032 & Cortes especiales de res & 3 \\
\hline A033 & Hamburguesas de res para asar & 3 \\
\hline A034 & Molida de res & 3 \\
\hline A035 & Pulpa de res en trozo & 3 \\
\hline A036 & Carne de otras partes de la res & 3 \\
\hline A037 & Vísceras de res & 3 \\
\hline A038 & Bistec de puerco (de cualquier parte que se saque) & 3 \\
\hline A039 & Pierna de puerco en trozo & 3 \\
\hline A040 & Pulpa de puerco en trozo & 3 \\
\hline A041 & Molida de puerco & 3 \\
\hline A042 & Costilla y chuleta de puerco & 3 \\
\hline A043 & Espaldilla de puerco & 3 \\
\hline A044 & Codillo de puerco & 3 \\
\hline A045 & Carne de otras partes del puerco & 3 \\
\hline A046 & Vísceras de puerco & 3 \\
\hline A047 & Carne enchilada & 3 \\
\hline A048 & Chicharrón de puerco & 3 \\
\hline A049 & Chorizo con cualquier condimento y color y longaniza & 3 \\
\hline A050 & Chuleta ahumada de puerco & 3 \\
\hline A051 & Machaca y carne seca & 3 \\
\hline A052 & Jamón de puerco & 3 \\
\hline
\end{tabular}




\begin{tabular}{|c|c|c|}
\hline ENIGH code & ENIGH description & WIOD sector \\
\hline A053 & Mortadela, queso de puerco y salami, bolonia de carnes surtidas & 3 \\
\hline A054 & Lardo procesado (tocino) & 3 \\
\hline A055 & Salchichas y salchichón & 3 \\
\hline A056 & Otras carnes procesadas & 3 \\
\hline A057 & Pierna, muslo o pechuga de pollo con hueso & 3 \\
\hline A058 & Pierna, muslo o pechuga de pollo sin hueso & 3 \\
\hline A059 & Pollo entero o en piezas excepto, pierna, muslo y pechuga & 3 \\
\hline A060 & Vísceras y otras partes del pollo & 3 \\
\hline A061 & Otras aves & 3 \\
\hline A062 & Chorizo de pollo, jamón y nugget, salchicha, mortadela, etcétera & 3 \\
\hline A063 & Borrego: carnero y borrego & 3 \\
\hline A064 & Chivo y cabrito & 3 \\
\hline A065 & Otras carnes: caballo, conejo, iguana, jabalí, rana, tortuga, venado & 3 \\
\hline A066 & Pescado entero limpio y sin limpiar & 3 \\
\hline A067 & Filete de pescado & 3 \\
\hline A068 & Atún enlatado & 3 \\
\hline A069 & Salmón y bacalao procesado & 3 \\
\hline A070 & Pescado ahumado, seco, nugget, sardina, etcétera & 3 \\
\hline A071 & Anguilas, angulas, hueva de pescado, mantarraya, pejelagarto, etcétera & 3 \\
\hline A072 & Camarón fresco & 3 \\
\hline A073 & Mariscos frescos & 3 \\
\hline A074 & Mariscos procesados & 3 \\
\hline A075 & Leche pasteurizada de vaca & 3 \\
\hline A076 & Leche condensada & 3 \\
\hline A077 & Leche evaporada & 3 \\
\hline A078 & Leche en polvo entera o descremada & 3 \\
\hline A079 & Leche modificada o maternizada & 3 \\
\hline A080 & Leche no pasteurizada (leche bronca) & 3 \\
\hline A081 & Otras leches: de burra, de cabra, de soya & 3 \\
\hline A082 & Queso amarillo en rebanadas o para untar & 3 \\
\hline A083 & Queso añejo y cotija & 3 \\
\hline A084 & Queso chihuahua & 3 \\
\hline A085 & Queso fresco & 3 \\
\hline A086 & Queso manchego & 3 \\
\hline A087 & Queso oaxaca o asadero & 3 \\
\hline A088 & Otros quesos & 3 \\
\hline A089 & Crema & 3 \\
\hline A090 & Mantequilla & 3 \\
\hline A091 & Bebidas fermentadas de leche & 3 \\
\hline A092 & Otros derivados de la leche & 3 \\
\hline A093 & Huevo de gallina blanco y rojo & 3 \\
\hline A094 & Otros huevos: codorniz, pata, pava etcétera & 3 \\
\hline
\end{tabular}




\begin{tabular}{|c|c|c|}
\hline ENIGH code & ENIGH description & WIOD sector \\
\hline A095 & Aceite vegetal: canola, cártamo, girasol, maíz, etcétera & 3 \\
\hline A096 & Aceite de coco, oliva, soya & 3 \\
\hline A097 & Margarina & 3 \\
\hline A098 & Manteca de puerco & 3 \\
\hline A099 & Manteca vegetal & 3 \\
\hline A100 & Otros aceites: de bacalao, de tiburón, de tortuga, enjundia & 3 \\
\hline A101 & Betabel y camote & 1 \\
\hline A102 & Papa & 1 \\
\hline A103 & Rábano & 1 \\
\hline A104 & Otros tubérculos & 1 \\
\hline A105 & Harina para puré de papa & 3 \\
\hline A106 & Papas fritas en bolsa o a granel & 3 \\
\hline A107 & Acelgas, espinacas y verdolagas & 1 \\
\hline A108 & Aguacate & 1 \\
\hline A109 & Ajo & 1 \\
\hline A110 & Brócoli & 1 \\
\hline A111 & Calabacita y calabaza & 1 \\
\hline A112 & Cebolla & 1 \\
\hline A113 & Chayote & 1 \\
\hline A114 & Chícharo & 1 \\
\hline A115 & Chile jalapeño & 1 \\
\hline A116 & Chile poblano & 1 \\
\hline A 117 & Chile serrano & 1 \\
\hline A118 & Otros chiles & 1 \\
\hline A119 & Cilantro & 1 \\
\hline A120 & Col y repollo & 1 \\
\hline A121 & Ejote & 1 \\
\hline A122 & Elote & 1 \\
\hline A123 & Epazote & 1 \\
\hline A124 & Jitomate & 1 \\
\hline A125 & Lechuga & 1 \\
\hline A126 & Nopal & 1 \\
\hline A127 & Pepino & 1 \\
\hline A128 & Perejil y yerbabuena & 1 \\
\hline A129 & Tomate verde & 1 \\
\hline A130 & Zanahoria & 1 \\
\hline A131 & Otras verduras & 1 \\
\hline A132 & Germinados de maíz, de soya, de trigo & 1 \\
\hline A133 & Chiles envasados & 3 \\
\hline A134 & Chile secos o en polvo & 3 \\
\hline A 135 & Verduras y legumbres envasadas & 3 \\
\hline A136 & Verduras y legumbres congeladas & 3 \\
\hline
\end{tabular}




\begin{tabular}{|c|c|c|}
\hline ENIGH code & ENIGH description & WIOD sector \\
\hline A137 & Frijol en grano & 1 \\
\hline A138 & Garbanzo en grano & 1 \\
\hline A139 & Haba amarilla o verde en grano & 1 \\
\hline A140 & Lenteja en grano & 1 \\
\hline A141 & Otras leguminosas en grano & 1 \\
\hline A142 & Frijol procesado & 3 \\
\hline A143 & Otras leguminosas procesadas & 3 \\
\hline A144 & Semillas a granel & 1 \\
\hline A145 & Semillas envasadas & 1 \\
\hline A146 & Semillas procesadas & 1 \\
\hline A147 & Anona, chirimoya, guanábana & 1 \\
\hline A148 & Cereza, frambuesa, fresa, zarzamora & 1 \\
\hline A149 & Chabacano, durazno, melocotón & 1 \\
\hline A150 & Chicozapote y mamey & 1 \\
\hline A151 & Ciruela y jobo & 1 \\
\hline A152 & Guayaba & 1 \\
\hline A153 & Lima & 1 \\
\hline A154 & Limón & 1 \\
\hline A155 & Mandarina, nectarina, tangerina & 1 \\
\hline A156 & Toronja & 1 \\
\hline A157 & Mango & 1 \\
\hline A158 & Manzana y perón & 1 \\
\hline A159 & Melón & 1 \\
\hline A160 & Naranja & 1 \\
\hline A161 & Papaya & 1 \\
\hline A162 & Pera & 1 \\
\hline A163 & Piña & 1 \\
\hline A164 & Pitahaya y tuna & 1 \\
\hline A165 & Plátano macho y de castilla & 1 \\
\hline A166 & Plátano verde y tabasco & 1 \\
\hline A167 & $\begin{array}{l}\text { Otros plátanos (chiapas, dominico, guineo, manzano, dorado, } \\
\text { portalimón y roatan) }\end{array}$ & 1 \\
\hline A168 & Sandía & 1 \\
\hline A169 & Uva & 1 \\
\hline A170 & Otras frutas: garambullo, granada, higo, jícama, kiwi, etcétera & 1 \\
\hline A171 & Frutas en almíbar y conserva & 3 \\
\hline A172 & Frutas cristalizadas, enchiladas y secas & 3 \\
\hline A173 & Azúcar blanca y morena & 3 \\
\hline A174 & Miel de abeja & 1 \\
\hline A175 & Otras azúcares y mieles & 3 \\
\hline A 176 & Café tostado en grano molido & 3 \\
\hline A177 & Café tostado soluble & 3 \\
\hline
\end{tabular}




\begin{tabular}{|c|c|c|}
\hline ENIGH code & ENIGH description & WIOD \\
\hline A178 & Flor y hojas para té & \\
\hline A179 & Té soluble (cualquier sabor) & \\
\hline A180 & Chocolate en tableta & \\
\hline A181 & Chocolate en polvo & \\
\hline A182 & Otros chocolates & \\
\hline A183 & Canela & \\
\hline A184 & Clavo & \\
\hline A185 & Yerbas de olor & \\
\hline A186 & Concentrados de pollo y tomate & \\
\hline A187 & Mayonesa & \\
\hline A188 & Mole en pasta o en polvo & \\
\hline A189 & Mostaza & \\
\hline A190 & Pimienta & 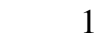 \\
\hline A191 & Sal & . \\
\hline A192 & Salsas dulces y picantes & . \\
\hline A193 & Vinagre & \\
\hline A194 & Otros aderezos, especies y salsas & . \\
\hline A195 & Cereal de arroz, avena, plátano, manzana, mixto para bebé & , \\
\hline A196 & Papillas para bebé & tis \\
\hline A197 & Jugos de frutas y verduras de cualquier combinación para bebé & \\
\hline A198 & Pizzas preparadas & 2 \\
\hline A199 & Carnitas & \\
\hline A200 & Pollo rostizado & \\
\hline A201 & Barbacoa y birria & \\
\hline A202 & Otros alimentos preparados: atole, flautas, guisados, hot-dog, & \\
\hline
\end{tabular}

A203 Hongos frescos: champiñones, huitlacoche y setas 1

A204 Insectos: chapulines, chinicuiles, escamoles, gusanos de maguey, 1

A205 Flanes, gelatinas y pudines en polvo 3

A206 Cajetas, dulces de leche, jamoncillos y natillas 3

A207 Ates, crema de cacahuate, jaleas, mermelada 3

A208 Helados, nieves y paletas de hielo 3

A209 Otras golosinas 3

A210 Molienda de nixtamal 3

A211 Otros gastos relacionados con la preparación de alimentos 3

A212 Alimentos y/o bebidas en paquete 3

A213 Alimento para animales domésticos 3

A214 Alimento para animales para uso del hogar 3

A215 Agua natural embotellada 3

A216 Agua mineral, quina, desmineralizada con o sin sabor 3

A217 Agua preparada y jugos naturales 3 


\begin{tabular}{|c|c|c|}
\hline ENIGH code & ENIGH description & WIOD sector \\
\hline A218 & Jugos y néctares envasados & 3 \\
\hline A219 & Concentrados y polvos para preparar bebidas & 3 \\
\hline A220 & Refrescos de cola y de sabores & 3 \\
\hline A221 & Bebida energética & 3 \\
\hline A222 & $\begin{array}{l}\text { Bebidas fermentadas de maíz, hielo, jarabe natural, lechuguilla, sangrita, } \\
\text { tascalate, tepache y tuba }\end{array}$ & 3 \\
\hline A223 & Coñac y brandy & 3 \\
\hline A224 & Cerveza & 3 \\
\hline A 225 & Anís (licor) & 3 \\
\hline A226 & Jerez & 3 \\
\hline A227 & Licor o cremas de frutas & 3 \\
\hline A228 & Aguamiel, pulque, tlachique & 3 \\
\hline A229 & Aguardiente, alcohol de caña, charanda, mezcal & 3 \\
\hline $\mathrm{A} 230$ & Ron añejo, blanco, con limón & 3 \\
\hline A231 & Rompope & 3 \\
\hline A232 & Sidra blanca y rosada & \\
\hline A233 & Tequila añejo, azul y blanco & 3 \\
\hline A234 & Vino de mesa blanco, rosado, tinto & 3 \\
\hline A235 & Vodka & 3 \\
\hline A236 & Whisky & 3 \\
\hline A237 & Bebida alcohólica preparada & 3 \\
\hline A238 & Otras bebidas alcohólicas: champaña & 3 \\
\hline A239 & Cigarros & 3 \\
\hline A240 & Puros & 3 \\
\hline A241 & Tabaco en hoja y picado & 3 \\
\hline A 242 & $\begin{array}{l}\text { Despensa de alimentos que otorgan organizaciones privadas o de } \\
\text { gobierno }\end{array}$ & 3 \\
\hline A243 & Desayuno & 22 \\
\hline A244 & Comida & 22 \\
\hline A245 & Cena & 22 \\
\hline A246 & Entrecomidas & 22 \\
\hline A247 & Otros eventos fuera de casa & 22 \\
\hline B001 & Metro o tren ligero & 23 \\
\hline B002 & Autobús & 23 \\
\hline B003 & Trolebús o metrobús & 23 \\
\hline B004 & Colectivo, combi o microbús & 23 \\
\hline B005 & Taxi, radio-taxi (sitio) & 23 \\
\hline B006 & Autobús foráneo & 23 \\
\hline B007 & Otros transportes: lancha, panga o peaje & 24 \\
\hline $\mathrm{C} 001$ & Detergentes (polvo, líquido, pasta, gel) & 9 \\
\hline $\mathrm{C} 002$ & Jabón de barra & 9 \\
\hline $\mathrm{C} 003$ & Blanqueadores & 9 \\
\hline
\end{tabular}




\begin{tabular}{|c|c|c|}
\hline ENIGH code & ENIGH description & WIOD sector \\
\hline $\mathrm{C} 004$ & Suavizantes de telas & 9 \\
\hline $\mathrm{C} 005$ & Limpiadores (en polvo o líquido) & 9 \\
\hline $\mathrm{C} 006$ & Servilletas y papel absorbente & 7 \\
\hline $\mathrm{C} 007$ & Platos y vasos desechables, papel aluminio y encerado & 7 \\
\hline $\mathrm{C} 008$ & Escobas, trapeadores, recogedor & 16 \\
\hline $\mathrm{C} 009$ & Fibras, estropajos, escobetas, pinzas para ropa, lazos & 16 \\
\hline $\mathrm{C} 010$ & Jergas y trapos de cocina & 4 \\
\hline $\mathrm{C} 011$ & Cerillos & 16 \\
\hline $\mathrm{C} 012$ & Pilas & 14 \\
\hline $\mathrm{C} 013$ & Focos & 14 \\
\hline $\mathrm{C} 014$ & Cera y limpia muebles & 9 \\
\hline $\mathrm{C} 015$ & Insecticidas líquido, en polvo, pastilla, raid eléctrico & 9 \\
\hline $\mathrm{C} 016$ & Desodorante ambiental y sanitario & 9 \\
\hline $\mathrm{C} 017$ & Recipientes de lámina (cubetas, tinas, etcétera) & 12 \\
\hline $\mathrm{C} 018$ & Recipientes de plástico (cubetas, tinas, mangueras, etcétera) & 10 \\
\hline $\mathrm{C} 019$ & Otros artículos & 9 \\
\hline $\mathrm{C} 020$ & Servicio doméstico & 34 \\
\hline $\mathrm{C} 021$ & Lavandería & 34 \\
\hline $\mathrm{C} 022$ & Tintorería & 34 \\
\hline $\mathrm{C} 023$ & Jardinería & 34 \\
\hline $\mathrm{C} 024$ & Otros servicios: fumigación, etcétera & 34 \\
\hline D001 & Jabón de tocador & 9 \\
\hline D002 & Lociones y perfumes & 9 \\
\hline D003 & Pasta dental y enjuague bucal & 9 \\
\hline D004 & Hilo y cepillo dental & 16 \\
\hline D005 & Champús, enjuagues, tratamiento para el cabello & 9 \\
\hline D006 & Tintes y líquidos para permanente & 9 \\
\hline D007 & Desodorante y talco & 9 \\
\hline D008 & Bronceadores y bloqueadores & 9 \\
\hline D009 & Crema para el cuerpo, para la cara y tratamiento facial & 9 \\
\hline D010 & Gel, spray, mousse para el cabello & 9 \\
\hline D011 & Crema para afeitar y rastrillos & 9 \\
\hline D012 & $\begin{array}{l}\text { Cosméticos, polvo y maquillaje sombra, lápiz labial, delineador de ojos, } \\
\text { etcétera }\end{array}$ & 9 \\
\hline D013 & Esmalte para uñas & 9 \\
\hline D014 & Papel sanitario, pañuelos desechables & 7 \\
\hline D015 & Toallas sanitarias & 7 \\
\hline D016 & Pañales desechables & 7 \\
\hline D017 & Artículos de tocador para bebé & 7 \\
\hline D018 & Cepillos y peines & 16 \\
\hline D019 & Artículos eléctricos: rasuradora, secadora, etcétera & 13 \\
\hline D020 & Reparación y/o mantenimiento de los artículos anteriores & 21 \\
\hline
\end{tabular}




\begin{tabular}{|c|c|c|}
\hline ENIGH code & ENIGH description & WIOD sector \\
\hline D021 & $\begin{array}{l}\text { Otros: donas y mariposas para el cabello, limas de uñas, pasadores, } \\
\text { etcétera }\end{array}$ & 16 \\
\hline D022 & Corte de cabello y peinado & 34 \\
\hline D023 & Baños y masajes & 34 \\
\hline D024 & Permanentes y tintes & 34 \\
\hline D025 & Manicure & 34 \\
\hline D026 & Otros servicios: rasurar, depilar, etcétera & 34 \\
\hline E001 & Preescolar & 32 \\
\hline E002 & Primaria & 32 \\
\hline E003 & Secundaria & 32 \\
\hline E004 & Preparatoria o bachillerato & 32 \\
\hline E005 & Profesional & 32 \\
\hline E006 & Maestría y doctorado & 32 \\
\hline E007 & Educación Técnica & 32 \\
\hline E008 & Estancias infantiles (excepto preprimaria) & 32 \\
\hline E009 & Enseñanza adicional & 32 \\
\hline E010 & Educación especial para discapacitados & 32 \\
\hline E011 & Internados & 32 \\
\hline E012 & Cuidado de niños (persona particular) & 33 \\
\hline E013 & Transporte escolar & 23 \\
\hline E014 & Libros para la escuela & 7 \\
\hline E015 & $\begin{array}{l}\text { Gastos recurrentes en educación, como: credenciales, seguro médico, } \\
\text { seguro de vida, cuotas a padres de familia }\end{array}$ & 32 \\
\hline E016 & $\begin{array}{l}\text { Pago de imprevistos como: derecho a examen, examen extraordinario, } \\
\text { cursos de regularización, etcétera }\end{array}$ & 32 \\
\hline E017 & Equipo escolar: máquinas de escribir, calculadora, etcétera & 32 \\
\hline E018 & $\begin{array}{l}\text { Gastos recurrentes en educación técnica: credenciales, seguro médico, } \\
\text { seguro de vida, cuotas a padres de familia }\end{array}$ & 32 \\
\hline E019 & $\begin{array}{l}\text { Pago de imprevistos para educación técnica, como: derecho a examen, } \\
\text { cursos de regularización, etcétera }\end{array}$ & 32 \\
\hline E020 & Material para la educación adicional & 32 \\
\hline E021 & Reparación y/o mantenimiento de equipo escolar & 32 \\
\hline E022 & Enciclopedia y libros (excluya los de la escuela) & 7 \\
\hline E023 & Periódicos & 7 \\
\hline E024 & Revistas & 7 \\
\hline E025 & Audiocasetes, discos y discos compactos & 7 \\
\hline E026 & Otros & 16 \\
\hline E027 & Cines & 34 \\
\hline E028 & Teatros y conciertos & 34 \\
\hline E029 & $\begin{array}{l}\text { Centros nocturnos (incluye alimentos, bebidas, tabaco, entrada, } \\
\text { propinas, etcétera) }\end{array}$ & 34 \\
\hline E030 & Espectáculos deportivos & 34 \\
\hline
\end{tabular}




\begin{tabular}{|c|c|c|}
\hline ENIGH code & ENIGH description & WIOD sector \\
\hline E031 & Lotería y juegos de azar & 34 \\
\hline E032 & Cuotas a centros sociales, asociaciones, clubes, etcétera & 34 \\
\hline E033 & Renta de casetes para videojuegos, discos compactos y videocasetes & 30 \\
\hline E034 & $\begin{array}{l}\text { Otros gastos de recreación: museo, ferias, juegos mecánicos, balnearios, } \\
\text { etcétera }\end{array}$ & 34 \\
\hline F001 & Instalación de la línea de teléfono particular & 27 \\
\hline F002 & Teléfonos celulares, pago inicial y equipo & 27 \\
\hline F003 & Compra de tarjeta para servicio de teléfono celular & 27 \\
\hline F004 & Teléfono público & 27 \\
\hline F005 & Estampillas para correo, paquetería, telégrafo & 27 \\
\hline F006 & Otros servicios: Internet público, fax público, etcétera & 27 \\
\hline F007 & Gasolina Magna & 8 \\
\hline F008 & Gasolina Premium & 8 \\
\hline F009 & Diesel y gas & 8 \\
\hline F010 & Aceites y lubricantes & 8 \\
\hline F011 & Reparación de llantas & 19 \\
\hline F012 & Pensión y estacionamiento & 19 \\
\hline F013 & Lavado y engrasado & 19 \\
\hline F014 & Otros servicios: encerado, inflado de llantas, etcétera & 19 \\
\hline G001 & Cuota por la vivienda recibida como prestación en el trabajo & 28 \\
\hline G002 & Cuota de la vivienda en otra situación & 28 \\
\hline G003 & Cuota o pago a otro hogar & 28 \\
\hline G004 & Alquiler de terrenos & 30 \\
\hline G005 & Recolección de basura & 34 \\
\hline G006 & Cuotas de vigilancia & 31 \\
\hline G007 & Cuotas de administración & 31 \\
\hline G008 & Otros servicios & 31 \\
\hline G009 & Gas licuado de petróleo & 8 \\
\hline G010 & Petróleo & 8 \\
\hline G011 & Diesel & 8 \\
\hline G012 & Carbón & 8 \\
\hline G013 & Leña & 6 \\
\hline G014 & Combustible para calentar & 8 \\
\hline G015 & Velas y veladoras & 16 \\
\hline G016 & Otros combustibles: cartón, papel, etcétera & 7 \\
\hline G101 & Renta o alquiler de la vivienda & 29 \\
\hline G102 & Estimación del alquiler de la vivienda que es prestada & 29 \\
\hline G103 & Estimación del alquiler de vivienda propia y se está pagando & 29 \\
\hline G104 & Estimación del alquiler de la vivienda que es propia & 29 \\
\hline G105 & Estimación del alquiler de vivienda intestada o en litigio & 29 \\
\hline G106 & Estimación del alquiler de la vivienda en otra situación & 29 \\
\hline H001 & Pantalones para niño de 0 a 4 años & 4 \\
\hline
\end{tabular}




\begin{tabular}{|c|c|c|}
\hline ENIGH code & ENIGH description & WIOD sector \\
\hline H002 & $\begin{array}{l}\text { Trajes, sacos, conjuntos, abrigos, gabardinas e impermeables para niño } \\
\text { de } 0 \text { a } 4 \text { años }\end{array}$ & 4 \\
\hline $\mathrm{H} 003$ & Camisas para niño de 0 a 4 años & 4 \\
\hline H004 & Playeras para niño de 0 a 4 años & 4 \\
\hline H005 & Camisetas para niño de 0 a 4 años & 4 \\
\hline H006 & Suéteres, sudaderas y chambritas para niño de 0 a 4 años & 4 \\
\hline H007 & Pants para niño de 0 a 4 años & 4 \\
\hline H008 & Trusas y bóxer para niño de 0 a 4 años & 4 \\
\hline H009 & Calcetines, calcetas y tines para niño de 0 a 4 años & 4 \\
\hline H010 & Calzones de hule para niño de 0 a 4 años & 4 \\
\hline H011 & Pañales de tela para niño de 0 a 4 años & 4 \\
\hline H012 & Telas, confecciones y reparaciones para niño de 0 a 4 años & 4 \\
\hline H013 & $\begin{array}{l}\text { Otras prendas de vestir: baberos, delantales, fajillas, batas, pijamas, } \\
\text { etcétera para niño de } 0 \text { a } 4 \text { años }\end{array}$ & 4 \\
\hline H014 & Pantalones para niña de 0 a 4 años & 4 \\
\hline H015 & $\begin{array}{l}\text { Trajes, sacos, conjuntos, abrigos, gabardinas e impermeables para niña } \\
\text { de } 0 \text { a } 4 \text { años }\end{array}$ & 4 \\
\hline H016 & Vestidos y faldas para niña de 0 a 4 años & 4 \\
\hline H017 & Playeras para niña de 0 a 4 años & 4 \\
\hline H018 & Camisetas para niña de 0 a 4 años & 4 \\
\hline H019 & Suéteres, sudaderas y chambritas para niña de 0 a 4 años & 4 \\
\hline H020 & Blusas para niña de 0 a 4 años & 4 \\
\hline H021 & Pants para niña de 0 a 4 años & 4 \\
\hline H022 & Pantaletas para niña de 0 a 4 años & 4 \\
\hline H023 & Calcetas, tobilleras y tines para niña de 0 a 4 años & 4 \\
\hline $\mathrm{H} 024$ & Calzones de hule para niña de 0 a 4 años & 4 \\
\hline H025 & Pañales de tela para niña de 0 a 4 años & 4 \\
\hline H026 & Telas, confecciones y reparaciones para niña de 0 a 4 años & 4 \\
\hline H027 & $\begin{array}{l}\text { Otras prendas de vestir: baberos, delantales, fajillas, batas, pijamas, } \\
\text { etcétera ( para niña de } 0 \text { a } 4 \text { años }\end{array}$ & 4 \\
\hline H028 & Pantalones para niño de 5 a 17 años & 4 \\
\hline H029 & Camisas para niño de 5 a 17 años & 4 \\
\hline H030 & Playeras para niño de 5 a 17 años & 4 \\
\hline H031 & $\begin{array}{l}\text { Trajes, sacos, abrigos, gabardinas e impermeables para niño de } 5 \text { a } 17 \\
\text { años }\end{array}$ & 4 \\
\hline H032 & Chamarras para niño de 5 a 17 años & 4 \\
\hline H033 & Suéteres y sudaderas para niño de 5 a 17 años & 4 \\
\hline H034 & Trusas y bóxer para niño de 5 a 17 años & 4 \\
\hline H035 & Camisetas para niño de 5 a 17 años & 4 \\
\hline H036 & Calcetines, calcetas y tines para niño de 5 a 17 años & 4 \\
\hline H037 & Pants para niño de 5 a 17 años & 4 \\
\hline H038 & Telas, confecciones y reparaciones para niño de 5 a 17 años & 4 \\
\hline
\end{tabular}




\begin{tabular}{|c|c|c|}
\hline ENIGH code & ENIGH description & WIOD sector \\
\hline H039 & $\begin{array}{l}\text { Otras prendas de vestir para hombre: corbatas, batas, pijamas, etcétera } \\
\text { para niño de } 5 \text { a } 17 \text { años }\end{array}$ & 4 \\
\hline H040 & Pantalones para niña de 5 a 17 años & 4 \\
\hline H041 & Blusas para niña de 5 a 17 años & 4 \\
\hline H042 & Playeras para niña de 5 a 17 años & 4 \\
\hline H043 & $\begin{array}{l}\text { Trajes, sacos, conjuntos, abrigos, gabardinas e impermeables para niña } \\
\text { de } 5 \text { a } 17 \text { años }\end{array}$ & 4 \\
\hline H044 & Vestidos para niña de 5 a 17 años & 4 \\
\hline H045 & Faldas para niña de 5 a 17 años & 4 \\
\hline H046 & Suéteres y sudaderas para niña de 5 a 17 años & 4 \\
\hline H047 & Chamarras para niña de 5 a 17 años & 4 \\
\hline H048 & Calcetas, tobilleras, tines y mallas para niña de 5 a 17 años & 4 \\
\hline H049 & Pantaletas y fajas para niña de 5 a 17 años & 4 \\
\hline H050 & Brassieres para niña de 5 a 17 años & 4 \\
\hline H051 & Fondos y corpiños para niña de 5 a 17 años & 4 \\
\hline H052 & Medias, pantimedias y tobimedias para niña de 5 a 17 años & 4 \\
\hline H053 & Pants para niña de 5 a 17 años & 4 \\
\hline H054 & Telas, confecciones y reparaciones para niña de 5 a 17 años & 4 \\
\hline H055 & $\begin{array}{l}\text { Otras prendas de vestir para mujer: rebozo, pijamas, camisones, batas, } \\
\text { etcétera para niña de } 5 \text { a } 17 \text { años }\end{array}$ & 4 \\
\hline H056 & Pantalones para hombre de 18 o más años & 4 \\
\hline H057 & Camisas para hombre de 18 o más años & 4 \\
\hline H058 & Playeras para hombre de 18 o más años & 4 \\
\hline H059 & $\begin{array}{l}\text { Trajes, sacos, conjuntos, abrigos, gabardinas e impermeables para } \\
\text { hombre de } 18 \text { o más años }\end{array}$ & 4 \\
\hline H060 & Suéteres y sudaderas para hombre de 18 o más años & 4 \\
\hline H061 & Chamarras para hombre de 18 o más años & 4 \\
\hline H062 & Trusas y bóxer para hombre de 18 o más años & 4 \\
\hline H063 & Camisetas para hombre de 18 o más años & 4 \\
\hline H064 & Calcetines, calcetas y tines para hombre de 18 o más años & 4 \\
\hline H065 & Pants para hombre de 18 o más años & 4 \\
\hline H066 & Telas, confecciones y reparaciones para hombre de 18 o más años & 4 \\
\hline H067 & $\begin{array}{l}\text { Otras prendas de vestir para hombre: corbatas, batas, pijamas, etcétera } \\
\text { para hombre de } 18 \text { o más años }\end{array}$ & 4 \\
\hline H068 & Pantalones para mujer de 18 o más años & 4 \\
\hline H069 & Blusas para mujer de 18 o más años & 4 \\
\hline H070 & Playeras para mujer de 18 o más años & 4 \\
\hline H071 & $\begin{array}{l}\text { Trajes, sacos, conjuntos, abrigos, gabardinas e impermeables para mujer } \\
\text { de } 18 \text { o más años }\end{array}$ & 4 \\
\hline H072 & Vestidos para mujer de 18 o más años & 4 \\
\hline H073 & Faldas para mujer de 18 o más años & 4 \\
\hline H074 & Suéteres y sudaderas para mujer de 18 o más años & 4 \\
\hline
\end{tabular}




\begin{tabular}{|c|c|c|}
\hline ENIGH code & ENIGH description & WIOD sector \\
\hline H075 & Chamarras para mujer de 18 o más años & 4 \\
\hline H076 & Calcetas, tobilleras, tines y mallas para mujer de 18 o más años & 4 \\
\hline H077 & Pantaletas y fajas para mujer de 18 o más años & 4 \\
\hline H078 & Brassieres para mujer de 18 o más años & 4 \\
\hline H079 & Fondos y corpiños para mujer de 18 o más años & 4 \\
\hline H080 & Medias, pantimedias y tobimedias para mujer de 18 o más años & 4 \\
\hline H081 & Pants para mujer de 18 o más años & 4 \\
\hline H082 & Telas, confecciones y reparaciones para mujer de 18 o más años & 4 \\
\hline H083 & $\begin{array}{l}\text { Otras prendas de vestir para mujer: rebozos, pijamas, camisones, batas, } \\
\text { etcétera para mujer de } 18 \text { o más años }\end{array}$ & 4 \\
\hline H084 & Zapatos para niño de 0 a 4 años & 4 \\
\hline H085 & Botas para niño de 0 a 4 años & 4 \\
\hline H086 & Tenis para niño de 0 a 4 años & 4 \\
\hline H087 & Huaraches para niño de 0 a 4 años & 4 \\
\hline H088 & Sandalias para baño o descanso para niño de 0 a 4 años & 4 \\
\hline H089 & Pantuflas para niño de 0 a 4 años & 4 \\
\hline H090 & Zapatos y sandalias para vestir para niña de 0 a 4 años & 4 \\
\hline H091 & Botas para niña de 0 a 4 años & 4 \\
\hline H092 & Tenis para niña de 0 a 4 años & 4 \\
\hline H093 & Huaraches para niña de 0 a 4 años & 4 \\
\hline H094 & Sandalias para baño o descanso para niña de 0 a 4 años & 4 \\
\hline H095 & Pantuflas para niña de 0 a 4 años & 4 \\
\hline H096 & Zapatos para niño de 5 a 17 años & 4 \\
\hline H097 & Botas para niño de 5 a 17 años & 4 \\
\hline H098 & Tenis para niño de 5 a 17 años & 4 \\
\hline H099 & Huaraches para niño de 5 a 17 años & 4 \\
\hline $\mathrm{H} 100$ & Sandalias para baño o descanso para niño de 5 a 17 años & 4 \\
\hline H101 & Pantuflas para niño de 5 a 17 años & 4 \\
\hline H102 & Zapatos y sandalias para vestir para niña de 5 a 17 años & 4 \\
\hline H103 & Botas para niña de 5 a 17 años & 4 \\
\hline H104 & Tenis para niña de 5 a 17 años & 4 \\
\hline $\mathrm{H} 105$ & Huaraches para niña de 5 a 17 años & 4 \\
\hline H106 & Sandalias para baño o descanso para niña de 5 a 17 años & 4 \\
\hline H107 & Pantuflas para niña de 5 a 17 años & 4 \\
\hline H108 & Zapatos para hombre de 18 o más años & 4 \\
\hline H109 & Botas para hombre de 18 o más años & 4 \\
\hline H110 & Tenis para hombre de 18 o más años & 4 \\
\hline H111 & Huaraches para hombre de 18 o más años & 4 \\
\hline H112 & Sandalias para baño o descanso para hombre de 18 o más años & 4 \\
\hline H113 & Pantuflas para hombre de 18 o más años & 4 \\
\hline H114 & Zapatos y sandalias para vestir para mujer de 18 o más años & 4 \\
\hline H115 & Botas para mujer de 18 o más años & 4 \\
\hline
\end{tabular}




\begin{tabular}{|c|c|c|}
\hline ENIGH code & ENIGH description & WIOD sector \\
\hline H116 & Tenis para mujer de 18 o más años & 4 \\
\hline H117 & Huaraches para mujer de 18 o más años & 4 \\
\hline H118 & Sandalias para baño o descanso para mujer de 18 o más años & 4 \\
\hline H119 & Pantuflas para mujer de 18 o más años & 4 \\
\hline H120 & Servicio de limpieza y reparación de calzado & 21 \\
\hline H121 & Crema para calzado & 9 \\
\hline H122 & Otros: agujetas, cepillos, etcétera & 16 \\
\hline H123 & Bolsas & 5 \\
\hline $\mathrm{H} 124$ & Cinturones, carteras y monederos & 5 \\
\hline H125 & Diademas & 16 \\
\hline H126 & Encendedores, cigarreras y polveras & 16 \\
\hline H127 & Joyería de fantasía & 16 \\
\hline H128 & Portafolios & 16 \\
\hline H129 & Relojes de pulso & 14 \\
\hline H130 & Sombreros, gorros y cachuchas & 4 \\
\hline H131 & Otros accesorios: lentes oscuros, etcétera & 14 \\
\hline H132 & Artículos y accesorios para el cuidado del bebé & 16 \\
\hline H133 & Reparación y/o mantenimiento de los artículos anteriores & 21 \\
\hline H134 & $\begin{array}{l}\text { Uniformes y prendas de vestir para actividades educativas, artísticas y } \\
\text { deportivas }\end{array}$ & 4 \\
\hline H135 & Prendas de vestir para eventos especiales derivados de la educación & 4 \\
\hline H136 & Telas, confecciones y reparaciones & 4 \\
\hline I001 & Vajilla completa de cristal, barro, plástico, etcétera & 16 \\
\hline I002 & Piezas sueltas de vajilla de cristal, barro, plástico, etcétera & 16 \\
\hline I003 & Recipientes o cajas de plástico para la cocina & 16 \\
\hline I004 & Vasos, copas y jarras de cristal, plástico, cerámica, etcétera & 16 \\
\hline I005 & Cubiertos & 16 \\
\hline I006 & $\begin{array}{l}\text { Plantas y flores artificiales, objetos de cerámica, orfebrería, porcelana, y } \\
\text { otros artículos decorativos }\end{array}$ & 16 \\
\hline I007 & Accesorios de hule y plástico: jabonera, tapetes, espejos, etc. & 16 \\
\hline I008 & Reloj de pared o mesa & 16 \\
\hline I009 & Batería de cocina y piezas sueltas & 16 \\
\hline I010 & Olla express & 16 \\
\hline I011 & Otros utensilios: tijeras, abrelatas, pinzas para hielo, etc. & 16 \\
\hline I012 & Herramientas: martillo, pinzas, taladro, etcétera & 16 \\
\hline I013 & Reparación y/o mantenimiento de los artículos anteriores & 16 \\
\hline I014 & Colchones & 4 \\
\hline I015 & Colchonetas & 4 \\
\hline I016 & Cobertores y cobijas & 4 \\
\hline I017 & Sábanas & 4 \\
\hline I018 & Fundas & 4 \\
\hline I019 & Colchas, edredones & 4 \\
\hline
\end{tabular}




\begin{tabular}{|c|c|c|}
\hline ENIGH code & ENIGH description & WIOD sector \\
\hline I020 & Manteles y servilletas & 4 \\
\hline I021 & Toallas & 4 \\
\hline $\mathrm{I} 022$ & Cortinas & 4 \\
\hline I023 & Telas, confecciones y reparaciones de artículos anteriores & 4 \\
\hline I024 & Hilos, hilazas y estambres & 4 \\
\hline I025 & Agujas, cierres, botones y broches & 4 \\
\hline I026 & Otros artículos: hamacas, almo-hadas, cojines, etc. & 4 \\
\hline $\mathrm{J} 001$ & $\begin{array}{l}\text { Honorarios por servicios profesionales: cirugía, anestesia, etcétera, } \\
\text { durante el parto }\end{array}$ & 33 \\
\hline J002 & Hospitalización, durante el parto & 33 \\
\hline J003 & $\begin{array}{l}\text { Análisis clínicos y estudios médicos: Rayos X, ultrasonido, etcétera, } \\
\text { durante el parto }\end{array}$ & 33 \\
\hline $\mathrm{J} 004$ & Medicamentos recetados y material de curación, durante el parto & 9 \\
\hline J005 & Servicios de partera, durante el parto & 33 \\
\hline J006 & Otros: servicio de ambulancia, etcétera, durante el parto & 33 \\
\hline J007 & Consultas médicas, durante el embarazo & 33 \\
\hline J008 & Consultas, placas, puentes dentales y otros, durante el embarazo & 33 \\
\hline J009 & Medicamentos recetados, durante el embarazo & 9 \\
\hline J010 & Vitaminas y complementos alimenticios, durante el embarazo & 3 \\
\hline J011 & $\begin{array}{l}\text { Análisis clínicos y estudios médicos: rayos X, ultrasonidos, durante el } \\
\text { embarazo }\end{array}$ & 33 \\
\hline J012 & Hospitalización durante el embarazo (no parto) & 33 \\
\hline J013 & Servicios de partera, durante el embarazo & 33 \\
\hline J014 & Hierbas medicinales, remedios caseros, etcétera, durante el embarazo & 9 \\
\hline J015 & $\begin{array}{l}\text { Otros servicios: ambulancia, aplicación de inyecciones, vacunas, } \\
\text { etcétera, durante el embarazo }\end{array}$ & 33 \\
\hline J016 & Consultas médico general & 33 \\
\hline J017 & Consultas médico especialista (pediatría y ginecología, etc.) & 33 \\
\hline J018 & Consultas dentales (placas dentales o prótesis dentales, etc.) & 33 \\
\hline J019 & Análisis clínicos y estudios médicos: rayos $\mathrm{X}$ & 33 \\
\hline J020 & Medicamentos recetados para: diarrea, infecciones y malestar estomacal & 9 \\
\hline $\mathrm{J} 021$ & Medicamentos recetados para: gripe & 9 \\
\hline J022 & Medicamentos recetados para: piel & 9 \\
\hline J023 & Medicamentos recetados para: alergias & 9 \\
\hline J024 & Medicamentos recetados para: tos & 9 \\
\hline $\mathrm{J} 025$ & Medicamentos recetados para: infecciones de la garganta & 9 \\
\hline J026 & Medicamentos recetados para: fiebre & 9 \\
\hline J027 & Medicamentos recetados para: inflamación & 9 \\
\hline J028 & Medicamentos recetados para: otras infecciones (antibióticos) & 9 \\
\hline J029 & Medicamentos recetados para: dolor de cabeza y migraña & 9 \\
\hline $\mathrm{J} 030$ & Medicamentos recetados para: otro tipo de dolores & 9 \\
\hline J031 & Medicamentos recetados para: presión arterial & 9 \\
\hline
\end{tabular}




\begin{tabular}{|c|c|c|}
\hline ENIGH code & ENIGH description & WIOD sector \\
\hline J032 & Medicamentos recetados para: diabetes & 9 \\
\hline J033 & Medicamentos recetados para: vitaminas & 9 \\
\hline J034 & Medicamentos recetados para: anticonceptivos & 9 \\
\hline J035 & Otros medicamentos recetados & 9 \\
\hline J036 & Consultas médicas para el control de peso & 33 \\
\hline J037 & Medicamentos y productos para el control de peso & 9 \\
\hline J038 & Tratamiento para el control de peso & 33 \\
\hline J039 & Honorarios por servicios profesionales: cirujano, anestesista, etc. & 33 \\
\hline J040 & Hospitalización & 33 \\
\hline J041 & Análisis clínicos y estudios médicos (rayos X, electros, etc.) & 33 \\
\hline $\mathrm{J} 042$ & Medicamentos recetados y material de curación & 9 \\
\hline J043 & $\begin{array}{l}\text { Otros: servicios de ambulancia, oxígeno, suero, sondas, bolsas de } \\
\text { diálisis y de orina, cómodos, etc. }\end{array}$ & 33 \\
\hline J044 & Medicamentos sin receta para: diarrea, infecciones y malestar estomacal & 9 \\
\hline J045 & Medicamentos sin receta para: gripe & 9 \\
\hline J046 & Medicamentos sin receta para: piel & 9 \\
\hline J047 & Medicamentos sin receta para: alergias & 9 \\
\hline J048 & Medicamentos sin receta para: tos & 9 \\
\hline J049 & Medicamentos sin receta para: infecciones de la garganta & 9 \\
\hline J050 & Medicamentos sin receta para: fiebre & 9 \\
\hline J051 & Medicamentos sin receta para: inflamación & 9 \\
\hline J052 & Medicamentos sin receta para: otras infecciones (antibióticos) & 9 \\
\hline J053 & Medicamentos sin receta para: dolor de cabeza y migraña & 9 \\
\hline J054 & Medicamentos sin receta para: otro tipo de dolores & 9 \\
\hline J055 & Medicamentos sin receta para: vitaminas & 9 \\
\hline J056 & Medicamentos sin receta para: presión arterial & 9 \\
\hline J057 & Medicamentos sin receta para: diabetes & 9 \\
\hline J058 & Medicamentos sin receta para: anticonceptivos & 9 \\
\hline J059 & Otros medicamentos sin receta & 9 \\
\hline J060 & Algodón, gasas, vendas, etc. & 33 \\
\hline J061 & Alcohol, merthiolate, solución antiséptica, etcétera & 33 \\
\hline J062 & Consultas con el curandero, huesero, quiropráctico, etcétera & 33 \\
\hline J063 & Medicamento naturista, hierbas medicinales, remedios caseros & 9 \\
\hline J064 & Medicamento homeopático & 9 \\
\hline J065 & Anteojos y lentes de contacto & 14 \\
\hline J066 & Aparatos para sordera & 14 \\
\hline J067 & $\begin{array}{l}\text { Aparatos ortopédicos y para terapia, silla de ruedas, andadera, muletas, } \\
\text { etcétera }\end{array}$ & 14 \\
\hline J068 & Reparación y mantenimiento de aparatos ortopédicos & 14 \\
\hline J069 & $\begin{array}{l}\text { Otros: pago de enfermeras y personal al cuidado de enfermos, terapias, } \\
\text { etcétera }\end{array}$ & 33 \\
\hline $\mathrm{J} 070$ & Cuotas a hospitales o clínicas & 33 \\
\hline
\end{tabular}




\begin{tabular}{|c|c|c|}
\hline ENIGH code & ENIGH description & WIOD sector \\
\hline J071 & Cuotas a compañías de seguros & 28 \\
\hline J072 & Cuotas de seguro popular & 28 \\
\hline K001 & Ventilador & 13 \\
\hline K002 & Aparatos telefónicos & 13 \\
\hline K003 & Identificador de llamadas, fax, etc. & 13 \\
\hline K004 & Aparatos de aire acondicionado para casa (incluye refrigeración o clima) & 13 \\
\hline K005 & Máquina de coser y accesorios & 13 \\
\hline K006 & Cocina integral & 13 \\
\hline K007 & Estufa de gas & 13 \\
\hline K008 & Estufa de otro combustible: electricidad, petróleo & 13 \\
\hline K009 & Refrigerador & 13 \\
\hline K010 & Licuadora & 13 \\
\hline K011 & Batidora & 13 \\
\hline K012 & Plancha & 13 \\
\hline K013 & Extractor de jugos & 13 \\
\hline K014 & Horno de microondas & 13 \\
\hline K015 & Lavadora & 13 \\
\hline K016 & Aspiradora & 13 \\
\hline K017 & Calentador de gas & 13 \\
\hline K018 & Calentador de otro combustible & 13 \\
\hline K019 & Lámparas eléctricas (incluye candiles) & 13 \\
\hline K020 & Lámparas de otro combustible & 13 \\
\hline K021 & Tanque de gas e instalación & 13 \\
\hline K022 & Lavadero, tinaco y bomba de agua & 13 \\
\hline K023 & Compra e instalación de paneles solares y planta de luz propia & 13 \\
\hline K024 & Otros aparatos: tostador, calefactor, horno eléctrico, etcétera & 13 \\
\hline K025 & Reparación, y/o mantenimiento de los artículos anteriores & 13 \\
\hline K026 & Juego de recámara & 16 \\
\hline K027 & Piezas sueltas de recámara: camas, tocadores, literas, etcétera & 16 \\
\hline K028 & Juego de comedor o antecomedor & 16 \\
\hline K029 & Piezas sueltas para comedor o antecomedor (mesas, sillas) & 16 \\
\hline K030 & Juego de sala & 16 \\
\hline K031 & Piezas sueltas para sala (mesa de centro) Muebles & 16 \\
\hline K032 & Muebles para cocina (gabinete, mesa, etcétera) & 16 \\
\hline K033 & Muebles para baño (taza, tina, tina de hidromasaje, etcétera) & 16 \\
\hline K034 & Muebles para jardín & 16 \\
\hline K035 & Alfombras y tapetes & 16 \\
\hline K036 & Otros muebles: libreros, escritorio, mesa para televisión, etcétera & 16 \\
\hline K037 & Reparación y/o mantenimiento de los artículos anteriores & 16 \\
\hline K038 & Materiales para reparación y mantenimiento & 16 \\
\hline K039 & Servicios de reparación y mantenimiento & 18 \\
\hline K040 & Materiales para ampliación y remodelación & 18 \\
\hline
\end{tabular}




\begin{tabular}{|c|c|c|}
\hline ENIGH code & ENIGH description & WIOD sector \\
\hline K041 & Servicios para ampliación y remodelación & 18 \\
\hline K042 & Materiales para reparación y mantenimiento & 18 \\
\hline K043 & Servicios de reparación y mantenimiento & 18 \\
\hline K044 & Materiales para ampliación, construcción y remodelación & 18 \\
\hline K045 & Servicios para ampliación, construcción y remodelación & 18 \\
\hline L001 & Radio y radio despertador & 13 \\
\hline L002 & Estéreo y modular & 13 \\
\hline L003 & Grabadora & 13 \\
\hline L004 & Televisión blanco y negro (incluye portátil) & 13 \\
\hline L005 & Televisión color (incluye portátil), LCD y plasma & 13 \\
\hline L006 & Lector de DVD y Blu-Ray (incluye portátil) & 13 \\
\hline L007 & Computadora & 13 \\
\hline L008 & Accesorios para computadora (mouse, memorias usb, etc) & 13 \\
\hline L009 & Decodificador de T.V., control remoto, etcétera & 13 \\
\hline L010 & Accesorios: bocinas, audífonos, antena aérea, control remoto, etc. & 13 \\
\hline L011 & Videocasetes, cartuchos y discos para videojuegos & 13 \\
\hline L012 & Reproductor de discos compactos, MP3 y IPod (MP4) & 13 \\
\hline L013 & Reproductor de discos compactos, DVD para vehículos y autoestéreo & 13 \\
\hline L014 & Alquiler de televisión, videocaseteras, computadoras, etcétera & 30 \\
\hline L015 & Otros aparatos: Walkman, etc. & 13 \\
\hline L016 & Reparación y/o mantenimiento de los artículos anteriores & 13 \\
\hline L017 & Proyectores & 14 \\
\hline L018 & Cámaras fotográficas y de video & 14 \\
\hline L019 & Material fotográfico, películas & 9 \\
\hline L020 & Servicio fotográfico, revelado e impresión & 30 \\
\hline L021 & Otros artículos y servicios: tripié, alquiler de equipo, proyectores, etc. & 14 \\
\hline L022 & Reparación y mantenimiento de los artículos anteriores & 21 \\
\hline L023 & Juguetes, juegos de mesa & 16 \\
\hline L024 & Juegos electrónicos, videojuegos & 16 \\
\hline L025 & Instrumentos musicales & 16 \\
\hline L026 & Artículos de deporte y cacería (aparatos para ejercicio, etcétera) & 16 \\
\hline L027 & Artículos de jardinería: plantas, flores, macetas, tierra, abonos & 1 \\
\hline L028 & Reparación y/o mantenimiento de los artículos anteriores. & 21 \\
\hline L029 & Compra y cuidado de animales domésticos: patos, perros, etcétera & 1 \\
\hline M001 & Transporte foráneo & 23 \\
\hline M002 & Transporte ferroviario & 23 \\
\hline M003 & Transporte aéreo & 25 \\
\hline M004 & Servicio de carga y mudanza & 23 \\
\hline M005 & Cuotas de autopista & 26 \\
\hline M006 & Otros: lancha, barco, carreta, alquiler de vehículos, etcétera & 24 \\
\hline M007 & Automóvil y/o guayín & 19 \\
\hline M008 & Camioneta (pick up) & 19 \\
\hline
\end{tabular}




\begin{tabular}{|c|c|c|}
\hline ENIGH code & ENIGH description & WIOD sector \\
\hline M009 & Motoneta, motocicleta & 19 \\
\hline M010 & Bicicleta & 15 \\
\hline M011 & Otros: remolque, lancha, triciclo, etcétera & 15 \\
\hline M012 & Llantas & 19 \\
\hline M013 & Acumulador & 19 \\
\hline M014 & Refacciones: bujías, bandas, filtros, etcétera & 19 \\
\hline M015 & Partes de vehículos: vidrios, salpicaderas, etcétera & 19 \\
\hline M016 & Accesorios: espejos, manijas, antenas, etcétera & 19 \\
\hline M017 & Servicios de afinación, alineación y balanceo & 19 \\
\hline M018 & Otros servicios: ajuste de motor, de frenos, hojalatería, pintura, etcétera & 19 \\
\hline N001 & $\begin{array}{l}\text { Servicios profesionales de abogados, notarios, arquitectos, etcétera (no } \\
\text { médicos) }\end{array}$ & 31 \\
\hline N002 & Funerales y cementerios & 34 \\
\hline N003 & Paquetes para fiesta (salón, comida, orquesta) & 22 \\
\hline N004 & Gastos turísticos: paquetes, hospedajes, alimentos, tours, etcétera & 26 \\
\hline N005 & Hospedaje o alojamiento sin fines turísticos (con o sin alimentos) & 22 \\
\hline N006 & Gastos en cargos comunales para festividades locales & 34 \\
\hline N007 & Contribuciones para obras del servicio público local & 31 \\
\hline N008 & Seguro de automóvil & 28 \\
\hline N009 & $\begin{array}{l}\text { Seguros contra incendio, daños y riesgos para la vivienda, educación y } \\
\text { seguro de vida (no capitalizable) }\end{array}$ & 28 \\
\hline N010 & Otros gastos diversos no comprendidos en las categorías anteriores & 21 \\
\hline N011 & Indemnizaciones pagadas a terceros & 34 \\
\hline N012 & Pérdidas y robos en dinero (excluya negocios) & 34 \\
\hline N013 & Ayuda a parientes y personas ajenas al hogar (en dinero) & 34 \\
\hline N014 & $\begin{array}{l}\text { Contribuciones a instituciones benéficas en dinero, iglesias, cruz roja, } \\
\text { incluye servicios eclesiásticos }\end{array}$ & 34 \\
\hline N015 & $\begin{array}{l}\text { Servicios del sector público: expedición de pasaporte, actas, títulos, } \\
\text { etcétera }\end{array}$ & 31 \\
\hline N016 & $\begin{array}{l}\text { Trámites para vehículos: licencias, placas, verificación vehicular, } \\
\text { etcétera }\end{array}$ & 31 \\
\hline R001 & Energía eléctrica & 17 \\
\hline R002 & Agua & 17 \\
\hline R003 & Gas natural & 17 \\
\hline R004 & Impuesto predial & 31 \\
\hline R005 & Largas distancias de línea particular & 27 \\
\hline R006 & Llamadas locales de línea particular & 27 \\
\hline R007 & Teléfonos celulares (plan mensual) & 27 \\
\hline R008 & Internet & 27 \\
\hline R009 & Televisión de paga & 27 \\
\hline R010 & Paquete de Internet y teléfono & 27 \\
\hline R011 & Paquete de Internet, teléfono y televisión de paga & 27 \\
\hline
\end{tabular}




\begin{tabular}{llc}
\hline ENIGH code & ENIGH description & WIOD sector \\
\hline R012 & Tenencia vehicular & 19 \\
R013 & Alarmas para la casa & 18 \\
T901 & Alimentos, bebidas y tabaco & 3 \\
T902 & Transporte (pasajes) & 23 \\
T903 & Artículos o servicios destinados a la limpieza y cuidados de la casa & 9 \\
T904 & Artículos o servicios destinados a cuidados personales & 9 \\
T905 & Artículos o servicios destinados a educación, cultura y recreación & 34 \\
T906 & Artículos o servicios destinados a la comunicación y servicios para & 27 \\
& vehículos & \\
T907 & Artículos o servicios destinados a vivienda y servicios de conservación & 21 \\
T908 & Último recibo pagado & 21 \\
T909 & Prendas de vestir, calzado y accesorios & 21 \\
T910 & Cristalería, blancos y utensilios domésticos & 16 \\
T911 & Artículos o servicios destinados a cuidados de la salud & 33 \\
T912 & Enseres domésticos y mantenimiento de la vivienda & 21 \\
T913 & Artículos de esparcimiento & 21 \\
T914 & Artículos o servicios destinados al transporte & 23 \\
T915 & Gastos diversos & 16 \\
T916 & Erogaciones financieras y de capital & 28 \\
\hline
\end{tabular}





\section{Appendix C}

Table C.1 ENIGH-WIOD reduced matching and carbon intensities

\begin{tabular}{|c|c|c|c|c|}
\hline \multirow[b]{2}{*}{ Item } & \multirow[b]{2}{*}{ WIOD code } & \multirow[b]{2}{*}{ WIOD description } & \multicolumn{2}{|c|}{$\mathrm{CI}(\mathrm{kg} / \mathrm{MXN})$} \\
\hline & & & $\mathrm{CO}_{2}$ & $\mathrm{CO}_{2} \mathrm{e}$ \\
\hline Electricity & 17 & Electricity, Gas and Water Supply & 0.290 & 0.297 \\
\hline Motor Fuels & 8 & Coke, Refined Petroleum & 0.217 & 0.222 \\
\hline Gas & 8 & Electricity, Gas and Water Supply & 0.140 & 0.140 \\
\hline Public Transport & 23 & Inland Transport & 0.029 & 0.031 \\
\hline \multirow[t]{2}{*}{ Food } & 1 & Agriculture & 0.032 & 0.173 \\
\hline & 3 & Food processing & 0.016 & 0.044 \\
\hline \multirow[t]{20}{*}{ Other } & 4 & Textiles & 0.017 & 0.024 \\
\hline & 5 & Leather, Footwear & 0.013 & 0.019 \\
\hline & 6 & Wood and Wood Products & 0.018 & 0.047 \\
\hline & 7 & Pulp, Paper & 0.019 & 0.020 \\
\hline & 8 & Chemicals and Products & 0.014 & 0.022 \\
\hline & 9 & Rubber and Plastics & 0.013 & 0.015 \\
\hline & 10 & Other Non-Metallic Mineral & 0.056 & 0.100 \\
\hline & 11 & Basic Metals and Fabricated Metal & 0.021 & 0.028 \\
\hline & 12 & Machinery & 0.005 & 0.006 \\
\hline & 13 & Electrical and Optical Equipment & 0.008 & 0.009 \\
\hline & 14 & Transport Equipment & 0.008 & 0.010 \\
\hline & 15 & Manufacturing; Recycling & 0.022 & 0.027 \\
\hline & 16 & Construction & 0.018 & 0.023 \\
\hline & 17 & Sale Motor Vehicles and Fuel & 0.017 & 0.019 \\
\hline & 18 & Wholesale and Commission Trade & 0.008 & 0.010 \\
\hline & 19 & Retail Trade & 0.012 & 0.014 \\
\hline & 20 & Hotels and Restaurants & 0.025 & 0.026 \\
\hline & 21 & Water Transport & 0.147 & 0.152 \\
\hline & 22 & Air Transport & 0.013 & 0.075 \\
\hline & 23 & Other Transport & 0.018 & 0.019 \\
\hline
\end{tabular}




\begin{tabular}{lllll}
\hline & & & \multicolumn{2}{c}{$\mathrm{CI}(\mathrm{kg} / \mathrm{MXN})$} \\
\cline { 3 - 4 } Item & WIOD code & WIOD description & $\mathrm{CO}_{2}$ & $\mathrm{CO}_{2} \mathrm{e}$ \\
\hline 24 & Post and Telecommunications & 0.008 & 0.009 \\
25 & Financial Intermediation & 0.004 & 0.005 \\
26 & Real Estate Activities & 0.004 & 0.004 \\
27 & Renting of M\&Eq and Other & 0.009 & 0.010 \\
28 & Public Admin and Defence & 0.015 & 0.016 \\
29 & Education & 0.012 & 0.012 \\
30 & Health and Social Work & 0.011 & 0.013 \\
31 & Other Services & 0.013 & 0.101 \\
\hline
\end{tabular}




\section{Appendix D}

Table D.1 SUSENAS-WIOD Matching 2014

\begin{tabular}{|c|c|c|}
\hline SUSENAS code & SUSENAS description & WIOD sector \\
\hline 1 & CEREALS [R.2-R.9] & \\
\hline 2 & Rice & 3 \\
\hline 3 & Glutinous rice & 3 \\
\hline 4 & Fresh corn with husk & 3 \\
\hline 5 & Dryshelled corn/corn rice & 3 \\
\hline 6 & Rice meal & 3 \\
\hline 7 & Corn meal & 3 \\
\hline 8 & Wheat flour & 3 \\
\hline 9 & Others & 3 \\
\hline 10 & TUBERS [R.11-R.19] & \\
\hline 11 & Cassava & 1 \\
\hline 12 & Sweet potatoes & 1 \\
\hline 13 & Sago flour & 1 \\
\hline 14 & Taro & 1 \\
\hline 15 & Potatoes & 1 \\
\hline 16 & Dried cassava & 1 \\
\hline 17 & Flour dried cassava & 1 \\
\hline 18 & Cassava flour & 1 \\
\hline 19 & Others & 1 \\
\hline 20 & FISH/SHRIMP/SQUID/SHELL [R.21-R.52] & \\
\hline 21 & Yellow tail/fusiliers & 1 \\
\hline 22 & Eastern tuna/skipjack tuna & 1 \\
\hline 23 & Mackerel & 1 \\
\hline 24 & Trevallies & 1 \\
\hline 25 & Indian mackerel & 1 \\
\hline 26 & Anchovies & 1 \\
\hline 27 & Milk fish & 1 \\
\hline 28 & Snake head & 1 \\
\hline 29 & Mozambique tilapia & 1 \\
\hline
\end{tabular}




\begin{tabular}{|c|c|c|}
\hline SUSENAS code & SUSENAS description & WIOD sector \\
\hline 30 & Common carp & 1 \\
\hline 31 & Catfish & 1 \\
\hline 32 & Barramundi & 1 \\
\hline 33 & Baronang & 1 \\
\hline 34 & Others & 1 \\
\hline 35 & Shrimp & 1 \\
\hline 36 & Common squid/cuttle fish & 1 \\
\hline 37 & Mud crab/swim crab & 1 \\
\hline 38 & Cockle/snail & 1 \\
\hline 39 & Others & 1 \\
\hline 40 & Indian mackerel & 1 \\
\hline 41 & Mackerel & 1 \\
\hline 42 & Eastern tuna/skipjack tuna & 1 \\
\hline 43 & Anchovies & 1 \\
\hline 44 & Trevallies & 1 \\
\hline 45 & Snakeskin gourame & 1 \\
\hline 46 & Milk fishes & 1 \\
\hline 47 & Snake head & 1 \\
\hline 48 & Canned fish & 1 \\
\hline 49 & Others & 1 \\
\hline 50 & Shrimps & 1 \\
\hline 51 & Common squids & 1 \\
\hline 52 & Others & 1 \\
\hline 53 & MEAT [R.54-R.70] & \\
\hline 54 & Beef & 3 \\
\hline 55 & Buffalo meat & 3 \\
\hline 56 & Lamb meat & 3 \\
\hline 57 & Pork & 3 \\
\hline 58 & Broiler meat & 3 \\
\hline 59 & Local chicken meat & 3 \\
\hline 60 & Other poultry meat & 3 \\
\hline 61 & Other meat & 3 \\
\hline 62 & Dried beef & 3 \\
\hline 63 & Shredded fried meat & 3 \\
\hline 64 & Canned meat & 3 \\
\hline 65 & Others & 3 \\
\hline 66 & Liver & 3 \\
\hline 67 & Innards excluding liver & 3 \\
\hline 68 & Trimming & 3 \\
\hline 69 & Bone (untrimmed) & 3 \\
\hline 70 & Others & 3 \\
\hline
\end{tabular}

EGGS AND MILK [R.72-R.84] 


\begin{tabular}{|c|c|c|}
\hline SUSENAS code & SUSENAS description & WIOD sector \\
\hline 72 & Broiler egg & 3 \\
\hline 73 & Local chicken egg & 3 \\
\hline 74 & Duck egg & 3 \\
\hline 75 & Quail egg & 3 \\
\hline 76 & Other egg & 3 \\
\hline 77 & Salted egg & 3 \\
\hline 78 & Fresh milk & 3 \\
\hline 79 & Preserved milk & 3 \\
\hline 80 & Sweet canned liquid milk & 3 \\
\hline 81 & Canned powder milk & 3 \\
\hline 82 & Baby powder milk & 3 \\
\hline 83 & Cheese & 3 \\
\hline 84 & Milk product & 3 \\
\hline 85 & VEGETABLES [R.86-R.114] & \\
\hline 86 & Spinach & 3 \\
\hline 87 & Swamp cabbage & 3 \\
\hline 88 & Cabbage & 3 \\
\hline 89 & Chinese cabbage & 3 \\
\hline 90 & Mustard greens & 3 \\
\hline 91 & Beans & 3 \\
\hline 92 & String bean & 3 \\
\hline 93 & Tomato & 3 \\
\hline 94 & Carrot & 3 \\
\hline 95 & Cucumber & 3 \\
\hline 96 & Cassava leaf & 3 \\
\hline 97 & Aubergine & 3 \\
\hline 98 & Bean sprout & 3 \\
\hline 99 & Squash & 3 \\
\hline 100 & Unripe corn & 3 \\
\hline 101 & Soup/stir-fried vegetables & 3 \\
\hline 102 & Sour vegetable soup & 3 \\
\hline 103 & Young jackfruit & 3 \\
\hline 104 & Unripe papaya & 3 \\
\hline 105 & Mushroom & 3 \\
\hline 106 & Petai beans & 3 \\
\hline 107 & Stink beans & 3 \\
\hline 108 & Onion & 3 \\
\hline 109 & Garlic & 3 \\
\hline 110 & Chillies & 3 \\
\hline 111 & Green chili & 3 \\
\hline 112 & Cayenne pepper & 3 \\
\hline 113 & Canned vegetable & 3 \\
\hline
\end{tabular}




\begin{tabular}{|c|c|c|}
\hline SUSENAS code & SUSENAS description & WIOD sector \\
\hline 114 & Others & 3 \\
\hline 115 & LEGUMES [R.116-R.126] & \\
\hline 116 & Peanuts without shell & 3 \\
\hline 117 & Peanuts with shell & 3 \\
\hline 118 & Soybean & 3 \\
\hline 119 & Mungbean & 3 \\
\hline 120 & Red kidney bean & 3 \\
\hline 121 & Other bean & 3 \\
\hline 122 & Tofu, soybean curd & 3 \\
\hline 123 & Fermented soybean cake & 3 \\
\hline 124 & Fermented soybean paste & 3 \\
\hline 125 & Fermented soya cake & 3 \\
\hline 126 & Others & 3 \\
\hline 127 & FRUITS [R.128-R.150] & \\
\hline 128 & Orange & 1 \\
\hline 129 & Mango & 1 \\
\hline 130 & Apple & 1 \\
\hline 131 & Avocado & 1 \\
\hline 132 & Rambutan & 1 \\
\hline 133 & Lanzon & 1 \\
\hline 134 & Durian & 1 \\
\hline 135 & Zalacca & 1 \\
\hline 136 & Pineapple & 1 \\
\hline 137 & "Ambon" banana & 1 \\
\hline 138 & "Raja" banana & 1 \\
\hline 139 & Other banana & 1 \\
\hline 140 & Papaya & 1 \\
\hline 141 & Rose-apple & 1 \\
\hline 142 & Sapodilla & 1 \\
\hline 143 & Carambola & 1 \\
\hline 144 & Spanish plum & 1 \\
\hline 145 & Watermelon & 1 \\
\hline 146 & Melon & 1 \\
\hline 147 & Jack fruit & 1 \\
\hline 148 & Tomato & 1 \\
\hline 149 & Canned fruit & 1 \\
\hline 150 & Others & 1 \\
\hline 151 & OILS AND FATS [R.152-R.157] & \\
\hline 152 & Coconut oil & 3 \\
\hline 153 & Corn oil & 3 \\
\hline 154 & Other frying oil & 3 \\
\hline 155 & Coconut & 3 \\
\hline
\end{tabular}




\begin{tabular}{|c|c|c|}
\hline SUSENAS code & SUSENAS description & WIOD sector \\
\hline 156 & Margarine & 3 \\
\hline 157 & Others & 3 \\
\hline 158 & BEVERAGES [R.159-R.166] & \\
\hline 159 & Cane sugar & 3 \\
\hline 160 & Brown sugar & 3 \\
\hline 161 & T e a & 3 \\
\hline 162 & Powdered/bean coffee & 3 \\
\hline 163 & Instant cocoa & 3 \\
\hline 164 & Powdered cocoa & 3 \\
\hline 165 & Syrup & 3 \\
\hline 166 & Others & 3 \\
\hline 167 & SPICES [R.168-R.180] & \\
\hline 168 & Salt & 3 \\
\hline 169 & Candlenut & 3 \\
\hline 170 & Coriander & 3 \\
\hline 171 & Pepper & 3 \\
\hline 172 & Tamarind & 3 \\
\hline 173 & Nutmeg & 3 \\
\hline 174 & Clove & 3 \\
\hline 175 & Fish paste & 3 \\
\hline 176 & Soya sauce & 3 \\
\hline 177 & Monosodium glutamate & 3 \\
\hline 178 & Chili sauce/tomato sauce & 3 \\
\hline 179 & Spice & 3 \\
\hline 180 & Other spice & 3 \\
\hline 181 & MISCELLANEOUS FOOD ITEM [R.182-R.190] & \\
\hline 182 & Instant noodle & 3 \\
\hline 183 & Wheat noodle & 3 \\
\hline 184 & Rice noodle & 3 \\
\hline 185 & Macaroni & 3 \\
\hline 186 & Crisps & 3 \\
\hline 187 & Fried chips & 3 \\
\hline 188 & Seaweed & 3 \\
\hline 189 & Porridge in package & 3 \\
\hline 190 & Others & 3 \\
\hline 191 & $\begin{array}{l}\text { PREPARED FOOD AND BEVERAGES [ } \\
\text { R.192-R.222] }\end{array}$ & \\
\hline 192 & Ordinary bread & 3 \\
\hline 193 & Other bread & 3 \\
\hline 194 & Cookies & 3 \\
\hline 195 & Boil or steam cake & 3 \\
\hline 196 & Fried food & 3 \\
\hline
\end{tabular}




\begin{tabular}{|c|c|c|}
\hline SUSENAS code & SUSENAS description & WIOD sector \\
\hline 197 & Porridge of mung bean & 3 \\
\hline 198 & Kind of salad with peanuts sauce & 3 \\
\hline 199 & A plate of rice accompanied by a mixture of dishes & 3 \\
\hline 200 & Fried rice & 3 \\
\hline 201 & Rice & 3 \\
\hline 202 & Rice steamed in a banana leaf or coconut leaf & 3 \\
\hline 203 & Soup & 3 \\
\hline 204 & Roasted meat on skewer/satay & 3 \\
\hline 205 & Noodle (with meatball/boiled/fried) & 3 \\
\hline 206 & Instant noodle & 3 \\
\hline 207 & Snack for children & 3 \\
\hline 208 & Fish (fried, roasted, etc) & 3 \\
\hline 209 & Chicken/meat (fried, roasted, etc) & 3 \\
\hline 210 & Other prepared food & 3 \\
\hline 211 & Mineral water (bottle) & 3 \\
\hline 212 & Mineral water (gallon) & 3 \\
\hline 213 & Packed tea & 3 \\
\hline 214 & Packed juice & 3 \\
\hline 215 & $\mathrm{CO} 2$ drink & 3 \\
\hline 216 & Health drink & 3 \\
\hline 217 & Other drinks (coffee, milk, etc) & 3 \\
\hline 218 & Ice cream & 3 \\
\hline 219 & Other ice & 3 \\
\hline 220 & B e e r & 3 \\
\hline 221 & Wine & 3 \\
\hline 222 & Other alcoholic beverage & 3 \\
\hline 223 & TOBACCO AND BETEL [R.224-R.229] & \\
\hline 224 & Clove filter cigarettes & 3 \\
\hline 225 & Clove non filter cigarettes & 3 \\
\hline 226 & Cigarettes & 3 \\
\hline 227 & Tobacco & 3 \\
\hline 228 & Betel/areca nut & 3 \\
\hline 229 & Others & 3 \\
\hline 230 & $\begin{array}{l}\text { HOUSING AND HOUSEHOLD FACILITY } \\
\text { [R.231-R.260] }\end{array}$ & \\
\hline 232 & rent and house maintenance & 29 \\
\hline 233 & rent and house maintenance & 29 \\
\hline 234 & rent and house maintenance & 29 \\
\hline 235 & rent and house maintenance & 29 \\
\hline 236 & rent and house maintenance & 29 \\
\hline 238 & electricity & 17 \\
\hline 240 & water & 17 \\
\hline
\end{tabular}




\begin{tabular}{|c|c|c|}
\hline SUSENAS code & SUSENAS description & WIOD sector \\
\hline 242 & LPG & 8 \\
\hline 244 & city gas & 17 \\
\hline 246 & kerosene & 8 \\
\hline 248 & generator fuel & 8 \\
\hline 250 & generator: Lubricant oil & 8 \\
\hline 251 & generator: maintenance and repair & 21 \\
\hline 253 & charcoal/coal/briket & 8 \\
\hline 254 & Firewood and other fuel & 6 \\
\hline 255 & $\begin{array}{l}\text { Others (flashlight, storage battery, matches, mosquito } \\
\text { repellent, lamp, air freshener, Liquid floor cleaner, etc) }\end{array}$ & 9 \\
\hline 256 & Post and Telecomunication:Phone bill (home) & 27 \\
\hline 257 & Mobile phone bill & 27 \\
\hline 258 & Phone card/public phone/phone shop & 27 \\
\hline 259 & Post stuff (stamp, etc.) & 27 \\
\hline 260 & Others (internet) & 27 \\
\hline 261 & GOODS AND SERVICES [R.262-R.302] & \\
\hline 262 & Bathing soap, toothpaste, and shampoo & 27 \\
\hline 263 & Cosmetic articles & 27 \\
\hline 264 & Treatment of skin, face, nails, hair & 27 \\
\hline 265 & Laundry soap (bars, powders, creams, and liquid) & 27 \\
\hline 266 & $\begin{array}{l}\text { Clothes maintenance material (softener and fragrances, } \\
\text { bleacing, lubricant, camphor, etc) }\end{array}$ & 27 \\
\hline 267 & $\begin{array}{l}\text { Newspapers, magazine, books, and stationeries (exluding } \\
\text { for education) including magazine rent }\end{array}$ & 27 \\
\hline 268 & Other stuffs (tissue, baby diaper, satai stick, etc.) & 27 \\
\hline 269 & Health Care:Public Hospital & 33 \\
\hline 270 & Private Hospital & 33 \\
\hline 271 & Sub ordinary Public Health Center & 33 \\
\hline 272 & $\begin{array}{l}\text { Medical Doctor (including private medical doctor in } \\
\text { public hospital) }\end{array}$ & 33 \\
\hline 273 & Paramedical & 33 \\
\hline 274 & Traditional treatment & 33 \\
\hline 275 & Traditional birth attendant & 33 \\
\hline 276 & $\begin{array}{l}\text { Drug costs (only drugs purchased in pharmacies, drug } \\
\text { stores, etc) }\end{array}$ & 9 \\
\hline 277 & Self treatment/take medicine without recipe & 9 \\
\hline 278 & Purchasing traditional medicine & 9 \\
\hline 279 & Purchasing glasses, hand/leg artificial, \& wheel chair & 16 \\
\hline 280 & Health Preventive Cost Pregnancy examination cost & 33 \\
\hline 281 & Children Under-fives immunization cost & 33 \\
\hline 282 & Medical check-up & 33 \\
\hline 283 & Contraception cost & 33 \\
\hline
\end{tabular}




\begin{tabular}{|c|c|c|}
\hline SUSENAS code & SUSENAS description & WIOD sector \\
\hline 284 & vitamin, medicine herbs, etc. & 33 \\
\hline 285 & School fee and non/formal education cost & 32 \\
\hline 286 & School fee & 32 \\
\hline 287 & Other cost of school contribution & 32 \\
\hline 288 & Text books & 32 \\
\hline 289 & Stationery (pen, pencil, eraser, ruler, calculator, etc.) & 32 \\
\hline 290 & Non-formal education cost & 32 \\
\hline 292 & motor vehicle fuel: gasoline & 19 \\
\hline 294 & motor vehicle fuel: diesel & 19 \\
\hline 296 & motor vehicle fuel: lubricant & 19 \\
\hline 297 & $\begin{array}{l}\text { motor vehicle service and repair (brake fluid, battery acid, } \\
\text { battery, brake, clutch, etc.) }\end{array}$ & 19 \\
\hline 298 & Transport expenses (bus, train, plane, etc.) & 23 \\
\hline 299 & $\begin{array}{l}\text { Hotel, inn, cinema, theater, sports, set-top box, cable TV } \\
\text { subscriptions (excluding transport and purchase of goods } \\
\text { for recreation) }\end{array}$ & 22 \\
\hline 300 & Domestic servant, security, and driver (salary or wages) & 35 \\
\hline 301 & $\begin{array}{l}\text { Financial service charge (ATM services, credit card } \\
\text { services, transfer fees, etc.) }\end{array}$ & 28 \\
\hline 302 & $\begin{array}{l}\text { Other services (ID card, driver's license, birth certificate, } \\
\text { copy, photo, etc.) }\end{array}$ & 34 \\
\hline 303 & $\begin{array}{l}\text { CLOTHING, FOOTWEAR, AND HEADGEAR } \\
\text { [R.304-R.311] }\end{array}$ & \\
\hline 304 & Ready-made clothes for men & 4 \\
\hline 305 & Ready-made clothes for women & 4 \\
\hline 306 & Ready-made clothes for children & 4 \\
\hline 307 & Materials clothing for men, women, and children & 4 \\
\hline 308 & $\begin{array}{l}\text { Wages sewing, repairing clothes, sewing thread, and other } \\
\text { goods for the purposes of tailoring }\end{array}$ & 4 \\
\hline 309 & Footwear (shoes, sandals, socks, etc) & 5 \\
\hline 310 & $\begin{array}{l}\text { Headgear for men, women, and children (hat, cap, scarf, } \\
\text { etc..) }\end{array}$ & 4 \\
\hline 311 & Others (towel, belt, shoe polish, tie, laundry, etc.) & 4 \\
\hline 312 & DURABLE GOODS [R.313-R.329] & \\
\hline 313 & Furniture & 6 \\
\hline 314 & $\begin{array}{l}\text { Household furnishings (sewing machines, refrigerators, } \\
\text { fans, washing machines, air conditioners, etc..) }\end{array}$ & 14 \\
\hline 315 & $\begin{array}{l}\text { Household equipments (mattresses, pillows, tablecloths, } \\
\text { bed linen, ashtrays, pillowcases, blankets, mats, curtains, } \\
\text { rugs, etc..) }\end{array}$ & 16 \\
\hline
\end{tabular}




\begin{tabular}{|c|c|c|}
\hline SUSENAS code & SUSENAS description & WIOD sector \\
\hline 316 & $\begin{array}{l}\text { Home appliances (iron, broom, scissors, knives, machetes, } \\
\text { hoes, saws, vacuum cleaner, coat hanger, soldering } \\
\text { equipment, etc..) }\end{array}$ & 16 \\
\hline 317 & $\begin{array}{l}\text { Kitchen utensils (rack plate, stove, pots, pans, buckets, } \\
\text { kitchen knives, pans, spoons, flasks, plates, glasses, } \\
\text { mixers, rice cookers, blenders, microwaves, ovens, and } \\
\text { other dishes made of glass / ceramic / melamine / plastic, } \\
\text { etc..) }\end{array}$ & 16 \\
\hline 318 & $\begin{array}{l}\text { Decoration stuff (wall hangings, aquariums, decorative } \\
\text { items made of ceramic, porcelain, onyx, marble, wood, } \\
\text { etc..) }\end{array}$ & 14 \\
\hline 319 & Furniture and utensils repairs & 21 \\
\hline 320 & Hand phone and other accessories & 14 \\
\hline 321 & Watch, clock, camera, glasses, and repairs & 14 \\
\hline 322 & Umbrella, bag, and repairs & 16 \\
\hline 323 & Jewelry and repairs & 16 \\
\hline 324 & Toys and repair, imitation jewelry & 16 \\
\hline 325 & $\begin{array}{l}\text { Electronics (Television, radio, video, DVD, cassette, } \\
\text { cassette radio, guitar, piano / organ, computer) and repair }\end{array}$ & 14 \\
\hline 326 & $\begin{array}{l}\text { Tools and sports equipment (chess, racket, ball, net, bet, } \\
\text { sticks, including bathing suits, soccer shoes, wheels shoes } \\
\text {, goggles) and repairs }\end{array}$ & 16 \\
\hline 327 & $\begin{array}{l}\text { Vehicles (cars, motorcycles, bicycles, etc..) and major } \\
\text { repairs }\end{array}$ & 19 \\
\hline 328 & Domestic animal and plant maintenance & 1 \\
\hline 329 & $\begin{array}{l}\text { Other durable goods (electrical installation / phone / tap, } \\
\text { swing, stroller, etc..) and repairs }\end{array}$ & 14 \\
\hline 330 & TAXES AND INSURANCES [R.331-R.336] & \\
\hline 331 & Buildings and land taxes & 28 \\
\hline 332 & Motor and non-motor vehicle taxes & 28 \\
\hline 333 & $\begin{array}{l}\text { Other contributions (dues RT / RW, trash, security, } \\
\text { cemetery, parking, etc..) }\end{array}$ & 28 \\
\hline 334 & Health insurance & 28 \\
\hline 335 & $\begin{array}{l}\text { Live insurance and general insurance (death insurance, } \\
\text { accident, car, house, etc..) }\end{array}$ & 28 \\
\hline 336 & Others (ticket, Income Tax, etc..) & 28 \\
\hline 337 & PARTIES AND CEREMONIES [R.338-R.343] & \\
\hline 338 & Wedding & 34 \\
\hline 339 & Circumcision and birthday & 34 \\
\hline 340 & Religious festival (chair rental, tent rental, etc..) & 34 \\
\hline 341 & Pilgrimage cost & 34 \\
\hline
\end{tabular}


182

\begin{tabular}{clc}
\hline SUSENAS code & SUSENAS description & WIOD sector \\
\hline 342 & $\begin{array}{l}\text { Religious/traditional ceremony (called Ustad, Reverend, } \\
\text { offerings, etc..) }\end{array}$ & 34 \\
343 & Funeral expenses & 34 \\
\hline
\end{tabular}

